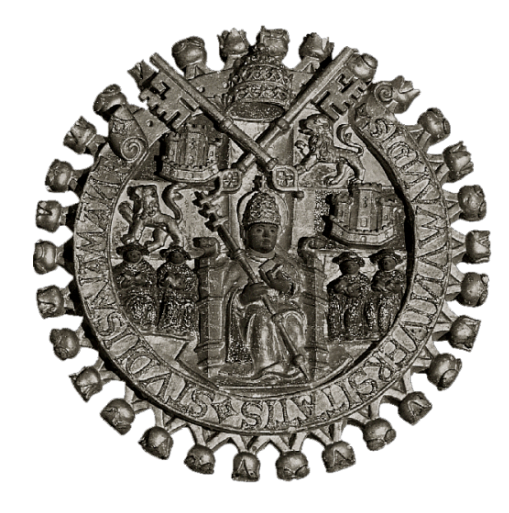

TESIS DOCTORAL

Paula Aguilar PeÑa

\title{
ESTRATEGIAS DE CORTESÍA VERBAL Y ATENUACIÓN CORTÉS UTILIZADAS EN DEBATES SEMIPAUTADOS DE JÓVENES Y ADUlTos MAYORES DE SANTIAGO DE CHILE
}

Dirigida por D. Julio Borrego Nieto y D. César Hernández Alonso 



\section{INDICE}

1 INTRODUCCIÓN — 1

2 Hipótesis DE TRABAJO _ 11

2.1 Un cambio en las actitudes lingüisticas de los chilenos ___ 11

2.2 La selección de las estrategias discursivas___ 12

3 DESCRIPCIÓN DE LOS OBJETIVOS __ 17

3.1 Objetivo general — 17

3.2 Objetivos especificos __ 17

4 LA MUESTRA: EL CORPUS __ 19

5 La ARgumentaCión EN El DEBATE __ 23

5.1 El debate —23

5.2 El concepto de argumentación __ 24

5.2.1 Estructura interna de la argumentación _ 28

5.2.2 Elementos de la argumentación __ 30

5.3 Formas de razonamiento __ 34

5.4 Indicadores de fuerza argumentativos __ 36

5.5 Los marcadores argumentativos __ 39 
6 RECORRIDO POR LAS PROPUESTAS Y ESTUDIOS CRÍTICOS SOBRE CORTESÍA VERBAL

6.1 Algunos antecedentes y fundamentos teóricos 47

6.2 La pragmática lingüística 48

6.2.1 El principio de cooperación: un importante antecedente para los estudios teóricos de la cortesía verbal 50

6.2.2 Los contenidos implícitos 52

6.2.3 La relevancia, el modelo del código y el modelo inferencial de la comunicación: Sperber y Wilson 55

7 LA CORTESÍA LINGÜÍSTICA EN LA CONVERSACIÓN 61

7.1 Algunos aspectos sobre la conversación 61

7.2 La cortesía lingüística como estrategia conversacional 63

7.3 Estudios y teorías sobre cortesía verbal 67

7.3.1 Estudios y propuestas iniciales 67

7.3.2 Acercamiento al modelo de Brown P. y Levinson S. 71

7.3.3 La perspectiva de Watts 80

7.3.4 El modelo de cortesía verbal propuesto por Leech 85

7.3.5 La cortesía según Haverkate 88

7.4 Perspectivas para abordar la cortesía verbal 94

7.5 Los indicadores de fuerza discursiva de cortesía verbal 95

7.6 La atenuación lingüística como estrategia de cortesía 97 
8 Metodología propuesta: AdeCUACión DE UN MOdElo PARA EL ESTUdio DE LA CORTESÍA VERBAL 105

8.1 Metodología de análisis del corpus 106

9 ANÁLISIS DEL CORPUS DE REFERENCIA 117

9.1 Análisis del corpus de los jóvenes 117

9.2 Análisis del debate de los adultos mayores 205

10 RESULTADOS DEL ANÁLISIS 273

10.1 Resultados del análisis de los episodios temáticos del debate de los jóvenes 273 10.2 Resultados del análisis de los episodios temáticos del debate de los adultos mayores 286

11 CONCLUSIONES 297

12 Bibliografía 303 



\section{AgRADECIMIENTOS}

Agradezco a la Universidad de Salamanca por otorgame la beca de estudios del Banco Santander que me permitió iniciar mi formación de tercer ciclo y permanecer en Salamanca durante el periodo de docencia e investigación.

Muy especialmente le agradezco a don Julio Borrego Nieto por el apoyo permanente que me ha brindado, desde mi llegada a esta casa de estudios, y por su dedicación en la dirección de mi tesis; asimismo a don César Hernández Alonso de quien tuve la suerte de recibir una excelente orientación teórica, además de su guía y ánimo durante la elaboración de este proyecto. Fue muy importante haber conocido a profesores como ellos, con tan alta calidad profesional y talento académico. Dejo aquí constancia de mi más profunda y sincera admiración, respeto por su sabiduría y agradecimiento por la capacidad de entrega en la enseñanza de la lingüística.

Agradezco a la Academia Chilena de Lengua, en especial a nuestro querido Director don Alfredo Matus Olivier, por apoyarme para lograr la concreción de mi tesis y permitirme viajar reiteradamente a España por asuntos de esta investigación. Le agradezco al profesor don Alfredo Matus la gran generosidad intelectual y emocional que siempre me ha ofrecido.

Quiero agradecer a mi familia, especialmente a mis padres, por animarme a iniciar y luego concretar esta investigación, ayudarme y apoyarme siempre en todos mis asuntos y subirme el ánimo. A mi novio Fernando Muñoz (o pololo, como decimos en Chile), por animarme tanto, hacerme reír y ayudarme en las últimas etapas de este proyecto.

A mis amigos de Chile, Perú y Uruguay que conocí en mi estadía en Salamanca. Gracias a todos por su amistad, su ayuda y tantas horas de alegría. 



\section{INTRODUCCIÓN}

El propósito de este estudio es realizar, desde una perspectiva pragmalingüística, una descripción de las estrategias de cortesía verbal utilizadas en debates coloquiales y semiespontáneos de un grupo de hablantes del español de Santiago de Chile. Se describirá, en primer término, la interacción discursiva de un grupo de estudiantes de la Pontificia Universidad Católica de Chile y, en segundo, de un grupo de adultos de la tercera edad; todo esto con el fin de describir las estrategias de cortesía empleadas de forma sistemática por estos dos grupos etarios de personas y poder comprobar así que existen diferencias en la formalización gramatical de estas estrategias comunicativas en debates coloquiales. De forma particular, se detallará la utilización de atenuaciones verbales corteses que si bien se sabe que pueden incrementar el distanciamiento social, según esta investigación también permiten a los hablantes del español usado en Chile mantener los lazos de filiación y, en algunos casos, incrementar el acercamiento en la interacción comunicativa.

Los estudios sobre cortesía verbal han llegado a ser una de las áreas de investigación dentro de la lingüística a las que más tiempo se les ha dedicado en las últimas dos décadas debido, principalmente, a su destacada contribución teórica y metodológica en análisis discursivos $\mathrm{y}$, sin duda, a sus constantes conexiones con otras áreas, como la sociolingüística y sociopragmática, etnografía de la comunicación, adquisición y enseñanza de segundas lenguas y análisis de la conversación. Todo ello ha contribuido, inevitablemente, al crecimiento del interés por su estudio y a su próspera consideración.

La relevancia de esta tesis radica precisamente en ser un aporte en investigaciones sobre la cortesía verbal en el discurso oral, debido a que se propone un modelo original de aplicación en análisis discursivos, específicamente enfocado en el género discursivo

\footnotetext{
${ }^{1}$ La muestra está constituida por trece hablantes del español de Santiago de Chile. Se cree que este corpus dará cuenta de ciertos aspectos y estrategias comunicativas interactivas de la lengua, si bien no dará, evidentemente por su extensión, cuenta de todas estas estrategias.
} 
'debate', inserto en una situación comunicativa semipautada ${ }^{2} \mathrm{y}$, por tanto, semiespontánea. Dicho modelo está basado en un componente teórico que integra conceptos tomados de estudios lingüísticos iniciales de la filosofía analítica respecto a la interacción comunicativa, de la pragmalingüística, y del análisis del discurso y de la conversación.

De este modo, al analizar el corpus se combinaron enfoques propios del análisis de la conversación con los de la pragmática y el análisis del discurso; esto debido a que algunos principios teóricos y metodológicos del análisis de la conversación proporcionan gran ayuda a los estudios de la conversación desde perspectivas más inmanentes. Además, es razonable tener en cuenta que, cuando se analiza la conversación, manifestación discursiva más "prototípica y natural” (Briz, 2004: 13), y se pretenden explicar los mecanismos lingüísticos usados por los seres humanos, "es conveniente considerar también las estructuras o patrones de comportamiento social que se reflejan en la conversación" (Llorente, 1996: 58, 59).

Con la intención de realizar una reflexión sobre las bases teóricas que sustentarán esta investigación en particular, se revisaron las teorías de la cortesía a través de la síntesis de los modelos teóricos fundadores propuestos por Brown P. y Levinson S. (1978/1987); Lakoff (1973) y Leech (1998), así como la extensa lista de estudios críticos y consideraciones metodológicas realizados por Briz y Bravo (2004); Escandell (1995, 2006); Haverkate (1994, 2004); Kerbrat-Orecchioni, (2004, 1998, 1992, 1983); Watts (2003); Wierzbicka (1991), entre otros.

Dicha descripción lingüística del marco de referencia de la teoría de la cortesía se realizó considerando aspectos pragmáticos, es decir, interpretando los enunciados y las estrategias de cortesía implícitas en ellos, además de todos los elementos que intervienen en el circuito de la comunicación (emisor, receptor, canal, circunstancias y código) (Gutiérrez Ordóñez, 2002) así, los enunciados siempre se describirán como parte de un proceso de

\footnotetext{
${ }^{2}$ Semipautada en el sentido de que no se han establecido turnos para cada uno de los participantes en ambos debates, ni tiempo de duración de cada uno de los turnos. Sin embargo, sí se propusieron los temas a debatir.
} 
enunciación completo. En esta investigación, por tanto, se ha adoptado una perspectiva funcional basada en el principio de que el lenguaje debe explicarse desde sus funciones esenciales, la comunicación y la interacción, dada la creencia de que son estas funciones las que modelan al propio lenguaje (Llorente, 1996).

Por otra parte, el fenómeno de la cortesía debe ser entendido, además, dentro de un marco social del lenguaje. Siguiendo a Van Dijk:

Esta interpretación más amplia del discurso en la sociedad y cultura constituye el punto culminante de los estudios del discurso. En un marco de semejante complejidad y amplitud podemos ir más allá de los límites del mero estudio discursivo de las combinaciones de oraciones, de la coherencia, de los actos de habla, de los turnos de la conversación y de los cambios de tópico. Aunque muchas propiedades de estas estructuras y estrategias son relativamente autónomas $e$ independientes del contexto, muchas otras interactúan con las propiedades de los contextos local y social (Van Dijk, 2000: 47,48).

En efecto, si bien estudiar el fenómeno de la cortesía entendida como un conjunto de estrategias conversacionales (Escandell, 2006) ayudaría a delimitar más fácilmente el objeto de estudio dentro de una teoría del lenguaje, es importante considerar que la cortesía es, a la vez, un fenómeno sociocultural. Por tanto, describir las manifestaciones lingüísticas de la cortesía requiere de enfoques interdisciplinarios en los cuales se deben considerar conceptos teóricos y metodológicos que forman parte de ciencias que estudian otras actividades humanas (Bravo, 2004).

Siguiendo la propuesta de esta última autora, podemos definir la cortesía al calificarla como "lingüística, comunicativa, conversacional y estratégica". El apelativo “lingüística”, dice Bravo, se debe a que es objeto de estudio de la lingüística y, por cierto, debido a que se realiza gracias al uso de la lengua; "comunicativa", en tanto que es objeto de estudio de las ciencias del lenguaje en general; "conversacional" puesto que la interacción 'modelo"3 en la cual se aplica este tipo de cortesía es en forma mínima de un

\footnotetext{
${ }^{3}$ Bravo describe la conversación como la interacción comunicativa 'modelo' en la que se aplica la cortesía, sin embargo, se entiende que lo está haciendo en uso muy restringido. Tal descripción implica que la cortesía
} 
diálogo entre personas físicamente presentes que mantienen una relación 'idealmente' simétrica en cuanto a sus derechos a participar en el intercambio de contribuciones comunicativas, y "estratégica" ya que depende de las elecciones libres ${ }^{4}$ de un hablante en el contexto de la situación de habla en la que se producen. Gracias a este proceso de adjetivación múltiple al fenómeno de la cortesía, se ha delimitado su ámbito de competencia y descrito el punto de partida y objeto de interés de esta investigación.

En este estudio, siguiendo una propuesta interactiva y social del discurso, se supone que la acción de manifestar cortesía es una actividad que no está sujeta solo a reglas generales o universales, pues es innegable que las personas en todo el mundo realizan esta actividad de distinto modo (Van Dijk, 2000). De hecho, las confusiones más comunes entre los participantes de una conversación (intra o extraculturalmente diferentes) surgen debido a que tienen diferentes concepciones de cómo se es cortés, si bien están implícitamente de

sea tenida como una estrategia conversacional en el sentido de que siempre se está pensando en el receptor del mensaje, con el cual se mantiene un vínculo comunicativo y al cual se tiene en mente durante la preparación de un discurso oral o escrito. Sabido es que en la variedad de géneros discursivos existentes, incluyendo los textuales, se observan estrategias de cortesía verbal y atenuación. En un monólogo, por ejemplo, es posible observar estrategias lingüísticas de reconociento al otro, aminoramiento de la imagen del interlocutor, etc. Así como también es posible observar técnicas de atenuación en editoriales de prensa que intenten mitigar el impacto que pudiera causar en sus lectores una crítica excesivamente severa o, por otra parte, dar pie al reconocimento a cierta tendencia política usando estrategias corteses.

${ }^{4}$ Esta aparente libertad que creemos tener en el momento de seleccionar nuestras estrategias comunicativas, que conforman los enunciados que estructuran nuestros discursos, es ciertamente relativa si consideramos la presión que ejerce el entorno social en nuestras conductas e interacciones verbales ya que "en toda sociedad la producción del discurso está a la vez controlada, seleccionada y redistribuida por un cierto número de procedimientos que tienen por función conjurar los poderes y peligros, dominar el acontecimiento aleatorio y esquivar su pesada y temible materialidad (...) El discurso (...) las prohibiciones que recaen sobre él, revelan muy pronto, rápidamente, su vinculación con el deseo y con el poder" (Foucault, 1992: 5,6). Con todo, algo de libertad nos queda, pues a pesar de lo dirigida y manipulada que puedan estar nuestras interacciones por el entorno social es innegable que realizamos elecciones léxicas, sintácticas y pragmáticas al entablar cualquier contacto lingüístico. 
acuerdo en que la cortesía es apropiada para el discurso ${ }^{5}$. Esta discrepancia se produce debido a que existen tres estrategias básicas de cortesía (distancia, deferencia y camaradería) y cada cultura adopta una como la principal y, además, se obtiene su definición de forma convencional (Lakoff, 1990).

Una vez revisado el contexto teórico en el que se inserta la cortesía verbal, se observa que existen dos grandes enfoques en los que se ha especializado su estudio, esto es, por un lado, aquellos que presentan un acercamiento más general y de tendencia universalista, que buscan llegar a generalizaciones sobre lo que es la cortesía y, por otro, propuestas que proclaman que solo deben describirse los fenómenos de cortesía contextualizados socioculturalmente.

En esta investigación se intentará desarrollar una metodología de análisis que permita observar ciertas estrategias comunicativas de uso sistemático integrando ambas posturas, con la intención de obtener una descripción profunda del objeto de estudio. Todo esto ya que se considera que es importante no olvidar las cuestiones metodológicas, pues no pueden ser tratadas aisladamente, "sino en relación con la teoría o aparato conceptual que subyace a un análisis o acercamiento particular del fenómeno en estudio" (Murillo, 2004: 53); por tanto, en esta investigación si bien se tuvieron en consideración las propuestas metodológicas empleadas hasta ahora en la investigación sobre cortesía, se ha hecho hincapié en sus supuestos teórico-epistemológicos y en su relación con metodologías de investigación empleadas en otras disciplinas de las ciencias sociales.

Por ello, se propone un enfoque de análisis y, posteriormente un modelo de análisis que, si bien forja sus cimientos en el modelo clásico de Brown P. y Levinson S. , pues

\footnotetext{
${ }^{5}$ En este estudio se considera, entonces, que la cortesía es universal si se tiene en consideración que en todas las sociedades humanas se constata la existencia de comportamientos que permiten mantener un mínimo de armonía entre los interlocutores, a pesar de los riesgos de conflictos que están inherentemente relacionados con toda interacción; y al mismo tiempo, que la cortesía no es universal, en la medida en que sus formas y condiciones de aplicación varían de una sociedad a otra. (Kerbrat-Orecchioni, 2004: 39)
} 
permite dar cuenta de principios universales del uso del lenguaje, además, con ciertas modificaciones, describe el funcionamiento de la cortesía en una cultura en particular. Así, esta perspectiva permitiría realizar una descripción que incluya las dos tendencias descritas anteriormente pues permite observar elementos lingüísticos (nivel sintáctico y léxico) sin dejar de lado el contexto situacional y cultural ${ }^{6}$.

Ciertamente, todos los valores pragmáticos son sensibles al contexto, pues puede ocurrir que el entorno situacional, el acompañamiento prosódico y gestual, modifiquen el valor de base del enunciado y, por esta razón, “el ejercicio de la cortesía exige a quien la emplea que evalúe correctamente el conjunto del contexto para poder producir e interpretar correctamente un enunciado cortés”, o no cortés (Kerbrat-Orecchioni, 2004: 48). Dicha evaluación de estos actos comunicativos se cree que solo puede ser realizada por un hablante de la lengua materna y además conocedor de las valoraciones socioculturales que posean estas estrategias comunicativas corteses en contexto.

Por otra parte, ya que el corpus de esta investigación corresponde a grabaciones de debates, se revisará también la teoría de la argumentación, propuestas de modelos argumentativos y los rasgos generales de este género discursivo. Todo ello para facilitar el proceso de análisis y poder describir adecuadamente la función de los enunciados y desentrañar su rol como acto discursivo en este proceso comunicativo.

Se entiende así que se propondrá un modelo de análisis que permita realizar una descripción de las estrategias conversacionales de cortesía así como también, facilitar la descripción del funcionamiento de elementos lingüístico-pragmáticos (técnicas argumentativas, atenuación lingüística con el fin de ser cortés, etc.) que sirvan para marcar la orientación cortés de un enunciado. Para lograr dicho objetivo se considerarán elementos

\footnotetext{
${ }^{6} \mathrm{Al}$ realizar el análisis de cada uno de los episodios temáticos del corpus, se tuvo en consideración el valor diferencial de ciertas unidades léxicas; por tanto, en todo momento se describe el léxico, fraseología en general y usos sintácticos propios del español hablado en Santiago de Chile, ubicando cada uno de estos rasgos lingüísticos en un contexto sociopragmático.
} 
socioculturales que ayuden a entender actitudes lingüísticas implícitas en la conversación y sus valoraciones, por medio de una exposición detallada de usos diferenciales del español de Santiago de Chile presentes en el corpus, destacando así sus rasgos sintácticos distintivos y léxico particular.

Veamos el siguiente fragmento extraído del corpus de trabajo ${ }^{7}$ para observar específicamente cómo se tratará el tema de la diferencialidad en el léxico y en los aspectos sintácticos del español de Chile:

(...) H2: <[.pero a mí me parece que eso $e^{h}$ algo muy bueno]

M2: ¿ah?

H2: me parece que $e^{h}$ algo muy bueno.

M2: ¿qué cosa?

H2: a mí me parece muy bueno que la ${ }^{h}$ mujeres puedan hacer eso, ¿cachai?

M2: no: a mí también, lo encuentro excelente, pero:-

H2: y que exista una religión católica, me parece también muy bueno pero no puede como, su ${ }^{h}$ creencias, ahí está lo que dice el Rorro, no las puedes imponer, es necesario ¿cachai? que exista $\rightarrow$

M2: pero yo estoy hablando desde un punto fuera de, de religión, fuera de pensamiento político estoy hablando de eso mismo.

H2: pero el problema es cuando intentan imponerlas porque-

M2: a mí no me están imponiendo ninguna religión al estar a favor o en contra.

H2: con el tema de la pastilla VAN A IMPONER.

M2: <[.no tiene relación ]

M2: YO, puedo hablar desde un punto completamente ateo al decir que mi, mi opinión es proteger la vida

H2:: si po.

\footnotetext{
${ }^{7}$ El fragmento pertenece al episodio 3 de las grabaciones de los jóvenes universitarios.
} 
M2: y no me refiero a ninguna religión, no te estoy imponiendo ninguna religión con eso.

H2: pero si eso es lo que estaban diciendo, o sea, Gonzalo.

H2:no, no, si eso fue, no $e^{h}$ que-

M2: bueno e:

M3: pero yo creo que este $e^{h}$ un tema nuevo porque la sociedad está cambiando ahora, osea, no sé, nuestros papás no tenían estos atados porque antes, no sé, mi mama no pensaba tener relacio:ne $e^{h}$ antes de casarse con alguien, pero $e^{h}$ que es muy cierto, o sea ahora, ahora la $^{h}$ mujeres, o sea bueno, porque lo ${ }^{h}$ hombre ${ }^{h}$ siempre se han a costado con todo el mundo, \{risas\}como que nunca le ha importado tanto la virginidad como a las mujeres porque las mujeres somos las que tenemos que cargar el problema, entonces $\rightarrow$ M2: <[.y a la ${ }^{h}$ que se $\left.l e^{h} j^{h} g a\right](. .$.

En este fragmento, se apela a la pertenencia al mismo grupo mediante el uso de marcadores de identidad de grupo (Brown P. y Levinson S. , 1987), estos son: uso de voseo $\operatorname{verbal}^{8}$ (vai, cachai) y léxico espontáneo $\left(p o^{9}, \operatorname{cachar}^{10}\right.$, atado $\left.{ }^{11}\right)$. El uso de estas estrategias intensifica la pertenencia al grupo y los identifica como miembros del mismo, pues es léxico espontáneo que no usarían si no estuvieran conversando entre pares. Así mismo, la aspiración de la $s$ al final de sílaba, principalmente, da cuenta de la situación espontánea en la que se encuentran los interlocutores. La aspiración de la sílaba $s$, al

${ }^{8}$ Se observará más adelante que el uso del voseo verbal en el español hablado en Chile está restringido a situaciones informales. (cfr. pág. 42)

9 “pos. marc. disc. Pues; se usa para enfatizar o remarcar una aseveración u orden.espon. Observ. Normalmente sufre acortamiento hasta llegar a pronunciarse [po] o simplemente [p]”. (DUECh, 2010)

10 “cachar.tr. Percibir con la visión o los oídos. espon (...).2. tr. Conocer, tener conocimiento.espon. (...) 3. tr. Entender, comprender.Espon. (...)4. tr. Suponer, creer.espon”. (DUECh, 2010)

11، atado. m. Problema. espon. "Don Pepe dijo que el atado es que todavía hay restos de autoritarismo dentro de los colegios “. (La Cuarta, 28.11.97, p.7)”. (DUECh, 2010) 
término de sílaba o palabra, es un rasgo transversal del español de Chile principalmente observado en situaciones espontáneas.

Respecto a la temática de este fragmento y cómo se va desarrollando el tema propuesto sobre el uso de la 'píldora del día después', podemos decir que M3 apela con mucho acierto a puntos de vista, opiniones, actitudes, conocimiento, empatía comunes de su grupo. Busca el acuerdo al describir el proceso por el que ha pasado la generación de sus padres (y por ende, la de los padres de todo el grupo) hasta su generación actual y cómo el conservadurismo clásico de la sociedad chilena hoy se ha liberalizado de estructuras antiguas. Además, sabe que puede bromear con el machismo y otras creencias estereotipadas presentes en la sociedad chilena, pues tiene la certeza de que sus compañeros comparten su apreciación sobre estas actitudes. La risa producida por su broma permite reducir la imposición de las posturas contrarias y evita volver al proceso de contraargumentación en el que se encontraba el debate. Como se verá en las páginas que siguen, Leech insiste en que la risa, a causa de bromas en un intercambio comunicativo, constituye una actitud cortés que está dentro de las máximas de cortesía que este autor propone; específicamente dentro de la máxima de simpatía: "Reduzca al mínimo la falta de simpatía entre el yo y el otro: aumente al máximo la simpatía entre el yo y el otro" (cfr. pág. 63).

Este breve fragmento del corpus permite mostrar cuál será la perspectiva desde la que se analizará el uso de estrategias discursivas y, particularmente, léxico diferencial del español de Chile en el corpus. 



\section{HiPÓTESIS DE TRABAJO}

Esta investigación está sustentada en la siguiente hipótesis de trabajo: se sostiene que los dos corpus orales que se han recogido en debates coloquiales para llevar a cabo esta investigación, difieren en la formalización gramatical de estrategias de cortesía verbal y atenuación, cuando esta atenuación es usada como estrategia de cortesía verbal ${ }^{12}$. Esto debido a que el rasgo etario de las personas que conforman cada uno de los grupos que debaten es diferente: mientras el grupo 1 está constituido por jóvenes de 18 y 19 años, el grupo 2 lo conforman personas de 60 y hasta 67 años.

Específicamente, se cree que las interacciones dialógicas de jóvenes de Santiago de Chile han cambiado en los últimos años respecto a la percepción clásica que se ha obtenido tradicionalmente en análisis descriptivos comunicativos sobre el español de Chile. Se cree que en debates espontáneos, actualmente, los jóvenes seleccionan estrategias verbales más directas y confrontacionales en el momento de manifestar una postura contraria, contradecir a alguien en enfrentamientos verbales o encarar puntos de vista disímiles; en efecto, se cree que se ha ido modificando la "selección que hace el hablante de aquellas estructuras sintáctico-semánticas que cree que sirven óptimamente para conseguir que el oyente acepte el acto ilocutivo y reaccione de manera positiva ante el mismo" (Haverkate, s/fecha: 375).

\subsection{Un cambio en las actitudes lingüísticas de los chilenos}

Desde la llegada de los gobiernos democráticos, en 1990, la sociedad chilena ha cambiado en varios aspectos. Es una constante que en discusiones políticas y reflexiones filosófico-legales surja la pregunta acerca de si las instituciones públicas han sido capaces de responder a las expectativas de estos cambios políticos, sociológicos, morales y tecnológicos por los que la sociedad ha ido atravesando. Esta pregunta, sin duda, requiere,

\footnotetext{
${ }^{12}$ En este estudio se describirán estrictamente los atenuantes utilizados con el fin de apelar a la cortesía. Se profundizará en esta delimitación con más detalle en las páginas que siguen.
} 
en primer lugar, de una nueva forma de observar y analizar las necesidades sociales. Desentrañar estas perspectivas implica describir cuáles han sido estos cambios sociológicos.

Uno de los cambios importantes parece ser la transición de esta sociedad, conformista y con mentalidad jerárquica, hacia una sociedad que demanda participación e inclusión. Como indica el informe de desarrollo humano en Chile, del año 2009, del Programa de Desarrollo las Naciones Unidas (PNUD), el entorno de seguridad y estabilidad que se consolidó durante los 90, "provocó una importante reducción del temor a los conflictos y a la expresión de las diferencias, miedos característicos de la cultura política del país" (Informe PNUD 2009: 37); un importante cambio que, de forma simultánea, "alentó la expresión de las demandas sociales" (Informe PNUD 2009: 37). Este movimiento social ha iniciado una variada gama de demandas en los últimos años de parte de grupos de distinta índole: estudiantes universitarios y escolares, minorías sexuales, movimientos indígenas, feministas, minorías políticas, entre otros. Organizados colectivamente, estos grupos muestran una mayor disposición a exigir nuevas prácticas de parte de sus instituciones públicas con el objetivo de alcanzar sus derechos y lograr cambios.

En cuanto a la actitud de los chilenos frente al conflicto, la diversificación de sus demandas y su disposición a tomar medidas, estas investigaciones realizadas por el $P N U D$ muestran un cambio significativo desde el año 2001 hasta 2004. El porcentaje de personas que cree que es necesario evitar conflictos se redujo de 70, en 2001, a 56, en 2004. En contraste, el porcentaje de personas que piensan que los conflictos necesitan ser confrontados de manera que sus problemas subyacentes puedan ser identificados aumentó de 20, en 2001, a 42, en 2004. Con estos datos, el informe 2004 del PNUD sugiere como su hipótesis de trabajo que "la sociedad chilena se encuentra hoy más preparada que antes para aceptar el conflicto y apropiarse de la libertad" (Informe PNUD 2004: 41).

\subsection{La selección de las estrategias discursivas}

En el proceso de selección en la interacción verbal, o actos alocutivos (Haverkate, s/fecha), el hablante del español de Chile ha sido descrito tradicionalmente, en estudios 
realizados con anterioridad a 1990, como un interlocutor que tiene una excesiva delicadeza en el momento de debatir o dar órdenes, es decir, que se caracteriza por seleccionar enunciados alejados de la imposición y cercanos más bien, al ruego o la petición, aunque con intención ilocutiva de mandato. Son precisamente estos rasgos de la interacción comunicativa los que se cree que actualmente no son representativos de los hablantes jóvenes y son, más bien, propios del grupo etario 2, conformado por adultos mayores.

Tradicionalmente, desde una perspectiva prosódica, la percepción del característico "cantadito" 13 del chileno ${ }^{14}$, al que se le suelen atribuir influencias producto del contacto con lenguas indígenas, ${ }^{15}$ se considera que puede permitir suavizar, por ejemplo, la modalidad

${ }^{13}$ La palabra "cantadito" en el español de Chile está registrada en el Diccionario de americanismos; no obstante, no incluye la marca diatópica $C h$ y está definida así: "cantadito: I.1.m. $M x, G u, H o, E S, N i, P a, C u$, $P R, V e ; E c: S$, fest. Modo de hablar de una persona que muestra su variedad dialectal en la entonación y la particular pronunciación de ciertos sonidos." (Diccionario de americanismos, 2010); se espera que en una próxima edición de este diccionario su actualización permita corregir la ausencia de esta marca diatópica. La autora de esta investigación, y colaboradora en la redacción de esta obra lexicográfica panhispánica, deja expresa constancia de que la Comisión de Lexicografía de la Academia Chilena de la lengua informó en su momento respecto al uso de esta palabra; no obstante, las premuras y la tremenda cantidad de información que recoge este diccionario facilitaron desfases de este tipo, falencias que se irán corrigiendo en futuras ediciones.

${ }^{14}$ Aunque de forma que no puede ser considerada exactamente una descripción científica, los estudios pioneros sobre la descripción del Español de Chile realizados por el lingüista Ambrosio Rabanales (1992) detallan esta particularidad: "tono blando y suave". Además describe los aspectos fonológicos, morfosintácticos y léxicos que comparte la norma general a lo largo del todo el país.

${ }^{15}$ Existe cierta polémica respecto al grado de influencia que ejercen las lenguas amerindias en el español de América. Sin duda, estas discusiones teóricas van más allá de la influencia singular de determinada lengua sobre el español (Zimmermann, 1995); en efecto, la ideología de los investigadores los divide y de forma inevitable sus posturas se pueden distribuir en dos sectores, a saber: los que intentan demostrar que las características principales del español de cierta región se deben a la fuerte influencia de las lenguas indígenas y los que proponen demostrar que tal influencia ha sido mínima. Un importante antecedente referido al español de Chile son los estudios del investigador y lingüista alemán Rodolfo Lenz, quien realizó un intento por explicar las peculiaridades del español de Chile, considerando la influencia del mapuche en muchos de 
deóntica de un enunciado; si bien esto no impide, claro está, trasmitir por ello su fuerza ilocutiva. Evidentemente que no sería posible afirmar, sin realizar un estudio fonético previo que sirva de sustento, que la tonalidad suave se haya ido modificando de una generación a otra; no obstante, se percibe que los jóvenes están familiarizados a intercambios comunicativos ciertamente más directos, menos atenuados y con más confrontación retórica. Por tanto, precisamente la selección de estas estrategias sintácticas particulares, con o sin atenuación de cortesía, más o menos corteses, pueden haber ido modificándose con el tiempo y son estas innovaciones, en cuanto a la elección de una estrategia frente a otra, los rasgos interesantes de describir para este estudio ${ }^{16}$.

estos rasgos, lo que evidentemente permitiría introducirlo en el primero de estos "bandos". En 1893, Lenz publicó un polémico y lúcido artículo titulado "Beiträge zur Kenntnis de Amerikanospanischen" en el que analiza la evolución demográfica, la historia cultural chilena y describe los sistemas fonológicos mapuches y los del español chileno. Propone la existencia de más de diez rasgos que distinguen el español de Chile del resto de los dialectos españoles, producto de la influencia del sustrato sobre el español hablado en ese país. Compara exhaustivamente el sistema fonético de esta lengua indígena con el del español hablado en Chile y propone, como conclusión de todas sus investigaciones, que el español coloquial de Chile es principalmente español con sonidos araucanos (Correa, M., 2001). Por su parte, Rodolfo Oroz, reconocido lingüista chileno, se opone a dicha propuesta araucanista, argumentando que Lenz, equivocadamente, calificó de peculiares una serie de fenómenos en la pronunciación chilena que son causados por la lengua araucana desplazada y que este concluyó, adelantadamente, que el español coloquial de Chile era español con fonética araucana. De forma categórica, Oroz indica que esos fenómenos fonéticos que Lenz creyó de origen araucano son comunes a todas las variedades del español hablado en América; por tanto, expone que las particularidades fonéticas del español chileno (seseo, yeísmo, aspiración de -s al final de sílaba, etc.) son características comunes del español americano. Acepta, no obstante, la participación del influjo sustratista en dos sectores: préstamos lexicográficos y en aspectos de la entonación del español vulgar chileno.

${ }^{16}$ La líder del movimiento estudiantil chileno, Camila Vallejo, recalca en entrevista con el diario El País precisamente el cambio discursivo que se ha producido en las interacciones de los jóvenes de hoy en día: “(...) P. ¿Qué diferencia a su generación de la de sus padres? R. Nuestra generación no tiene temor. Y por eso, a diferencia de nuestros padres, no nos cuesta denunciar que en Chile hay abuso, represión, que los empresarios están robando y que los políticos muchas veces son unos sinvergüenzas (..)”. (Diario El País , [en línea] [edición del 15/1/2012]. Disponible en la Web: www.elpaís.com. ) 
Asimismo, se cree que las estrategias atenuantes corteses, pueden ser utilizadas, en algunos casos, según esta investigación, también con el fin de obtener cercanía y ganar la confianza de los interlocutores. Si bien es cierto que desde un punto de vista pragmalingüístico, no es posible afirmar que toda atenuación involucra un acto de cortesía verbal $^{17}$, la atenuación, específicamente la referida a la cortesía, conforma en sí misma una estrategia comunicacional relevante dentro de las estrategias comunicativas verbales, pues reflejan actitudes socioculturales e incluso puede llegar a dar cuenta de las aspiraciones de camaradería que se pretende establecer con el otro.

Estas serán, entonces, las hipótesis que se proponen y que se tratarán de probar en la presente investigación.

\footnotetext{
${ }^{17}$ Actos verbales que tienen atenuación y que representan actos ilocutivos como prevenir, curar o reparar o, por ejemplo, no involucrarse en exceso, no pueden ser considerados como cortesía en sí mismos, si no que como actos ilocutivos atenuados.
} 



\section{DESCRIPCIÓN DE LOS OBJETIVOS}

\subsection{Objetivo general}

El objetivo general es describir, analizar y contrastar, desde una perspectiva pragmalingüística, las estrategias de cortesía verbal y atenuación verbal cortés en dos debates coloquiales de dos diferentes grupos etarios de personas, de nacionalidad chilena, hablantes del español de Santiago de Chile.

\subsection{Objetivos especificos}

1. Describir, clasificar y analizar la selección que hacen los hablantes de aquellas estructuras sintáctico-semánticas que expresen cortesía verbal (positiva y negativa) y atenuación cortés y que se cree sirven, además, óptimamente para conseguir que el oyente acepte el acto ilocutivo y reaccione de manera positiva ante el mismo.

2. Describir el proceso argumentativo utilizado en cada uno de los episodios temáticos (Van Dijk, 1982) en los que fue dividido el corpus, clasificando cada uno de los elementos constitutivos de este proceso discursivo.

3. Explicitar las diferencias, a través de un estudio de contraste, entre los corpus orales pertenecientes a los dos grupos etarios.

4. Describir este encuentro comunicativo en particular, el debate, género argumentativo por excelencia, cuyo eje principal es la capacidad de enfrentarse al otro a través de la expresión de puntos de vista disímiles, con el riesgo consiguiente de atentar contra su imagen; por todo esto, la interacción entre sus participantes, esto es, sus estrategias de acercamiento, de atenuación, de cortesía, resultan cruciales, pues permiten mantener la complicidad y la conciencia de pertenencia al grupo. 

El corpus está constituido por dos debates de hablantes chilenos que totalizan dos horas de grabación. El primer coloquio lo conforman siete estudiantes, tres hombres y cuatro mujeres, de segundo año de la carrera Licenciatura en letras de Facultad de letras de la Pontificia Universidad Católica de Chile. La edad de los jóvenes voluntarios fluctúa entre los 18 y 19 años. Fueron seleccionados jóvenes de un nivel sociocultural homogéneo ${ }^{18}$, todos los jóvenes pertenecen a una clase socioeconómica media-alta.

En el segundo coloquio participó un grupo de seis personas, cinco mujeres y un hombre, cuya edad fluctúa entre los 60 y 67 años. Se considera que todo el grupo pertenece a un nivel sociocultural similar que puede ser descrito como medio-alto.

Antes de comenzar la grabación se les explicó a los participantes que el objetivo del encuentro era describir y estudiar las diferentes percepciones y posturas que surgieran a partir de la discusión de los temas propuestos. Una vez terminado el debate, se les informó que formarían parte de un estudio lingüístico y se les solicitó su autorización para analizar las grabaciones que se realizaron durante los encuentros.

${ }^{18}$ Un indicador que permite hacer una clasificación sociocultural común en Chile, es usar como datos pertinentes los siguientes: el barrio en el que viven y el colegio en el que estudiaron. En Chile, siguiendo a Montecino (2005), el consumo cumple la función de localizar a los portadores de ellos en la cadena de la estratificación, puesto que opera como signos visibles del dinero que poseen. "En ese aspecto los principales indicadores son la casa, la cual forma un todo con el barrio en el que está situada (...) A los rasgos anteriores, hay que agregar (...) la educación como un bien. El colegio y la universidad funcionan como marca de clase, como signo de estatus" (Montecino, 2005: 17). En este caso, los jóvenes de la muestra han sido capaces de acceder a una de las dos universidades más selectivas del país y provienen de colegios privados o semiprivados de buena calidad educacional, hecho que permite describirlos como miembros de una clase social medio-alta. Por su parte, los adultos mayores poseen estudios de nivel superior y viven en una de las comunas más prestigiosas de Santiago, situación que también los acerca a una clase medio-alta. 
El primer debate se realizó en una de las salas de reuniones de la Facultad de letras, en torno a una mesa redonda, donde se compartió también un pequeño cóctel y bebidas. La mediadora en el debate fue una profesora de Literatura ${ }^{19}$ de la misma universidad, cercana a los estudiantes, precisamente para evitar que estos se cohibieran al momento de dar su opinión. La profesora les explicó que se esperaba que hubiera posturas diferentes entre los estudiantes; asimismo podían expresar su opinión tanto si esta era coincidente con la de sus compañeros, como si difería de ella.

El segundo coloquio se realizó en la casa de uno de los participantes, en torno a una mesa, donde se compartió también un pequeño cóctel y bebidas. La mediadora en este caso fue la propia investigadora pues es amiga de todos los adultos, hecho que permite no interferir en el ambiente distendido y de confianza que permitió que los participantes expresaran sus opiniones sin inhibición.

Los temas que se discutieron en los dos debates fueron los siguientes:

a. La píldora del día después y su prohibición en nuestro país.

b. ¿Es posible permitir el matrimonio homosexual en una sociedad como la chilena?, ¿qué pasaría con la adopción de niños?

c. ¿Cuál es la percepción de los jóvenes sobre la calidad de las universidades privadas en comparación a las universidades estatales?

\section{d. ¿Consideran adecuado el método de acceso a las universidades de nuestro país?}

En las próximas páginas se abordarán temas relativos al género discursivo 'debate’, tipo de discurso en el que se desarrolla la actividad lingüística que será analizada en esta

\footnotetext{
${ }^{19}$ Agradezco la gentileza y ayuda de Rocío Rodríguez Ferrer, profesora del Departamento de Literatura de la Pontificia Universidad Católica, en la organización, planificación y realización de este debate en el que participaron sus estudiantes de pregrado.
} 
investigación. Además, se revisarán los procesos retóricos propios de este tipo de discurso, particularmente, la argumentación, formas de razonamiento y uso de falacias. Se cree fundamental integrar a este análisis elementos lingüísticos que permitan describir las interacciones verbales y las temáticas que se producen en los debates que conforman el corpus de esta investigación. Todo esto con la intención de desentrañar posibles contenidos implícitos y así lograr entender adecuadamente el proceso enunciativo de forma global. 



\section{$5 \quad$ LA ARGUMENTACIÓN EN EL DEBATE}

\subsection{El debate}

Como se sabe, la riqueza y diversidad de los géneros discursivos es inmensa porque las posibilidades de la actividad humana son inagotables y porque en cada esfera de la praxis existe todo un repertorio de géneros discursivos que se diferencia y crece a medida de que se desarrolla y se complica la esfera misma (Bajtin, 2002). Las situaciones comunicativas argumentativas concretas más frecuentes son la discusión, el debate y el consejo o reproche, pues son estos tipos de géneros discursivos, específicamente, los que manifiestan con mayor soltura las estrategias de argumentación y, por extensión, de persuasión, pues existe el afán de convencer al interlocutor utilizando para ello particulares estrategias lingüísticas. De entre ellas, se han elegido como objeto de este estudio las que ofrecen componentes de atenuación y cortesía.

$\mathrm{Si}$ bien el debate puede ser algunas veces considerado como la práctica argumentativa por excelencia, "la teoría del debate no es la teoría de la argumentación; y el debate no es la única forma de interacción argumentativa. El consejo es también, y de modo específico, un tipo básico de interacción y plenamente argumentativo" (Plantin, 2004: 125). Los intereses involucrados en cada uno de estos procesos comunicativos no son los mismos: mientras en el debate hay una confrontación directa de los intereses y la voz de cada participante es la voz de un interés, pues hay generalmente una identificación de las personas con los puntos de vista defendidos, en el caso del consejo hay un solo interés, el de la persona que pide consejo; rasgo que permite, en un principio, que no haya confrontación (Plantin, 2004).

Siguiendo a Plantin (2004), promover el debate es también incentivar una forma agresiva de argumentación si bien es una actividad eficaz para el desarrollo de las competencias argumentativas. La confrontación de los puntos de vista implica un modo de relación con el otro que puede llevar a romper la relación cordial entre los participantes de la argumentación, por tanto, el debate puede dividir al grupo de alguna forma. Asimismo, 
en un debate una opinión va a prevalecer en contra de la otra, es decir, que uno de los participantes se encuentra, al final, en una posición disminuida y el otro en una elevada. Así, debatir es introducir una forma de violencia en las relaciones humanas. Por todo esto, de acuerdo con la teoría de las “imágenes” planteada por Erving Goffman (1956) y con las de cortesía lingüística y no lingüística (Brown/ Levinson (1978/1987); Lakoff (1973); Leech (1983); Briz/ Bravo (2004); Escandell (1995, 2006); Haverkate (1994, 2004); Kerbrat-Orecchioni, (1992, 2004); Watts (2003); Wierzbicka (1991)), el debate implica un riesgo para la propia imagen y un posible daño a la imagen del otro.

El debate, es "una práctica pública de la argumentación sobre un tema predefinido, en un encuentro cara a cara, en el cual los turnos de habla y la sucesión de los subtemas son más o menos explícita y estrictamente regulados y arbitrados" (Plantin, 2004: 124). Es un tipo de interacción casi exclusivamente oral, está basado en la polémica, en el enfrentamiento de opiniones divergentes sobre un tema de interés social. Es común que en el debate participe un moderador que es el encargado de presentar el tema que será motivo de discusión y de ordenar y distribuir de manera idealmente ecuánime los tiempos y turnos de los participantes, así como de cerrar el tema que se discutió. El debate, idealmente se estructura en cinco momentos básicos: presentación, exposición, desarrollo, último mensaje y despedida (Plantin, 2004).

En este estudio en particular se estudiará, exclusivamente, el género debate, pues es esta la situación lingüística recogida en el corpus de esta investigación que permitirá analizar, describir y contrastar las estrategias discursivas entre jóvenes y personas de mayor edad. Si bien se trata más bien de coloquios, pues los participantes no deben defender solo uno de los puntos de vista planteados, se entiende que es un encuentro para debatir y exponer temas y criterios divergentes.

\subsection{El concepto de argumentación}

Muchos estudios coinciden al definir la argumentación como la operación discursiva orientada a influir sobre un público determinado (Bassols, M. y A. Torrent (1997); Alvarez, M. (1994); Alvarez, G. (1996)), considerando que el objetivo del 
argumentador es ofrecer una información lo más completa posible para intentar persuadir al destinatario mediante un razonamiento.

Según Vignaux (1986), toda argumentación es un conjunto de razonamientos que apuntalan una afirmación, una tesis. Para Plantin (2001) la argumentación es un discurso que tiende a convencer a un destinatario sobre cierto punto de vista, a persuadirlo de realizar cierta acción, o a reforzar en él convicciones ya existentes. De este modo, la argumentación intenta influir, transformar o reforzar las creencias o los comportamientos de las personas que constituyen su objetivo.

Dentro de las perspectivas lingüísticas actuales, es importante destacar los trabajos realizados por Anscombre y Ducrot (1994), respecto a la argumentación. Los autores adoptan una posición frente al concepto y análisis del discurso argumentativo basada en los desarrollos teóricos realizados en los trabajos sobre enunciación y actos de habla. Defienden que la argumentación está inscrita en la lengua; en las frases mismas se presentan elementos que permiten distender acotadamente los hilos, direcciones y alcances progresivos de toda argumentación. Definen argumentación desde dos perspectivas, una retórica y una perspectiva lógica; para la retórica, la argumentación comprende el conjunto de estrategias que organizan un discurso persuasivo y, para la perspectiva lógica, una argumentación es un tipo de razonamiento.

Por su parte, Van Dijk (1997), desde una perspectiva cognitiva, afirma que la argumentación funciona como una estrategia discursiva que se dirige a unos cambios específicos del sistema de creencias del oyente/lector, destacando así su función de persuasión. Este autor plantea algunas propiedades generales de la argumentación, enfatizando que una teoría de la argumentación debe ser multidisciplinaria, puesto que incluye propiedades lógicas, filosóficas, gramaticales, textuales, cognitivas, sociocognitivas, sociales y culturales.

En efecto, una teoría de la argumentación debe describir y explicar un cierto número de requisitos específicos (estructuras o estrategias) que debe contener todo discurso para poder clasificarse como argumentativo. A nivel de análisis textual, la argumentación, por lo 
tanto, puede caracterizarse en términos semánticos y esquemáticos (superestructurales).

La argumentación, para Van Dijk, se define formalmente en términos de estructuras jerárquicas de categorías convencionales, como son las categorías clásicas de premisa y conclusión, o bien en términos de propuestas contemporáneas de subcategorías adicionales de premisa, como son por ejemplo, justificaciones y fundamentaciones, etc. Los fundamentos y las funciones de la argumentación son esencialmente cognitivos.

Otra perspectiva sobre el análisis y la evaluación del discurso argumentativo que sintetiza aspectos de la filosofía y la lingüística es expuesta por Eemeren V. y Grootendorst R. (2002) en el modelo de la pragmadialéctica. Esta perspectiva reúne intuiciones pragmáticas, relativas a los actos de habla, e intuiciones dialécticas, relativas a la discusión crítica. Su aplicación permite estudiar el discurso argumentativo como una instancia de la comunicación y las interacciones verbales normales y, al mismo tiempo, evaluar siguiendo un cierto estándar de razonabilidad. Partiendo de la base de que la pragmática es el estudio del uso del lenguaje, se reconoce la necesidad de una convergencia entre normatividad y la descripción empírica, concibiendo el estudio de la argumentación como parte de una "pragmática normativa".

Por lo que respecta a la evolución del concepto de argumentación, Wenzel (1992) plantea tres perspectivas distintas, pero interrelacionadas: la retórica, la dialéctica y la lógica que se han complementado con los aportes de la sicología y de la sociología sobre la persuasión:

1) La perspectiva retórica enfoca el argumentar como un proceso. Para el retórico, argumentar es un modo de apelar, un modo de persuadir y una conducta típica de personas que usan símbolos para comunicarse; su propósito práctico es la persuasión. Esta perspectiva construye la argumentación como un proceso persuasivo, creado para satisfacer las necesidades de las personas que buscan convencer a otras.

Los estudios realizados bajo esta perspectiva intentan señalar los recursos de representación simbólica, considerados típicamente lingüísticos, a fin de expresar nuestra comprensión de cómo son las cosas y cómo deberían ser, de manera que resulten 
atractivas para otras personas. El propósito teórico de la retórica es comprender las condiciones para un argumentar efectivo, considerando siempre que el criterio fundamental para las reglas de la retórica es la eficacia. El enunciador es un actor social ingenuo y los auditores son una audiencia particular, ya sea real o construida por el que argumenta, en definitiva, son las personas a las que él se dirige.

2) La perspectiva dialéctica enfoca la argumentación como procedimiento. Argumento, dice el dialéctico, es un método disciplinado del discurso para someter a un test crítico las tesis; se promueve un análisis crítico de las expresiones, respecto a cómo son las cosas son o a cómo deberían ser.

El propósito teórico consiste en explicar las condiciones para una argumentación simple y crítica. A nivel teórico, la perspectiva dialéctica incluye todos los estudios de formas del discurso que buscan comprender las condiciones que afectan la toma de decisión crítica. El enunciador es un abogado consciente porque la dialéctica requiere el reconocimiento de otra persona que de, alguna manera, se enfrenta y se opone a nosotros.

3) La perspectiva lógica enfoca el argumento como producto. Argumento, para el lógico, es un conjunto de proposiciones que consiste en premisas y conclusión o apoyo y pretensión. El propósito práctico es el juicio y el propósito teórico es establecer estándares para argumentos correctos. Los argumentos son construidos como cosas o productos que pueden ser abstraídos del proceso de interacción comunicativa que se produce en la dialéctica o la retórica. Como estudio teórico, la lógica, trata de descubrir o desarrollar cánones de inferencias correctas que nos capacitan para establecer ciertas expresiones como un conocimiento confiable. Los lógicos se centran en un conjunto de proposiciones que son abstraídas del contexto comunicativo, objetivado y despersonalizado y contemplado como una construcción de una potencial importancia epistemológica. Las reglas del lógico son inferenciales explícitas y su estándar es la corrección (validez) del argumento. El enunciador es explicador impersonal y el auditor es la audiencia universal.

Según Wenzel, el reconocimiento de las tres perspectivas, que se complementan y enriquecen mutuamente, puede ser especialmente beneficioso para clarificar las diferentes 
clases de estudios críticos o evaluativos del argumento.

El presente estudio se encuentra más cercano a una perspectiva lógica ya que, mediante la abstracción de proposiciones se realizará un acercamiento a los procesos argumentativos de cada debate. Se intentará aisladar el proceso argumentativo de cada episodio temátivo ${ }^{20}$ y describirlo para poder asignarle un tema de discusión general a cada segmento en el que se dividará el corpus de trabajo. Se cree que este proceso permitirá describir de forma detallada este evento de comunicación.

\subsubsection{Estructura interna de la argumentación}

Como se dijo en el apartado anterior, existen diversas proposiciones teóricas sobre la estructura de los textos argumentativos; en primer lugar, se presentarán las perspectivas lingüística y cognitiva y, en segundo lugar, la perspectiva pragmadialéctica.

Lo Cascio (1998) aborda la problemática de la argumentación desde una perspectiva lingüística, diferenciándola de los estudios anteriores que se basaban en aspectos filosóficos o retóricos. Este autor distingue tres componentes en toda argumentación: en primer lugar, el tema que, en otras palabras, es aquello de lo que se discute; luego, el contexto, que es el lugar textual que define la situación comunicativa; según este autor, se pueden considerar lugares textuales canónicos para la argumentación una conversación, una discusión oral, una disputa, un debate, una entrevista, un artículo científico de investigación, una demostración matemática o filosófica, un texto publicitario, un mitin político, un alegato ante el tribunal. Cada uno de estos contextos tiene una estructura propia generada por su propia naturaleza.

Por último, los protagonistas: un emisor (protagonista) (p1) y un posible interlocutor antagonista (p2). En el texto escrito se puede presuponer que el que escribe imagine a propósito la presencia de un interlocutor fingido, el cual, por simulación, puede

\footnotetext{
${ }^{20}$ La segmentación en la que se dividirá el corpus de trabajo será explicada más adelante en la descripción de la metodología.
} 
presentar objeciones ficticias. Conviene señalar también que en el mensaje escrito la estructura del razonamiento debe ser clara y que es preciso explicitar cada componente y marcarlo con las formas o exponentes lingüísticos correctos para que su función sea comprendida por el lector

En cuanto a la estructura interna, Lo Cascio (1998) postula: una fase inicial en la que se definen el tema de la disputa, la posición de los protagonistas y antagonistas; una fase de apertura, en la que se decide encaminar una discusión mediante una forma de argumentación y se formula una opinión por parte de uno de los protagonistas; una fase en la que se introducen los argumentos y los contraargumentos, donde realmente se desarrolla la discusión efectiva, y, por último, la fase conclusiva, en la que se hace clara la resolución de la disputa. La conclusión puede ser a favor de uno u otro de los protagonistas pero también puede tener como resultado que o p1 o p2 deban revisar parcial o totalmente su opinión.

Ahora bien, desde una perspectiva cognitiva, Van Dijk propone que la argumentación expresa una estructura de conocimiento preexistente; dicha estructura puede ser específica o general. Se dice que es específica, por pertenecer a un suceso o situación que el orador ha experimentado personalmente, leído u oído; esta estructura de creencia (subjetiva) se llama modelo y se almacena en la memoria episódica. Por otro lado, la argumentación puede expresar estructuras de creencia general y socialmente compartida. Gran parte de la argumentación se fija en las conexiones existentes entre los modelos y las creencias generales (Van Dijk, 1997: 209).

La mayoría de las argumentaciones incluyen características generales como creencias compartidas socioculturalmente, que se representan como esquemas de conocimiento (guiones), actitudes o ideologías, normas y valores. En suma, el ser humano no solamente argumenta individualmente sus creencias personales, sino como integrante de un grupo.

Según Van Dijk, la teoría de la argumentación parte, en primer lugar, del presupuesto que implica el recuento estructural de la "lógica textual" informal y, en 
segundo término, de las estrategias discursivas de persuasión, por una parte, y, por otra, del análisis funcional de las representaciones y estrategias cognitivas y sociales. (Van Dijk, 1997: 210)

En cuanto a la perspectiva pragmadialéctica, esta propone un estudio sobre el discurso argumentativo que supere tanto el enfoque exclusivamente normativo, ejemplificado por la lógica moderna, como el enfoque exclusivamente descriptivo, ejemplificado por la lingüística contemporánea, pues, este enfoque de la argumentación combina, de forma sistemática, los aspectos descriptivos y normativos.

Así, la lingüística, especialmente la pragmalingüística, puede hacerle justicia al aspecto descriptivo que propone este modelo y, a su vez, el desarrollo de las intuiciones puede basarse en la teoría de los actos de habla, inspirada por los filósofos del lenguaje. Incorporando nociones lógicas, especialmente las de la "nueva dialéctica" relativas a la validez, la consistencia y otros criterios determinantes de la racionalidad, este enfoque puede hacerse cargo también del aspecto normativo. Sus autores proponen que al tratar de producir una convergencia de los diferentes ángulos, en cierto sentido, se estaría "estimulando un regreso integrador a las raíces clásicas del estudio de la argumentación, ejemplificadas en la analítica, dialéctica y retórica aristotélicas” (Van Eemeren y G., 2002:29). En otras palabras, lo que se propone este enfoque de la argumentación es explicar los puntos de vista pragmadialécticos teóricos teniendo una filosofía crítico-racionalista de trasfondo.

\subsubsection{Elementos de la argumentación}

Al definir la estructura interna de la argumentación y su organización lingüística, Lo Cascio toma como base la teoría de Toulmin (1974). El modelo propuesto por Toulmin considera una macro y una microestructura, es decir, una secuencia de argumentos que tienen una función justificativa. Dentro de las categorías o funciones argumentativas Toulmin distingue los siguientes elementos en la argumentación, a saber: argumentos (data), o datos; tesis (claim), la opinión o pretensión, y la regla general (warrant) o garantía -elementos que figuran siempre en la argumentación de forma explícita o implícita. Luego, 
distingue otros elementos que no se encuentran necesariamente presentes: fuente (backing), fundamento de las garantías; calificador (qualifier), elemento que caracteriza, y reserva (rebuttal), informaciones o datos que conducen a conclusiones o tesis hacia las que se está prevenido.

El modelo propuesto por Toulmin expone lo siguiente:

\section{Cuadro número 1}

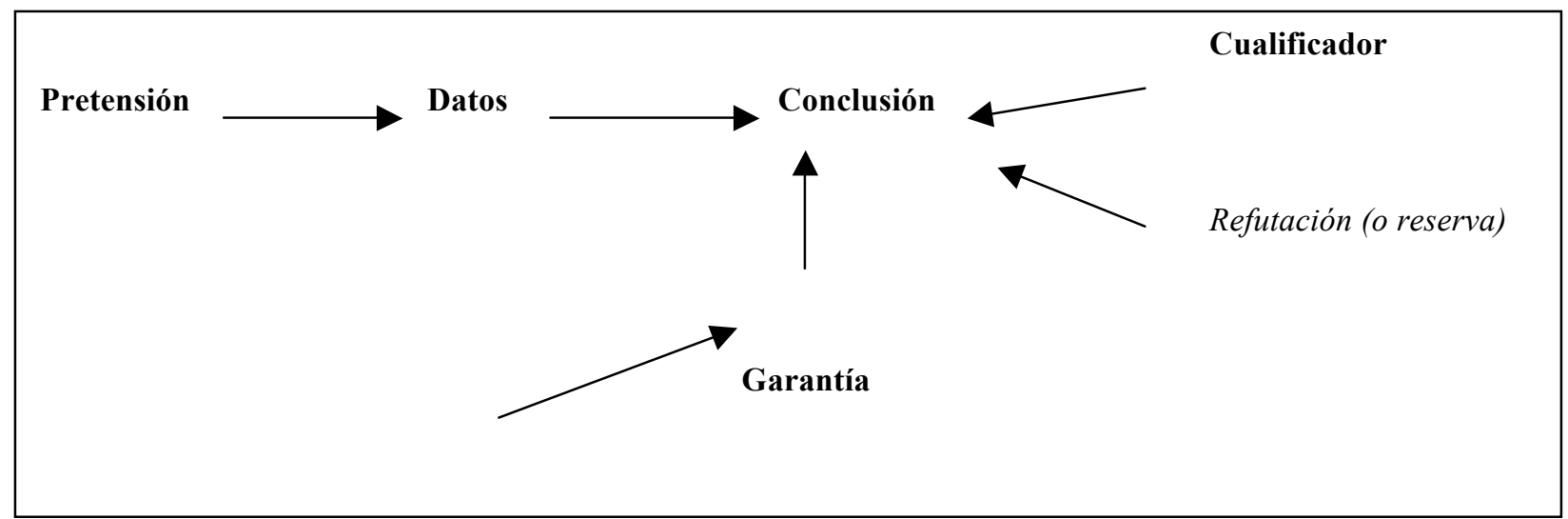

Veamos el funcionamiento de su estructura mediante un ejemplo:

- "No te acerques a ese perro porque es muy bravo". (Pretensión)

- "Ese perro es de raza rottweiler". (Datos)

- "Generalmente, los perros de raza rottweiler son bravos". (Garantía)

- "Los rottweiler son perros asesinos que incluso pueden llegar a matar a sus amos". (Apoyo)

- "Probablemente...". (Calificador)

- "A menos que este perro haya sido adiestrado y sea manso". (Refutación)

- "Por lo tanto, no te acerques a ese perro". (Conclusión)

Basándose en esos planteamientos, Lo Cascio distingue tres elementos obligatorios en la argumentación (ARG): argumento o dato, (A); regla general, (RG), y la tesis, opinión 
o conclusión $(\mathbf{O})$. Por lo tanto:

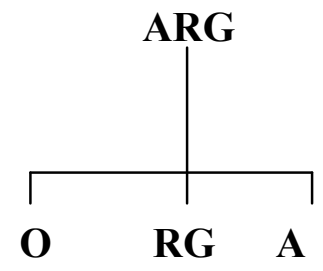

La categoría RG debe ser siempre el conectivo semántico-lógico entre A y $\mathrm{O}$, y su presencia, por lo tanto, es indispensable. En el ámbito lingüístico es facultativo.

Lo Cascio afirma que una opinión que no se apoye en argumentos no es una argumentación. Del mismo modo, un texto es argumentativo sólo si contiene explícitamente formulados una tesis y al menos un dato que la justifique.

Este autor identifica también otras categorías facultativas: el calificador (C), el refuerzo (RE) y la reserva (R). El calificador puede ser deóntico (expresar la obligación de algo) o epistémico (expresar la probabilidad indicando si los enunciados son verdaderos o falsos). El refuerzo muestra que el argumento elegido es lo suficientemente potente como para justificar la opinión defendida. La reserva tiene la función de indicar que a partir de un mismo dato se puede llegar a distintas conclusiones que podrían desarrollar otro razonamiento que llevaría a otra conclusión.

Por otra parte, Perelman, Ch. y Olbrechts-T. L. (1989) proponen en sus postulados otros conceptos para describir los elementos que constituyen el evento argumentativo: “discurso", "orador" y "auditorio" que significan, respectivamente, la argumentación, el que la presenta y aquellos a quienes va dirigida. En su estudio no diferencian el hecho de que se trate "de una presentación de palabra o por escrito (...), discurso en forma y expresión fragmentaria del pensamiento" (1989: 38). Desde esta perspectiva toda argumentación se desarrolla en función de un auditorio y pretende la adhesión de los individuos, por lo tanto, fija su atención en el interés que debe tener el emisor de un mensaje en conocer previamente las características del auditorio y adecuarse a ellas; por lo tanto, supone la existencia de un contacto intelectual entre los interlocutores. Todo este planteamiento podría derivarse en que las opiniones de una persona dependen de su 
medio social, de su entorno, de la gente con la que trata y entre la que vive, pues intenta adecuar su discurso al medio sociocultural en el que vive.

Tomando como base esos planteamientos, Alvarez (1996) propone un modelo interactivo de la argumentación que incluye a los sujetos de la interacción y al conjunto de saberes que circulan entre ellos. Si bien es un modelo más complejo, permite, de manera más certera, dar cuenta del carácter de la argumentación cotidiana. Para este autor, la argumentación no es sólo una operación lógica; esto es debido a que el argumentador quiere siempre actuar sobre las opiniones del otro, quiere obtener alguna acción, ya sea fisica o mental.

De este modo, identifica en un texto argumentativo los siguientes elementos (no necesariamente explícitos y en un orden canónico): objeto, que es aquello sobre lo que se argumenta; tesis adversa, la opinión preexistente; tesis propuesta, la opinión del $\operatorname{argumentador;}_{\text {premisas }^{21}}$, juicios o principios que se dan por aceptados; argumentos, aserciones que apoyan la tesis, y conclusión, que confirma la tesis propuesta. (1996:160)

Por su parte, el enfoque pragmadialéctico tiene una filosofía crítico-racionalista como trasfondo. De esta manera, da forma al ideal de razonabilidad de una discusión crítica. El aspecto dialéctico consiste en que hay dos partes que intentan resolver una diferencia de opinión mediante el intercambio metódico de pasos (moves) en una discusión. El aspecto pragmático está representado por la descripción de los pasos (moves) de la discusión como actos de habla. En esta teoría pragmadialéctica la argumentación es descrita como un acto de habla complejo cuyo propósito es contribuir a la resolución de una diferencia de opinión o una disputa. Una característica de este enfoque es que se aspira a externalizar, funcionalizar, socializar y dialectificar el objeto de estudio de la argumentación (Eemeren V. y Grootendorst R., 2002), es decir, intenta describir el

\footnotetext{
${ }^{21}$ Se produce una confrontación de denominaciones para un mismo elemento de la argumentación. Mientras Alvarez señala que los juicios que se dan por aceptados son premisas, Lo Cascio postula las reglas generales (RG). En este estudio se considerará la denominación establecida por Lo Cascio.
} 
proceso lógico que subyace en la exposición de una tesis y su(s) argumento(s), teniendo en cuenta los elementos implícitos de estos actos verbales en una situación comunicativa.

\subsection{Formas de razonamiento}

Al querer justificar una opinión o desarrollar un punto de vista o reflexionar para tomar una decisión se utilizan distintas formas de razonamiento. Es así como, al momento de argumentar, nuestra mente pone en funcionamiento diversas formas de razonamiento. Hernández, M. y Pazos, J. (1988: 236) las describen partiendo de tres aserciones: A1, A2 y A3. La primera es de tipo general y las otras dos son de clase particular. De este modo, A2 hace referencia a la primera parte de la aserción de tipo general, mientras que A3 concierne a la segunda parte de A1. Entonces, al basarse en las diferencias entre las aserciones particulares, se pueden establecer los siguientes métodos de razonamiento:

a) Razonamiento Deductivo: En este caso, a partir de A1 y A2 se obtiene A3. Por ejemplo:

A1: "Todos los hombres son mortales" (premisa mayor)

A2: "Pepe es hombre" (premisa menor)

A3: "Pepe es mortal" (conclusión).

Se parte de la verdad de la aserción general y de la primera particular para obtener como consecuencia la verdad de la segunda aserción particular. Este método no aporta información realmente nueva, pues toda la información obtenida por deducción a partir de las premisas dadas estaba comprendida ya implícitamente en las propias premisas; no obstante, sí proporciona una seguridad absoluta de la verdad de la conclusión, siempre y cuando se esté seguro de que las premisas son ciertas. 
b) Razonamiento Inductivo: parte de la verdad de las dos aserciones particulares, tales como:

A2: "estos objetos tienden a moverse hacia el centro de la tierra"

A3: "estos objetos son pesados",

A1: "Todos los objetos pesados tienden a moverse hacia el centro de la tierra".

A partir de un cierto número de casos particulares concretos, se obtiene como consecuencia la verdad de la aserción general. El método inductivo aporta información realmente nueva, pues la premisa mayor solo puede deducirse, si se sabe que las particulares son siempre verdaderas. Sin embargo, esto no es así puesto que el número de casos de que se dispone será siempre limitado, aun cuando sea elevadísimo. Por lo demás, la seguridad que proporciona este método depende del número de casos particulares que se hayan podido estudiar, así como de las aserciones concretas con las que se ha de enfrentar en cada caso. Este método permite obtener reglas generales a partir de la observación de un gran número de casos concretos o de la realización de un gran número de experimentos.

c) Razonamiento Abductivo (o Razonamiento Causal): es un método de razonamiento cuya conclusión es plausible. Es decir, en la abducción se parte de la verdad de una aserción general, tal como:

A1: “Todos los cuadros de Goya presentan ciertas características concretas Cj”.

Y de la verdad de la segunda aserción particular.

A3:"Este cuadro de autor desconocido presenta ciertas características concretas Cj”.

Obteniéndose como consecuencia la verdad de la primera aserción particular.

A2:'Este cuadro es de Goya". 
La abducción también aporta conocimiento nuevo, pues la primera aserción particular, no puede deducirse aunque se sepa que la segunda aserción particular es siempre verdadera. Por esta razón, la seguridad que proporciona este método es menor que la de los precedentes y se apoya, sobre todo, en los conocimientos de los expertos en ciertos campos del saber.

Este es el método más utilizado en las ciencias del hombre y de la medicina, pues permite clasificar casos particulares a partir de la observación de ciertas características que se cumplen en dichos casos, como aplicaciones de la aserción general para permitir obtener cierto grado de certidumbre sobre la aplicabilidad de dicha clasificación.

A media que se pasa del razonamiento deductivo al abductivo (o razonamiento causal), pasando por el inductivo, se aumenta la capacidad de conocimiento que, eventualmente, puede adquirirse, pero a costa de perder la seguridad de que el razonamiento efectuado, y sobre todo la conclusión alcanzada, sea correcto.

Se creyó fundamental revisar esta descripción con las formas de razonamiento pues al argumentar, o plantear nuestras hipótesis, exponemos nuestros puntos de vista siguiendo alguno de estos procesos mentales. Revisar esta clasificación y aplicarla a los procesos argumentativos que forman parte del corpus de trabajo permitirá reconocer con mayor facilidad los elementos de la argumentación que forman parte de la estuctura interna de cada interacción comunicativa.

Una vez descritos los elementos internos de la argumentación, se analizarán aquellos elementos que afectan igualmente el proceso argumentativo.

\subsection{Indicadores de fuerza argumentativos}

Otro tema importante expuesto por Lo Cascio es el de los indicadores de fuerza, exponentes lingüísticos que sirven para conectar los enunciados y para indicar su papel 
dentro del discurso. Hacen las veces de conectivas discursivas, o marcadores discursivos ${ }^{22}$, y pueden clasificarse según la función que realizan. Algunos marcan la tesis, otros los datos o los argumentos, otros la regla general y otros la reserva, la fuente, o categorías mayores como la argumentación misma.

Considerando la naturaleza de los indicadores de fuerza, se pueden distinguir los indicadores de fuerza que:

1. introducen el macroargumento (ARG) y tienen la función de marcar el texto argumentativo completo e indicar que alguien está realizando, o pretende realizar, un macroacto argumentativo: Ahora me explico, el razonamiento es este, ahora se demuestra por qué, son algunas de las formas genéricas, discursivas y conversacionales de este tipo;

2. introducen un argumento o un dato. Cuando se quiere justificar una opinión o desarrollar un punto de vista se utilizan distintas formas de razonamiento que son introducidas por indicadores de fuerza que anteceden un argumento. Algunos indicadores de fuerza justificadores son: puesto que, porque, de hecho, en efecto, dado que, ya que, ya que es cierto que, también porque, considerando que, partiendo del hecho que, y la prueba es que, y eso es porque, luego, y el uso del gerundio;

\footnotetext{
${ }^{22}$ No parece haber un acuerdo generalizado sobre la definición de "marcador discursivo". En efecto, "a variety of terms are used to refer to these elements. Among them are discourse marker (e.g. Shiffrin 1987), pragmatic marker (e.g. Fraser 1996, Brinton 1996), discourse particle (e.g. Schourup 1985; Abraham 1991; Kroon 1995), pragmatic particle (Östman 1981), pragmatic expression (e.g. Erman 1987) or connective (Blakemore 1987, 1988). The terminological diversity reflects both the wide range of linguistics approaches that have been employed for their study, and the multiplicity of functions which these elements are said to fulfil". (Jucker y Ziv, 1998: 1,2.)
} 
3. introducen la tesis o conclusión y son formas conclusivas: por consiguiente, así pues, por tanto, he aquí que, por eso, se sigue que, por lo cual puede sostenerse que, por ello, si (...) entonces;

4. introducen la regla general, a partir de la cual "si se tienen ciertos datos o argumentos se pueden sostener $\mathrm{y}$, por lo tanto, se justifican ciertas tesis $\mathrm{u}$ opiniones"(Lo Cascio, 1998:123). Algunos ejemplos de indicadores de fuerza son: $a$ partir de, dado que, y eso porque, dice que;

5. introducen la modalidad o el calificador, "elemento que caracteriza, aunque relativizándolas, las tesis aducidas o los argumentos propuestos" (Lo Cascio, 1998:123). Son indicadores de fuerza modales: quizá, probablemente, es probable que, necesariamente, poder+infinitivo, deber de+infinitivo, futuro (elemento morfológico con función modal y no de tiempo verbal);

6. introducen la fuente, la autoridad. Son formas que apoyan a los garantes, es decir, "datos ulteriores para sostener las tesis y que permiten garantizar las reglas generales o la verdad de los datos". “(Lo Cascio, 1998:123) Algunos ejemplos son: como dice (...), según (...);

7. introducen una reserva, relativizando el punto de vista que es presentado. Algunos ejemplos de este tipo de indicador de fuerza son: a no ser que, salvo que, a menos que, excepto que, si/si no, aunque;

8. introducen un refuerzo para la justificación presentada. Algunos ejemplos de este tipo de indicador de fuerza son: sin contar con, si se tiene en cuenta el hecho de que, observemos que, no obstante, a pesar de que, si bien, aunque;

9. introducen una contraopinión, permitiendo alternar con opiniones contrarias. Indicadores de fuerza que permiten alternar son: sin embargo, no obstante que, a pesar de que, pero.

Lo relevante de teoría de Lo Cascio radica en el hecho de que los temas han sido desarrollados mediante análisis sintáctico- textuales, no solo considerando la 
pragmática y la semántica, sino que también proporcionando herramientas para llevar a cabo un análisis lingüístico y gramatical del discurso argumentativo.

\subsection{Los marcadores argumentativos}

Una visión distinta, que proporciona una terminología diferente, es la que postulan Anscombre y Ducrot (1994). Ellos definen los marcadores argumentativos como los elementos lingüísticos que sirven para marcar la orientación argumentativa de un enunciado. La teoría distingue dos tipos fundamentales de marcadores argumentativos (según su ámbito de acción):

1. Operadores argumentativos: los que afectan a un único enunciado. Un operador argumentativo es un morfema que, aplicado a un enunciado, modifica el potencial argumentativo de su contenido. El abanico de posibilidades de utilizar un determinado enunciado como argumento queda modificado -en general suele quedar restringido- por la adición del operador argumentativo.

2. Conectores argumentativos: los que enlazan dos o más enunciados. Un conector argumentativo es un morfema (adverbio, locución, conjunción subordinante o coordinante) que enlaza dos o más enunciados que intervienen en una estrategia argumentativa única. Mientras que el operador actúa desde el interior de un enunciado los conectores convierten en una unidad argumentativa a un conjunto de enunciados.

De este modo, observamos que la teoría de la argumentación presentada por Anscombre y Ducrot (1994) se ocupa de los medios formales que proporciona la lengua a sus hablantes para orientar argumentativamente sus enunciados de modo que exista coherencia respecto a todo lo argumentado, más allá de lo verosímil o de la veracidad; paralelamente, se ocupa también de los medios formales que sirven al destinatario para construir su interpretación.

En el próximo apartado, presentaremos otro aspecto que incide en el proceso 
argumentativo: las falsas argumentaciones.

\subsection{Las falacias}

En la mayoría de las argumentaciones cotidianas se utilizan argumentos que infringen el código de buen comportamiento en el acto de argumentar. Estos argumentos “ilegales”, usando la terminología escogida por Lo Cascio (1998: 291-292), que no tienen relación con las tesis puestas en discusión y que son muy utilizadas en la praxis argumentativa, tradicionalmente son conocidos como falacias.

De este modo, Lo Cascio expone algunos ejemplos de los falsos argumentos que han sido catalogados y clasificados por la retórica antigua y que utilizaremos en nuestro análisis.

El siguiente cuadro presenta una reelaboración que Lo Cascio ha hecho con las taxonomías establecidas por la antigua retórica sobre falacias:

\section{Cuadro número 2}

\begin{tabular}{|l|l|}
\hline Argumentum ad personam & $\begin{array}{l}\text { Se ejerce una presión sobre la persona, } \\
\text { poniendo en discusión la credibilidad de } \\
\text { quien se presenta como adversario. }\end{array}$ \\
\hline Argumentum ad hominem & $\begin{array}{l}\text { El argumento se basa únicamente en el } \\
\text { universo del protagonista específico sin } \\
\text { considerar valores universales. }\end{array}$ \\
\hline Argumentum ad verecundiam & $\begin{array}{l}\text { Apelar al prestigio, a la fama o al cargo de } \\
\text { las personas. }\end{array}$ \\
\hline Argumentum ad misericordiam & $\begin{array}{l}\text { Apelar a la piedad como un argumento a } \\
\text { favor de un trato especial. }\end{array}$ \\
\hline Argumentum ad populum & Apelar a las emociones de una multitud. \\
\hline
\end{tabular}




\begin{tabular}{|l|l|}
\hline Argumentum ad consequentiam & $\begin{array}{l}\text { Sirve para juzgar negativamente una } \\
\text { afirmación, una tesis, no mediante } \\
\text { argumentos externos, sino a través de las } \\
\text { consecuencias que pueden derivarse de tales } \\
\text { afirmaciones. }\end{array}$ \\
\hline Argumentum ad ignorantiam & $\begin{array}{l}\text { Se apela a la ignorancia del oponente para } \\
\text { probar el punto de vista contrario, a partir de } \\
\text { información incompleta. }\end{array}$ \\
\hline Petitio principii & $\begin{array}{l}\text { Usar de un modo implícito la conclusión } \\
\text { como una premisa. }\end{array}$ \\
\hline Ignoratio elenchi & $\begin{array}{l}\text { Se argumenta a partir de información dada } \\
\text { por el oponente; no se pone en discusión la } \\
\text { tesis a defender. }\end{array}$ \\
\hline Prgumentum ad baculum & $\begin{array}{l}\text { Se infiere desde la observación de dos } \\
\text { hechos sucesivos en el tiempo que el } \\
\text { antecedente es causa del consecuente. }\end{array}$ \\
\hline Post hoc, ergo propter hoc & $\begin{array}{l}\text { Se persuade a través del temor y de la } \\
\text { amenaza dirigida hacia el oponente. }\end{array}$ \\
\hline
\end{tabular}

Por su parte, López (1996) estudia las distorsiones de la argumentación desde un punto de vista racional, presentación que es útil para realizar un primer acercamiento a la forma en que se puede manipular la información para persuadir.

López postula que las argumentaciones deficientes son aquellas que no han respetado el "Principio de cooperación", definido por Grice (1975) postulados que ya se revisaron anteriormente en este estudio.

Tomando como base que el incumplimiento de estas máximas incluidas en el principio cooperativo de Grice produce ciertos efectos de sentido o ciertas sanciones sociales ajustadas a la gravedad de la trasgresión, López clasifica estas distorsiones en dos grandes grupos: el primero es el de las argumentaciones que tienen fallas en el 
proceso de comunicación y el segundo grupo está formado por distorsiones basadas en la debilidad de las razones. En cuanto a las razones que influyen en las distorsiones del primer grupo estas son las siguientes:

1. Las personas que intervienen en una argumentación no deben impedir que el interlocutor establezca un punto de vista o lo critique. Así, excluir temas en una conversación distorsionaría el proceso comunicativo.

2. Presionar al interlocutor para que no establezca un tema o la eliminación física del oponente supone amenazar al oponente, hecho que, evidentemente, afecta el proceso. Una variación de esta técnica es someter al opositor a una suerte de chantaje emocional a fin de manipular las emociones de la otra persona.

3. Realizar un ataque personal, en un intento de eliminar al oponente como un interlocutor serio, desacreditando su derecho a establecer un punto de vista o a criticarlo.

4. Evadir la obligación de fundamentar un punto de vista, es decir, presentar un punto de vista como si no necesitara fundamentación.

5. Traspasar la obligación de dar razones al interlocutor para explicar por qué considera falso el punto de vista que cuestiona. Esta deficiencia no es más que una estrategia para ocultar la debilidad de las razones a favor de un punto de vista o la absoluta carencia de ellas.

6. En una disputa, en lugar de cuestionar un punto de vista, se puede asumir el punto de vista contrario y tratar de mostrar sus fundamentos. Esta estrategia es, sin embargo, peligrosa puesto que se corre el riesgo de distorsionar el punto de vista del oponente. De este modo, modificar el punto de vista del oponente puede producir una falla en la argumentación.

7. En lugar de proporcionar razones, el que argumenta puede jugar con las emociones y prejuicios de la audiencia. En este caso se 
estaría manipulando las emociones de una audiencia.

8. Usar un lenguaje poco claro puede tener graves inconvenientes para la comunicación. La falta de claridad puede llevar a malos entendidos. Usar palabras desconocidas por el interlocutor impide que se entienda el mensaje ( López, 1996:87).

En cuanto a las distorsiones basadas en la debilidad de las razones, presentan modalidades como las siguientes:

1. Con la intención de provocar una impresión lógica (de evidencia) se pueden presentar las razones como si se tratara de algo perfectamente lógico, es decir, como si no se necesitara una ulterior investigación.

2. Una falla más profunda se produce si las premisas son inconsistentes. E1 caso más grave ocurre cuando dos razones son contradictorias, es decir, una es la negación de la otra. Otra manera de provocar inconsistencia es asumir dos posiciones contrarias.

3. Las expresiones del tipo "si...entonces", permiten establecer condiciones necesarias y suficientes para un evento. Si estas condiciones se confunden, entonces surgen dos argumentos incorrectos (al afirmar el consecuente).

4. Una argumentación puede conducir a errores si se hace una incorrecta atribución de las propiedades del todo a las partes y viceversa. Las propiedades no se transfieren automáticamente del todo a la parte y de la parte al todo. En algunos casos se puede producir una argumentación correcta, pero en otros no. Por ejemplo, “este sillón es blanco. Por lo tanto, los brazos del sillón son blancos", presenta un correcto proceso argumentativo pero no lo es: "este sillón es pesado, por lo tanto, su respaldo es pesado".

Ciertamente que las clasificaciones que se han presentado no son exhaustivas, se sabe que las falacias son numerosísimas y que en la vida cotidiana estas constituyen 
incluso la norma. Tomando esto en consideración, se ha incluido en las plantillas de análisis de esta investigación un segmento para describir aquellas falsas argumentaciones que se encuentren en el corpus y que no sean estrictamente las descritas por la retórica clásica o que correspondan a adaptaciones de las mismas; esto sucede posiblemente porque los argumentos, o falsos argumentos, se van adaptando a los usos sociales y a las necesidades de expresión de los hablantes para intentar ser cada vez más certeros o parecerlo. Es el caso de la falacia llamada reductio ad Hitlerum ${ }^{23}$, falacia que si bien puede ser clasificada dentro de la del tipo ad hominem, corresponde más bien a una subclasificación de esta, pues recurre directamente a la figura de Hitler (o a los ideales del nazismo), la cual es comparada con los argumentos a los que alude el interlocutor. Reductio ad Hitlerum es una falacia que más o menos corresponde a la siguiente proposición: "Adolf Hitler o el partido nazi apoyaban X; por lo tanto, X debe ser malo".

Veamos una muestra tomada del corpus de esta investigación que corresponde al episodio $\mathrm{N}^{\circ} 8$ del debate de los jóvenes. En esta parte del debate, los estudiantes están discutiendo sobre las diferencias que puede haber entre relaciones homosexuales y heterosexuales; uno de ellos (H1) propone que no es normal ni natural un tipo de relación homosexual, inmediatamente es criticado por su postura extremista y es catalogado de nazi:

(...) H1: $e^{h}$ como una química | diferente, entonce ${ }^{h} \mid$ eso según yo, $e^{h}$ imposible que se dé entre homosexuale $^{h} \rightarrow$

M2: < [ ¿y cuál y dónde e $e^{h}$ tá la limitación de sentir amor por un hombre? $\rightarrow$ ]>

$H 2<$ [ ¿lo hai sentido para saber?]

$H 1:<[$ no]

H1. $<\left[\right.$ no e $e^{h}$ que e $e^{h}$ pera]

$M 2:<$ [o por una mujer]

M1: < [ $e^{h}$ que yo creo que lo que diferencia a-]

H1: $<$ [mira yo creo que puede exi ${ }^{h}$ tir un cariño-]

${ }^{23}$ La expresión reductio ad Hitlerum o argumentum ad nazium fue creada originalmente por Leo Strauss, profesor de la Universidad de Chicago. 
M2: < La la mujer que tu ama $a^{h}$ la diferencia ${ }^{h}$ de TODO el re ${ }^{h}$ to de lo ${ }^{h}$ sere $^{h}$ vivo que están en la tierra:]

H1: $<$ [no e $e^{h}$ que lo que pasa e $e^{h}$ que mira]

M2: $<\left[e^{h}\right.$ lo $\mathrm{mi}^{h}$ mo la persona que yo amo puede ser hombre yo la voy amar igual]

H1:< [pero $e^{h}$ diferente, porque mira yo puedo sentir un amor muy profundo $\mid$ muy profundo $\mid$ por un amigo, pero ese amor no puede traspasar-]

M2: < [o:bvio]>

H1: ese amor no puede traspasar| no $e^{h}$ que $e^{h}$ un amor di ${ }^{h}$ tinto, al amor que yo voy a sentir | por por la: como por la pareja ese amor $\rightarrow$

M2: $<$ [pero $e^{h}$ que, $e^{h}$ que mira]

H1: ese tipo de amor $\rightarrow$

M2: $<$ [Gonzalo] $\rightarrow$

H1: no lo puedo no lo puedo e: se me va no tengo la palabra pero una persona de $\mathrm{mi}^{\mathrm{mi}}{ }^{\boldsymbol{h}}$ mo sexo $\mid$ no puedo $\mid$ dar ese amor porque $\rightarrow$

M2: $<$ [¿y qué pasa si una persona si siente eso?]

H1: $<$ [no, pero $e^{h}$ que naturalmente es imposible sentirte atraído sexualmente]

M2: $<$ [NO, pero ¿qué pasa con los homosexuales, son antinaturale ${ }^{h}$ ?]

H1: yo creo que tienen un problema.

M2: GONZALO estai, NO: ¿CÓMO VAN A SER ANTINATURALE ${ }^{\boldsymbol{h}}$ dos personas que se ama:n?

H1: $<\left[e^{h}\right.$ antinatural ¿qué tiene que ver-?]

$M 1:<[N O:]$

H2: es que es como NAZI tu postura po:

H1: $<\left[e^{h}\right.$ que yo, $e^{h}$ mi postura, mira- $]$

H2: $\underline{N A Z I(\ldots)}$

Se observa así que la postura extremista de este joven es desprestigiada al ser comparada con la actitud o ideales nazis por medio de este falso argumento; estrategia que, sin duda, fue más eficaz que haber argumentado las razones de por qué su modo de pensar es poco tolerante o inadecuado.

Esta fue una muestra del tipo de nuevas falacias que también serán descritas en esta investigación. 

VERBAL

"El estudioso de la cortesía debe imponerse la mayor prudencia (...) Tal es la dura condición del lingüista, condenado a una suerte de esquizofrenia: es a un tiempo un hablante ordinario, que juzga al otro según la medida de sus propias normas, y un 'meta-hablante', que debe relativizar esas mismas normas y esforzarse por comprender las de los otros. Ya que, de una reflexión sistemática acerca de las variaciones culturales, puede esperarse que contribuya a luchar contra los reflejos xenófobos, cuya fuente, muy a menudo, reside en el desconocimiento de la amplitud de las variaciones que afectan a las normas comunicativas $y$, más específicamente, a las reglas de la cortesía lingüística".

C. Kerbrat-Orecchioni, en Pragmática sociocultural: estudios sobre el discurso de cortesía en español. “¿Es universal la cortesía?” (2004: 52).

\subsection{Algunos antecedentes y fundamentos teóricos}

Una sólida fundamentación teórica da cuenta de la tradición que el proceso de la cortesía ha tenido a la luz de la historia. Las diferentes teorías propuestas sobre cortesía lingüística tienen su origen en la pragmática lingüística de las últimas décadas del siglo $\mathrm{XX}$, donde convergieron disciplinas disímiles y complementarias como la lingüística, la filosofía y la psicología social. Así, estas concepciones teóricas de la cortesía forjan sus cimientos en las teorías de los actos de habla (Austin/Searle) y el principio de cooperación expuesto por el filósofo Grice P. (1975), que constituyó el primer paso al describir las máximas conversacionales, de obligada mención en pragmática. Debido a que son temas conocidos y ya muy estudiados, en el siguiente acápite se expondrán de forma muy 
resumida dichas bases teóricas, solo para situar en su contexto la teoría que subyace.

\subsection{La pragmática lingüistica}

Por mucho tiempo, la pragmática fue considerada una parte de la lingüística que servía para estudiar todos aquellos fenómenos de lengua que eran inabarcables para la semántica o la gramática. No obstante, a partir de la década del 60 surgió una serie de discusiones teóricas que tuvieron como objetivo dilucidar la función de la pragmática en los estudios de la lengua y, posteriormente, se comenzaron a considerar y a integrar de forma explícita en la descripción lingüística aspectos del lenguaje, como el uso y contexto; aspectos en los cuales otras disciplinas no habían reparado.

A partir de la propuesta del filósofo Austin $\left(1962^{24}\right)$ la pragmática comienza a tener una base sólida a través de la filosofía analítica. A partir de entonces, se observa al lenguaje como un medio para hacer cosas con palabras, lo que implicó que el lenguaje no se concibiera ya como un mero instrumento de comunicación, sino también como un medio de acción. Este nuevo enfoque pone de manifiesto la dimensión interpersonal del lenguaje y la dimensión ejecutiva de los actos lingüísticos, distinguiéndose así dos tipos de actos básicos que forman parte de la emisión de un enunciado: actos constatativos, que dan cuenta del estado de las cosas del mundo, y los actos realizativos, que implican que cada vez que se emite un enunciado se realiza una acción. Se establece así, que estos actos de habla son las unidades básicas de la comunicación humana.

Más tarde, Austin afirmó que la realización de actos comunicativos no se limita a un subgrupo de enunciados, que -tal como se dijo antes- originalmente había denominado realizativos, sino que todo enunciado implica la realización simultánea de, al menos, dos

\footnotetext{
${ }^{24}$ La fecha de la edición de 1962 corresponde a la primera edición en inglés (Oxford University Press); en esta investigación se revisó la edición en español de 1971.
} 
tipos de acto: acto locutivo, que corresponde a la formulación de una oración con sentido y referencia concretos, y acto ilocutivo, que es la realización de una función comunicativa.

En 1969, Searle retoma los postulados de Austin y propone una nueva clasificación de los actos de habla que forman parte de la enunciación, así como también una sistematización más exhaustiva de la naturaleza de las condiciones necesarias para llevarlos a cabo. Expuso que aunque en apariencia el número de actos ilocutivos es infinito, se pueden clasificar en cinco grupos, a saber: actos asertivos, directivos, compromisorios, expresivos y declarativos. $^{25}$

En definitiva, con esta nueva propuesta teórica se puede interpretar que se pretendía, en primer lugar, evidenciar la dimensión interaccional del lenguaje que proporcionó las bases para lo que hoy se conoce como pragmática; en segundo lugar, exponer un nexo entre los actos de habla y las formas gramaticales, posicionando así a la pragmática como una disciplina complementaria a la gramática, ya que tiene un objeto de estudio centrado en factores extralingüísticos, que se ven reflejados e inciden en los factores lingüísticos, y, por último, realizar una taxonomía que determinara los distintos tipos de actos realizables por medio del lenguaje, cuya aplicación a realizaciones concretas en cualquier lengua nativa pondría de manifiesto la correspondencia entre la esencia del acto de habla y su referente gramatical $^{26}$.

25 Esta concepción del lenguaje distingue tres dimensiones que conlleva todo acto de habla: a. Fuerza locutiva (decir X) b. Fuerza ilocutiva (decir X implica que se realiza Y) c. Fuerza perlocutiva (efectos de la emisión de una expresión en determinadas circunstancias). En desarrollos posteriores de la teoría de los actos de habla se les prestó mayor atención a los actos ilocutivos.

${ }^{26}$ A pesar de las críticas que puede haber recibido la Teoría de los actos de habla propuesta por Searle en cuanto a sus principios de clasificación, se debe valorar el fuerte impacto que significó para el desarrollo de diversos dominios del estudio del discurso natural, como son: la pragmática transcultural, estudio de la variación en los modos de realización de los actos de habla en las distintas culturas; en la pragmática evolutiva, campo de estudio enfocado en la adquisición de las aptitudes pragmáticas de los niños en su 
Cierto es que, desde la perspectiva de la Teoría de los actos de habla, un análisis de intercambios comunicativos permitiría comprender la manera en la que los participantes reales de un determinado intercambio lingüístico utilizan significados implícitos en el proceso de enunciación; sin embargo, cuando se realiza un análisis pragmático exhaustivo no debe bastar con desvelar tales complejidades, pues se deberían considerar, además, las señales lingüísticas y paralingüísticas mediante las cuales cada participante codifica e interpreta los enunciados del otro y, por supuesto, cómo se toma en consideración la cortesía y la manera en que cada interlocutor reconoce las intenciones comunicativas del otro.

Este último concepto, propuesto en la teoría de P. Grice, será comentado en la siguiente sección.

\subsubsection{El principio de cooperación: un importante antecedente para los estudios teóricos de la cortesía verbal}

El principio de cooperación, definido por Grice en $1975^{27}$, es un antecedente directo de los estudios sobre cortesía verbal, debido a que es entendido como una de las propuestas teóricas iniciales que intenta poner de manifiesto el carácter interaccional que posee el lenguaje y definir así su dependencia con el contexto; se centra en los principios que regulan la interpretación de los enunciados y propone un análisis de la lógica que rige la conversación. Esta propuesta "parte del supuesto de que nuestros intercambios de mensajes no pueden ser una sucesión inconexa de emisiones" (Gutiérrez Ordóñez, 2002:44) y que, por este motivo, debe haber una serie de normas que regulen este intercambio.

primera lengua, y en la pragmática interlingüística, estudio sobre la adquisición y realización de habilidades pragmáticas en una segunda lengua (Blum-Kulka, Shoshana, 2000).

${ }^{27}$ Si bien en 1967 P. Grice presentó su teoría en una conferencia titulada "lógica y conversación”, recién en 1975 fue publicada (Gutiérrez Ordóñez, 2002). 
En esta teoría se presenta una serie de principios, no normativos, no prescriptivos, que se suponen aceptados tácitamente por los participantes de una conversación. Son esfuerzos de cooperación en los que cada participante reconoce un propósito o un conjunto de propósitos comunes o al menos una dirección aceptada para todos.

La propuesta teórica de la interacción conversacional planteada por Grice está compuesta, principalmente, por una serie de normas, a las que les da el nombre de categorías, y que se concretan en la de cantidad, cualidad, relación y modalidad. Estas categorías están conformadas por máximas que ejemplifican su respectiva función y son las siguientes:

\section{Categoría}

1. Categoría de cantidad: se relaciona con la cantidad de información que debe darse.

2. Categoría de cualidad se relaciona con la calidad de la información que debe darse.

3. Categoría de relación se relaciona con la adecuación de la información que debe darse.

4. Categoría de modalidad se relaciona con la manera en que debe darse la información.

\section{Máximas que comprende}

a. "que su contribución sea todo lo informativa que requiera el propósito del diálogo".

b. "que su contribución no sea más informativa de lo necesario".

c. "intente que su contribución sea verdadera". Se especifica así: "no diga algo que crea falso" y "no diga algo de lo que no tenga pruebas suficientes".

d. "diga cosas relevantes". Se espera que las intervenciones de los participantes en la conversación se relacionen con aquello de lo que se está hablando.

e. "sea claro" y se complementa con "evite la oscuridad de expresión"; "evite la ambigüedad"; "sea breve"; "sea ordenado".

Las máximas propuestas no son principios de conducta, sino que descripciones que sirven para regular y evaluar el comportamiento lingüístico. Estas regulaciones y evaluaciones cumplen un rol protagónico en la interacción verbal, considerando que el incumplimiento de alguna de ellas puede producir ciertos efectos de sentido o ciertas 
sanciones sociales ajustadas a la gravedad de la trasgresión.

A través de sus postulados, Grice expone que estos principios pueden afectar la conducta humana en general, no solo la conversación, pues de forma evidente la actividad lingüística está presente en todas las acciones que el ser humano realiza. Radica aquí un rasgo muy interesante de esta propuesta, ya que revitaliza la importancia de la comunicación verbal y de los métodos lingüísticos que permitirían a los hombres convivir gratamente en sociedad.

Dado que este modelo está enfocado en la interacción verbal, se establece una importante distinción entre lo que se dice y lo que se comunica: mientras que lo que se dice corresponde al contenido proposicional del enunciado, lo que se comunica involucra toda la información que es transmitida y que se caracteriza por tener un contenido implícito, denominado implicatura ${ }^{28}$.

\subsubsection{Los contenidos implícitos}

Como se dijo anteriormente, Grice distingue entre lo que se dice y lo que se comunica. Lo que se dice es, básicamente, el contenido proposicional del enunciado, entendido desde el punto de vista lógico. Por otra parte, lo que se comunica es toda la información transmitida por el enunciado ya que además del contenido proposicional,

\footnotetext{
${ }^{28}$ D.Wilson y D. Sperber (1998) constituye un interesante artículo crítico sobre la teoría de la conversación de Grice. Específicamente, explica el alcance de las máximas y de la teoría pragmática; afirma que la distinción entre semántica y pragmática no puede reducirse a la distinción entre decir e implicar. Intenta demostrar que la distinción fundamental realizada por Grice, entre lo que se dice (como algo dado por reglas semánticas) y lo implícito conversacionalmente (como algo dado por las máximas conversacionales), no es exhaustiva. Las máximas desempeñan un papel en la desambiguación, en la asignación de referencia y, más en general, en la determinación de la proposición expresada por un enunciado así como en la determinación de sus implicaturas conversacionales. Sperber y Wilson concluyen, al menos en este punto, que el alcance de las máximas y, por tanto, de la teoría pragmática, es más amplio que lo propuesto por Grice. La contribución fundamental de Sperber y Wilson se concreta en la presentación de la Teoría de la relevancia.
} 
existe un contenido implícito, denominado implicatura. Existen dos clases de implicaturas: convencionales y no convencionales.

- Implicatura convencional: es aquella que deriva directamente de los significados de las palabras y no de factores contextuales o situacionales.

- Implicatura no convencional: es aquella que se genera por la intervención de otros principios y conforma una clase muy extensa, dependiendo de la naturaleza de los principios involucrados. Existe una subclasificación de este tipo de implicaturas:

a. implicatura conversacional: los principios que hay que invocar son los que regulan la conversación.

b. implicatura no conversacional: los principios en juego son de otra naturaleza (estética, social o moral). Las implicaturas conversacionales pueden ser generalizadas o particularizadas. Las implicaturas generalizadas son las que no dependen directamente del contexto de emisión; las implicaturas particularizadas son las que dependen decisivamente de dicho contexto.

Las implicaturas se producen de la combinación de tres clases de elementos: la información que contiene el enunciado, los factores que configuran el contexto y la situación de emisión, y los principios conversacionales. Las implicaturas son el camino para la reconstrucción del contenido real de la proposición y surgen para "tender el puente necesario entre la aparente violación de una máxima y la presunción de que, a pesar de ello, el principio de cooperación sigue vigente" (Escandell, 2006:85).

Al proponer una serie de principios que regulan la conversación y que poseen la característica de no ser normativos, existe de forma evidente, la posibilidad de incumplimiento o defectibilidad de los mismos. Grice propone una caracterización de los tipos de incumplimientos y de sus correspondientes efectos:

\section{Incumplimiento o defectibilidad}

\section{Efecto}


Violación encubierta, discreta y sin Puede provocar un error de interpretación ostentación de una máxima. por parte de los interlocutores; por tanto, el hablante es responsable de engañar o de correr el riesgo de hacerlo.

Supresión abierta de las máximas y del El interlocutor se niega a colaborar, pues principio. no puede hacerlo de forma adecuada.

Conflicto o colisión entre el cumplimiento Se elige una en detrimento de las otras. de las diferentes máximas.

Incumplimiento o violación abierta de una Se viola una máxima pero existe sujeción de las máximas. a las demás.

El modelo propuesto por este autor y las máximas que lo complementan forman parte de un modelo clásico dentro de la pragmática; pese a ello, no ha estado libre de críticas respecto a su enfoque, que ha sido critcado por su posible reduccionismo (Escandell, 2006) pues, entre otras cosas, en el caso de que se cumplieran de manera estricta las máximas del principio de cooperación, se entregaría información sin ambigüedades, rasgo muy difícil de encontrar en intercambios comunicativos coloquiales ${ }^{29}$.

Retomando los postulados de Grice, señala que puede haber otras máximas que complementen su modelo; otras clases de máximas (estéticas, sociales, morales, etc.) tales como sea cortés, que normalmente son observadas por los participantes en el intercambio comunicativo y que también pueden generar implicaturas no convencionales (Grice, 1989).

\footnotetext{
${ }^{29}$ Por su parte, Wierzbicka (1991) critica las teorías de los actos de habla y de la conversación (Searle, Grice) puesto que han tendido a asumir que la manera característica de hablar de la mayoría de la población blanca americana representa "la manera humana normal de hablar" y que puede considerarse, contando variaciones menores, la forma predominante de hablar en cualquier otra sociedad humana; todo lo cual esta autora considera como una ilusión etnocéntrica. En sus estudios de pragmática transcultural se insiste en la importancia de describir los rasgos determinantes y específicos de cada cultura o bien los rasgos universales compartidos por todos los hablantes alrededor del mundo.
} 
La evidencia de la cooperación en la propuesta de Grice abre una nueva perspectiva a los estudios pragmáticos ${ }^{30}$. Luego de la exposición de su modelo teórico, la interacción entre los hablantes comienza a ocupar un lugar importante en los estudios posteriores enfocados en la cortesía y la relevancia verbal.

\subsubsection{La relevancia, el modelo del código y el modelo inferencial de la comunicación: Sperber y Wilson}

La teoría de la relevancia, propuesta por D. Sperber y D. Wilson (1994), puede dar la impresión, en un primer acercamiento, de tratarse de un desarrollo más extenso de la categoría de relación expuesta por Grice ("sé relevante"); sin embargo, es un interesante análisis del fenómeno cognitivo en determinados procesos comunicativos (Gutiérrez Ordoñez, 2002).

Entre sus principales diferencias podemos destacar que el principio de la relevancia es mucho más explícito que el principio de cooperación y las máximas de Grice. Este último principio supone que la comunicación implica un grado de cooperación muy alto, ya que son normas que el emisor y el oyente deben conocer y poner en práctica para poder comunicarse adecuadamente. Generalmente, los emisores cumplen las normas pero también pueden infringirlas para alcanzar determinados efectos y el oyente utiliza el conocimiento que tenga de estas normas para interpretar la conducta comunicativa.

El principio de relevancia, por el contrario, es una generalización sobre la comunicación ostensivo-inferencial. Los emisores y los oyentes no necesitan conocer el principio de relevancia para comunicarse; es más, los emisores no siguen el principio de relevancia y no podrían violarlo aunque quisieran. El principio de relevancia se aplica sin

\footnotetext{
${ }^{30}$ Considerando que tanto el principio de cooperación como los estudios sobre la cortesía verbal se centran en la interacción comunicativa es importante hacer la siguiente distinción: el primero lo hace considerando la eficacia de la información entregada entre dos hablantes, mientras que los estudios sobre la cortesía que se revisarán más adelante, consideran relevantes aspectos socioculturales en las interacciones comunicativas, así como su mantenimiento tomando en cuenta las relaciones entre los interlocutores.
} 
excepción: todo acto de comunicación ostensiva comunica una presunción de relevancia. Lo que el oyente utiliza en la comprensión inferencial no es el principio general sino el hecho de que una determinada presunción de relevancia haya sido comunicada por un determinado acto de comunicación. De forma sucinta, ya que es sobradamente conocida, se expondrá en las próximas líneas la intención de la propuesta de Sperber y Wilson.

El objetivo de estos planteamientos es exponer el mecanismo deductivo explícito para describir así los procesos y estrategias que conducen desde el significado literal hasta la interpretación pragmática. Se intenta demostrar que si bien una lengua es un código que empareja representaciones fonéticas y representaciones semánticas de oraciones, existe un vacío entre la representación semántica de las oraciones y los pensamientos realmente comunicados por los enunciados. Este vacío no se llena con más codificación, sino con inferencia. Se plantea, así, que existe una alternativa al modelo del código de la comunicación, esto es: el modelo inferencial, debido a que la comunicación ha sido descrita como un proceso de reconocimiento mediante inferencias en el que se observa la intención del emisor.

Cierto es que un enunciado posee una serie de propiedades diferentes, tanto lingüísticas como no lingüísticas. Las gramáticas generativas aíslan las propiedades puramente lingüísticas de los enunciados y describen una estructura lingüística común, la oración compartida por toda una serie de enunciados que se diferencian tan solo por sus propiedades no lingüísticas. Así, la representación semántica de una oración no puede dar cuenta de propiedades no lingüísticas como, por ejemplo, el momento y el lugar de emisión del enunciado, la identidad del hablante y sus intenciones, etc.

Estos autores ponen en jaque la funcionalidad biunívoca de la clásica teoría del código en el proceso de comunicación y promulgan que para justificar este modelo del código de la comunicación verbal, habría que demostrar que todos los casos de asignación de referente pueden resolverse mediante reglas que combinan automáticamente propiedades del contexto con propiedades semánticas del enunciado. Del mismo modo, insisten en que habría que demostrar que también la desambiguación, la recuperación de las actitudes proposicionales, las interpretaciones figurativas y el significado implícito pueden analizarse 
en términos similares; sin embargo, no se ha propuesto nada que se acerque a tal demostración.

En efecto, los procesos inferenciales se diferencian bastante de los procesos de descodificación. Un proceso inferencial parte de un conjunto de premisas y desemboca en una serie de conclusiones que derivan de forma lógica de las premisas, o, por lo menos, están garantizadas por las mismas. Según el modelo inferencial propuesto, la comunicación se consigue cuando el emisor proporciona indicios de sus intenciones y el oyente infiere sus intenciones a partir de dichos indicios. Un proceso de descodificación, por otra parte, se inicia de una señal y desemboca en la recuperación de un mensaje que es asociado a la señal por un código subyacente. En general, las conclusiones no son asociadas a sus premisas por un código, y las señales no garantizan el mensaje que transmiten.

En esta teoría un concepto fundamental es el de contexto que es el conjunto de premisas que se emplean para interpretar un enunciado; es una construcción psicológica, un subconjunto de los supuestos que afectan la interpretación de un enunciado y que el oyente tiene sobre el mundo. El intento de toda teoría pragmática es describir de qué forma consigue encontrar el oyente, para cada enunciado concreto, un contexto que le permite comprenderlo adecuadamente. La noción de efecto contextual es fundamental para establecer una definición de la relevancia. Tener efectos contextuales es una condición necesaria para la relevancia; se entiende así que cuanto mayores son los efectos contextuales, mayor es la relevancia.

Tenemos así que un supuesto es relevante en un contexto si tiene algún efecto en dicho contexto. Entonces, un supuesto, para ser relevante en un contexto tiene que guardar alguna conexión con ese contexto. Cuanto más débil es el efecto contextual de un supuesto menos relevante será. Ahora bien, el esfuerzo del procesamiento implicado en conseguir efectos contextuales es el segundo factor que hay que tomar en consideración para establecer los grados de relevancia. El esfuerzo de procesamiento es un factor negativo: en igualdad de condiciones cuanto mayor sea el esfuerzo de procesamiento menor será la relevancia. 
En síntesis, un supuesto es relevante en un contexto en la medida en que sus efectos en dicho contexto sean importantes. Asimismo, un supuesto es relevante en un contexto en la medida en que el esfuerzo requerido para su procesamiento en dicho contexto sea moderado. El tratamiento de los actos de habla que se presenta en esta teoría, ilustra la pertinencia general del principio de relevancia. Este principio permite derivar complejas y exactas inferencias no demostrativas acerca de la intención informativa del emisor. Con el principio, lo único que se necesita es que las propiedades del estímulo ostensivo coloquen al proceso inferencial sobre el camino correcto; para esto no se necesita codificar la intención informativa del emisor con gran detalle. Por consiguiente, los indicadores de fuerza ilocutiva, tales como el modo enunciativo o imperativo, solo tienen que hacer manifiesta una propiedad bastante abstracta de la intención informativa del hablante: la dirección en la que hay que buscar la relevancia del enunciado.

Ahora bien, obtenemos como deducción de estos planteamientos que un hablante puede ser más eficaz que otro según la forma en que guía a su audiencia en esta búsqueda de la relevancia en el enunciado, esto es, en la medida en que puede producir efectos contextuales en el discurso más fuertes, y efectivos, o más suaves y, por tanto, menos eficaces. Como se dijo antes, los emisores y los oyentes no necesitan conocer el principio de relevancia para comunicarse, pues los emisores no siguen el principio de relevancia y no podrían violarlo aunque quisieran. Sin embargo, ya que el principio de relevancia se aplica sin excepción y todo acto de comunicación ostensiva comunica una presunción de relevancia siempre contamos con que hay una determinada presunción de relevancia que ha sido comunicada por un determinado acto de comunicación; lo estratégico involucra estar conscientes de cómo lograr seleccionar (o crear) enunciados que sean más relevantes para nuestros emisores. Evidentemente, la fuerza de los efectos contextuales que produzcan nuestros enunciados está ligada al conocimiento de mundo que compartan los interlocutores en una conversación; esto es debido a que solo este conocimiento previo permite realizar 
las inferencias necesarias para poder asignarle grados de relevancia a la conversación de un interlocutor $^{31}$.

Se ha revisado hasta aquí cómo fue tomando cuerpo, a través de la exposición de teorías de filósofos y teóricos del lenguaje, la concepción de pragmática, no como una disciplina sino como una perspectiva de estudio lingüístico. Pragmática es, por tanto, un modo de hacer lingüística, incorporando todas las instrucciones del entorno y analizando la interrelación mutua entre lo llamado intra y extralingüístico (Fuentes, 2000).

Ya descrita la perspectiva en la que se encuentra inserto el fenómeno de la cortesía verbal, se expondrán en el siguiente apartado las teorías que definen esta estrategia conversacional.

31 Una exposición de la teoría de la relevancia permite construir puentes entre la relevancia y la cortesía verbal, aunque sus autores no lo mencionen directamente. Entre más relevante es una propuesta temática, menos energía invertirá el receptor en interpretarla; sin embargo, más energía deberá invertir el emisor en desarrollarla, ya que, en primer lugar, el interlocutor idealmente (pues para ello debe existir una intención positiva de la comunicación), tiene en cuenta a su interlocutor al entablar un acto comunicativo y, en segundo lugar, se preocupa de proponer temas que cree que este domina, es decir, que supone que este puede inferir con sus conocimientos previos. En síntesis, para que el emisor sea relevante en su proceso comunicativo debe tener en cuenta quién es su interlocutor y cuáles son los conocimientos previos que este tiene sobre determinado tema y sus posibles efectos contextuales, incluso si quiere atacarlo o contradecirlo. Esta estrategia comunicativa sin duda involucra un acto de cortesía verbal pues el que habla tiene en cuenta el conocimiento que comparte con el interlocutor y debe averiguar lo que el otro sabe sobre un tema determinado. Si bien se puede realizar un acto verbal irónico o un ataque en apariencia no cortés que tenga estas características, sí se pensó en el otro al construir su mensaje y, en este sentido, sí habría cortesía en ese acto de comunicación. 



\section{LA CORTESÍA LINGÜÍSTICA EN LA CONVERSACIÓN}

\subsection{Algunos aspectos sobre la conversación}

Podemos afirmar que la conversación es la forma fundamental de la interacción oral (Van Dijk, 1983) y la actividad lingüística básica de la comunicación humana en la que se ponen en práctica todos los elementos que conforman nuestra competencia comunicativa, aptitud que, principalmente, nos permite adecuar apropiadamente nuestros discursos en contextos determinados; no obstante, y al mismo tiempo, es una actividad en la que los hablantes no solo ponen en acción su competencia comunicativa sino que también entran en juego "los procedimientos empleados para la construcción de un orden social" (Schiffrin, 1990:323), pues es un vehículo a través del cual se construyen socialmente identidades, relaciones y situaciones.

Un rasgo particular de la conversación es, en primer lugar, el no tener estructuras categoriales para los participantes, por tanto, toda persona puede participar en una conversación; en segundo lugar, generalmente no hay restricciones fijas en cuanto a su contenido temático, siempre y cuando, el tema no se haya especificado de antemano, en el caso de que se trate de una conversación específica o semipautada ${ }^{32}$, por ejemplo; y en tercer lugar, tampoco existen limitaciones de contextos sociales, esto es, todos los contextos sociales son aptos para entablar una conversación.

La conversación oral coloquial implica decir algo con una intención específica para lograr exitosamente determinadas metas (Briz, 2001). En general, en los procesos comunicativos intentamos seguir ciertos planes que responden a principios o normas de textualidad, de cohesión y coherencia, de informatividad y de pertinencia o relevancia, en

32 Las grabaciones que conforman el corpus de esta investigación corresponden a conversaciones semipautadas pues, como se explicó anteriormente, no se han establecido turnos para cada uno de los participantes en ambos debates, ni tiempo de duración de cada uno de los turnos. Sin embargo, sí se propusieron los temas a debatir. 
un contexto dado. Así, los criterios de eficacia, adecuación y efectividad guían y controlan en cierto sentido la producción lingüística. Siguiendo esta perspectiva interaccional, Briz (2001) propone que la conversación es una "negociación" en la que se argumenta, por una parte, para conseguir un fin concreto y, por otra, se negocia el acuerdo, se interactúa y se mantiene una relación cooperativa regulada por una serie de normas de conducta social. Se podría concluir que esta "negociación" comunicativa se puede comparar con la construcción común de una obra.

Kerbrat Orecchioni postula, por su parte, que las conversaciones conforman “discursos construidos colectivamente" (Kerbrat-Orecchioni, 1998:3), es decir, toda interacción verbal es una sucesión de eventos que conforman un "texto" elaborado en forma conjunta entre sus interlocutores, sometiendo su discurso a reglas de organización interna. Y es precisamente gracias a este incesante "bricolaje interactivo" que los diferentes participantes de una conversación consiguen, más allá de la heterogeneidad constitutiva, construir juntos textos coherentes.

En cuanto a su constitución como evento comunicativo oral, la conversación está conformada por unidades que la estructuran. Así, el turno de palabra se considera la “unidad básica de la organización conversacional” (Tusón, 2008: 55). La conversación se concibe, pues, como un texto formado por varias voces que se organizan a partir de la alternancia de estos turnos de palabra conformados por emisiones informativas. Los mecanismos por los que se rige el cambio de turno son principalmente dos: la heteroselección, que consiste en la selección por parte del que habla del siguiente hablante y la autoselección, que se produce cuando una de las personas presentes toma un turno sin que el que tiene la palabra lo haya seleccionado. Es común que estos mecanismos funcionen relativamente bien ya que los interlocutores son capaces de reconocer lo que se denominan lugares apropiados para la transición, que pueden estar señalados por una pregunta, una entonación descendente seguida de una pausa, un gesto, etc. (Calsamiglia y Tusón, 2008).

A cada una de las emisiones comunicativas se les denomina intervención. Las intervenciones, por su parte, pueden ser de inicio o de reacción: de inicio, cuando intentan 
provocar una respuesta en el interlocutor, y de reacción, en forma de respuestas cooperativas.

Cuando termina la intervención de inicio de un hablante se produce la llamada alternancia de turno, que comienza cuando el interlocutor da inicio a su intervención reactiva, la que debe ser aceptada por el interlocutor. Es importante destacar que no solamente hay alternancia de turno cuando se produce un cambio de hablante, sino que dicho cambio debe ir acompañado de un reconocimiento y una aceptación por parte del interlocutor. Así, el turno implica una intervención, pero no toda intervención constituye un turno. La intervención o movimiento es la unidad máxima desde el punto de vista monologal.

Otra unidad estructural de la conversación es el intercambio, unidad dialogal mínima, conformado por dos intervenciones sucesivas, una de inicio y una de reacción, de distintos hablantes. El intercambio mínimo es el par adyacente típicamente representado en los pares ofrecimiento-aceptación (o rechazo), saludo-saludo, pregunta-respuesta, etc. (Tusón, 2008)

Vemos así que la interacción comunicativa es el escenario en el que se van construyendo relaciones particulares entre los interlocutores, las cuales pueden adoptar matices de distanciamiento, familiaridad, dominio o conflicto, dependiendo de la posición de cercanía o distancia o de cómo se manejen las relaciones de control y poder. Y es este "bricolaje interactivo", tomando los conceptos de Kerbrat Orecchioni, el que permite que los diferentes participantes de una conversación consigan construir textos coherentes que permitan, con mayor o menor suerte, comunicarse con sus interlocutores. Todo esto, desde luego, dependiendo de la precisión con la que se utilicen las estrategias conversacionales que se describirán en los capítulos siguientes.

\subsection{La cortesía lingüistica como estrategia conversacional}

Como se dijo anteriormente, la concepción teórica de cortesía tiene su origen en los estudios pragmáticos iniciales de los años 60, que propiciaron discusiones teóricas sobre la 
función de la pragmática en los estudios de la lengua y dilucidaron ciertos aspectos del lenguaje que otras disciplinas nunca habían integrado en su teoría: el uso y contexto. Gracias a esta nueva perspectiva, el lenguaje deja de ser un simple objeto de descripción y es considerado como un medio de acción.

En un principio, existía una visión clásica de la cortesía, que estaba centrada en los aspectos más claramente convencionales y sociales; se entendía la cortesía como algo formal, superfluo, pues se consideraba que reflejaba y perpetuaba una organización social jerárquica rígida.

Semejante caracterización difícilmente podría encajar con los intereses teóricos de una disciplina que pretendía analizar todo aquello que trascendiera lo puramente codificado (Escandell, 1995). Por esta razón, no debe resultar extraño que los estudios sobre cortesía no encontraran un lugar cómodo en la pragmática hasta que esta concepción tradicional no se vio sustituida por otra sustancialmente distinta. En este nuevo enfoque, la cortesía iba a entenderse como resultado de una necesidad humana de mantener el equilibrio en las relaciones interpersonales y su manifestación externa sería el conjunto de estrategias lingüísticas de las que puede valerse un hablante para evitar o reducir al mínimo el conflicto con su interlocutor, cuando los intereses de ambos no son coincidentes ${ }^{33}$.

Frente a la concepción tradicional, que destacaba los aspectos sociales, en este nuevo enfoque prima el aspecto individual, creativo y estratégico de la cortesía. Ser cortés no es solo seguir unas reglas externas, consiste, sobre todo, en saber evitar los conflictos. La noción de cortesía ha cambiado, por tanto, de una concepción formal a una concepción funcional (Escandell, 1995).

Esta perspectiva funcionalista incluye los puntos de vista de los usuarios y se aproxima a consideraciones sociales que permiten que los hablantes tengan acceso y

\footnotetext{
${ }^{33}$ Esta perspectiva funcional es la predominante en los trabajos de Lakoff (1973), Leech (1983) o Brown and Levinson $(1978,1987)$.
} 
controlen los recursos del lenguaje. Es así como, desde esta perspectiva interaccional funcional, la cortesía es entendida como una estrategia conversacional, ya que el lenguaje es el medio que permite mantener las relaciones interpersonales y es una herramienta que permite alcanzar determinados objetivos.

A modo de síntesis explicativa y organizativa Gudrun (1999) presenta una interesante perspectiva taxonómica de los estudios sobre la cortesía verbal, en la que propone que existen diferentes conceptos del fenómeno cortés dependiendo del estado de la investigación de la cortesía lingüística, el cual parece corresponder con determinados acercamientos paradigmáticos. Brevemente se describirá dicha taxonomía:

1. Punto de vista causal-determinista: Esta manera de abordar la cortesía propone que las normas sociales están obligadas a dirigir el sistema lingüístico relevante desde afuera y, por ende, dejar sus rastros en su léxico y gramática. Estos rastros pueden ser descritos por los lingüistas como un inventario de formas. Tal como ocurre en los estudios precientíficos sobre el comportamiento social y buenas costumbres, la cortesía es entendida, según este punto de vista, como "sentido común”, en las maneras de mostrar respeto al otro, estrategia que es usada para alcanzar los propios objetivos.

2. Lo indirecto en la cortesía: Este acercamiento es el punto central de interés de la pragmática, específicamente en las discusiones teóricas sobre la función de los actos de habla en la cortesía verbal. Aunque nace desde diferentes posturas teóricas y metodológicas, los tres clásicos acercamientos son los realizados por Lakoff, Leech, y Brown y Levinson, pues estos estudios son los que han intentado describir lo indirecto en la cortesía tomando como base de sus discusiones sus particulares interpretaciones de lo propuesto por Searle y Grice. El éxito de esta postura radica no solo en la habilidad de describir las implicaturas y su función interactiva, sino que también otorga una mejor forma a los conceptos de tacto y respeto.

3. Acercamiento a la cortesía como apoyo a las relaciones sociales: Los estudios 
pioneros en esta perspectiva corresponden a Erving Goffman, autor que propone la noción de face y los rituales de interacción social relacionados con ella. Desde esta perspectiva, la cortesía es considerada más allá de la función de un solo enunciado, se considera parte de una combinación estructural, una acción completa o una secuencia de acciones.

Las posturas aquí descritas no son incompatibles en análisis que pretendan abarcar una descripción completa de las estrategias de cortesía; sin ir más lejos, en esta investigación se han tenido en cuenta estas observaciones puesto que el análisis del discurso enfocado en la cortesía (Bravo, 2004) incluye, ciertamente, la descripción de aspectos lingüísticos que son definidos como parte de interacciones sociales determinadas, lo que obliga a relacionar lo lingüístico con lo social, y dichos rasgos lingüísticos se consideran estrategias comunicacionales implicadas en la conversación. Del mismo modo, en esta investigación se describirán los indicadores gramaticales de atenuación cortés (Kerbrat-Orecchioni) así como también los indicadores gramaticales de cortesía positiva y negativa (Kerbrat-Orecchioni/Brown P. y Levinson S. ) siempre analizados en su contexto comunicativo que determinará su función y el contenido proposicional implícito.

Lo interesante de revisar la taxonomía propuesta por este autor es que, al considerar de forma global esta descripción y sus diferentes puntos de vista, se revelan los variados aspectos formales y funcionales de este objeto de estudio que es onomasiológicamente bastante engorroso de definir.

Alejado de las taxonomías y retomando una visión estratégica de la cortesía, Haverkate (1994) considera que la racionalidad constituye la base de estas estrategias verbales en general y, especialmente, de la cortesía lingüística. Argumenta que esta racionalidad es inherente en todo acto cortés y se manifiesta de dos modos distintos: por medio de la justificación del acto de habla y por medio de la valorización del balance entre coste-beneficio, es decir, según este autor el carácter de seres racionales nos permite planificar nuestras estrategias corteses y decidir si ejecutarla de forma indirecta o directa y plasmarla en un acto de habla. 
Desde una perspectiva pragmática, el carácter indirecto de los enunciados sugiere que las diferentes lenguas proporcionan a quienes las hablan modos alternativos de conseguir objetivos comunicativos determinados; en usos reales, los enunciados indirectos y las constantes violaciones a las máximas conversacionales planteadas por Grice son la norma y no la excepción, ya que muchos hablantes no expresan sus intenciones de la forma más clara y explícita posible. Como se dijo anteriormente, Grice ya había observado que el cumplimiento de las máximas podría estar en conflicto directo con asuntos de cortesía.

Dado que las teorías sobre la cortesía verbal aspiran a explicar las motivaciones sociales de los enunciados indirectos y sus implicancias sociales, su estudio se ha configurado como una de las ramas más singulares y prometedoras de la pragmática.

\subsection{Estudios y teorías sobre cortesía verbal}

\subsubsection{Estudios y propuestas iniciales}

Los estudios pioneros sobre la cortesía tienen su referente en los planteamientos de Goffman, E. (1959) que, si bien tienen un cariz más psicológico social, se considera una importante fuente de inspiración para estudios lingüísticos posteriores. Este autor fue uno de los primeros en profundizar en la importancia de los aspectos de tipo contextual y de uso en el momento de hacer estudios lingüísticos de la comunicación hablada. "Sus planteamientos iniciales son sociolingǘsticos, en el sentido amplio del término, al emprender un análisis de distintas formas de habla entendiendo en todo momento que un factor que no se puede olvidar de ninguna forma es la situación social” (Nieto, 1995: 21).

$\mathrm{Su}$ principal aporte fue introducir el concepto de "imagen personal" (face) o imagen que una persona proyecta durante un contacto en particular. Según Goffman, los participantes del proceso social tienen la necesidad de ser apreciados por otros y la necesidad de sentirse libres; de este modo, denomina "imagen positiva" a la necesidad de ser apreciado e "imagen negativa" a la necesidad de no ser molestado. Este autor proponía, además, que la interacción social (incluyendo la comunicación verbal) debe estudiarse considerando que los participantes se esfuerzan por lograr cierta estabilidad en 
sus relaciones con los demás, evitando vulnerar la imagen del otro. Explica que, ya que hay actos que inevitablemente amenazan la imagen, es necesario reducir esta afrenta, manteniendo la estabilidad. Y es precisamente la cortesía la encargada de evitar o reparar el daño causado por estos “actos que amenazan la imagen”(AAI) ${ }^{34}$. Así: cuanto mayor es la amenaza contra la estabilidad, mayor es la necesidad de cortesía.

Propone que hay dos tipos de cortesía: la "cortesía solidaria" que es el trabajo de imagen que apunta hacia la imagen positiva y la "cortesía respetuosa", la que se refiere a la imagen negativa (Renkema, 1999). En síntesis, Goffman en su tiempo fue precursor acertadamente de reflexiones sobre una serie de puntos que más adelante han sido esenciales para análisis lingüísticos orales más profundos.

En 1973, Lakoff desarrolla una propuesta sobre la cortesía, desde una perspectiva pragmática, que reduce el uso de la cortesía a principios que, a simple vista, parecen un símil de las máximas del principio de cooperación de Grice. Toma como base tres áreas de comportamiento pragmático iniciales, que son: "las suposiciones del hablante con respecto a sus relaciones con el oyente, la situación de este hablante en el mundo real en el momento de expresarse y el grado en que se desea cambiar una o ambas condiciones (o reforzarlas)" (Lakoff, 1973: 265).

Plantea, así, máximas de la competencia pragmática:

\section{Sea claro.}

\section{Sea cortés.}

Para explicar la primera de estas máximas se basa en la propuesta realizada por Grice sobre las reglas de claridad en la conversación que forman parte de su modelo conversacional. Sostiene que esta máxima está orientada al cumplimiento de reglas

\footnotetext{
${ }^{34}$ O FTA (face threatening act)
} 
destinadas a que el hablante divulgue el contenido denotativo de su acto de habla tan claramente y con tan poca confusión como le sea posible.

No obstante, cuando la claridad entra en conflicto con la cortesía, la mayoría de las veces esta última se impone debido a que los participantes en una conversación cotidiana, generalmente, consideran más importante evitar la ofensa que conseguir el objetivo de la claridad. Lakoff insiste en el hecho de que en la mayoría de las conversaciones informales, la comunicación real de ideas importantes es algo secundario respecto al mero hecho de afirmar y estrechar las relaciones. De ahí que las máximas conversacionales se respeten de forma estricta solo en aquellos intercambios comunicativos en los que el contenido que se comunica sea más importante que el acto de dialogar.

En efecto, el comportamiento verbal cortés en la sociedad constituye un hecho fundamental para las relaciones sociales. Todo individuo intuitivamente lo utiliza para proteger su imagen o mejorarla dentro del grupo donde se desenvuelve; además, esta actuación lingüística cortés permitir evaluar las suposiciones con respecto al grado de acercamiento que tiene el interlocutor con el oyente o su ascendencia dentro de una comunidad. Esta evaluación en muchos casos está por encima del objetivo informativo, primando entonces el hecho de expresar, no tanto la claridad enunciativa, como la revalidación de su imagen como ser social a través del uso adecuado de estrategias conversacionales que le permitan estrechar las relaciones individuales y con el grupo. Estas negociaciones que se producen dentro de determinados grupos sociales han suscitado, entre muchas otras consideraciones, el interés por los estudios de género y cortesía.

Al respecto, Mills (2003) desafía, en su propuesta, la noción estereotipada de que las mujeres son necesariamente más corteses que los hombres, como proponen muchos 
estudios de lengua y género citados en sus investigaciones ${ }^{35}$. Mills discute la compleja relación entre género y cortesía, y argumenta que, aunque hay circunstancias en las cuales hablantes femeninos, siguiendo el estereotipo femenino que guía su comportamiento, pudieran llegar a presentarse y actuar en sociedad de una forma más cortés que los hombres, existen muchísimas circunstancias en las que mujeres actúan tan descortésmente como los hombres. Se intenta, así, mostrar que la cortesía y la descortesía son, en esencia, juicios realizados de acuerdo a las intervenciones comunicativas y a los criterios de las personas en general y que no consiste en una simple clasificación de tipos de discurso particulares. Lo interesante de este estudio es que se examina a fondo la manera en que los hablantes negocian, en prácticas comunicativas reales y cotidianas, siguiendo su propia percepción de estereotipos de género.

Por su parte, Briz (2001), en sus estudios de la descripción del español coloquial, propone que con frecuencia la conversación espontánea parece transgredir los principios y las reglas, tanto de cooperación como de cortesía. A pesar de esto, que no es ni más ni menos que consecuencia de lo directa que es la conversación coloquial, no puede afirmarse que esta sea descortés. Cierto es, entonces, que la cortesía y la descortesía de un acto de habla dependen en muchas ocasiones de la interpretación que de esta hacen los interlocutores; por tanto, volvemos a considerar lo implicado que está el factor sociocultural en la descripción de dichas estrategias comunicativas.

Retomando los planteamientos de Lakoff, para ejemplificar más detalladamente la segunda máxima de competencia pragmática ya propuesta (i.e. "sea cortés"), propone tres máximas de cortesía:

\section{a. No importune}

\footnotetext{
35 Entre estos estudios de género y cortesía destacan las investigaciones realizadas por Hans J. Ladegaard (2004) (Institute of language and communication, University of Southern Denmark) en la socialización verbal de niños, con la intención de obtener una completa descripción de su competencia pragmática y dilucidar, así, si el fenómeno cortés es más propio en niñas o en niños en sus horas de juego y esparcimiento.
} 


\section{b. Ofrezca alternativas}

\section{c. Haga que $O$ se sienta bien, compórtese amigablemente.}

Aclara que dos o más de estas máximas pueden actuar al mismo tiempo, reforzándose mutuamente, pero también puede efectuarse una elección entre ellas, y entonces la elegida anulará a las otras. El modelo propuesto por Lakoff está basado en la creencia de que las máximas de cortesía que se proponen pueden diferir dialectalmente en su aplicabilidad, pero su esquema básico es el mismo universalmente.

Posteriormente, en 1978, basándose en la propuesta de Goffman, Brown P. y Levinson S. llevaron a cabo estudios teóricos sobre la relación entre la intensidad de la amenaza a la imagen y la cortesía desde una concepción lingüística. El modelo propuesto es un complemento del modelo de cooperación de Grice y explica los motivos y el funcionamiento de la cortesía en las lenguas.

\subsubsection{Acercamiento al modelo de Brown P. y Levinson S.}

La propuesta teórica de Brown P. y Levinson S. parte de dos supuestos fundamentales: en primer lugar, que toda sociedad tiene que controlar la agresividad de sus miembros. La cortesía presupone, por tanto, la existencia de ese potencial agresivo y trata de contrarrestarlo para incentivar las buenas relaciones sociales; y, en segundo lugar, que la comunicación es una conducta racional que busca la máxima eficacia; "en este sentido, la comunicación está sujeta al principio de cooperación de Grice, entendido como el marco socialmente neutro en el que se desarrollan los intercambios comunicativos y que presupone su racionalidad y eficacia. Se considera también que uno solamente se aparta de él cuando tiene una buena razón para hacerlo; y la cortesía (...) puede ser una de estas buenas razones" (Escandell, 2006: 154).

Este modelo presenta dos propiedades básicas en lo que respecta a los individuos y que permite explicar su comportamiento comunicativo:

a. Racionalidad: cada individuo posee un modo de razonamiento que se puede 
definir con precisión y que lo conduce en la obtención de los fines que persigue, es decir, los medios necesarios para intentar conseguir dichos fines. Está ligada al principio de cooperación de Grice.

b. Imagen pública (face): esta es la noción central de la teoría y significa que

cada individuo tiene y reclama para sí una cierta imagen pública (prestigio) que quiere conservar. Está ligada a la cortesía. Los autores explican que esta imagen puede ser positiva o negativa:

Central to our model is a highly abstract noticion of 'face' which consists of two specific kinds of desires ('face-wants') attributed by interactants to one another: the desire to be unimpeded in one's actions (negative face), and the desire (in some respects) to be approved of (positive face). (Brown P. y Levinson S. , 1987: 13. ) $^{36}$

La imagen negativa es el deseo de tener libertad, de no sufrir imposiciones de ningún tipo y de conservar la independencia; mientras que la imagen positiva es el deseo de ser aprobado y apreciado por los demás, de forma tal que se lo incluya en un determinado grupo social ${ }^{37}$.

Bravo (2004) reconoce que los investigadores de la cortesía critican, coincidente y recurrentemente, la descripción propuesta de la imagen negativa que se define en el

\footnotetext{
36 "El centro de nuestro modelo lo ocupa una noción muy abstracta que consiste en dos clases específicas de deseos (face wants), que los interactuantes se atribuyen mutuamente: el deseo de que uno no vea impedidos sus actos (imagen negativa) y el deseo de que los actos de uno sean aprobados (hasta cierto punto) (imagen positiva)". (traducción y cita del texto en Calsamiglia y Tusón, 1999: 162)

37 Al estudiar las estrategias comunicativas se deberían, por tanto, estudiar los contextos socioculturales que abarcan comportamientos, actitudes y valores que son conocidos, aceptados y practicados en determinada comunidad de habla. Estos contextos están relacionados con los deseos de imagen de los hablantes que Bravo denomina “imagen de autonomía y de afiliación” (Bravo, 2004); esta imagen de autonomía contempla el deseo del individuo de verse y de ser visto como alguien con contorno propio dentro de un determinado grupo social.
} 
modelo de Brown P. y Levinson S., debido a la falta de universalidad que adquiere este concepto en diferentes culturas. No obstante, debido a que el concepto de imagen social (face) y su relación con la cortesía trasciende las fronteras culturales, se ha convertido "en un instrumento metodológico que permite dar cuenta de las implicancias sociales de la interacción hablada" (Bravo, 2004: 23).

En estudios de lenguas no anglófonas, se insiste, además, de manera constante, en que esta imagen negativa, es decir, los deseos de preservación del territorio personal, entendido como no ingerencia en los asuntos privados y respeto por la libertad de acción, no parece coincidir en todas las sociedades pues irrefutablemente no está configurada del mismo modo en cada contexto social. Por esta razón, la aplicación directa de este modelo, esto es, sin adaptaciones culturales, puede resultar engañosa y poco certera. Por tanto, se deben considerar aspectos culturales implicados antes de concretar un análisis aplicando este clásico esquema interaccional.

Volviendo a la descripción del modelo, el funcionamiento de la cortesía para Brown P. y Levinson S. está basado en el mantenimiento a salvo, por parte de los individuos, de su imagen pública. Para ello no se debe atentar contra la imagen pública de los demás. En el caso de que esta situación llegara a suceder y que, por tanto, se produzcan acciones que amenazan la imagen pública (AAIP), estas se deben minimizar con el uso de estrategias comunicativas. Es lógico que el emisor intente suavizar la amenaza -a no ser que pretenda atentar contra la imagen de su interlocutor- y para ello es necesario hacer uso de la cortesía.

El nivel de cortesía depende de tres factores:

a. Poder relativo (P) del destinatario con respecto al emisor (eje vertical).

b. Distancia social (D) que es el grado de contacto y familiaridad entre los interlocutores (eje horizontal).

c. Grado de imposición (G), es decir, la gravedad del acto que atenta contra la imagen pública (AAIP). 
El riesgo de un acto se calcula, así, a partir de la suma de estos tres factores y se puede representar en la siguiente fórmula:

$$
\text { Riesgo (AAIP) } X=(\mathbf{D}+\mathbf{P}+\mathbf{G}) X
$$

Teniendo en cuenta este cálculo, el emisor elegirá la estrategia adecuada para cuidar su imagen y la de su interlocutor. Como se dijo antes, cuando se comete un acto que amenaza la imagen pública, se recurre a estrategias de cortesía que permiten enmendar la falta. El modelo propuesto en esta teoría distingue los siguientes cinco tipos de estrategias posibles:

\section{ESTRATEGIAS mediante las cuales se puede realizar una AAIP (Brown P. y}

\section{Levinson S. , 1987)}

I. Abiertas y directas (bold on record). Realizar la AAIP abiertamente sin suavizarla de ninguna forma.

II. Abiertas e indirectas (cortesía positiva). Suavizar la AAIP por medio de una corrección positiva.

III. Abiertas e indirectas (cortesía negativa). Suavizar la AAIP por medio de una corrección negativa.

IV. Encubiertas (off record). Realizar la AAIP de forma que pase inadvertida por los presentes excepto por las dos personas directamente implicadas.

V. Evitar AAIP (ideal)

Se expondrán brevemente, en los siguientes cuadros, las estrategias verbales más interesantes al realizar un análisis discursivo (I, II, III, en el gráfico), pues son técnicas destinadas a potenciar tanto la cortesía positiva como negativa y, lo más importante, son detectables textualmente. Estas son: abiertas directas y abiertas indirectas (negativa y positiva), es decir, se explican aquí solo las estrategias de tipo abiertas (I, II, III) debido a que son indispensables si se quiere realizar un análisis lingüístico de las técnicas explícitas de cortesía verbal, objetivo también de esta investigación. Puede, evidentemente, haber alguna distinción en el énfasis de cada una dependiendo del modelo de análisis del discurso por el que se esté influido; para esta investigación las tres estrategias tendrán igual 
relevancia al momento de ser descritas.

La cortesía negativa es una acción compensatoria dirigida a la imagen negativa del destinatario, esto es, hacia su deseo de que no se dificulte su libertad de acción ni se estorbe su atención. Es la esencia del comportamiento respetuoso, del mismo modo que la cortesía positiva es la esencia del comportamiento distendido.

Algunas de las estrategias dirigidas a este tipo de acción son:

Estrategias de Cortesía Negativa (Brown P. y Levinson S. , 1987)

Estrategia de acción

Sea Directo
Sugerencia explicativa de esta estrategia

Sea convencionalmente directo ${ }^{38}$
No presuma /asuma

Pregunte, no sea asertivo.

No coaccione a su oyente $(\mathbf{O})$ : dele - Sea pesimista, asuma que seguramente O opciones para actuar; sea indirecto; no no va a hacer A. asuma que $\mathrm{O}$ puede/quiere hacer A. Haga - Minimice el grado de imposición (G) explícitos los valores G (grado de - Muestre deferencia. imposición), $\mathrm{P}$ (poder relativo), $\mathrm{D}$ (distancia social) .

Comunique que H (el hablante) no - Pida disculpas. quiere afectar a $\mathbf{O}$. - Impersonalice a $\mathrm{H}$ y O: evite la primera y segunda persona del singular.

- Plantee las AAI (acciones que amenazan la imagen pública) como una regla general.

Compense otros deseos de O, - Plantee abiertamente que ha contraído derivados de la imagen negativa. una deuda con $\mathrm{O}$, o que $\mathrm{O}$ no está en deuda

\footnotetext{
${ }^{38}$ Directo en el sentido de ser lo suficientemente preciso y claro en el mensaje que se le dirige al interlocutor.
} 
con $\mathrm{H}$.

La cortesía positiva [el hablante $(\mathrm{H})$ quiere los deseos del oyente $(\mathrm{O})$ ] es una compensación dirigida a la imagen positiva del destinatario, a su deseo perenne de que sus deseos (o las acciones/adquisiciones/valores que resultan de ellos) se perciban como algo deseable. La compensación consiste en satisfacer parcialmente ese deseo comunicando que los propios deseos (o algunos de ellos) son en cierto sentido similares a los del destinatario. Algunas de las estrategias comunicativas dirigidas a cumplir este tipo de acción son las siguientes:

Estrategias de Cortesía Positiva (Brown P. y Levinson S. , 1987)

Estrategia de acción Sugerencia explicativa de esta estrategia Apele a la pertenencia al mismo grupo Use marcadores de identidad de grupo. que 0 .

Apele al "terreno común".

- Intensifique el interés hacia O.

- Exagere (interés, aprobación, simpatía con $\mathrm{O}$ )

- Fíjese, atienda a O (a sus intereses, deseos, necesidades, bienes).

Apele al punto de vista, opiniones, - Busque el acuerdo.

actitudes, conocimiento, empatía - Evite el desacuerdo.

comunes. - - Presuponga/ suscite/ manifieste el terreno común.

- Bromee.

Exprese que H y $\mathrm{O}$ son cooperativos. - Ofrezca, prometa.

Indique que $\mathbf{H}$ conoce los deseos de $\mathbf{O}$ - Sea optimista.

y los está teniendo en cuenta.

Manifieste o presuponga que conoce $y$ se preocupa por los deseos de $O$. 
Apele a la reflexibilidad

(si $O$ desea [que $O$ tenga $X]$, entonces

$H$ desea [que $O$ tenga $X$ ] y si $H$ desea [que $H$ tenga $X$ ] entonces $O$ desea [que $H$ tenga $\mathrm{X}]$ ).
- Incluya a ambos, $\mathrm{H}$ y O, en la actividad.

- Dé (o pida) razones.

- Asuma o manifieste reciprocidad.

- Haga regalos a O (bienes, simpatía, comprensión, cooperación).

Respecto a este modelo y, específicamente, respecto de las estrategias de cortesía así formuladas, Kerbrat-Orecchioni considera que es muy productivo, ya que permite explicar muchos hechos discursivos cuya existencia, de otro modo, permanecería poco clara, como es el caso de los actos de habla indirectos; no obstante, propone una serie de acondicionamientos que pretenden solucionar ciertas debilidades del modelo que restringen, a su modo de ver, sus capacidades descriptivas.

Efectivamente, desde la perspectiva de la propuesta de Brown P. y Levinson S., la gran mayoría de los actos de habla que uno realiza a lo largo de su vida, son potencialmente amenazadores para una $\mathrm{u}$ otra de las imágenes presentes. "Por ejemplo, los actos impositivos, como la petición, son potencialmente amenazadores para la imagen negativa del destinatario (su territorio, entonces), y los actos vejatorios, como la crítica o el reproche, son potencialmente amenazadores para su imagen positiva (su amor propio). En cuanto a un acto como la orden, arriesga amenazar simultáneamente ambas imágenes del destinatario. Esta propiedad constitutiva de los actos de habla viene a contrariar gravemente la universal necesidad de imagen (face-want) y crea un serio riesgo para el buen desarrollo de la interacción" (Kerbrat-Orecchioni, 2004: 42).

Esta investigadora propone que es indispensable, entonces, prever un lugar en el modelo teórico para ciertos actos que son de alguna manera la parte positiva de los AAIP, pues son actos valorizadores de la imagen del otro, si bien sirven para mitigar el impacto que pueda causar una pregunta posterior o le petición de un favor. En efecto, un gran número de nuestros comportamientos corteses corresponden perfectamente a esta definición ya que la cortesía también consiste, más positivamente, en producir "antiamenazas"; esto se debe a que si bien ciertos actos de habla son potencialmente 
amenazadores para las imágenes de los interlocutores, otros son, por el contrario, valorizadores de esas mismas imágenes, como el agradecimiento, el augurio, el cumplido (cuando son usados para mitigar la petición de algo o la intromisión en un asunto personal del otro), que en la teoría de Brown P. y Levinson S. son considerados verdaderos AAIP ${ }^{39}$ para la imagen negativa del destinatario, "mientras que son, ante todo y sobre todo, actos halagadores para la imagen positiva de ese mismo destinatario"(2004: 43). Propone, así, incorporar los "actos agradadores de imagen" 40 pues se tornaría así un modelo más potente y coherente ${ }^{41}$.

En esta investigación, en particular, se tomarán como base del análisis las siguientes categorías propuestas por Kerbrat-Orecchioni (2004:44) que se plantean como un aporte al modelo clásico de Brown P. y Levinson S.:

\section{Cuadro número 3}

Estrategias de cortesía positiva: A presta a B algún servicio (FFA) y entonces le toca a B producir un FFA (agradecimiento o gentileza), de restablecer el equilibrio ritual entre los interactuantes. Cuanto más importante es el FFA, tanto debe serlo igualmente el FFA recíproco.

Estrategias de cortesía negativa: A comete contra B alguna ofensa (FTA) que inmediatamente intenta reparar por medio de una excusa (FFA). Cuanto mayor es el peso del FTA, tanto más debe ser importante el trabajo reparador.

\footnotetext{
${ }^{39}$ FTA, en inglés face threatening act.

${ }^{40}$ En inglés FFA, face flattering acts.

${ }^{41}$ A pesar de dichas modificaciones que propone al modelo de Brown and Levinson, Kerbrat.Orecchioni reconoce que dentro del campo de la pragmática interaccional y del dominio más particular de los fenómenos de la cortesía, no hay un competidor serio a este modelo. Las únicas alternativas relevantes que comenta son la teoría del rapport management (manejo de buenas relaciones) elaborado por Spencer-Oatey y la teoría de conversational contract (contrato conversacional) presentada por Fraser.
} 
Siguiendo esta propuesta, los actos de habla podrían entonces ser descritos como, o bien, agradadores de la imagen o, por otro, actos que van contra la imagen, o un complejo de estos dos componentes. Como consecuencia de todo esto, se observan dos tipos de cortesía: la cortesía negativa, que consiste en evitar los actos amenazadores de la imagen o en suavizar su realización utilizando para ello alguna estrategia verbal suavizadora, y la cortesía positiva, que consiste en realizar algún acto agradador de la imagen. Vemos así que el desarrollo de una interacción, según Kerbrat-Orecchioni, aparece como un incesante y delicado juego de equilibrios entre actos amenazadores y actos agradadores de la imagen.

Tomando en cuenta que el modelo de Brown P. y Levinson S. fue concebido para poner en evidencia ciertos principios universales del uso del lenguaje, esta propuesta también intenta describir ciertas diferencias en el funcionamiento de la cortesía de una cultura a otra. Discrepancias, por cierto, "superficiales que solo constituyen la parte emergente del témpano formado por el conjunto de las representaciones y valores de una sociedad dada" (Kerbrat-Orecchioni, 2004: 50).

Por su parte, Wierzbicka (1991), respecto a la problemática de los actos de habla propuesto en el modelo de Brown P. y Levinson S., propone y discute a fondo en sus estudios la posibilidad de que los hablantes evalúen de la misma manera los actos de habla en todas las culturas y que los mismos actos sean igualmente amenazantes, prescindiendo así de los valores culturales subyacentes.

En síntesis, la búsqueda de universalidad del lenguaje, tomando como base una cultura específica, ha sido un rasgo de la propuesta teórica de los estudios de cortesía de Brown P. y Levinson S., y dicho rasgo ha dado lugar a vivas contraversias.

No cabe duda de que no habría ningún problema en el hecho de centrarse en asuntos universales más que en los aspectos específicos del lenguaje usados en una cultura, si, efectivamente, la búsqueda de la universalidad es tomada desde una verdadera universalidad, es decir, desde una posición cultural independiente; no obstante, como un número de estudios ha demostrado (Matsumoto, 1988; Tannen, 1984; Watts, 2003), las herramientas básicas conceptuales introducidas y propuestas por Brown P. y Levinson S. 
(en particular la noción de face) tienen una fuerte concepción anglocentrista (Wierzbicka, 1991). Pese a ello, es necesario siempre destacar los puntos principales de esta teoría pues representa la publicación más importante en estudios de cortesía en su intento por describir el lenguaje en uso (Watts, 2003).

\subsubsection{La perspectiva de Watts}

Watts (2003), en sus estudios sobre la cortesía, considera que, a partir de 1990, ha surgido una gran cantidad de críticas a la propuesta de Brown P. y Levinson S. y que estas nuevas perspectivas han permitido observar las estrategias corteses de una forma más completa. Por esta razón, el estudio de las formas verbales de la interacción social ha progresado a tal nivel que hay disponible una serie de métodos alternativos para estudiar el fenómeno de la cortesía. Sin embargo, ninguna de estas propuestas nuevas ha sido capaz de invalidar la conceptualización realizada por Brown P. y Levinson S. , aunque han servido para refinar su acercamiento.

Propone, además, que uno de los aportes principales realizados por Brown P. y Levinson S. fue considerar que la cortesía verbal es una característica universal del lenguaje en uso, es decir, que todos los lenguajes del mundo poseen los medios para expresar cortesía. No obstante, esta búsqueda de lo universal está basada en una conceptualización idealizada de cortesía, que no considera la forma en que los grupos participantes luchan por la cortesía en las interacciones sociales.

Watts considera, por tanto, que esta teoría universalista de la cortesía pasa por alto que los medios que sirven para expresarla difieren radicalmente en sus realizaciones en los diversos idiomas existentes. Watts es enfático al afirmar que esta pretensión de considerar la cortesía como un fenómeno universal de la interacción social, particularmente de la interacción verbal, necesita estudiarse, no solo desde un foco primario que permita únicamente describir las realizaciones lingüísticas de la cortesía, sino también considerando la complejidad de la interacción social en sí misma y el rol que la cortesía juega en ella.

En sus planteamientos Watts considera los factores socioculturales y funcionales de la cortesía verbal desde una perspectiva interaccional y discursiva; propone un 
interesante estudio sobre el fenómeno que presenta innovaciones respecto a las consideraciones presentadas en los modelos anteriores y en el que utiliza una gran cantidad de datos tomados de situaciones de habla reales. Este autor expone que el objetivo principal del estudio de la cortesía debe ser racionalizar nociones de sentido común acerca de qué es la cortesía o descortesía para los interlocutores. Para ello, crea un modelo basado en el concepto de la práctica social de Bourdieu que intenta mostrar que los términos "cortesía” y "descortesía" solo pueden ser apropiadamente examinados cuando están confrontados discursivamente. Prueba de ello es que, luego de gran cantidad de análisis, llega a la conclusión de que incluso enriqueciendo los extractos de los diálogos con la ayuda de la contextualización, no quedan eliminadas diferentes interpretaciones respecto a una actuación cortés o descortés de los participantes o a la evaluación positiva o negativa de la actuación; aunque inevitablemente, el comportamiento abiertamente descortés, por supuesto, difícilmente recibirá otra interpretación que no sea negativa.

La reflexión de este autor es muy interesante y ha sido de gran ayuda en el momento de realizar el análisis del corpus de esta investigación en busca de estrategias corteses (de acuerdo con los modelos aplicados) ya que fue recurrente encontrar enunciados cuya función parece ser no cortés ${ }^{42}$ (o incluso descortés en otros casos), aunque bien pudiera encajar con alguna de las estrategias corteses negativas descritas por algunos autores (Kerbrat-Orecchioni; Brown P. y Levinson S. , principalmente). Por todo esto, tal como lo plantea Watts, es necesario confrontar discursivamente la cortesía y la no cortesía al realizar el análisis, pues son fenómenos que se complementan, es decir, la ausencia de cortesía implica necesariamente la presencia de no cortesía y viceversa; así como también tener claro que un enunciado puede ser no cortés pero no necesariamente por eso descortés.

\footnotetext{
${ }^{4}$ Para llegar a la oposición cortés/ no cortés se han seguido las investigaciones realizadas por Haverkate (1994), en las que se profundizará más adelante. Este autor afirma que, respecto a la oposición cortés y no cortés, es importante destacar que la cortesía inherente a los actos de habla corteses es de tipo positivo y que la calificación no cortés no debe entenderse como antónimo de cortés, sino en sentido complementario. Por tanto, no cortés no implica necesariamente descortés.
} 
Veamos algunos ejemplos tomados del corpus ${ }^{43}$ que permiten mostrar de forma más clara esta vacilación entre la descripción de las estrategias corteses y las no marcadas (no corteses) que mencionamos:

M1: (...)aunque esté muy en contra yo creo que cualquier persona la va a usar igual de toda ${ }^{h}$ manera $^{h}$.

M2: yo no estoy de acuerdo con eso.

M1: sí |yo pienso eso.

M2: porque yo soy: contraria, en el sentido de que soy una persona provida, y todo lo que para mí atente o esté potencialmente atentando contra una vida o ya sea vida en potencia es contraria a $\mathrm{mi}^{h}$ principio $^{h} \rightarrow$

M1: < [.pero por eso no:| no se sabe-]

M2: ya sea esté en esa situación o no, el mismo hecho de que no se sepa, no me da la certeza de que no lo hago, asi que no lo ocuparía, ¿me entiende ${ }^{h}$ ?

M1: si po| pero eso es lo que digo yo+ hay mucha ${ }^{h}$ persona ${ }^{h}$ que no lo dicen pero en el momento cambian de opinión $\rightarrow$ como en mucha ${ }^{h} \cos a^{h}$.

Como se observa en este fragmento, hay una clara confrontación de opiniones entre M1 y M2. Ahora bien, no obstante el enfrentamiento de posturas divergentes, podemos observar que hay presencia de algunas estrategias que contienen cortesía verbal (negativa) en esta breve muestra, como las siguientes:

\section{Cuadro número 4}

\begin{tabular}{|l|l|l|}
\hline Estrategias de & Estrategias de reparación de un acto descortés ${ }^{44}$ (Kerbrat-Orecchioni \\
cortesía & $(2004: 44)): \quad$ A comete contra $\quad$ B alguna ofensa $\quad$ (FTA) que \\
negativa & inmediatamente intenta reparar por medio de una excusa (FFA). Cuanto \\
\hline
\end{tabular}

${ }^{43}$ Este fragmento forma parte del episodio temático $\mathrm{N}^{\circ} 2$ del debate entre jóvenes de la PUC. En este fragmento en particular dos chicas (M1 y M2) están confrontando sus opiniones sobre el uso de la "pastilla del día después”. 
mayor es el peso del FTA, tanto más debe ser importante el trabajo reparador.

M1: $<$.pero por eso no:| no se sabe- $]$

M1 intenta llegar a un acuerdo, quiere justificar la postura que planteó y que molestó a su interlocutora. M1 quiere que M2 se dé cuenta de que es posible llegar a un acuerdo por medio del argumento de que no se sabe si la "pastilla del día después" es o no abortiva.

Comunique que $\mathrm{H}$ (el hablante) no quiere afectar a $\mathbf{O}$ (Brown P. y Levinson S. , 1987). - Pida disculpas. Impersonalice a $\mathrm{H}$ y O: evite la primera y segunda persona del singular. Plantee las AAI (acciones que amenazan la imagen pública) como una regla general.

M1: si po, pero eso es lo que digo yo + hay mucha ${ }^{\mathrm{h}}$ persona $^{\mathrm{h}}$ que no lo dicen pero en el momento cambian de opinión $\rightarrow$ como en mucha ${ }^{\mathrm{h}} \cos ^{\mathrm{h}}$.

M1 intenta impersonalizar sus argumentos, evitando las formas personales al decir que "hay mucha ${ }^{\mathrm{h}}$ persona $^{\mathrm{h}}$ que no lo dicen pero en el momento cambian de opinión”.

Se observa entonces que pese al enfrentamiento evidente de posturas, se aprecian estos intentos de M1 por ser cortés en el enfrentamiento; sin embargo, se evidencian

\footnotetext{
${ }^{44}$ El nombre de esta estrategia no corresponde a ninguna clasificación realizada por Kerbrat-Orecchioni previamente. Corresponde a un parafraseo, creado por la autora de esta investigación, correspondiente a esta técnica verbal.
} 
estrategias que si bien podrían describirse dentro de estas clasificaciones corteses, no parecieran aparentemente tener rasgos de cortesía verbal. Veamos esta muestra del corpus:

\section{Cuadro número 5}

\begin{tabular}{|l|l|}
$\begin{array}{l}\text { Estrategias de } \\
\text { positiva }\end{array}$ & $\begin{array}{l}\text { (Brown P. y Levinson S. , 1987): Apele al “terreno común". - Intensifique } \\
\text { el interés hacia O. } \\
\text { - Exagere (interés, aprobación, simpatía con O) }\end{array}$ \\
$\begin{array}{l}\text { M2: yo no estoy de acuerdo con eso. } \\
\text { M1: } \text { sí } \mid \text { yo pienso eso. }\end{array}$ & $\begin{array}{l}\text { La fuerza ilocutiva de este enunciado es justamente el desacuerdo, M2 no } \\
\text { quiere suavizar la confrontación respecto a lo que M1 está diciendo, todo lo } \\
\text { contrario, quiere manifestar su desacuerdo. Ahora bien, se podría decir, } \\
\text { además, que existe interés de parte de M2, pues escuchó atentamente lo que } \\
\text { decía M1 y sus argumentos para luego presentar una contraargumentación } \\
\text { pertinente y relevante. } \\
\text { Toda esta reflexión permitiría incluir esta estrategia dentro de las estrategias } \\
\text { de cortesía positiva que se describen aquí. Sin embargo, se cree que en este } \\
\text { segmento es posible describir interés de parte del interlocutor (como se } \\
\text { especifica en la descripción de Brown y L.), ciertamente, pero no } \\
\text { aprobación. Por tanto, no podríamos afirmar que este enunciado contenga } \\
\text { connotaciones corteses, corresponde más bien a una estrategia no marcadas, } \\
\text { no cortés. }\end{array}$ \\
\hline
\end{tabular}

Como hemos visto, los estudios de este autor constituyen un relevante aporte debido, principalmente, a su interesante propuesta centrada en describir cómo debe evaluarse si un comportamiento es cortés o no cortés. Si bien Watts no intenta presentar otra teoría sobre la cortesía, aspira a ayudar a encontrar la forma en que se debería estudiar la interacción social, mostrando cómo nuestras nociones comunes sobre comportamiento 
social, dada la lucha discursiva entre los participantes de la interacción social, son constitutivas de nuestras actuaciones sociales cotidianas.

\subsubsection{El modelo de cortesía verbal propuesto por Leech}

Otra tentativa que aporta antecedentes al estudio de las estrategias corteses es la expuesta por G. Leech (1983), la cual también está desarrollada en forma de máximas que funcionan como complemento a los principios conversacionales de Grice. Intenta mostrar cómo el principio de cooperación y el principio de cortesía interactúan en la interpretación de los mensajes no directos. El desafío de su teoría es, entonces, poder explicar la necesidad de una "retórica", entendida como el conjunto de principios a observar cuando se planifican o interpretan mensajes.

Para Leech, la cortesía se expresa de dos formas posibles: como una cortesía relativa y como una cortesía absoluta.

La cortesía relativa se caracteriza por mantener el equilibrio existente o modificarlo para mejorar la relación o para aumentar la distancia. La denomina "relativa" porque depende de los interlocutores y de sus posiciones sociales; se mide en coste y beneficio, tanto para el emisor como para el destinatario, y queda ejemplificada en el siguiente esquema:

\section{Cuadro número 6}

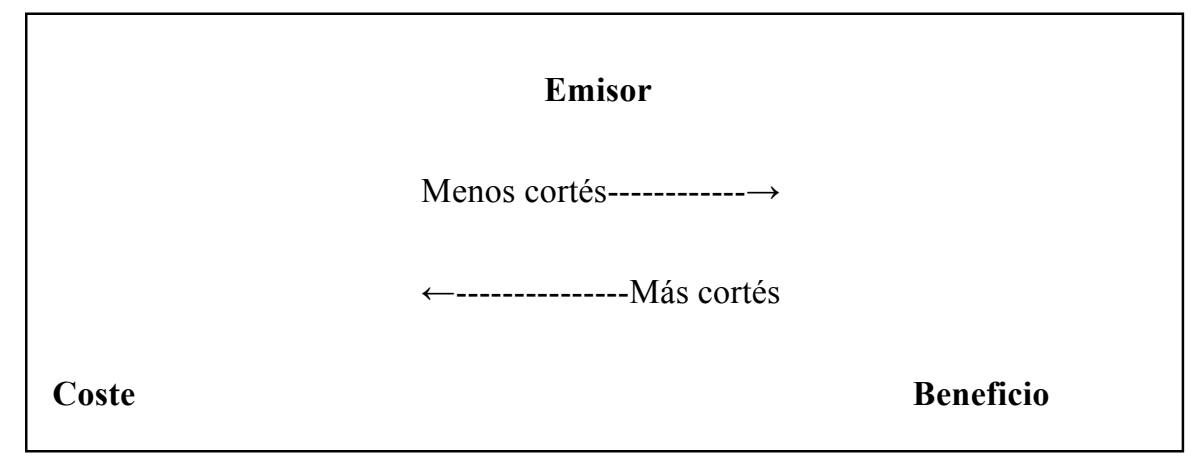

Por su parte, la cortesía absoluta, tal como su nombre lo indica, es denominada 
así debido a que, según Leech, algunos enunciados son inherentemente corteses y otros inherentemente descorteses.

Clasifica así las acciones en cuatro categorías de acuerdo con las intenciones que las subyacen $^{45}$.

\section{Acciones}

1. Acciones que apoyan la cortesía

2. Acciones indiferentes a la cortesía

\section{Descripción}

Beneficio para el destinatario y coste para el emisor. Mejoran o mantienen la relación social. (saludar, agradecer, felicitar, ofrecer, invitar)

Aquellas en las que no hay un desequilibrio claro entre coste y beneficio para los interlocutores. (afirmar, informar, $\operatorname{anunciar}^{46}$ )

3. Acciones que entran en conflicto con Aquellas que implican algún tipo de coste la relación social. para el destinatario. (pedir, ordenar)

\section{Acciones dirigidas frontalmente Acciones que pretenden acrecentar la}

\footnotetext{
${ }^{45}$ Categorización acotada y resumida por $\mathrm{M}^{\mathrm{a}}$. V. Escandell.
}

${ }^{46}$ Dentro de estas cuatro categorías de acciones presentadas por Leech no se comenta qué ocurre con la acción que implique confrontar una opinión, esto es, presentar puntos de vista distintos a un interlocutor. Por una parte es posible dar por entendido que el autor incluye este tipo de acto verbal en la categoría Acciones indiferentes a la cortesía (afirmar, informar, anunciar), hecho que precisamente no se considera adecuado en la presente investigación pues se cree que este tipo de acto, el de confrontarse a un interlocutor presentando una opinión divergente, sí implica que se pueda actuar con un estrategia cortés o no, es decir, que no es indiferente a la cortesía. Por otra parte, también puede pensarse que el autor incluye este tipo de acto en la categoría Acciones dirigidas frontalmente contra la relación entre los interlocutores (amenazar, acusar, maldecir), sin embargo, por muy cortés que se intente ser al realizar acciones como estas, su fuerza ilocutiva siempre será atacar u ofender al interlocutor, no así en la confrontación de opiniones, particularmente en un debate. 


\section{contra la relación entre los distancia o destruir las relaciones interlocutores. existentes. (amenazar, acusar, maldecir)}

Vemos que el tratamiento lingüístico que se da a un determinado tipo de acto de habla estará, pues, en función de la relación previa existente entre los interlocutores y de los efectos (positivos o negativos) que pueda tener el acto sobre dicha relación. Se puede hablar en estos casos de estrategias de cortesía, ya que las formulaciones lingüísticas empleadas pueden utilizarse para amortiguar o para potenciar los efectos no deseados de un determinado acto.

Leech propone, además, una serie de máximas relacionadas con la conducta cortés. Explica que la cortesía se ocupa de la relación entre dos interlocutores (que denomina yo y otro) considerando, por cierto, las variaciones interculturales que pudieran existir entre ellos. Aclara que el término otro puede corresponder no solamente al interlocutor, sino también a las personas designadas por los pronombres en tercera persona. Las máximas que conforman este Principio de cortesía son presentadas por Leech de la siguiente manera:

I. Máxima de tacto

II. Máxima de generosidad

III. Máxima de aprobación

IV. Máxima de modestia

V. Máxima de acuerdo a. Reduzca al mínimo el coste para el otro: aumente al máximo el beneficio para el otro.

a. Reduzca al mínimo el beneficio para el yo: aumente al máximo el coste para el yo.

a. Reduzca al mínimo las críticas para el otro: aumente al máximo las alabanzas para el otro.

a. Reduzca al mínimo las alabanzas para el yo: aumente al máximo las críticas para el yo.

a. Reduzca al mínimo el desacuerdo entre el yo y el otro: aumente al máximo el acuerdo entre el yo y el otro. 
VI. Máxima de simpatía a. Reduzca al mínimo la falta de simpatía entre el yo y el otro: aumente al máximo la simpatía entre el yo y el otro.

Luego de revisar el modelo de cortesía de Leech, podemos decir que su propuesta pone en un mismo nivel el principio de cooperación y el principio de cortesía ya que, según lo expuesto en las máximas y tipos de acciones, los actos corteses se manifiestan tanto en el contenido de las conversaciones como en la forma en que son organizados y estructurados por los interlocutores (Moreno, 1998).

Por su parte, Brown P. y Levinson S. critican esta consideración teórica y argumentan que la proliferación de máximas en el trabajo de Leech no es útil y que la cortesía opera en un nivel distinto al principio de cooperación; consideran que este principio propuesto por Grice representa un marco representativo de la comunicación, mientras que la cortesía es una desviación (Mills, 2003).

En esta investigación en particular se cree que la clasificación cuádruple de las acciones verbales y su relación con la cortesía verbal expuesta por Leech es muy interesante ya que intenta desvelar las intenciones de cortesía que subyacen a cada uno de estos actos; no obstante, se cree que habría que aplicar estas categorías siempre considerando el contenido implícito de los enunciados y no solo teniendo en cuenta su forma gramatical, pues se puede dar el caso, por ejemplo, de que una acción como informar, que forma parte de la categoría Acciones indiferentes a la cortesía, sí esté entrando en conflicto con la relación social entre los interlocutores o directamente sea una acción que atente contra la relación entre los interlocutores.

\subsubsection{La cortesía según Haverkate}

Entre las investigaciones pioneras sobre el fenómeno de la cortesía en el mundo hispánico es importante destacar los estudios de Henk Haverkate. Este autor presenta un modelo de análisis constrastivo en el que están integradas las siguientes categorías: actos de discurso, actos paralingüísticos y actos metapragmáticos. El foco de interés es el estudio de la dimensión intercultural del proceso comunicativo, es decir, en términos 
más específicos, el análisis comparativo de la cortesía.

Examina, así, el potencial analítico de estos tres parámetros pragmalingüísticos para valorar el carácter positivo de la cultura española y elaborar una comparación entre las culturas española y holandesa. Considera que los actos discursivos son actos de habla incrustados en una situación comunicativa concreta y los clasifica en actos asertivos (decir, declarar), actos directivos (el ruego y la orden) y actos expresivos (el cumplido, el agradecimiento). Por su parte, los actos paralingüísticos se bifurcan en dos subclases fundamentales: actos cinésicos y actos proxémicos. En cuanto a los actos metapragmáticos, los define como aquellos realizados dentro del marco de la etiqueta conversacional, específicamente, la interrupción de los turnos de conversación.

En la propuesta de Haverkate se postula que la cortesía verbal es una forma de comportamiento humano regido por determinados principios de racionalidad. Dichos principios regulan actividades interaccionales para conseguir que se produzcan estados de cosas deseados. Las correspondientes operaciones teleológicas se manifiestan tanto en la realización de actos comunicativos como en los actos no comunicativos. En el último caso, el agente cortés efectúa actos puramente instrumentales y, debido a su naturaleza, estos aspectos normativos de la cortesía instrumental se describen en los manuales de urbanidad y no son de especial interés para estudios lingüísticos.

En cuanto al estudio de la cortesía tal y como se manifiesta en la interacción comunicativa, es indispensable partir de la distinción entre varios niveles de análisis. El siguiente cuadro sintetiza dichos niveles: 


\section{Estudios de cortesía verbal (Haverkate, 1994)}

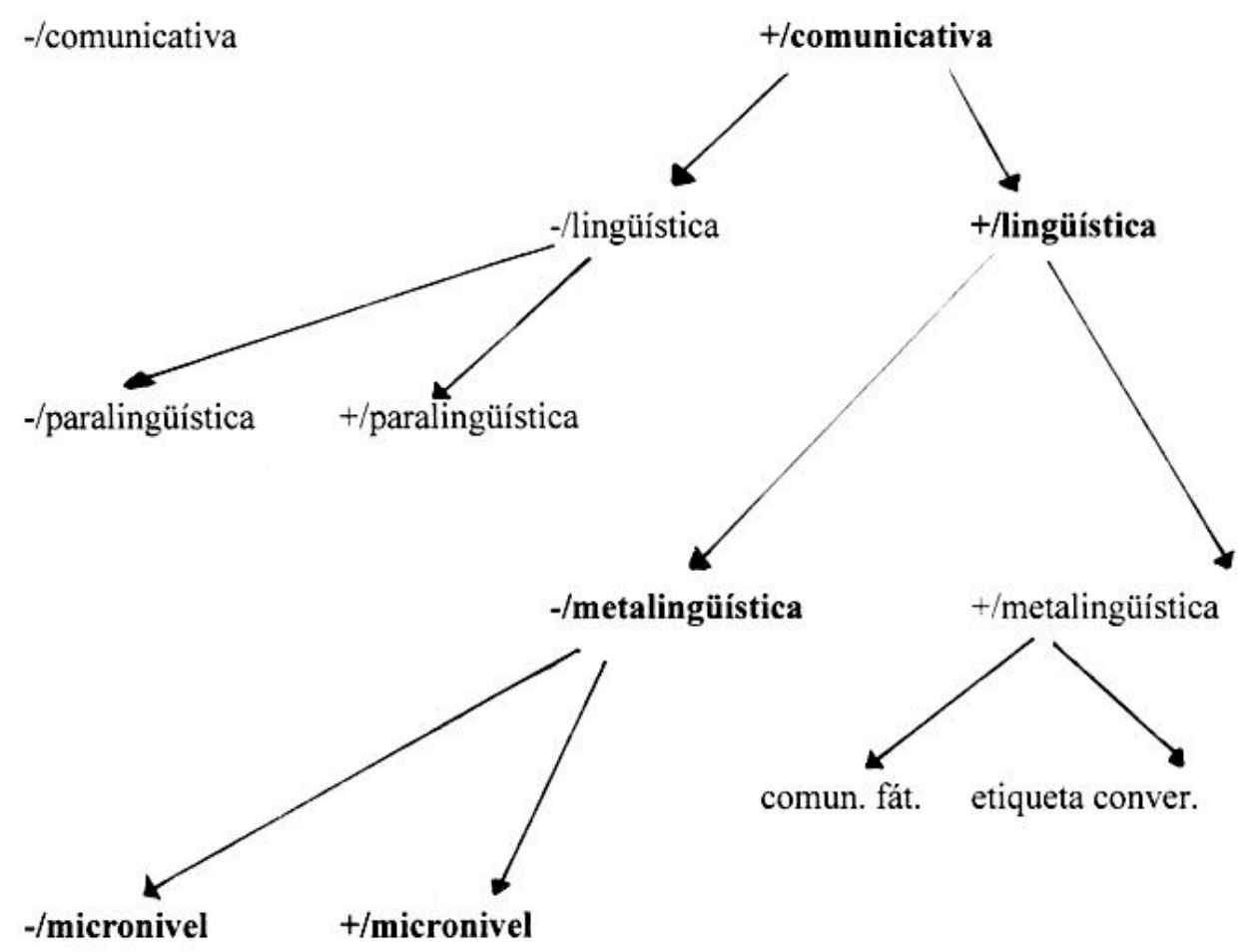

Este cuadro conforma la síntesis del objeto de estudio de un análisis lingüístico propuesto por Haverkate (1994). Se puede observar que el nivel de análisis sería propiamente lingüístico solo si se considera una descripción comunicativa de la cortesía, y, dentro de ella, se tienen en cuenta los rasgos lingüísticos (no metalingüísticos) y se analiza su micro y macro nivel. Por tanto:

Cortesía $\rightarrow+$ comunicativa $\rightarrow$ +lingüística $\rightarrow$-metalingüística $\rightarrow+$ micronivel y -micronivel

Este autor expresa que es necesario hacer una distinción entre actos de habla globales (macroactos) y locales (microactos) pues, en lo que concierne a la expresión de cortesía, no deben producirse discrepancias entre la micro y la macroestructura del discurso.

Así, en el micronivel del acto de habla, la cortesía se manifiesta a través de una variedad de categorías lingüísticas: selección de pronombres de tratamiento, uso del 
condicional o imperfecto de cortesía, realización indirecta del acto de habla, etc.

En el macronivel del discurso, la cortesía se determina por factores de coherencia y relevancia interaccional. Estos factores deben analizarse desde dos perspectivas, considerando el tipo de interacción comunicativa a analizar, es decir, si se analiza la cortesía en los turnos alternativos de dos interlocutores o en el turno de un solo hablante. Los ejemplos más característicos los encontramos en los actos exhortativos. En este tipo de actos se reconoce la tripartición de presecuencia, núcleo exhortativo y postsecuencia. La presecuencia sirve para justificar la petición del hablante, mientras que la postsecuencia expresa una motivación orientada hacia el oyente, especificándose si habrá algún beneficio para el oyente si se cumple la petición, por dar un ejemplo ${ }^{47}$.

Considerando como marco de referencia la tipología de los actos de habla ${ }^{48}$ elaborada por Searle (1976), Haverkate crea una metodología de análisis del micronivel del

47 En los actos exhortativos en los que se justifica el beneficio que habrá para el oyente si realiza la acción solicitada es posible observar la máxima de tacto (Reduzca al mínimo el coste para el otro; aumente al máximo el beneficio para el otro) propuesta por Leech (1983). "La cortesía es esencialmente asimétrica: lo que es cortés para $h$, o para una tercera persona, puede ser descortés para $s$; y viceversa. Las máximas de cortesía se justifican, precisamente, porque explican dicha asimetría, y sus consecuencias, sobre la base de lo no directo. (...) la clase de cortesía más importante en la sociedad de habla inglesa: la que cubre la utilización de la máxima de tacto. La máxima de tacto concierne a las categorías searlianas de las ilocuciones directivas y comisivas las cuales, en su contenido proposicional $\mathrm{X}$, refieren a una acción ejecutada por el oyente o el hablante, respectivamente. Esta acción puede denominarse $A$ y puede ser evaluada en términos de lo que $s$ presupone que es su coste, o beneficio, para s, o para h. (Leech ,1983:177-178).

48 Haverkate postula, además, que la categoría de la ironía verbal puede ser descrita apropiadamente siguiendo también el marco de la teoría de los actos de habla, tomando en cuenta la estructura componencial de los actos de habla y sus rasgos ilocucionarios y proposicionales. Argumenta que los hablantes utilizan la ironía para producir ciertos efectos perlocucionarios en sus oyentes, destruyendo sus patrones de expectativas y envolviéndolos en un tipo de interacción verbal que se caracteriza por la distancia interpersonal. (Haverkate, 1990). La relación entre cortesía e ironía verbal ha llevado a algunos estudiosos a realizar destacadas investigaciones sobre este tema (Haverkate, 1990; Alvarado Ortega, 2005) permitiendo describir el fenómeno cortés de una forma más completa, desde una perspectiva comunicacional y pragmática inserta en discursos 
acto de habla de acuerdo con la distinción de actos corteses y actos no corteses. El rasgo distintivo de estas categorías apunta a los efectos interaccionales que otorga la realización del acto de habla, por tanto, si esta no beneficia intrínsecamente al interlocutor, el acto no es cortés (ejemplos prototípicos de esta categoría: actos asertivos y exhortativos) y, por el contrario, cuando la realización del acto de habla redunda en beneficio del interlocutor, el acto es cortés (actos expresivos y permisivos).

Haverkate realiza, además, una importante contribución al estudio de los actos de habla al incluir, en la clásica categorización expuesta por Austin, un nuevo elemento descriptivo que permite llevar a cabo análisis del patrón interaccional tal como se manifiesta en la estructura lingüística de la locución: el acto alocutivo, que precisamente tiene que ver con las selecciones estratégicas que realizamos al escoger un enunciado y no otro en determinada situación comunicativa.

Esta nueva descripción de los actos comunicativos que hace Haverkate se incorpora en la metodología de esta investigación pues este estudio describirá las estructuras gramaticales de aquellos enunciados que se utilicen recurrentemente para lograr ciertos fines de cortesía, tanto negativa como positiva.

En cuanto a la oposición cortés y no cortés, es importante destacar que la cortesía inherente a los actos de habla corteses es de tipo positivo y que la calificación no cortés no debe entenderse como antónimo de cortés, sino en sentido complementario. Por tanto, no cortés no implica necesariamente descortés. Se puntualiza que, la categoría de actos no corteses se divide en dos subcategorías: los actos descorteses y los actos no descorteses.

reales. En esta línea, Alvarado (2005) ha propuesto un análisis de la ironía verbal en relación con la cortesía, que pretende demostrar la presencia de cortesía verbal en un enunciado de tipo irónico y que, en definitiva, y contrariamente a lo que se ha creído hasta el momento, es usada para producir cortesía. En su propuesta se propone un esquema de acuerdo a los efectos que tiene la ironía en un enunciado determinado. Se explica, así, que la ironía no tiene siempre un efecto negativo; por el contrario, también puede llevar consigo cortesía. De esta manera, se relaciona la cortesía con una ironía de efecto positivo. 
Los actos no descorteses son neutros en lo que respecta a la expresión intrínseca de cortesía (actos asertivos y exhortativos). Los actos descorteses, por su parte, tienen como representante más característico los actos expresivos que denotan un estado psicológico negativo del hablante respecto al oyente. (insultar, agraviar y expresar desprecio.) Importante es destacar que esta distinción que se acaba de hacer tiene que ver con los actos de habla y, por tanto, no se aplica a determinados tipos de oraciones.

La propuesta de Haverkate es importante por haber sido una fuente de inspiración para la investigación de la cortesía en el mundo hispánico. La escasa bibliografía de estudios en español con que se contaba en el momento de la presentación de los primeros modelos teóricos (Brown P. y Levinson S., Lakoff, Leech) contrasta positivamente con la lista de estudios dados a conocer en Oralia 4 y por el programa $\mathrm{EDICE}^{49}$, con investigaciones teóricas y empíricas sobre la cortesía en español que han ido llenando este vacío. Ahora bien, en estos estudios "la mayoría de las referencias bibliográficas que tienen que ver con el marco teórico provienen todavía de las publicaciones internacionales en inglés" (Bravo, 2004:1), lo que deja entrever la necesidad de realizar más estudios en esta área centrados en el español.

Sin duda, resultaría una tarea imposible, o al menos interminable, dar cuenta de tan extensa cantidad de títulos dedicados a la cortesía, así como citar cada una de las actas de congresos, artículos y publicaciones sobre el tema. A pesar de ello, se intentó aquí mostrar una perspectiva general y relevante de las teorías fundadoras y pioneras, así como de las críticas más importantes que han recibido estas propuestas.

Asimismo, se han contrastado diferentes perspectivas que se han utilizado en los acercamientos a esta estrategia verbal, lo que permitirá que en futuras aplicaciones de estos modelos lingüísticos se tengan en consideración las falencias y ventajas de cada uno de ellos.

\footnotetext{
${ }^{49}$ www.edice.org.
} 


\subsection{Perspectivas para abordar la cortesía verbal}

De lo expuesto en los apartados anteriores se desprende que existen diversos enfoques en los que se han especializado los estudios relativos al fenómeno cortés: "por un lado, aquellos que abogan por un abordaje de índole más general, más centrado en el enunciado y que buscan llegar a generalizaciones sobre lo que es la cortesía y, por otro, una propuesta que proclama que solo pueden describirse los fenómenos de cortesía en referencia a los contextos socioculturales en los que se producen" (Murillo, 2008:54).

Por tanto, luego de revisar los estudios más importantes sobre cortesía verbal se puede afirmar que la primera de estas perspectivas de estudio, es decir, aquella de carácter más pragmalingüístico, enfocada en la enunciación y en generalizaciones respecto a cómo funciona la cortesía en diferentes niveles de lengua, fue instaurada formalmente a través la propuesta teórica de Brown P. y Levinson S., pues se propone en esta obra el universalismo del concepto de cortesía. Más tarde, los estudios de Haverkate, también orientados siguiendo parámetros lingüísticos puramente tales, han sido de gran relevancia pues permiten describir las estrategias en la interacción comunicativa en situaciones específicas que atenten contra la cortesía verbal. Sus estudios, además, permiten realizar contrastes lingüísticos entre diferentes culturas, considerando ciertos aspectos socioculturales pero, sin duda, poniendo toda su fuerza en asuntos pragmalingüísticos.

En la senda más sociocultural, y como contrapropuestas al universalismo al que se tiende desde la otra perspectiva, observamos los estudios de Wierzbika y, en el mundo hispanohablante, Bravo, quien, como ya hemos comprobado, desde el título de sus trabajos insiste en la importancia de una pragmática sociocultural como alternativa para abordar los estudios sobre la cortesía verbal.

En el medio de esta tensión teórica, la propuesta realizada por Kerbrat- Orecchioni es considerada como una manera de relativizar estos enfoques y de permitir revalorizar los estudios pioneros de Brown P. y Levinson S., aunque, como vimos en detalle anteriormente, realizando ciertas actualizaciones y modificaciones al modelo clásico de 1987, con vistas a compatibilizar las variadas perspectivas y obtener una visión más 
completa del objeto de estudio.

Concretamente, en esta investigación se intentará crear un puente entre ambas perspectivas, planteando así la posibilidad de realizar un análisis profundo de la cortesía verbal, que considere de forma selectiva ambas partes y que permita obtener una descripción exhaustiva, se cree, del fenómeno.

Para realizar esta investigación se ha seguido, entonces, $y$ en un primer acercamiento, el modelo fundador en este tema (Brown P. y Levinson S. , 1987), con el fin de conseguir una primera descripción lingüística de las estrategias discursivas; para ello se han utilizado los conceptos que se consideraron más relevantes y aplicables de este modelo al que se le aplicarán las necesarias modificaciones propuestas por Kerbrat- Orecchioni (2004) para poder obtener así un análisis que se considera más adecuado. También se siguieron en todo momento las observaciones teóricas planteadas por Haverkate (1994) en el momento de realizar el análisis y otorgarle un valor pragmático a las unidades lingüísticas de los enunciados.

Por otra parte, para analizar la contraparte social y sociocultural de este fenómeno se seguirán de cerca los planteamientos de Bravo/Briz (2004) y sus estudios sobre la cortesía en español. Se cree que la utilización complementaria de estos enfoques y modelos permitirá crear una metodología más abierta y flexible y permitirá así observar el fenómeno de la cortesía verbal, con sus estrategias lingüísticas, inserto en eventos comunicativos reales y, en consecuencia, considerando sus particulares contextos socioculturales.

\subsection{Los indicadores de fuerza discursiva de cortesía verbal}

Dado que las principales estrategias discursivas que se describen en esta investigación son las relativas a los actos corteses, se intentará también dar cuenta de indicadores de fuerza que introduzcan un acto de cortesía positiva, negativa o de atenuación de la cortesía. Para ello se tomará como base lo expuesto por Lo Cascio en el momento de definir estos exponentes lingüísticos, pero creando una nueva denominación, esto es, un 
marcador discursivo presente en estrategias de cortesía verbal.

Se entiende así que estos marcadores discursivos sirven principalmente para indicar su papel dentro del discurso, clasificándose, por esta razón, según la función que realizan. En esta investigación en particular se describirán los indicadores de fuerza discursiva de cortesía presentes en el corpus analizado y que se exponen en el siguiente cuadro:

\section{Cuadro número 7}

\begin{tabular}{|l|l|}
\hline $\begin{array}{l}\text { Indicadores gramaticales de atenuación cortés } \\
\text { (Kerbrat-Orecchioni) (Haverkate). }\end{array}$ & $\begin{array}{l}\text { Marcas gramaticales que manifiesten } \\
\text { esta fuerza alocutiva (Haverkate, } \\
\text { s/fecha) del enunciado. }\end{array}$ \\
\hline $\begin{array}{l}\text { Indicadores gramaticales de cortesía positiva y } \\
\text { negativa }^{51} \quad \text { (Kerbrat-Orecchioni/Brown P. yarcas gramaticales que manifiesten } \\
\text { Levinson S. ) (Haverkate) }\end{array}$ & $\begin{array}{l}\text { esta fuerza alocutiva (Haverkate, } \\
\text { s/fecha) del enunciado. }\end{array}$ \\
\hline
\end{tabular}

En esta investigación, se intentará así describir y clasificar lingüísticamente conectores discursivos utilizados recurrentemente en enunciados que tengan como función principal manifestar cortesía a través de alguna de las estrategias recién mencionadas y funcionar como "trazos o señales de la actividad discursiva, asideros de los hablantes para la formulación de (..) mensajes" (Briz, A. e Hidalgo A., 1988:142). Para esto se seguirán las propuestas y terminología expuestas por Briz, A. e Hidalgo A. (1988) sobre los conectores pragmáticos metadiscursivos que participan en la organización del habla.

50 Se realizarán adaptaciones a las propuestas teóricas de estos autores. Todo esto ha sido expuesto previamente en la presentación teórica.

51 Se realizarán adaptaciones a las propuestas teóricas de estos autores. Todo esto ha sido expuesto previamente en la presentación teórica. 


\subsection{La atenuación lingüística como estrategia de cortesía}

La atenuación lingüística es una estrategia, un movimiento táctico para "ganar en el juego conversacional” (Briz, 2001:163). Son minimizadores del decir o lo dicho y también, de forma dialógica, del desacuerdo en macro o microactos de comunicación. La cortesía verbal es una de las manifestaciones de los atenuantes, pero no la única, "pues estos no son solamente ni siempre un modo cortés de expresión que regula la relación social” (Briz, 2001:145-146).

De forma recurrente en la bibliografía lingüística en torno a descripciones del español coloquial de Chile, se afirma que el español hablado en estas latitudes tiende al excesivo uso de atenuantes verbales (Montecino (2005); Puga (1997); Briz (2001)) utilizados como intentos de marcar cierto distanciamiento social producto de la marcada estratificación social presente en los países americanos, en contraste con el español peninsular. Así, se suele afirmar que:

El valor de los atenuantes en la conversación coloquial de muchos países latinoamericanos, sea el caso de Chile, Perú, México, etc., difiere del que posee en el español coloquial peninsular. Allá, además de su mayor frecuencia de uso (...) en dichas fórmulas se combina un valor estratégico y de distancia social. Allá [+estrategia conversacional] y [+norma social (distancia social)]; aquí, sobre todo, [+estrategia conversacional]. La meta, la estrategia o la distancia social, etc., son universales, pues aparecen en todas las lenguas, si bien las prioridades funcionales o preferencias, el modo de ponerlas en práctica, el cómo y el cuándo emplearlas es exactamente lo que varía en relación mutuamente dependiente con el conjunto de valores culturales. (Briz, 2001: 162)

Es cierto que las estrategias de atenuación verbal son recursos universalmente compartidos pero que difieren de una cultura a otra en cuanto a las formas que presentan; no obstante, se observa que no siempre estas atenuaciones lingüísticas cumplen un rol de 
distanciar socialmente a los interlocutores en las sociedades hispánicas a las que se alude; en efecto, se cree que sería un tanto generalizador asignarle en ellas estrictamente valor de distanciamiento, "[+estrategia conversacional] y [+norma social (distancia social)]"52, a dicha estrategia. En este punto, la pregunta que es posible plantearse es si efectivamente en el español hablado en Santiago de Chile se utilizan estrategias de atenuación verbal únicamente con la intención de marcar cierto distanciamiento social. Se cree que se podría tener también, en algunos casos, una intención comunicativa absolutamente contraria, esto es, formar lazos de respeto que permitan por medio del reconocimiento hacia el otro incentivar cierta cercanía con el interlocutor, por medio de este distanciamiento aparente de las formas lingüísticas, aunque parezca contradictorio.

No obstante, es importante ser precisos en cuanto a qué entendemos por atenuación. Como ya hemos mencionado anteriormente, en este estudio se describirá estrictamente la atenuación cuando esta tiene por fin realizar una estrategia de cortesía verbal, objeto de estudio central de esta investigación.

Cierto es que, contrariamente a lo que a veces se afirma, la cortesía no se identifica con la indireccionalidad; en primer lugar porque los actos que pudieran atacar la imagen

\footnotetext{
${ }^{52}$ Estudios descriptivos sobre el español de Chile (Rivadeneira (2009), Medel (2011)), por su parte, proponen que un uso más formal en el español de Chile, esto es, más cercano a la norma estándar panhispánica (dejando de lado, por ejemplo, el uso del voseo, ya sea pronominal o verbal, restringidos ambos a contextos coloquiales) tiene como propósito el distanciamiento social, además de la formalidad. La presente investigación se inclina por una postura más amplia: se cree que la utilización de un léxico formal no intenta en todos los casos marcar distanciamiento social; en algunas ocasiones se puede observar que, estos intentos del interlocutor por ser formal son utilizados con un propósito ilocutivo de reconocimiento al otro para entablar relaciones comunicativas cordiales, es decir, como una estrategia de cortesía negativa (Brown P. y Levinson S. , 1987), puesto que se intenta comunicar que "H (el hablante) no quiere afectar a O” y, más particularmente, intenta mediante el uso formal del lenguaje impersonalizar la situación comunicativa y acercarse al otro. Del mismo modo, se cree que este uso de atenuación cortés puede implicar además realizar actos inscritos en el tipo de actitud lingüística a las que Brown P. y Levinson S. describieron como estrategias de cortesía positiva pues podrían funcionar como marcadores de identidad de grupo.
} 
personal tienen la opción de ser suavizados por otros procedimientos (i.e. la adulación), pero también porque la atenuación solamente es cortés cuando intenta mitigar un acto que puede dañar la imagen personal del otro (Kerbrat-Orecchioni, 2004).

En efecto, un atenuante puede ser una forma de expresión cortés, pero no la única y a su vez, el atenuante, recubre también otros valores pragmáticos que están sometidos principalmente a principios de la retórica de la conversación. Briz (2001) sostiene, además, que en la conversación coloquial española se está constantemente mitigando y desrealizando lo dicho, o lo que está por decirse, siguiendo una tendencia de eficacia lingüística más que por asuntos de cortesía lingüística; así, este uso en apariencia cortés es solo la "máscara" que esconde el propósito comunicativo final.

Briz (2001) sistematiza los usos de la atenuación lingüística cortés en la conversación coloquial y establece que sus funciones semántico-pragmáticas pueden caracterizarse por dos intenciones principales que están en directa relación con el concepto de imagen (face):

a. Se aminoran cualidades, actitudes y acciones del yo.

b. Se aminoran cualidades negativas del tú.

En esta investigación se describirán tanto las estrategias de atenuación que estén dirigidas a minimizar el riesgo de ataque a la imagen del interlocutor o los interlocutores como también las que intenten aminorar cualidades, actitudes y acciones del yo. En este sentido, las descripciones lingüísticas que se harán en este estudio estarán centradas en atenuantes con función semántico-pragmática caracterizada en (b) y en (a) puesto que son principalmente estrategias de cortesía verbal, entendiendo que disminuyen la fuerza enunciativa de un FTA (face threatening act) o acto amenazador hacia la imagen del otro, siguiendo la terminología de Brown P. y Levinson S. (1987).

Comentemos un fragmento extraído del corpus, episodio número 4, para ver cómo se aplicarán estas categorías al análisis. 


\section{Cuadro número 8}

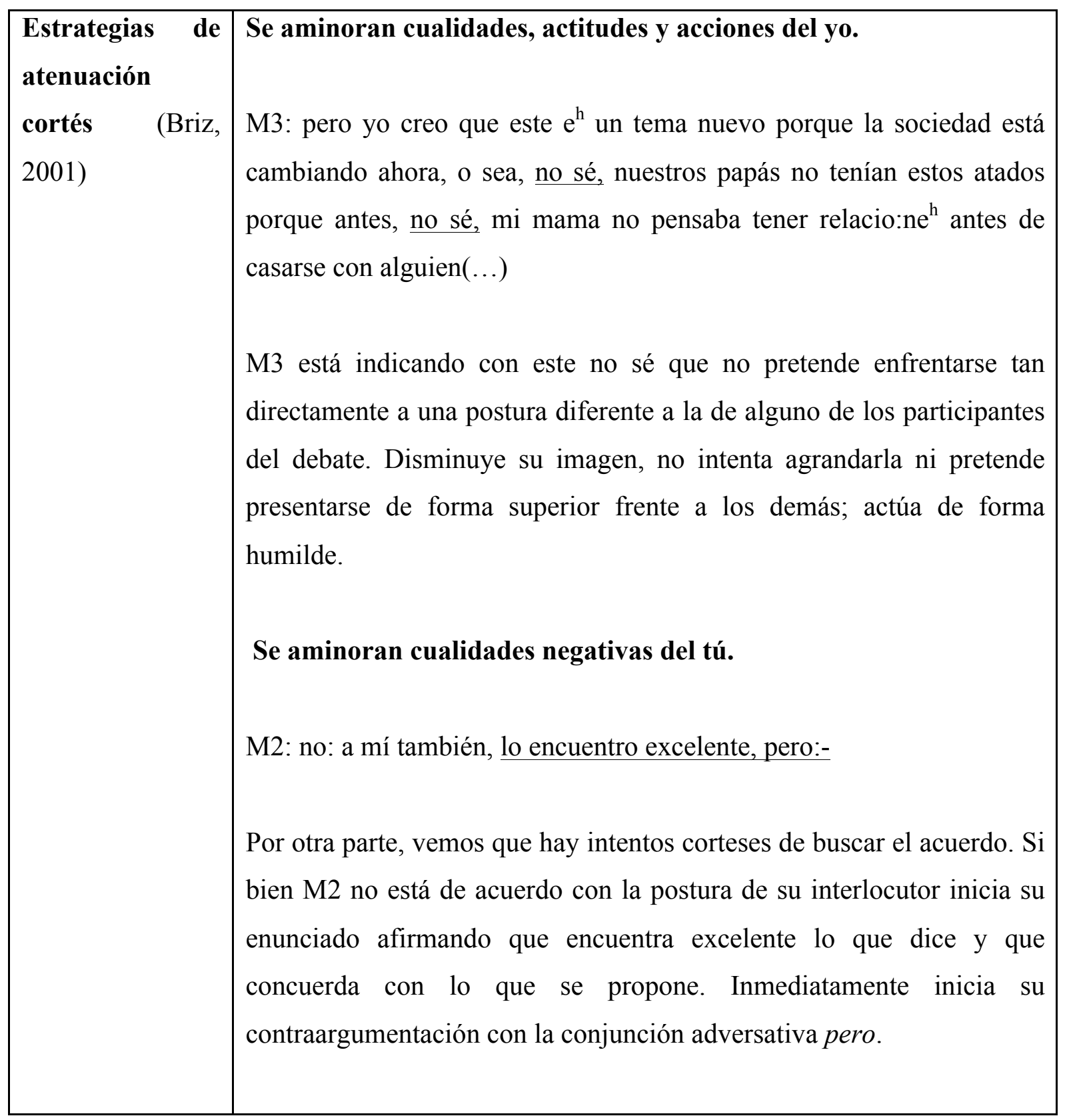

Por su parte, se ha observado cierta tendencia de jóvenes profesionales chilenos, y más especialmente abogados jóvenes, a realizar precisamente este tipo de estrategias (tanto las descritas en a., como en b. Para poder describirlas con más fidelidad, se observaron 
textos enviados por correo electrónico entre amigos y compañeros de profesión ${ }^{53}$. Veamos una pequeña muestra ${ }^{54}$ :

From: E.S.

Sent: Tuesday, October 18, 2011 12:16 AM

To: F.M.

Subject: confirma invitación

Apreciado F.,

Junto con saludar cordialmente, me permito confirmarte la realización del coloquio sobre "Uniones de hecho, igualdad de derecho y matrimonio homosexual. Un análisis desde la Constitución”, para el día lunes 21 de noviembre, a partir de las 18:00 horas, en nuestra Facultad de Derecho.

Contamos con tu valiosa participación, ya que tendremos dos paneles, dedicando el segundo íntegramente al análisis del debate y fallo (a esas alturas ya estará publicado) sobre la constitucionalidad del artículo 102 del Código Civil.

Te ruego me confirmes tu participación en este evento. En los próximos días te enviaré un detalle del programa para tu conocimiento y adopción de las medidas pertinentes.

Saludos afectuosos.

Si consideramos que el autor de este texto tiene 28 años y le escribe a un compañero y amigo de universidad que tiene 30 años, se podría pensar que no serían necesarias las excusas para solicitar o acordar un asunto, a menos que con estas estrategias estrategias de atenuación se esté intentando hacer algo más. Ambos son abogados y profesores universitarios, no existiría por tanto ninguna intención de distanciamiento social, los dos

\footnotetext{
${ }^{53}$ Este breve análisis se realizó antes de comenzar con el análisis del corpus de esta investigación como una forma de observar las estrategias de atenuación corteses usadas en el español de Chile.

54 El subrayado que destaca las estrategias de atenuación de cortesía es mío. Estos correos fueron seleccionados dentro de una seguidilla de envíos y respuestas del grupo Red de profesionales jóvenes, creado por un grupo de abogados chilenos.
} 
tienen la misma jerarquía; se piensa, así, que el protagonista de este correo no tiene una intención comunicativa de distanciamiento sino, por el contrario, de acercamiento, en el sentido de intentar crear lazos comunes, que los hagan parte de un mismo grupo distintivo frente al resto de los jóvenes profesionales. Para ello usa como marcadores de identidad de grupo un registro excesivamente formal, léxico no juvenil (aunque sean jóvenes) y esmerado. Lo que se observa es que mediante este uso de la atenuación cortés, el emisor quiere dejar en claro que pertenecen a un grupo de jóvenes con cierto grado de intelectualidad, que ha pasado por la universidad para estudiar una de las carreras con más reconocimiento social en el país y que por todo esto debería actuar como una persona seria, formal. Brown and Levinson inscriben este tipo de actitud lingüística dentro de las estrategias de cortesía positiva. Veamos la descripción de esta estrategia:

\section{Estrategia de Cortesía Positiva (Brown P. y Levinson S. , 1987)}

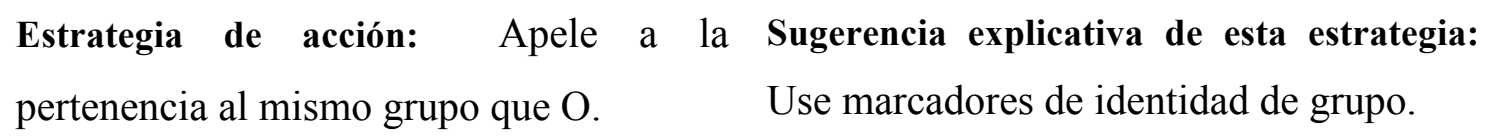

Se cree por tanto que estos rasgos de atenuación cortés intentan ser estrategias distintivas de este grupo de jóvenes profesionales.

Esta pequeña muestra permite observar el comportamiento atenuante cortés que existe entre jóvenes chilenos de profesión abogados, todos menores de 30 años. Esta actitud lingüística de constante atenuación en las formas parece indicar que en algunos grupos etarios de hablantes del español de Chile, la atenuación en las formas directas de tratar al otro, usando estrategias de cortesía positiva, no siempre corresponden a una intención comunicativa de distanciamiento sino que puede cumplir, además, un rol de acercamiento, en el sentido de que crea lazos diferenciadores y que los hace parte de un mismo grupo distintivo.

En definitiva, el trabajo de análisis de esta investigación pretende sugerir que el uso de estrategias de atenuación ya estén siendo usadas para minimizar el riesgo de ataque a la imagen de los interlocutores, ya para aminorar cualidades del yo (atenuación cortés), puede 
intentar también formar lazos de respeto que permitan por medio del reconocimiento hacia el otro incentivar cierta cercanía con el interlocutor y formar identidad grupal. 



\section{Metodología PROPUESTA: AdECUACiÓN DE UN MODELO PARA EL ESTUDIO DE LA CORTESÍA VERBAL}

Las teorías y modelos que se han desarrollado en las últimas décadas en torno a la cortesía verbal, si bien se caracterizan en su gran mayoría por estar inicialmente orientados a describir intercambios verbales entre hablantes anglófonos (Brown P. y Levinson S. (1978/1987); Lakoff (1973); Leech (1983); Watts (2003), entre otros), su aplicación permite dar cuenta de las estrategias y los mecanismos lingüísticos con los que contamos los hablantes de nuestra lengua española en el momento de enfrentarnos a situaciones comunicativas en las que prime no solo la entrega de información, sino también el mantenimiento de los lazos de camaradería y filiación ${ }^{55}$. Esto, por cierto, si apoyamos la postura de que la cortesía verbal es un rasgo lingüístico compartido por hablantes de diferentes lenguas y culturas $\mathrm{y}$, además, que constituye un rasgo aspiracional en los intercambios comunicativos, es decir, una estrategia percibida con un cariz positivo por los hablantes, independientemente de que la concreción de estas estrategias pueda variar entre culturas diferentes.

En efecto, al mismo tiempo, los resultados de la aplicación de estos modelos evidencian la existencia de diferencias socioculturales en el proceso de evaluación de parámetros con los cuales se describe lo que es costoso o beneficioso para los interlocutores. Todo esto implica que al estudiar las estrategias comunicativas se deben considerar los contextos socioculturales que abarcan comportamientos, actitudes y valores que son conocidos, aceptados y practicados en determinada comunidad de habla. Estos contextos están relacionados con los deseos de imagen de los hablantes que Bravo (2004) denomina "imagen de autonomía y de afiliación". Por tanto, la necesidad de incluir

\footnotetext{
${ }^{55}$ Así lo demuestran estudios descriptivos sobre el español (Briz (2004); Haverkate (2004), entre otros.) en los que se toman como base los conceptos del modelo clásico de Brown P. y Levinson S.
} 
aspectos socioculturales en los análisis de esta índole, así como de realizar una adecuada descripción de elementos lingüísticos en contexto, se hace, así, imprescindible.

En consecuencia, esta investigación, debido al sesgo ineludible de su investigadora, tendrá cierto carácter de subjetividad pues la interpretación y contextualización de los datos del análisis se basará en el conocimiento, apreciación personal y visión de mundo de la analista. Es importante mencionar que la lengua materna de la investigadora es el español hablado en Santiago de Chile lo que le ayudó a entender los contextos socioculturales en los que se inserta este proceso enunciativo en el que se obtuvo el corpus de análisis. Se refuerza así la idea de que el estudio de la cortesía está guiado, ineludiblemente, por las nociones de sentido común acerca de qué es la cortesía verbal, retomando y parafraseando las ideas de Watts (2003).

Luego de todo lo dicho hasta este punto, es posible afirmar que la aplicabilidad de los clásicos modelos orientados a describir las interacciones lingüísticas de la lengua inglesa a un corpus en español es plausible, considerando la cortesía verbal como una estrategia universal. Sin embargo, y al mismo tiempo, es posible afirmar que la cortesía no es universal, en la medida en que sus formas y condiciones de aplicación varían de una sociedad a otra (Kerbrat-Orecchioni, 2004). En efecto, si bien el modelo de corte anglosajón propuesto por Brown P. y Levinson S. será útil para reconocer los conceptos universales (face, cortesía negativa, cortesía positiva etc.), será necesario realizar las debidas adaptaciones (Kerbrat-Orecchioni, 2004). Los estudios de Haverkate (1994, 2004)/Kerbrat-Orecchioni (2004)/Bravo/Briz (2004) serán de gran utilidad en esta tarea, puesto que en sus análisis se señalan pautas a seguir para dicho acercamiento, considerando aspectos pragmáticos y socioculturales.

\subsection{Metodología de análisis del corpus}

La metodología para realizar el análisis del corpus está compuesta por cuatro etapas. La primera consiste en la transcripción de las grabaciones usando la convención que se consideró más adecuada para poder dar cuenta de las manifestaciones lingüísticas orales de forma simple y clara. Para este estudio en particular se estimó conveniente utilizar las 
convenciones de la trascripción de diálogos propuesta por Llorente (1996:335) debido a que su simbología es más próxima a la utilizada en los análisis de la conversación, lo que permite que las intervenciones sean leídas sin problema, a la vez que reflejan con claridad los rasgos del coloquio grabado, sin necesidad de precisiones estrictamente fonéticas. Así también, los diálogos han sido transcritos usando las normas ortográficas del español, dando cuenta, eso sí, en algunos casos, de algún rasgo característico de la pronunciación o énfasis lingüístico de algún hablante, aunque siempre utilizando grafemas del español. Tal convención de símbolos para la transcripción de los diálogos es la siguiente:

\begin{tabular}{|ll|}
\hline$[\mathbf{x x x}]>$ & segmento solapado con otro posterior \\
$<[. \mathbf{x x x}]$ & segmento solapado con otro anterior \\
$:$ & segmento fónico alargado \\
, & pausa breve o transición tonal en contextos que admiten la coma \\
& ortográfica \\
$\mid$ & pausa breve en cualquier otro contexto \\
$\|$ & pausa media (alrededor de un segundo) \\
$\mid \|$ & pausa larga (dos segundos o más) \\
$\{x x x\}$ & aclaraciones y acotaciones \\
$\{\mathbf{x x x}\} \mathbf{y y y}$ & segmento restaurado \\
$\mathbf{x x x}-$ & segmento inconcluso \\
{$[\mathrm{zzz}]$} & transcripción fonética de un segmento o palabra \\
+ & posible límite oracional interior de un enunciado \\
\hline & final de enunciado con entonación completa (intento de cesión de turno) \\
$\rightarrow$ & intento de mantener la palabra a pesar de la interrupción del otro \\
“xxx" & discurso referido \\
$\mathbf{H}$ & participante femenina \\
\hline
\end{tabular}


Se incluyen además los siguientes símbolos ${ }^{56}$ :

\begin{tabular}{|cl|}
\hline O & mediador en el coloquio \\
h & aspiración de la consonante $s$ \\
XXX & énfasis estilístico \\
\hline
\end{tabular}

La segunda etapa consiste en la segmentación de la transcripción del debate y la división de esta en episodios (Van Dijk, 1982) que corresponden a unidades semánticas del discurso, definidas en base a secuencias específicas de proposiciones, las cuales pueden resumirse en una macroproposición. Siguiendo a Bolívar (1995), esta unidad tiene propiedades lingüísticas y cognitivas, ya que cada episodio puede ser identificado por señales discursivas y, al mismo tiempo, corresponde a un segmento interpretado como importante y coherente para la estructura global del texto. Estos episodios pueden ser de diferente tamaño y pueden identificarse por señales del tipo: pausas o silencios en el lenguaje hablado, los cambios en la temática ${ }^{57}$ o en los tiempos verbales e introducción de

${ }^{56}$ El símbolo $h$ (aspiración de la consonante $s$ ) es un rasgo característico del español hablado en Chile; por esta razón, ha sido necesario incluir un símbolo que marque esta aspiración consonántica. Rabanales (1992), en sus investigaciones sobre el español de Chile, describe los aspectos fonológicos, morfosintácticos y léxicos que caracterizan a la norma general a lo largo de todo el país; entre otros rasgos destaca los dos siguientes: 1. Seseo, o articulación como [ş] predorsoposdental o dorsoprealveolar fricativa sorda con la lengua generalmente plana, tanto del fonema /s/ como del fonema $/ \theta /$ del español peninsular. 2. Aspiración de /s/ cuando precede a consonante y aspiración o pérdida completa en posición final de palabra antes de una pausa.

${ }^{57}$ Los cambios en la temática serán un rasgo discursivo relevante en la segmentación de los episodios que se hará en esta investigación. Por lo tanto, cada vez que alguno de los participantes proponga una desviación temática o profundice en algún aspecto del tema que se discute, se iniciará un nuevo episodio temático. En el estudio de los temas y cambios de tema hay que diferenciar entre lo que se puede llamar 'tema del discurso', (...) y 'tema del hablante'. El primero se podría definir en términos proposicionales, es decir, una proposición mencionada o ausente que equivaldría aproximadamente a sobre qué se habla. El segundo sería el tema que tendría en mente un hablante determinado cuando hace su contribución al discurso hablado (Nieto, 1995). Entonces, al ir segmentando el corpus en estos episodios temáticos se tendrán en cuentan los cambios tanto en el 'tema del hablante', como en el 'tema del discurso'. Una consecuencia evidente de los cambios temáticos es la exigencia que hace el interlocutor a sus oyentes de hacer inferencias que permitan relacionar el nuevo 
nuevos actores, principalmente. Los episodios están definidos por cadenas de proposiciones y no en términos de relaciones semánticas entre cláusulas definidas gramaticalmente.

Siguiendo con la metodología, se ubicarán cada uno de estos episodios proposicionales en plantillas que permitan realizar el análisis con mayor facilidad, pues se cree que esta segmentación permitirá realizar el estudio siguiendo una cronología temática oportuna para darle un seguimiento adecuado a cada enunciado.

La tercera etapa consiste en describir las estrategias de cortesía verbal. Para ello se utilizarán plantillas que describan estrategias de cortesía positiva y negativa y atenuación cortés de cada uno de los episodios de los debates. En primer lugar, siguiendo la descripción inicial de las estrategias de cortesía planteada por Brown P. y Levinson S. (1987), se intentarán reubicar estas estrategias en las categorías propuestas por KerbratOrecchioni $(2004)^{58}$. En segundo lugar, siguiendo los planteamientos de Briz (2001), se describirán las estrategias de atenuación cortés presentes en los intercambios comunicativos. En tercer lugar, una vez ya descritas estas estrategias, se detallarán los indicadores gramaticales que, de forma específica, permiten, en ciertos contextos enunciativos, expresar cortesía y atenuación cortés discursiva. Tomando los conceptos de Haverkate (s/fecha), se describirán las selecciones recurrentes de estructuras sintácticosemánticas que se cree que sirven de buena manera para conseguir aprobación de parte del interlocutor.

tema que propone con lo que se decía anteriormente. En este punto habría que reflexionar sobre lo que implica que un hablante opte por una forma que permita a los oyentes relacionar el nuevo tema de discurso con el procedente fácilmente; acto que sin duda involucra cortesía, pues es una opción estratégica que puede dar cuenta de que se está solidarizando con los participantes en cierto acto comunicativo para lograr los fines esperados. La perspectiva de los estudios de la relevancia (Sperber y Wilson, 1986), a través de la descripción de los efectos contextuales y las inferencias, permite realizar interesantes reflexiones y describir más profundamente aspectos como este en las interacciones verbales.

\footnotetext{
${ }^{58}$ Estas estrategias discursivas serán descritas en detalle en las páginas que siguen.
} 
La cuarta etapa se centrará en describir las técnicas argumentativas usadas en el proceso comunicativo de los debates. Llegado este punto es posible preguntarse, ¿cuál es la necesidad de revisar la teoría de la argumentación y las falacias utilizadas durante los procesos argumentativos en una investigación que está enfocada en describir las estrategias de cortesía verbal? o también ¿cuál es la conexión entre argumentación y cortesía verbal? pues bien, si se considera que los estudios y teorías del análisis del discurso, propuestos a partir de la década de los 60, abren una nueva perspectiva en los análisis discursivos al permitir que las investigaciones de estos análisis ya no estén centradas solo en la entrega de información literal sino también en los contenidos implícitos y en las estrategias que utiliza el emisor en esta selección de contenidos que envía en el proceso enunciativo, evidentemente que la forma en que justifique la entrega de esta información es también muy interesante y puede dar luces sobre cómo se estructuran y concatenan formalmente estas ideas de acuerdo a sus intenciones comunicativas. Por tanto, se cree que es de suma importancia no pasar por alto en este análisis el estudio del proceso argumentativo de cada episodio de los debates, lo que implica observar los argumentos y las estrategias de presentación de falsos argumentos, los clásicos de la antigua retórica y también algunas propuestas más modernas. Naturalmente, la cortesía verbal está implicada en todo este proceso comunicativo en la medida en que la imagen de los interlocutores puede ser atacada o valorada en el proceso de razonamiento. Se justifica así entonces la presencia de elementos de la teoría de la argumentación en esta investigación.

Siguiendo con el análisis lingüístico correspondiente a esta etapa, la descripción del proceso argumentativo está subdividida en dos áreas de aplicación: primero, se distinguirán los elementos constitutivos de cada episodio con el fin de describir la utilización de elementos facultativos y obligatorios en el proceso argumentativo que se desarrolló en cada episodio. En segundo lugar, se describirá la utilización de falsas argumentaciones basadas en la manipulación de los hechos. Se describirán las falacias descritas inicialmente por la retórica clásica pero con algunas adaptaciones (Lo Cascio (1998)) y se incluirán, además, posibles falacias no formales que se encuentren en el corpus de trabajo.

En el cuadro que sigue se recoge la pauta de contenidos que será aplicada en cada 
uno de los episodios temáticos de los dos debates. Sintetiza la base teórica que sustenta esta investigación y permite visualizar de forma clara los aspectos que se incluirán en el análisis $^{59}$. La innovación de esta investigación radica precisamente en la creación de esta guía de evaluación que permite describir las estrategias de interacción comunicativa insertas en este particular tipo de género discursivo, pues la creación de esta plantilla de análisis se realizó mediante una selección y adaptación de modelos previos. La plantilla de análisis es la siguiente:

Cuadro número 9: Plantilla de análisis con contenidos teóricos

\begin{tabular}{|c|c|}
\hline $\begin{array}{l}\text { Tipo de estrategia } \\
\text { indicador gramatical }\end{array}$ & Descripción \\
\hline $\begin{array}{l}\text { Estrategias de cortesía } \\
\text { positiva }\end{array}$ & $\begin{array}{l}\text { Estrategia de retribución de un acto alagador }{ }^{60} \text { (Kerbrat- } \\
\text { Orecchioni (2004:44)): A presta a B algún servicio (FFA) y } \\
\text { entonces B intenta producir un FFA (agradecimiento o } \\
\text { gentileza), para restablecer el equilibrio ritual entre los } \\
\text { interactuantes. Cuanto más importante es el FFA, tanto debe } \\
\text { serlo igualmente el FFA recíproco. } \\
\text { (Brown P. y Levinson S. , 1987): Apele al “terreno } \\
\text { común". - Intensifique el interés hacia O. } \\
\text { - Exagere (interés, aprobación, simpatía con O) } \\
\text { - Fíjese, atienda a O (a sus intereses, deseos, necesidades, } \\
\text { bienes). } \\
\text { Apele a la pertenencia al mismo grupo que O. Use } \\
\text { marcadores de identidad de grupo. } \\
\text { Apele al punto de vista, opiniones, actitudes, } \\
\text { conocimiento, empatía comunes. - Busque el acuerdo. }\end{array}$ \\
\hline
\end{tabular}

${ }^{59}$ La tabla que se presenta aquí contiene la síntesis teórica. En consecuencia, las plantillas en que se recogerán más adelante los resultados del análisis no mostrarán ya la definición de los conceptos a analizar. 


\begin{tabular}{|c|c|}
\hline & 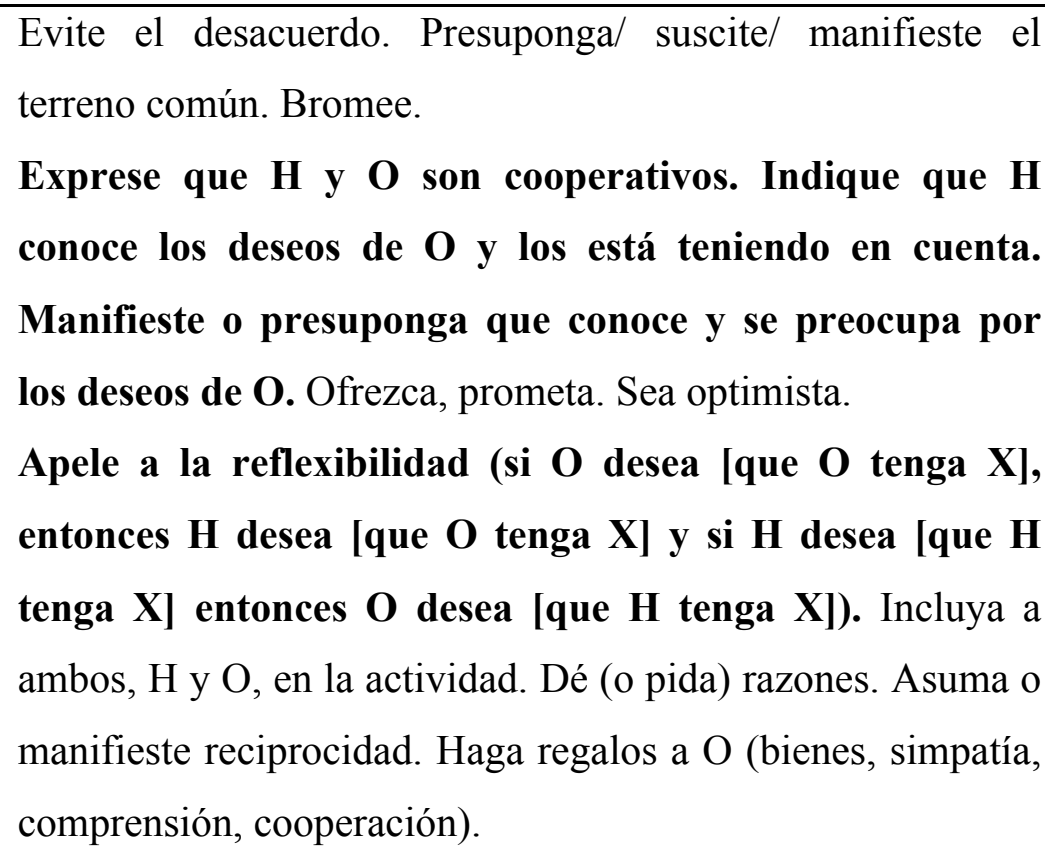 \\
\hline $\begin{array}{l}\text { Estrategias de cortesía } \\
\text { negativa }\end{array}$ & $\begin{array}{l}\text { Estrategias de reparación de un acto descortés }{ }^{\mathbf{6 1}} \text { (Kerbrat- } \\
\text { Orecchioni (2004:44)): A comete contra B alguna ofensa } \\
\text { (FTA) que inmediatamente intenta reparar por medio de una } \\
\text { excusa (FFA). Cuanto mayor es el peso del FTA, tanto más } \\
\text { debe ser importante el trabajo reparador. } \\
\text { Comunique que H (el hablante) no quiere afectar a O } \\
\text { (Brown P. y Levinson S. , 1987). - Pida disculpas. } \\
\text { Impersonalice a H y O: evite la primera y segunda persona } \\
\text { del singular. Plantee las AAI (acciones que amenazan la } \\
\text { imagen pública) como una regla general. }\end{array}$ \\
\hline
\end{tabular}

${ }^{60}$ El nombre de esta estrategia no corresponde a ninguna clasificación realizada por Kerbrat-Orecchioni previamente. Corresponde a un parafraseo, creado por la autora de esta investigación, correspondiente a esta técnica verbal.

${ }^{61}$ El nombre de esta estrategia no corresponde a ninguna clasificación realizada por Kerbrat-Orecchioni previamente. Corresponde a un parafraseo, creado por la autora de esta investigación, correspondiente a esta técnica verbal. 


\begin{tabular}{|c|c|}
\hline $\begin{array}{l}\text { Estrategias de atenuación } \\
\text { cortés (Briz, 2001) }\end{array}$ & $\begin{array}{l}\text { Se aminoran cualidades, actitudes y acciones del yo. Se } \\
\text { aminoran cualidades negativas del tú. }\end{array}$ \\
\hline $\begin{array}{l}\text { Indicadores gramaticales } \\
\text { de atenuación cortés } \\
\text { (Briz/Haverkate) }\end{array}$ & $\begin{array}{l}\text { Marcas gramaticales que manifiesten esta fuerza alocutiva } \\
\text { (Haverkate, s/fecha) del enunciado. }\end{array}$ \\
\hline $\begin{array}{l}\text { Indicadores } \text { gramaticales } \\
\text { de cortesía positiva y } \\
\text { negativa } \\
\text { Orecchioni/Brown } \quad \text { P. y } \\
\text { Levinson S.) (Haverkate) }\end{array}$ & $\begin{array}{l}\text { Marcas gramaticales que manifiesten esta fuerza alocutiva } \\
\text { (Haverkate, s/fecha) del enunciado. }\end{array}$ \\
\hline $\begin{array}{l}\text { Elementos indispensables } \\
\text { de la argumentación } \\
\text { (Lo Cascio (1998)) }\end{array}$ & $\begin{array}{l}\text { Tema del episodio: } \\
\text { Tesis: Pretensión que se quiere alcanzar. } \\
\text { Argumentos: Datos. } \\
\text { Regla General: La categoría RG debe ser siempre el } \\
\text { conectivo semántico-lógico entre la tesis y los (el) } \\
\text { argumento (s), y su presencia, por lo tanto, es indispensable. } \\
\text { En el ámbito lingüístico es facultativo. }\end{array}$ \\
\hline $\begin{array}{l}\text { Elementos facultativos de } \\
\text { la argumentación } \\
(\text { Lo Cascio (1998)) }\end{array}$ & $\begin{array}{l}\text { Refuerzo: El refuerzo muestra que el argumento elegido es } \\
\text { lo suficientemente potente como para justificar la opinión } \\
\text { defendida. } \\
\text { Calificador: El calificador puede ser deóntico (expresar la } \\
\text { obligación de algo) o epistémico (expresar la probabilidad } \\
\text { indicando si los enunciados son verdaderos o falsos). } \\
\text { Refutación, contraopinión o reserva: La reserva tiene la } \\
\text { función de indicar que a partir de un mismo dato se puede } \\
\text { llegar a distintas conclusiones que podrían desarrollar otro } \\
\text { razonamiento que llevaría a otra conclusión. } \\
\text { Fuentes: fuentes de información, declaraciones, documentos } \\
\text { que sirven de base para la elaboración o presentación de un } \\
\text { argumento. }\end{array}$ \\
\hline
\end{tabular}




\begin{tabular}{|c|c|c|}
\hline \multirow[t]{7}{*}{$\begin{array}{l}\text { Falacias argumentativas } \\
\text { (Lo Cascio (1998)) }\end{array}$} & $\begin{array}{l}\text { Argumentum ad } \\
\text { personam }\end{array}$ & $\begin{array}{l}\text { Se ejerce una presión sobre la persona, } \\
\text { poniendo en discusión la credibilidad de } \\
\text { quien se presenta como adversario. }\end{array}$ \\
\hline & $\begin{array}{l}\text { Argumentum ad } \\
\text { hominem }\end{array}$ & $\begin{array}{l}\text { El argumento se basa únicamente en el } \\
\text { universo del protagonista específico sin } \\
\text { considerar valores universales. }\end{array}$ \\
\hline & $\begin{array}{l}\text { Argumentum ad } \\
\text { verecundiam }\end{array}$ & $\begin{array}{l}\text { Apelar al prestigio, a la fama o al cargo } \\
\text { de las personas. }\end{array}$ \\
\hline & $\begin{array}{l}\text { Argumentum ad } \\
\text { misericordiam }\end{array}$ & $\begin{array}{l}\text { Apelar a la piedad como un argumento a } \\
\text { favor de un trato especial. }\end{array}$ \\
\hline & $\begin{array}{l}\text { Argumentum ad } \\
\text { populum }\end{array}$ & Apelar a las emociones de una multitud. \\
\hline & $\begin{array}{l}\text { Argumentum ad } \\
\text { consequentiam }\end{array}$ & $\begin{array}{l}\text { Sirve para juzgar negativamente una } \\
\text { afirmación, una tesis, no mediante } \\
\text { argumentos externos, sino a través de las } \\
\text { consecuencias que pueden derivarse de } \\
\text { tales afirmaciones. }\end{array}$ \\
\hline & $\begin{array}{l}\text { Argumentum ad } \\
\text { ignorantiam }\end{array}$ & $\begin{array}{l}\text { Se apela a la ignorancia del oponente para } \\
\text { probar el punto de vista contrario, a partir } \\
\text { de información incompleta. }\end{array}$ \\
\hline
\end{tabular}




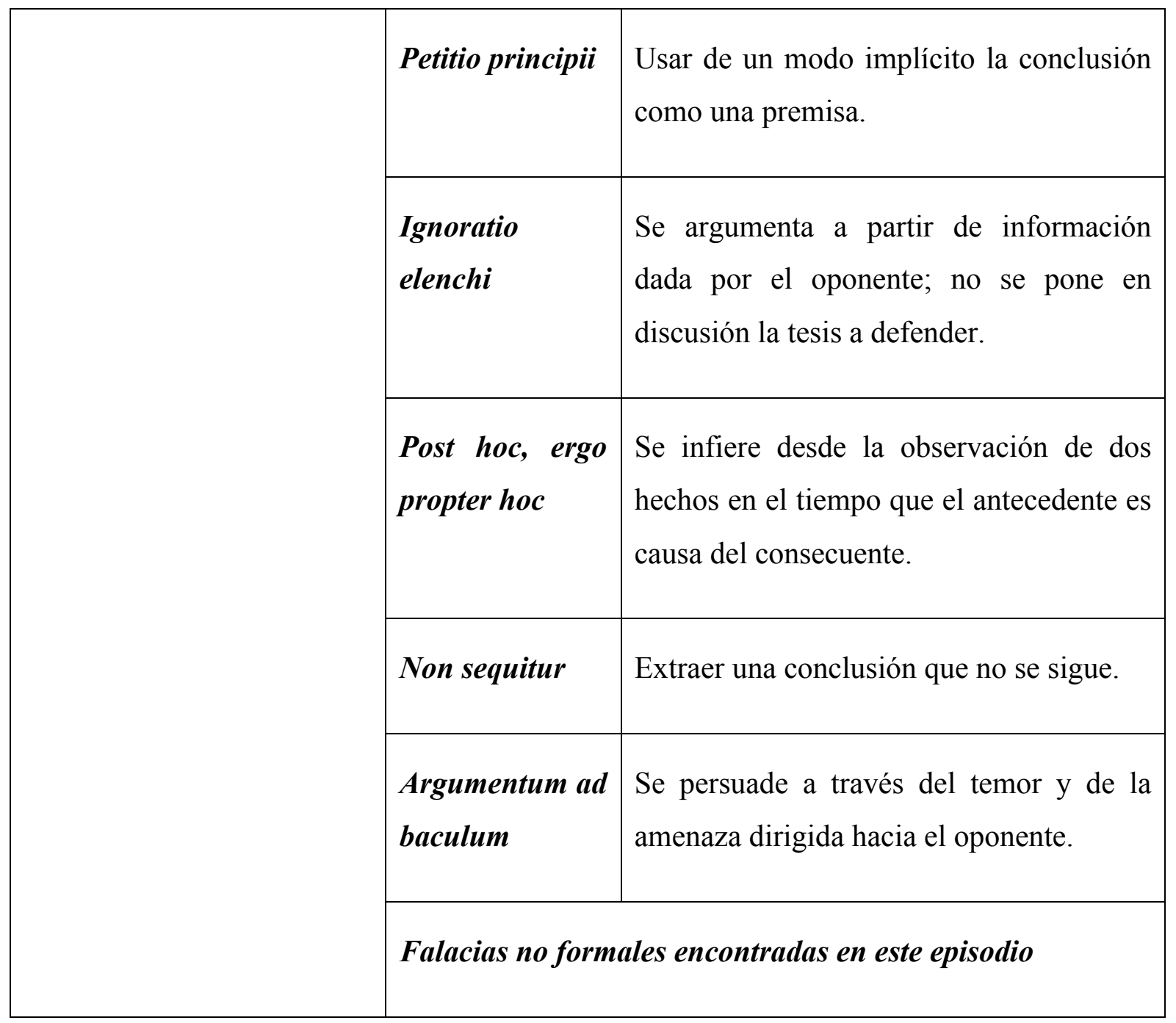

La última parte de esta investigación consistirá en la presentación de los resultados que se hayan obtenido luego de la aplicación de estas platillas al corpus. Se expondrá un análisis cualitativo con la información recién señalada que describa a modo de síntesis el uso de las estrategias de cortesía verbal y de atenuación de cortesía, la recurrencia de distorsiones en la argumentación y de los elementos internos del proceso argumentativo, así como también, la utilización reiterada de determinados marcadores gramaticales usados en el proceso de manifestar la cortesía en cada uno de los episodios de los dos debates. Junto 
con los resultados, y como notas al pie de página, se estimó oportuno informar sobre el significado de cierto léxico espontáneo y diferencial ${ }^{62}$ registrado en el corpus.

Una vez presentados los resultados se comentarán en las conclusiones las similitudes y diferencias comunicativas entre los dos tipos de debates y se establecerá si se observan estrategias contundentemente diferentes en los coloquios de los dos grupos etarios, es decir, si el rango edad es pertinentemente diferenciador a la hora de describir las estrategias de cortesía y atenuación cortés en esta muestra de hablantes del español de Chile.

${ }^{62}$ Al definir casi la totalidad de estas voces se utilizó el diccionario (diferencial) de uso del español de Chile, DUECh, obra lexicográfica realizada por la Academia Chilena de la Lengua en 2010. 
9 ANÁLISIS DEL CORPUS DE REFERENCIA

9.1 Análisis del corpus de los jóvenes ${ }^{1}$

\section{$\mathrm{N}^{\circ}$ de episodio: 1}

Se propone el primer tema de discusión: "La pastilla del día después y su prohibición en nuestro país". H1 (hombre que toma el primer turno de palabra ${ }^{2}$ ) comienza a hablar.

H1: oye que aburrío con eso ${ }^{\mathrm{h}}$ mail que mandaron por la: cue ${ }^{\mathrm{h}}$ tion de:-

H2: sí:, ¡pucha!.

H1: no ${ }^{\mathrm{h}}$ mandaron como $\mathrm{TRE}^{\mathrm{H}}$ gmail, osea-

M1: < [. a mí: me:- $]$

H2: llenaron toda la bandeja de $\mathrm{lo}^{\mathrm{h}}$ alumno $^{\mathrm{h}}$ de letras con $\mathrm{di}^{\mathrm{h}}$ cusione $^{\mathrm{h}}$.

H3: $<$ [. hicieron un:, pusieron una:- $]$

M1: Te juro que lo hubiera leído to: si hubiese tenido tiempo, lo encontré muy interesante.

H1: NO:, a mí me pareció: como: $\rightarrow$

M2: $<$ [el primer mail fue como ya:|]

H1: desubicao:.

M2: pero de pué $^{\text {h }}$ VEINTE mails sobre eso.

H1: de ${ }^{h}$ pués era desubicao es que: $\rightarrow$

H3: como que hicieron un foro por mail.

H1: pero era pa:, como, no era la:, de la píldora del día de $\mathrm{h}^{\mathrm{h}}$ pués sino que era otro método

${ }^{1}$ La síntesis del léxico diferencial (exclusivamente del léxico juvenil y coloquial) del español de Chile observado en el corpus está descrito en los resultados de este análisis, lugar en el que también se registran sus significados tomados de DUECh (2010).

${ }^{2}$ La abreviatura H corresponde a "hombre" y el número que lo acompaña al lugar en el que tomó su turno en este episodio temático. La abreviatura $\mathrm{M}$ corresponde a "mujer" y el número al lugar del turno en este epiacabineviatura H corresponde a "hombre" y el número que lo acompaña al lugar en el que tomó su turno en este episodio temático. La abreviatura M corresponde a "mujer" y el número al lugar del turno en este episodio. 
anticonceptivo.

M2:NO:, era de la píldora.

H3: NO:, era de la píldora.

H1: ¿era la píldora:?

M3: $\left\{\right.$ el di ${ }^{\mathrm{h}}$ positivo intrauterino y la píldora\}

H3: o sea mencionaban la píldora:.

H1: NO, era ese dispositivo:.

H3: NO:.

M3: \{el di ${ }^{\mathrm{h}}$ positivo intrauterino, la píldora\}

M4: ese era el tema su ${ }^{\mathrm{h}}$ citado, los problemas del día de la píldora del día de ${ }^{\mathrm{h}}$ pués.

H1: pero estaban di $\mathrm{i}^{\mathrm{h}}$ cutiendo por OTROS.

M4: [pero es que:]>

M3: $\mathrm{e}^{\mathrm{h}}$ que ese era el tema de ${ }^{\mathrm{h}}$ pués se desvió el tema, eso es lo que pasa después se desvió, hacia la biblia y:-

H1: claro, y pusieron el mail como informando y uno respondió como con su opinión y otro le respondió con oye, y te digo, y al final era como TREINTA mail ${ }^{\mathrm{h}} \mathrm{y}$ uno, yo me metí al mail a ver otra ${ }^{\mathrm{h}} \operatorname{cosa}^{\mathrm{h}} \mathrm{y}$ tenía como no sé cuanto ${ }^{\mathrm{h}}$.

M3: ya pero volvamos:

H1:ya pero volvamos al cuento de:

$\mathrm{O}:<$.ya: pero escuchemo $\rightarrow$ $\rightarrow$

M4: el tema es polémico

$\mathrm{O}$ : sí: es polémico

$\{$ risas $\}$

Descripción del episodio número 1

Elementos indispensables de la argumentación (Lo Cascio, 1998)

Tema del episodio: Correos electrónicos masivos en los buzones de entrada de los alumnos de la Facultad de letras.

Tesis: Fue desagradable el envío de correos masivos al correo electrónico de la universidad. 
Argumentos: Se recibió una gran cantidad de correos con respuestas de todos los participantes de la conversación por correo.

Regla General: (implícita) es molesto recibir una gran cantidad de correos masivos al correo electrónico porque esto puede hacer colapsar la bandeja de entrada impidiendo que se reciban nuevos mensajes.

\section{Elementos facultativos de la argumentación (Lo Cascio, 1998)}

Refuerzo: El envío de correos fue prácticamente un foro.

Calificador: Probablemente fue desubicado usar este medio para debatir sobre este tema.

Refutación o contraopinión: Es interesante saber las opiniones de otros compañeros sobre este tema por eso puede ser una buena medida hacer una consulta masiva de este tipo.

Falacias argumentativas (Lo Cascio, 1998)

Petitio principii: Usar de un modo implícito la conclusión como una premisa.

M1: Te juro que lo hubiera leído to: si hubiese tenido tiempo, lo encontré muy interesante. H1: NO:, a mi me pareció: como: $\rightarrow$

(..)

H1: desubicao:

Los protagonistas de este par de adyacencia no argumentan las razones de por qué encuentran interesante, por un lado, y desubicado, por otro, el envío de los correos masivos. La conclusión a la que llegan la exponen como una premisa.

Estrategias de cortesía positiva Apele al "terreno común" (Brown P. y Levinson S. , 1987).

- Intensifique el interés hacia $O$.

- Fíjese, atienda a $O$ (a sus intereses, deseos, necesidades, bienes).

M3: ya pero volvamos:

H1:ya pero volvamos al cuento de:

$O:<$ [.ya: pero escuchemoh $\rightarrow$ ]

M4: el tema es polémico

$O$ : sí: es polémico

$\{$ risas\}

H1 intensifica el interés hacia M3 parafraseando su sugerencia de volver al tema central de la conversación. H1 se fija en los intereses de M3 y los atiende. Por su parte, las risas de todos hacen que el ambiente se distienda . 


\section{Apele a la pertenencia al mismo grupo que O. Use marcadores de identidad de grupo.} (Brown P. y Levinson S. , 1987).

H1 oye que aburrio con esoh mail que mandaron por la: cuehtion de:-

H2 si:, ipuchai.

H1 noh mandaron como TREH gmail, osea-

M1 <. a mí: me:-]

H2 llenaron toda la bandeja de loh alumnoh de letras con dihcusioneh.

H3: < [. hicieron un:, pusieron una:-]

M1: Te juro que lo hubiera leido to: si hubiese tenido tiempo, lo encontré muy interesante.

H2 utiliza un marcador de identidad de grupo; se apela al terreno común al proponer un tema que incumbe a todos los estudiantes de la facultad; se cuenta una anécdota común a todos los participantes del debate. Este gesto es, indudablemente, cortés pues -como ya se comentó anteriormente- permite mantener una conversación relevante, ya que el tema es conocido por todos y pueden, por tanto, obtener las inferencias necesarias para comprender lo dicho. H1 también se refiere a la identidad del grupo al decir "nos mandaron".

Por otra parte, en cuanto al uso de léxico, se observa que este permite dar cuenta de un registro coloquial y espontáneo. El uso de palabras y de sintagmas como: cuestión, pucha, te juro que (...), muestra que estos jóvenes se sentían conversando entre pares, y constituye también, por tanto, un marcador de identidad de grupo.

Apele al punto de vista, opiniones, actitudes, conocimiento, empatía comunes. Busque el acuerdo. Evite el desacuerdo. Presuponga/ suscite/ manifieste el terreno común. Bromee. (Brown P. y Levinson S. , 1987).

H1 oye que aburrío con esoh mail que mandaron por la: cuehtion de:-

H2 si:, pucha.

En este par de adyacencia se busca el acuerdo. H2 quiere manifestar que también está molesto con el excesivo número de correos electrónicos masivos que recibió. El uso de la interjección (eufemística) coloquial pucha indica solidaridad con el otro interlocutor y entendimiento frente a su molestia, viene a simbolizar un yo también lo siento.

Veamos otro ejemplo que muestra un intento por evitar el desacuerdo:

H1 pero era pa:, como, no era la:, de la píldora del día dehpués sino que era otro método anticonceptivo.

M2 NO:, era de la píldora. 
H3 NO:, era de la píldora.

H1 ¿era la píldora:?

M3 \{el dihpositivo intrauterino y la píldora\}

H3 o sea mencionaban la pildora:

H1 NO, era ese dispositivo:

H3 NO:

M3 \{el dihpositivo intrauterino, la pildora\}

M4 ese era el tema suhcitado, los problemas del día de la píldora del día dehpués.

H1 pero estaban dihcutiendo por OTROS.

M4 [pero es que:]>

M3 eh que ese era el tema dehpués se desvió el tema, eso es lo que pasa después se desvió, hacia la biblia y:-

M3 intenta evitar constantemente el desacuerdo, opinando que las dos alternativas que se están discutiendo pueden ser válidas, puesto que ambos temas se trataron de alguna forma en este foro por correo electrónico.

Observemos en detalle este segmento en el que se relativiza el enfrentamiento:

H1 pero era pa:, como, no era la:, de la píldora del día dehpués sino que era otro método anticonceptivo.

M2 NO: era de la píldora.

H3 NO:, era de la píldora.

H1 iera la píldora:?

$\mathrm{H} 1$ en su segunda intervención pone en duda lo que afirma H3 y M2 por medio de una pregunta, lo que relativiza el enfrentamiento. Esta estrategia permite evitar de alguna manera el desacuerdo al pedir una mayor explicación a sus interlocutores.

\section{Estrategias de cortesía negativa}

Estrategias de reparación de un acto descortés (Kerbrat-Orecchioni (2004:44)): A comete contra B alguna ofensa (FTA) que inmediatamente intenta reparar por medio de una excusa (FFA). Cuanto mayor es el peso del FTA, tanto más debe ser importante el trabajo reparador.

En el siguiente fragmento, se observa que las risas también pueden ser usadas como medio reparador (además de ser una estrategia de cortesía positiva según las máximas de Leech, como se dijo antes). Veamos el siguiente fragmento:

H1: claro, y pusieron el mail como informando y uno respondió como con su opinión y otro le respondió con oye, y te digo, y al final era como TREINTA mailh y uno, yo me metí al mail a ver otrah cosah y tenía como no sé cuantoh. 
M3 ya pero volvamos:

H1 ya pero volvamos al cuento de:

$O<$ [.ya: pero escuchemoh $\rightarrow]$

M4: el tema es polémico

O sí: es polémico

$\{$ risas\}

Las risas utilizadas al finalizar este episodio suavizan el ataque hacia H1, acometida que tuvo como intención principal robarle el turno a este interlocutor, hacerlo callar y, además, proponer un cambio de tema.

Comunique que $\mathrm{H}$ (el hablante) no quiere afectar a $\mathrm{O}$ (Brown P. y Levinson S. , 1987). Pida disculpas. Impersonalice a $\mathrm{H}$ y $\mathrm{O}$ : evite la primera y segunda persona del singular. Plantee las AAI (acciones que amenazan la imagen pública) como una regla general.

En este fragmento se utiliza la técnica de la impersonalización:

H1 pero era pa:, como, no era la:, de la píldora del día dehpués sino que era otro método anticonceptivo.

M2 NO:, era de la píldora.

H3 NO:, era de la píldora.

H1 ¿era la píldora:?

M3 \{el dihpositivo intrauterino y la píldora\}

H3 o sea mencionaban la píldora:

H1 NO, era ese dispositivo:

H3 NO:

M3 \{el dihpositivo intrauterino, la píldora\}

M4 ese era el tema suhcitado, los problemas del día de la píldora del día dehpués.

H1 pero estaban dihcutiendo por OTROS.

H3, en su segunda intervención en este segmento, intenta impersonalizar el tema que se discute afirmando que "mencionaban (otros, en su discurso) la píldora", evitando así usar la primera y segunda persona del singular.

\section{Estrategias de atenuación cortés (Briz, 2001)}

Se aminoran cualidades negativas del tú:

M1 Te juro que lo hubiera leído to: si hubiese tenido tiempo, lo encontré muy interesante.

H1 NO:, a mi me pareció: como: $\rightarrow$

M2 < [el primer mail fue como ya: $\mid]$ 


\section{H1 desubicao:}

Se observa que el uso de como, por parte de H1, intenta minimizar el enfrentamiento causado por el adverbio de negación no en respuesta a un enunciado de M1. Esta es una estrategia oral y coloquial muy frecuente en el español de Chile, se usa como con el valor de más o menos, para minimizar el impacto de un enunciado, lo que matiza una posible agresión al interlocutor.

\section{Indicadores gramaticales de atenuación cortés (Briz/Haverkate)}

Marcas gramaticales que manifiesten esta fuerza alocutiva (Haverkate, s/fecha) del enunciado.

Uso de como para matizar las cualidades negativas del tú. Se usa con el valor de más o menos, lo que atenúa una posible agresión por parte del emisor.

Indicadores gramaticales de cortesía positiva y negativa (Kerbrat-Orecchioni/Brown P. y Levinson S. ) (Haverkate)

Marcas gramaticales que manifiesten esta fuerza alocutiva (Haverkate, s/fecha) del enunciado.

Estrategias de Cortesía Positiva (Brown P. y Levinson S. , 1987)

Apele al "terreno común".

- Uso de paráfrasis, es decir, una frase que imita la estructura de otra, lo que le otorga reconocimiento al emisor de dicho mensaje anterior y, además, muestra interés y aprobación de su contenido.

Apele a la pertenencia al mismo grupo que O. Use marcadores de identidad de grupo.

- $\quad$ La utilización de la primera persona plural ayuda a establecer lazos grupales entre los participantes.

- Uso de léxico espontáneo y coloquial.

- Relevancia temática: preferencia por anécdotas que son conocidos por todos y que los involucran a todos. 
Apele al punto de vista, opiniones, actitudes, conocimiento, empatía comunes. Busque el acuerdo. Evite el desacuerdo. Presuponga/ suscite/ manifieste el terreno común. Bromee.

- Uso de reformuladotes discursivos (Sí, pucha/ o sea/ pero es quel eso es lo que pasa) que intentan evitar constantemente el desacuerdo o mostrar aprobación, expresando, en el caso del desacuerdo, que las dos alternativas que se están discutiendo pueden ser válidas, puesto que ambos temas se trataron de alguna forma en este foro por correo electrónico.

- Risas: a través de la risa se distiende el ambiente, con la broma, y se suaviza la agresión cometida contra $\mathrm{H} 1$.

\section{Apele a la reflexibilidad: Dé (o pida) razones.}

La modalidad interrogativa del enunciado da flexibilidad al debate pues, por medio de ella, se pide la intervención del otro.

\section{$\mathrm{N}^{\circ}$ de episodio: 2}

O: y ustede ${ }^{\mathrm{h}}$ ¿qué opinan?

M1: No sé yo el otro día estaba hablando+ mi pololo me hizo una pregunta así como el típico: | tema: | que está en el momento + yo al menos le dije + alguna ${ }^{\mathrm{h}}$ persona $^{\mathrm{h}}$ ya piensan+ o sea eso no está totalmente como definido, eso lo que yo tenía claro, no está totalmente definido $\mathrm{si}^{\mathrm{h}}$ abortivo o no $\mathrm{e}^{\mathrm{h}}$ abortivo pero bueno alguno ${ }^{\mathrm{h}}$ dicen que sí otro ${ }^{\mathrm{h}}$ dicen que no | pero yo le dije el punto lo que yo creo que si una persona que está totalmente en co:ntra no sé por tema ${ }^{\mathrm{h}}$ religio:so ${ }^{\mathrm{h}}$ por lo que sea $\mid$ si está si se ve en el momento preciso de que tuvo relaciones por ejemplo y no se cuidó, según mi opinión la va a ocupar igual| aunque esté muy en contra, pero si ve $1 \mathrm{a}^{\mathrm{h}}$ posicione $^{\mathrm{h}}$ de que no no puedo| puedo estar embarazada o no sé qué aunque esté muy en contra yo creo que cualquier persona la va a usar igual de toda ${ }^{\mathrm{h}}$ manera $^{\mathrm{h}}$. 
M2: yo no estoy de acuerdo con eso.

M1: sí |yo pienso eso.

M2: porque yo soy: contraria, en el sentido de que soy una persona provida, y todo lo que para mí atente o esté potencialmente atentando contra una vida o ya sea vida en potencia es contraria a $\mathrm{mi}^{\mathrm{h}}$ principio $^{\mathrm{h}} \rightarrow$

M1: < [.pero por eso no:| no se sabe-]

M2: ya sea que esté en esa situación o no, el mismo hecho de que no se sepa, no me da la certeza de que no lo hago, así que no lo ocuparía, ¿me entiende ${ }^{\mathrm{h}}$ ?

M1: si po, pero eso es lo que digo yo + hay mucha ${ }^{\mathrm{h}}$ persona $^{\mathrm{h}}$ que no lo dicen pero en el momento cambian de opinión $\rightarrow$ como en mucha ${ }^{\mathrm{h}} \operatorname{cosa}^{\mathrm{h}}$.

M2: $\mathrm{e}^{\mathrm{h}}$ que $\rightarrow$ A ESO VOY YO, YO no creo que cambiaría de opinión aunque esté en una situación terrible $\rightarrow$

$\mathrm{M} 1:<\left[. \mathrm{e}^{\mathrm{h}}\right.$ que eso $\mathrm{e}^{\mathrm{h}}$ lo que digo yo porque- $]$

M2: por un, POR UN TEMA VALÓRICO, va en que la ${ }^{\mathrm{h}}$ per, que, en mi caso la pa ${ }^{\mathrm{h}}$ tilla e:| involucra ya un tema que es superior que $\mathrm{e}^{\mathrm{h}} \mathrm{el}^{\mathrm{h}} \mathrm{h}^{\mathrm{h}}$ valo $\mathrm{lo}^{\mathrm{h}}$ valore ${ }^{\mathrm{h}}$, creo que mi actuar está condicionado absolutamente a $\mathrm{mi}^{\mathrm{h}}$ valore $^{\mathrm{h}}$, por má ${ }^{\mathrm{h}}$ que me sienta en una situación muy heavy e: me cue ${ }^{h}$ tionaría mucho eso y creo que $\mathrm{e}^{\mathrm{h}}$ una cue $\mathrm{h}^{\mathrm{h}}$ tión que va de por vida, no sé si cargaría con esa cue ${ }^{\mathrm{h}}$ tión de por vida.

H1: yo pienso que va má ${ }^{\text {h }}$ que nada en cada uno porque, a ver| el hecho de solamente decir: "no: deberían prohibirla" estai imponiendo tu opinión yo creo a la de lo ${ }^{\mathrm{h}}$ demáh porque al fin y al cabo si, la prohíben o la permiten, uno está imponiendo una: verdad, una postura a gente que quizá no piense lo mismo, y yo siempre he pensado que uno no $\mathrm{e}^{\mathrm{h}}$ nadie como pa imponer mi verdad frente a la de $10^{\mathrm{h}}$ demá ${ }^{\mathrm{h}}$ o sea, independientemente si yo estoy de acuerdo o no pienso que debería estar la elección pa la gente que la quiere tomar o gente que no.

M2: ¿pero cree ${ }^{\mathrm{h}}$ que, que es una posibilidad de elección entregar un método y no, que no vaya de la mano con la educación y la certeza?

H1:NO:, por supuesto, pero-

M2: o sea, hasta qué punto yo puedo elegir si no tengo la certeza de lo que me están ofreciendo.

H1: no si yo no estoy diciendo- 
H2: $<$ [yo, yo igual tengo- $]$

H1: $<$ [. no po, si es correcto eso. $]$

M2: entonces eso ya no, no, no va en punto de elección, va en una defensa máxima que ya $\mathrm{e}^{\mathrm{h}}$ la relativización de $1 \mathrm{o}^{\mathrm{h}}$ valore $^{\mathrm{h}}$ a nivel casi mundial.

$\mathrm{H} 2:<[\operatorname{sip}]$

M3: Claro, es cómo tú veí el mundo o sea, no podí decirle a alguien sabí qué, yo opino esto pero tú haz lo que querai, no porque van a tomar ya osea ¿qué opino yo sobre la vida?, ¿CUÁNDO empieza la vida ¿cachái? Pa mí la vida empieza desde que se une óvulo y espermatozoide $\rightarrow$

$\mathrm{H} 1:<[$.por eso]

M3: PARA MI $\rightarrow$ cachái? y POR ESO yo mi opinión, ese es mi modo de ver la vida entonces si yo me planteo frente al mundo, esa es mi opinión, y yo estoy totalmente en contra de la píldora del día despué $\rightarrow$

$\mathrm{H} 1:<[$.pero no por eso $\rightarrow]$

M3: $<$ [pero pa to: el mundo sí]

$\mathrm{H1}:<$ [pero no por eso tení que imponer tu opinión al resto.]

M3: $<$ [pero yo, sí | porque- $]$

H2: $<$ [.yo encuentro:- $]$

M2: pero no es imponer, insisto, la el tema de imposición para ti va pa |e: |para:-

H1: si $\mathrm{e}^{\mathrm{h}}$ que hay una ley estai imponiendo una verdad.

M2: ¿las leyes son imposiciones?

H1: Sİ:, tú tení que seguirla ${ }^{\mathrm{h}}$ a cabalidad.

H2: $<$ [si: pero:- $]$

M2: ¿una verdad?

H1: o sea una verdad-

M2: IMPONER, imponer que la muer-, que matar es un delito ¿es una imposición o un valor que se está tomando antinatural?

H2: $<$ [si po no podí decir que imponer algo sea malo porque si es por eso, tendríamo ${ }^{\mathrm{h}}$ que toda ${ }^{\mathrm{h}} \mathrm{la}^{\mathrm{h}}$ leye $\rightarrow$ ]

M2: < [para mí la muerte es una antivalor completamente.]

H2: ¿cachái? No podí $\rightarrow$ no podí decir que porque algo $\mathrm{e}^{\mathrm{h}}$ impuesto está malo ¿cachái? 
Porque hay $\operatorname{cosa}^{\mathrm{h}}$ impuesta $^{\mathrm{h}}$ que igual son útile ${ }^{\mathrm{h}}$, valiosa ${ }^{\mathrm{h}}$ y que, por ejemplo, yo creo que a ti no te gustaría que llegara alguien a tu casa y te robara toda ${ }^{\mathrm{h}} \mathrm{tu}^{\mathrm{h}} \cos \mathrm{a}^{\mathrm{h}}$, violara $y$ matara a tu mamá, no cachái $\rightarrow$

M2: $<$ [ahora yo:- $]$

H2: existen, existen regla ${ }^{\mathrm{h}}$ que imponen que eso esté mal y existen castigo ${ }^{\mathrm{h}}$ detrás de eso, ¿cachái?.

M2: $<$ [ahá]

H3: $<$ [que esté mal o bien depende de cada uno, pero hay otra gente-]

M2: pero es que esa relativización de $10^{\mathrm{h}}$ valore $^{\mathrm{h}}$ es lo que hoy en día nos lleva a tener esta clase de di ${ }^{\mathrm{h}}$ cusione ${ }^{\mathrm{h}} \rightarrow$

H3: $<$ [pero esos son TUS valores.]

M2: el "DEPENDE DE CADA UNO" está llegando a un nivel, en que se está relativizando todo, para comodidad de nosotros, ¿estamos relativizando el límite de la vida porque es más cómodo no tener un hijo? |

H3: $<$ [pero esos son- $]$

M2: ¿me entiendes? Entonce ${ }^{\mathrm{h}}$, yo entiendo como lo que tú estás hablando sobre imposición, pero eso va netamente de la mano de la educación, la educación es la que nos da la libertad de escoger, yo no te puedo dar una libertar de escoger si antes no te educo $\mid \rightarrow$

H3: $<$ [no sí| totalmente de acuerdo]

M2: porque estoy relativizando los niveles de vida.

H3: $<$ [pero de toda ${ }^{\mathrm{h}}$ manera ${ }^{\mathrm{h}}$ hay que tener la opción de elegir].

H2: yo considero que $\mid$ ante $^{\mathrm{h}}$ de: $\rightarrow$, yo considero que sí $\mathrm{e}^{\mathrm{h}}$ importante como establecer, si la: pastilla:, $\mathrm{e}^{\mathrm{h}}$ buena o $\mathrm{e}^{\mathrm{h}}$ mala, pero hay que primero como definir un punto, de si $\mathrm{e}^{\mathrm{h}}$ anticonceptiva o $\mathrm{e}^{\mathrm{h}}$ abortiva $\mid \mathrm{y}$ despué ${ }^{\mathrm{h}}$ habría que definir el punto de si el aborto $\mathrm{e}^{\mathrm{h}}$, como una: | es una opción o no $\mathrm{e}^{\mathrm{h}}$ una opción porque existen, gente que dice que el aborto no es una opción porque: es asesinato [yo no estoy emitiendo juicio ${ }^{\mathrm{h}}$ personale $^{\mathrm{h}}$ | todavía] y: que dicen que, el aborto $\mathrm{e}^{\mathrm{h}}$ un asesinato y otro ${ }^{\mathrm{h}}$ que dicen que no, que una madre tiene derecho sobre su cuerpo, y que como ha:y un feto dentro de él que es su cuerpo entonces tiene derecho decir si no, si es o si no $\mid$ ahora, si partimo ${ }^{\mathrm{h}}$ que el aborto $\mathrm{e}^{\mathrm{h}}$ asesinato $\mathrm{y} \mathrm{e}^{\mathrm{h}}$ malo, entonce ${ }^{\mathrm{h}}$ hay que ver si la: pa-, yo no sé si la pastilla $\mathrm{e}^{\mathrm{h}}$ 
anticonceptiva o $\mathrm{e}^{\mathrm{h}}$ abortiva, lo que existen $\mathrm{pa}^{\mathrm{h}}$-yo sé que existen pastillas que, permiten la unión espermatozoide y óvulo y que pero que después hacen que eso se cague y se bote pero ya había: una:, prodíamo ${ }^{\text {hh }}$ decir que ya había una vida porque ya a existía vida humana porque ya se juntó el espermat-, el espermio con el óvulo $\rightarrow$

$\mathrm{M} 2:<[\mathrm{sí}]$

M1: y:, pero ello no, pero también hay pastillas que evitan eso, que hacen que: la: mujer como que secrete un ph y los espermios se mueren $\mid \mathrm{y}$ eso es pre-, no es abortivo es preconceptivo entonces ahí hay como que delimitar eso, y ahí, y ahí yo encuentro que teniendo esos puntos bien delimitados, es NECESARIO establecer un juicio, imponer algo | porque no podemos dejarlo así como que al azar y que claro, que la: que o sea si es por eso como que ya no queremos tener hijos entonces tuve un hijo y lo maté, no, ¿es correcto eso?

\section{Descripción del episodio número 2}

\section{Elementos indispensables de la argumentación (Lo Cascio ,1998)}

\section{Tema del epidisodio: La pastilla del día después.}

Tesis: La píldora del día después no debería estar a disposición de todo el mundo.

Argumentos: Al estar en venta en farmacias sin ninguna restricción se masificaría su uso de tal manera que la gente que incluso dice que no la tomaría en ningún caso decidiría hacerlo.

Regla General: La píldora del día después, usada sin prescripción médica, puede ser dañina para la mujer, además puede ser abortiva.

\section{Elementos facultativos de la argumentación (Lo Cascio, 1998)}

Refuerzo: Hay mucha gente que dice que no haría ciertas cosas debido a razones morales o personales pero luego las hace.

Calificador: Convendría tener la certeza de que no es abortiva o de que sí lo es, antes de distribuirla masivamente.

Refutación, contraopinión o reserva: Las personas que dicen que no tomarían la píldora del día después no lo harían en ningún caso debido a razones valóricas. La gente que sí 
quiere tomar esta pastilla debería tener la alternativa de poder hacerlo, de poder decidirlo libremente.

Falacias argumentativas (Lo Cascio, 1998)

Argumentum ad ignorantiam: Se apela a la ignorancia del oponente para probar el punto de vista contrario, a partir de información incompleta.

M1: < [.pero por eso no:| no se sabe-]

M2: ya sea que esté en esa situación o no, el mismo hecho de que no se sepa, no me da la certeza de que no lo hago, así que no lo ocuparía, ¿me entiende ${ }^{h}$ ?

Argumentum ad baculum: Se persuade a través del temor y de la amenaza dirigida hacia el oponente.

H2: ¿cachái? No podi $\rightarrow$ no podi decir que porque algo $e^{h}$ impuesto está malo ¿cachái? Porque hay cosa ${ }^{h}$ impuesta $^{h}$ que igual son útile ${ }^{h}$, valiosa ${ }^{h}$ y que, por ejemplo, yo creo que a ti no te gustaría que llegara alguien a tu casa y te robara toda ${ }^{h} \mathrm{tu}^{h} \cos ^{h}$, violara y matara a tu mamá, no cachái $\rightarrow$

\section{Falacias no formales encontradas en este episodio:}

Argumento de la pendiente resbaladiza: este argumento dice que si ocurre un evento, otros eventos peligrosos ocurrirán igualmente; sin embargo, no hay prueba de que otros eventos peligrosos sean causados por el primer evento.

Observamos este argumento falaz en el siguiente segmento:

M1: No sé yo el otro día estaba hablando + mi pololo me hizo una pregunta así como el típico: | tema: | que está en el momento + yo al menos le dije+ alguna ${ }^{h}$ persona ${ }^{h}$ ya piensan+o sea eso no está totalmente como definido, eso lo que yo tenía claro, no está totalmente definido si $e^{h}$ abortivo o no $e^{h}$ abortivo pero bueno alguno ${ }^{h}$ dicen que sí otro ${ }^{h}$ dicen que no | pero yo le dije el punto lo que yo creo que si una persona que está totalmente en co:ntra no sé por tema ${ }^{h}$ religio:so ${ }^{h}$ por lo que sea 1 si está si se ve en el momento preciso de que tuvo relaciones por ejemplo y no se cuidó, según mi opinión la va a ocupar igual $\mid$ aunque esté muy en contra, pero si ve la ${ }^{h}$ posicione $e^{h}$ de que no no puedo| puedo estar embarazada o no sé qué aunque esté muy en co:ntra yo creo que cualquier persona la va a usar igual de toda ${ }^{h}$ manera $^{h}$. 
En este argumento se afirma que si la pastilla del día después estuviera disponible para todo el mundo, incluso la gente que piensa que no la usaría, por motivos morales o religiosos, al poder obtenerla fácilmente, sí la usaría.

\section{Estrategias de cortesía positiva}

\section{Estrategia de retribución de un acto halagador (Kerbrat-Orecchioni (2004:44)):}

En este segmento se observa que M2 presta a H3 algún servicio (FFA) y entonces H3 intenta producir un FFA (agradecimiento o gentileza), para restablecer el equilibrio ritual entre los interactuantes.

H3: $<$ [pero esos son TUS valores.]

M2: el "DEPENDE DE CADA UNO" está llegando a un nivel, en que se está relativizando todo, para comodidad de nosotros, ¿estamos relativizando el límite de la vida porque es más cómodo no tener un hijo? | |

H3: < [pero esos son-]

M2: ¿me entiendes? Entonceh, yo entiendo como lo que tú estás hablando sobre imposición, pero eso va netamente de la mano de la educación, la educación es la que nos da la libertad de escoger, yo no te puedo dar una libertar de escoger si antes no te educo $\rightarrow$

H3: < [no sí| totalmente de acuerdo]

M2: porque estoy relativizando los niveles de vida.

H3: < [pero de todah manerah hay que tener la opción de elegir].

Se observa que M2 reconoce el punto de vista que está discutiendo con $\mathrm{H} 3$, parafrasea su postura y sintetiza su discurso usando la palabra "imposición". Esta estrategia funciona como un acto de reconocimiento a la propuesta discursiva de $\mathrm{H} 3 \mathrm{y}$, en definitiva, es un acto halagador ya que no solo demuestra que estaba atenta a lo que su compañero decía, si no que además es capaz de reconstruirlo y resumirlo temáticamente en una sola palabra. Frente a esta situación halagadora, H3 intenta ser gentil con ella y establece un acuerdo respondiéndole que está totalmente de acuerdo con su postura respecto a que la educación es crucial en el proceso de entrega de esta pastilla.

(Brown P. y Levinson S. , 1987): Apele al "terreno común".

- Intensifique el interés hacia $O$. 
H2: $<$ [sip]

(...)

M2: < [ahá]

(...)

M2: < [sí]

Estas respuestas permiten demostrar la aprobación hacia el interlocutor. Tienen una intención fática, es decir, su fuerza ilocutiva se dirige a mantener el contacto y demostrar así el interés.

\section{Apele a la pertenencia al mismo grupo que O. Use marcadores de identidad de grupo.} (Brown P. y Levinson S. , 1987)

M2: (...) por máh que me sienta en una situación muy heavy e: me cue htionaría mucho eso y creo que e h una cue htión que va de por vida, no sé si cargaría con esa cue h tión de por vida.

(...)

M3: Claro, es cómo tú veí el mundo o sea, no podí decirle a alguien sabíqué, yo opino esto pero tú haz lo que querai, no porque van a tomar ya o sea ¿qué opino yo sobre la vida?, ¿CUÁNDO empieza la vida? ¿cachái? Pa mi la vida empieza desde que se une óvulo y espermatozoide $\rightarrow$

El uso de léxico juvenil (heavy), voseo verbal (veí, podí, sabí, querai, cachái) léxico espontáneo (cuestión, cachar) intensifica la pertenencia al grupo y los identifica como miembros del mismo.

\section{Estrategias de atenuación cortés (Briz, 2001)}

Se aminoran cualidades, actitudes y acciones del yo (Briz, 2001):

O: y ustede ¿qué opinan?

M1: No sé yo el otro día estaba hablando + mi pololo me hizo una pregunta así como el típico: | tema: | que está en el momento + yo al menos le dije+ alguna ${ }^{h}$ persona ${ }^{h}$ ya piensan+o sea eso no está totalmente como definido, eso lo que yo tenía claro, no está totalmente definido si $e^{h}$ abortivo o no $e^{h}$ abortivo pero bueno alguno ${ }^{h}$ dicen que sí otro ${ }^{h}$ dicen que no

Al iniciar este episodio temático M1 inicia su turno indicando con este no sé, que no pretende enfrentarse tan directamente a una postura diferente a la de alguno de los 
participantes del debate. Disminuye su imagen, no intenta agrandarla ni pretende presentarse de forma superior frente a los demás, actúa de forma humilde.

\section{Se aminoran cualidades negativas del tú (Briz, 2001):}

Cuando hay un desacuerdo y se están afirmando cosas que a esta joven le parecen inexactas, se observa un uso reiterado de preguntas que permiten atenuar el ataque directo que desacreditaría al emisor de dichos enunciados, como en los siguientes ejemplos:

M2: ¿pero cree ${ }^{h}$ que, que es una posibilidad de elección entregar un método y no, que no vaya de la mano con la educación y la certeza?

(...)

M2: ¿las leyes son imposiciones?

(...)

M2: ¿una verdad?

(...)

En estos casos las preguntas atenúan el ataque pues se pudo haber usado una estrategia más directa y confrontacional. Por lo tanto, con esta estrategia, se aminoran las cualidades negativas del otro pues se evita enfrentar directamente los errores que se cree que tiene la argumentación del otro, mencionándolo explícitamente.

\section{Indicadores gramaticales de atenuación cortés:}

Se aminoran cualidades, actitudes y acciones del yo (Briz, 2001):

- Actitud lingüística mediante la cual se observa que se aminoran cualidades, actitudes y acciones del yo, la llamaremos "negación positiva del enunciado" (M1: No sé yo el otro día(...)). En este caso es usada para reducir posibles enfrentamientos al presentar su punto de vista de una forma insegura.

Se aminoran cualidades negativas del tú (Briz, 2001):

- Se realizan preguntas para mitigar en impacto del enfrentamiento de posturas diferentes con los otros participantes del debate.

Indicadores gramaticales de cortesía positiva y negativa (Kerbrat-Orecchioni/Brown P. y Levinson S. ) (Haverkate) 


\section{Indicadores gramaticales de cortesía positiva:}

- Paráfrasis de la propuesta del otro y síntesis de su propuesta discursiva.

- Uso de marcadores con intención fática para manifestar que se mantiene el contacto con el otro y la atención temática.

- Uso de léxico juvenil, voseo verbal, léxico espontáneo intensifica la pertenencia al grupo y los identifica como miembros del mismo.

\section{$\mathbf{N}^{\circ}$ de episodio: 3}

H1: personalmente creo que en el momento en que una persona comienza a tener relacione $^{\mathrm{h}}$ sexuale $^{\mathrm{h}}$, firma una especie de contrato, con uno mismo y con la otra persona donde uno asume una responsabilidad de que si, de esa relación va a nacer un hijo lo va a tener que, asumir, yo personalment- o sea PARA MI personalmente mi virginidad $\mathrm{e}^{\mathrm{h}}$ un tema súper importante yo:, PRETENDO llegar virgen al matrimonio, y: no me gustaría porque no-, o sea, porque no me gustaría|| estar en la situación de tener que pensar "le digo que se tome la pastilla o que no se la tome"| | ahora, si llegara esa situación yo creo que tomaría la decisión de que no se la tomara, porque yo no me gustaría, cargar con el cargo de concienc- cargar con la conciencia, en mi cabeza de que porque yo le dije "hah'lo", matamo" a un, a un $\rightarrow$

H2: < [.cachái pero ahí, ahí hay que definir si lo estai matando o evita te $\mid$ ahora, yo igual $\rightarrow]$

H1: $<$ [.posi:ble- $]$

M2: $<$.va por el hecho de que es una vida en potencia, no $\mathrm{e}^{\mathrm{h}}$ una simple vida $]$

$\mathrm{H} 1:<$.pero $\mathrm{e}^{\mathrm{h}}$ que para mí desde el momento en que se unan, ni siquiera- $]$

H2: $<$ [.sí po, pero a lo mejor, a lo mejor es-, pero por- no podí comparar la pastilla con el condón, ¿cachái?, porque el condón evita que: $10^{\mathrm{h}}$ espermio $^{\mathrm{h}}$ ingresen a la mujer.]

H1: pero $\mathrm{e}^{\mathrm{h}}$ que yo realmente no creo en los condo:ne $\mathrm{h}^{\mathrm{h}}$.

M2: $<$ [.pero $\mathrm{e}^{\mathrm{h}}$ que hay persona ${ }^{\mathrm{h}}$ que tienen la CONCEPCIÓN de que la relación sexual tiene como finalidad la procreación $\rightarrow$ ]

H2: $<$ [.pero hay- $]$

M2: y bajo ese punto de vista ya están estipulando sus límites de vida $\rightarrow$ 
H2: $<[. ¿$ cachái? $]$

M2: $<$ [.osea- $]$

H2: pero hay otro, otro punto de vista que es que la relación sexual, $\mathrm{e}^{\mathrm{h}}$ la expresión máxima del amor, que puede estar dentro o fuera del matrimonio $\rightarrow$

M2: claramente.

H2: entonce ${ }^{\mathrm{h}}$, claro, yo, puedo, por ejemplo, si yo amo mucho a: mi pareja, ya, y le quiero expresar mi amor y existe esa forma pero, yo sé que, por ejemplo, ahora, yo estoy pololeando y si yo, amo mucho a mi pareja y una opción, $\mathrm{e}^{\mathrm{h}}$ tener una relacione $\mathrm{e}^{\mathrm{h}}$ con ella, PERO yo no quiero que ella quede embarazada $\rightarrow$

M2: $<$ [.hay millone ${ }^{\mathrm{h}}$ de anticonceptivo $^{\mathrm{h}}$ que están a:- $]$

H2: porque ella va a entrar a la universida:d, ¿cachái? Entonce ${ }^{h} e^{h}$ bueno que exista la opción de un anticonceptivo, ahora $\mathrm{NO} \mathrm{E}^{\mathrm{H}}$ BUENO que exista la opción de matar a un, a un ser humano, ya sea, ser humano $\rightarrow$

M3: $<\left[. \mathrm{e}^{\mathrm{h}}\right.$ que $\left.\rightarrow\right]$

$\mathrm{H} 2$ : una celula.

M3: $e^{\mathrm{h}}$ que mira, más allá de eso, según mi per ${ }^{\mathrm{h}}$ pectiva, más allá de que sea una opción de vida de si $\mathrm{e}^{\mathrm{h}}$ abortiva si no $\mathrm{e}^{\mathrm{h}}$ abortiva etc. eso da lo mismo o sea- si uno tiene una concepción religiosa obviamente que va a ser abortiva porque yo soy católica y pa mi la: la: simple unión de un hombre con una mujer $\mathrm{e}^{\mathrm{h}}$ vida, simplemente, $\mathrm{y}$ da lo mismo, si va a haber guagüita no va a haber guagüita, etc, científicamente, se sabe que el espermio dura 78 horas, 78 horas en llegar al óvulo, con lo cual que la pastilla se tiene que tomar dentro de: si no sería abortiva ese es el argumento que dan los científicos pero para mí va mu:cho más allá de eso o sea | eh:, la pastilla anticonceptiva de cierta forma como que abre, una puerta hacia la promiscuidad, ahora si tú estás con tu pareja y tienes relaciones sexuales planifícate, tómate la pastilla anticonceptiva o ponte de acuerdo de otra manera ¿cachái? pero la pastilla del día después está ahí, entonces ahora va a llegar claro, se emborracha en una discotheque no sé qué, se acuesta con un gallo con cualquiera, y dice "ah la pastilla del día después".

H2: pero eso tiene muchas faceta $^{\mathrm{h}}$, porque $\mid$ mira $\mid$ pongámono $^{\mathrm{h}}$ en el caso, esa misma persona que podríamo ${ }^{\mathrm{h}}$ tildar de:, ¿irresponsable?, entonce ${ }^{\mathrm{h}}$ no se transforma por tener, ya por decir digamos que esa persona es irresponsable, se emborrachó, tuvo relacione ${ }^{\mathrm{h}}$, ¿no 
sería bueno que esa persona tuviera la facilidad de tener una pastilla? porque ¿le vai a dar a una persona así, la responsabilidad de criar un hijo? ¿Cachái? $\rightarrow$

$\mathrm{M} 2:<\left[\right.$.pero $\mathrm{e}^{\mathrm{h}}$ que $]>$

M3: $<[$. si pisaste el cordón, ASÚ:MELO $]>$

H2: existen pero $\mathrm{e}^{\mathrm{h}}$ que existen muchas faceta ${ }^{\mathrm{h}}$, pero si se puede evitar hasta cierto punto, además que, no podemo ${ }^{\mathrm{h}}$, no podemo ${ }^{\mathrm{h}} \rightarrow$

H3: no, yo no estoy de acuerdo en que la pastilla promueva la promiscuidad.

H2: no, yo tampoco estoy de acuerdo porque, con $\rightarrow \mathrm{pa}^{\mathrm{h}}$ tilla y sin pa tilla siempre ha habido promi ${ }^{\mathrm{h}}$ cuidad, hemo ${ }^{\mathrm{h}}$ estudiado que $10^{\mathrm{h}}$ griego $^{\mathrm{h}}$ hacían $\mathrm{la}^{\mathrm{h}}$ media $^{\mathrm{h}}$ orgía $^{\mathrm{h}}, \mathrm{y}$ teniendo, $\mathrm{NO}$ pero TENIENDO $\rightarrow$

M2: $<$ [.pero no vai a comparar de, la concepción de, tener hijo ${ }^{\mathrm{h}}$ en ese tiempo con ahora $]$

H2: no| pero, $\mathrm{e}^{\mathrm{h}}$ que igual ¿cachái? pero $\mathrm{e}^{\mathrm{h}}$ que mira la promi ${ }^{\mathrm{h}}$ cuidad va a existir o no, osi o no.

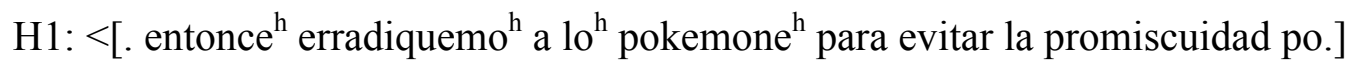

M2: $<\left[\right.$.pero $\mathrm{e}^{\mathrm{h}}$ que mira ¿sabí qué? $\left.\rightarrow\right]$

H2: no pero ahí te estai yendo-

M2: se está afirmando de: de hecho ${ }^{\mathrm{h}}$ muy básico ${ }^{\mathrm{h}}$, incluso la concepción AHORA, para una mujer, tener un hijo, significa limitar $\mathrm{tu}^{\mathrm{h}} \mathrm{tu}^{\mathrm{h}}$ expectativa $^{\mathrm{h}}$ de vida $\mathrm{la}^{\mathrm{h}}$ mujere $\mathrm{e}^{\mathrm{h}}$ ahora están, abarcando mucho ámbito laboral, tener un hijo te limita eso, entonce ${ }^{\mathrm{h}}$ es una concepción que socialmente ahora está tomando mayor importancia en cuanto al desarrollo vital de cada persona, sin embargo $\rightarrow$

$\mathrm{H} 2:<\left[\right.$.pero a mí me parece que eso $\mathrm{e}^{\mathrm{h}}$ algo muy bueno $]$

M2: ¿ah?

H2: me parece que $\mathrm{e}^{\mathrm{h}}$ algo muy bueno.

M2: ¿qué cosa?

H2: a mí me parece muy bueno que $1 \mathrm{a}^{\mathrm{h}}$ mujeres puedan hacer eso, ¿cachái?

M2: no: a mí también, lo encuentro excelente, pero:-

H2: y que exista una religión católica, me parece también muy bueno pero no puede como, $\mathrm{su}^{\mathrm{h}}$ creencias, ahí está lo que dice el Rorro, no las puedes imponer, es necesario ¿cachái? que exista $\rightarrow$

M2: pero yo estoy hablando desde un punto fuera de, de religión, fuera de pensamiento 
político estoy hablando de eso mismo.

H2: pero el problema es cuando intentan imponerlas porque-

M2: a mí no me están imponiendo ninguna religión al estar a favor o en contra.

H2: con el tema de la pastilla VAN A IMPONER.

M2: $<$.no tiene relación $]$

M2: YO, puedo hablar desde un punto completamente ateo al decir que mi, mi opinión es proteger la vida

H2:: si po.

M2: y no me refiero a ninguna religión, no te estoy imponiendo ninguna religión con eso.

H2: pero si eso es lo que estaban diciendo, o sea, Gonzalo.

H2:no, no, si eso fue, no $\mathrm{e}^{\mathrm{h}}$ que-

M2: bueno e:

M3: pero yo creo que este $\mathrm{e}^{\mathrm{h}}$ un tema nuevo porque la sociedad está cambiando ahora, o sea, no sé, nuestros papás no tenían estos atados porque antes, no sé, mi mama no pensaba tener relacio:ne $\mathrm{h}^{\mathrm{h}}$ antes de casarse con alguien, pero $\mathrm{e}^{\mathrm{h}}$ que es muy cierto, o sea ahora, ahora la ${ }^{\mathrm{h}}$ mujeres, o sea bueno, porque $1 \mathrm{o}^{\mathrm{h}}$ hombre $^{\mathrm{h}}$ siempre se han acostado con todo el mundo, \{risas\}como que nunca $1 \mathrm{e}^{\mathrm{h}}$ ha importado tanto la virginidad como a las mujeres porque las mujeres somos las que tenemos que cargar el problema, entonces $\rightarrow$

M2: $<$.y a la ${ }^{\mathrm{h}}$ que se $\left.1 \mathrm{e}^{\mathrm{h}} \mathrm{ju}^{\mathrm{h}} \mathrm{ga}\right]$

M3: ahora a las mujeres se les dan nuevas oportunidades, lo cual obviamente no está mal y obviamente si es que estoy en la universidad $\mathrm{e}^{\mathrm{h}}$ porque apoyo totalmente esas oportunidades e:, entonces las mujeres nos abrimos al campo de la sexualidad, al igual que el hombre, y yo creo que ahí está el punto o sea, en ese sentido como que hay mayor libertad, pero no se están tomando las, las e: las precauciones o sea, no, no junto con esta expansión de la sexualidad no se está: e: e: no se está: haciendo más e: como darle una educación como decía la Francisca, de decirle a los niños e: de determinada edad "chiquillos el condón, chiquillos existe el sida, chiquillos ya po te vai a embarazar, si empezai a tener relaciones tení que cuidarte", todavía hay muchas personas que quedan

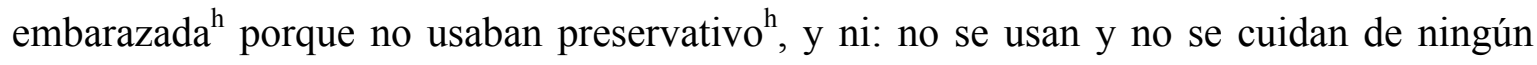
tipo o sea, no usaban ningún tipo de preservativo para cuidarse.

H2: $<$ [ahora, igual, si no-] 
M2: en todo caso el embarazo es lo mínimo que a una le puede ocurrir $\rightarrow$

H2: $<$ [sí, eso $]$

M2: $e^{\mathrm{h}}$ uno de $10^{\mathrm{h}}$ mínimos riesgo $^{\mathrm{h}}$ que se corre, procrear comparado con tomar alguna enfermedad máh heavy.

\section{Descripción del episodio número 3}

Elementos indispensables de la argumentación (Lo Cascio, 1998)

Tema del episodio: El inicio de las relaciones sexuales y los métodos de anticoncepción: la pastilla del día después.

Tesis: La pastilla del día después promueve la promiscuidad sexual.

Argumentos: La sexualidad debe ser tomada con responsabilidad, en pareja, asumiendo los riesgos que implica y tomando las precauciones para evitar un embarazo no deseado.

Regla General: El hecho de ser responsables con el inicio de la sexualidad, dejaría fuera la posibilidad de necesitar hacer uso de la pastilla del día después.

Elementos facultativos de la argumentación (Lo Cascio, 1998)

Refuerzo: Los jóvenes irresponsables que tienen relaciones bajos los efectos del alcohol y los que tienen después embarazos no deseados usarían este método más fácilmente y eso haría aumentar el libertinaje.

Calificador: Existen distintas formas de ver este tema porque quizás es mejor incluso que una chica que sea irresponsable en su vida tenga la alternativa de parar el proceso de un embarazo no deseado.

Refutación, contraopinión o reserva: Siempre ha habido promiscuidad en el mundo, esta pastilla no tiene por qué hacerla aumentar.

Fuentes: Anécdotas (tomadas de algún curso de su carrera) de la promiscuidad que ha habido en la historia del hombre.

Falacias argumentativas (Lo Cascio (1998))

Argumentum ad hominem: En este segmento el argumento se basa únicamente en el universo del protagonista específico sin considerar valores universales. 
H1: personalmente creo que en el momento en que una persona comienza a tener

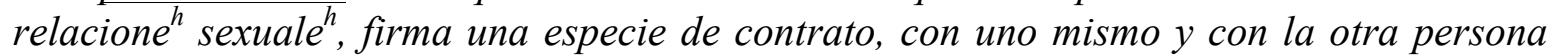
donde uno asume una responsabilidad de que si, de esa relación va a nacer un hijo lo va a tener que, asumir, yo personalment-o sea PARA MI personalmente mi virginidad $e^{h}$ un tema súper importante yo:, PRETENDO llegar virgen al matrimonio, y: no me gustaría porque no-, o sea, porque no me gustaría|| estar en la situación de tener que pensar "le digo que se tome la pastilla o que no se la tome"|| ahora, si llegara esa situación yo creo que tomaría la decisión de que no se la tomara, porque yo no me gustaría, cargar con el cargo de concienc- cargar con la conciencia, en mi cabeza de que porque yo le dije "hahlo", matamo a un, a un $\rightarrow$

Non sequitur: Extraer una conclusión que no se sigue.

H2: no, yo tampoco estoy de acuerdo porque, con $\rightarrow p a^{h}$ tilla y sin pa tilla siempre ha habido promi ${ }^{h}$ cuidad, hemo ${ }^{h}$ estudiado que $l^{h}$ griego $^{h}$ hacían $l^{h}$ media $^{h}$ orgía $^{h}, y$ teniendo, NO pero TENIENDO $\rightarrow$

(...)

H2: no| pero, $e^{h}$ que igual ¿cachái? pero $e^{h}$ que mira la promi ${ }^{h}$ cuidad va a existir o no, osi o no.

H1: < [. entonce $e^{h}$ erradiquemo ${ }^{h}$ a lo ${ }^{h}$ pokemone $^{h}$ para evitar la promiscuidad po.]

En este segmento se está discutiendo si la pastilla del día después promueve o no la promiscuidad, no quién es promiscuo en la sociedad chilena ni tampoco si hay que eliminarlos o segregarlos de nuestra sociedad.

\section{Estrategias de cortesía positiva}

(Brown P. y Levinson S. , 1987): Apele al “terreno común”. - Intensifique el interés hacia $O$.

Los enunciados de estos segmentos permiten demostrar la aprobación hacia el interlocutor. Estos conectores metadiscursivos (Briz, Hidalgo, 1998) tienen una fuerza ilocutiva que se dirige a mantener el contacto y demostrar así el interés.

M2: claramente.

(...)

H2: $<$ [sí, eso]

(...)

H2:: si po.

(...)

Apele a la pertenencia al mismo grupo que 0 . Use marcadores de identidad de grupo. (Brown P. y Levinson S. , 1987) 
M2: < [.pero no vai a comparar de, la concepción de, tener hijo ${ }^{h}$ en ese tiempo con ahora] H2: no| pero, e $e^{h}$ que igual ¿cachái? pero e $e^{h}$ que mira la promi $i^{h}$ cuidad va a existir o no, osi o no.

(...)

M2: $e^{h}$ uno de lo mínimos riesgo ${ }^{h}$ que se corre, procrear comparado con tomar alguna enfermedad máh heavy.

(...)

H2:: si po.

El uso de léxico juvenil (heavy), voseo verbal ${ }^{3}$ (vai, cachái) léxico espontáneo (po, cachar) intensifica la pertenencia al grupo y los identifica como miembros del mismo.

Apele al punto de vista, opiniones, actitudes, conocimiento, empatía comunes. - Busque el acuerdo. Evite el desacuerdo. Presuponga/ suscite/ manifieste el terreno común. Bromee.

En este segmento se manifiesta el acuerdo de dos interlocutores que están en contra de lo que se dice:

H3: no, yo no estoy de acuerdo en que la pastilla promueva la promiscuidad.

H2: no, yo tampoco estoy de acuerdo porque, con $\rightarrow p a^{h}$ tilla y sin pa tilla siempre ha habido promi ${ }^{h}$ cuidad, hemo ${ }^{h}$ estudiado que $l^{h}$ griego $^{h}$ hacían $l^{h}$ media $^{h}$ orgía $^{h}, y$ teniendo, NO pero TENIENDO $\rightarrow$

El siguiente fragmento muestra como el humor produce empatía y funciona como una estrategia cortés:

M3: (...) mi mama no pensaba tener relacio:ne $e^{h}$ antes de casarse con alguien, pero $e^{h}$ que es muy cierto, o sea ahora, ahora la ${ }^{h}$ mujeres, o sea bueno, porque lo hombre ${ }^{h}$ siempre se han a costado con todo el mundo, \{risas\} como que nunca le ha importado tanto la virginidad como a las mujeres porque las mujeres somos las que tenemos que cargar el problema

La broma que hace M3 causa un efecto positivo porque las risas de todos hacen que el ambiente se distienda.

\footnotetext{
${ }^{3}$ Se observó anteriormente que el uso del voseo verbal en el español hablado en Chile está restringido a situaciones informales. (cfr. pág. 42).
} 
Estrategias de atenuación cortés (Briz, 2001)

Se aminoran cualidades, actitudes y acciones del yo.

M3: pero yo creo que este $e^{h}$ un tema nuevo porque la sociedad está cambiando ahora, o sea, no sé, nuestros papás no tenían estos atados porque antes, no sé, mi mama no pensaba tener relacio:ne $e^{h}$ antes de casarse con alguien(...)

M3 está indicando al usar no sé que no pretende enfrentarse tan directamente a una postura diferente a la de alguno de los participantes del debate. Disminuye su imagen, no intenta agrandarla ni pretende presentarse de forma superior frente a los demás; actúa de forma humilde.

\section{Se aminoran cualidades negativas del tú.}

Por otra parte vemos que hay intentos corteses de buscar el acuerdo. Si bien M2 no está de acuerdo con la postura de su interlocutor inicia su enunciado afirmando que encuentra excelente lo que dice y que concuerda con lo que se propone. Inmediatamente inicia su contraargumentación con la conjunción adversativa:

M2: no: a mí también, lo encuentro excelente, pero:-

Indicadores gramaticales de atenuación cortés (Kerbrat-Orecchioni) (Haverkate)

Se aminoran cualidades, actitudes y acciones del yo (Briz, 2001):

Actitud lingüística mediante la cual se observa que se aminoran cualidades, actitudes y acciones del yo, la llamaremos "negación positiva del enunciado". En este caso es usada para reducir posibles enfrentamientos al presentar su punto de vista de una forma insegura.

Se aminoran cualidades negativas del tú (Briz, 2001):

Estrategia que consiste en reforzar, primero, lo positivo de la propuesta del otro para luego manifestar los puntos que se tienen en contra.

Indicadores gramaticales de cortesía positiva y negativa (Kerbrat-Orecchioni/Brown P. y Levinson S. ) (Haverkate)

Indicadores gramaticales de cortesía positiva: 
- Uso de marcadores con intención fática para manifestar que se mantiene el contacto con el otro y la atención temática.

- Uso de léxico juvenil, voseo verbal, léxico espontáneo intensifica la pertenencia al grupo y los identifica como miembros del mismo.

- Utilizar la broma para hacer más agradable la situación comunicativa.

\section{$\mathrm{N}^{\circ}$ de episodio: 4}

H1: yo estab- pensand- si se ponen a pensar en por qué nació la pastilla anticonceptiva $\mathrm{e}^{\mathbf{h}}$ un poco por eso, por qué $\mid$ en la, igual la sociedad no podemo ${ }^{\mathbf{h}}$, negar que ha cambiado mucho y la mujer tiene todas esas libertade ${ }^{\mathbf{h},}$ y ahora el ser humano, tanto hombre como mujer, se puede dar el gusto de tener relacione ${ }^{\mathrm{h}}$ por, tener relacione ${ }^{\mathrm{h}} \mid$ entonce ${ }^{\mathrm{h}}$ pero lo que no ha pasado $\mathrm{e}^{\mathbf{h}}$ que no han, logrado asumir, la responsabilidad que conlleva $\mathrm{e}^{\mathbf{h}}$ to porque, tener relacione $\mathrm{e}^{\mathrm{h}} \mathrm{e}^{\mathrm{h}}$ como jugar a la ruleta rusa por decirlo de alguna forma |sobre todo como $\mathrm{e}^{\mathbf{h}}$ tá hasta ahora con tanto mied-\{miedo $\}$, entonce ${ }^{\mathbf{h}}$ eh por eso que no ha sido too $1 \mathrm{o}^{\mathrm{h}}$ preservativo $^{\mathbf{h}}$ y la ${ }^{\mathbf{h}}$ pa $^{\mathbf{h}^{\mathbf{h}}}{ }^{1}{ }^{1} \mathrm{a}^{\mathbf{h}}$, el condón, to: eso.

M1: Sí pero también hay que pensar que por otro lado: | mira | yo soy de la concepción de que $\mathbf{a}^{\text {h }}$ palabra ${ }^{\text {h }}$ se las lleva el viento.

H1 : $<[$ sí $]$

M1: yo por eso digo: hay que $\mathrm{e}^{\mathbf{h}}$ tar en la situació:n y mucha ${ }^{\mathrm{h}} \mid$ me tocó vivirlo que iba a la iglesia| YO era una de las que dirigía | yo conocí a mucha ${ }^{\mathbf{h}}$ niña ${ }^{\mathbf{h}}$ he hablado con mucha ${ }^{\mathbf{h}}$ niña ${ }^{\mathbf{h}}$ hemos tocado su ${ }^{\mathbf{h}}$ experiencia sexuale ${ }^{\mathbf{h}}$ no teníamo ${ }^{\mathbf{h}}$ ningún problema con ese sentío| Mucha ${ }^{\mathbf{h}}$ de ella ${ }^{\mathbf{h}}$ "NO: pero cla:ro anticonceptivo ${ }^{\mathbf{h}}$ no: y no se qué: pastilla del día despué ${ }^{\text {h }}$ y bla bla bla"| LLEGÓ el momento y la ${ }^{\text {h }}$ ocuparon iguall y aunque $e^{\text {h }}$ tuvieran, eran eran muchísimo ${ }^{\text {h }}$ o sea muy cristiana ${ }^{\text {h }}$ no tengo nada que decir de su forma de su forma de vivir la religiosidad o de $\mathrm{su}^{\mathrm{h}}$ de $^{\mathrm{h}} \mathrm{h}^{\mathrm{h}}$ misma $^{\mathrm{h}}$ creencia $^{\mathrm{h}} \mid$ pero en el momento en verse entre, pucha ocupar una pastilla que al final no se sabe si aquí y allá, a: estar embarazada y vivirlo, y que eso va a SER $\mid$ ¿cachái? eligieron lo otro yo por eso en ningún momento la ${ }^{\mathrm{h}}$ juzgué como meno ${ }^{\mathrm{h}}$ cristiana $^{\mathrm{h}}$ menos no se qué $|\mathrm{NO}|$ pero en ese, POR QUÉ porque igual 
está lo que ustede ${ }^{\mathrm{h}}$ dicen o podría haber promiscuida:d que no se cuidan y no sé qué, pero por otro lado hay que verlo en un sentid- I me pasó con una que:, que: estaba usando condón y el condón se rompió | y yo por lo mismo no la juzgué ¿cachái? porque en: en: en el buen sentido igual estaba: estaba tomando una precaución ¿cachái? pero se ROMPIÓ o sea qué podía decirlo YO, o sea me ella decía que hago si e $\mathrm{e}^{\mathbf{h}}$ que voy a quedar embarazá- y yo ¿ ¿cachái? | pero porque ella también estaba en contra de la pastilla y no se qué pero en el momento cambia ¿cachái?

M2: pero ¿sabí ${ }^{\mathbf{h}}$ cúal eh el problema? $\rightarrow$ \{risas\}

M2: ¿sabí ${ }^{\mathbf{h}}$ cuál eh el problema? te teni ${ }^{\mathbf{h}}$ que preguntar si $\mathrm{e}^{\mathbf{h}}$ que esa ${ }^{\mathbf{h}}$ niñita ${ }^{\mathbf{h}}$ cuando fueron a comprar a la farmacia, se preguntaron-

M3: $<\left[\mathrm{e}^{\mathbf{h}_{\text {toy }}} \mathbf{d i}^{\mathbf{h}}\right.$ pue $\left.\mathrm{h}_{\text {ta }} \mathrm{a}-\right]>$

M2: NO, no solo eso ma ${ }^{\mathbf{h}}$ allá |de qué produce además| de no quedar embarazada la pa ${ }^{\mathbf{h}}$ tilla | es una bomba, hormonal ENORME: | Si una niñita NO CONOCE SU: interior, si no va al médico y sabe cómo su organismo re ${ }^{\mathbf{h}}$ ponde, puede quedar $\mathrm{e}^{\mathbf{h}}$ teril | con esa sola pa tilla puede darle cáncer al útero $\rightarrow$

M3 < [ahá]

$\mathrm{H} 1<[\mathrm{mmm}]$

M2: puede: un montón de $\operatorname{cosa}^{\mathbf{h}}$ | puede quedar MÁS ENCIMA embarazada porque todavía no se asegura| ¿cachái? $\rightarrow$

$\mathrm{H} 1<$ [no po-, si no existe na:, cien por ciento: $]>$

M2: todavía no se asegura si es que la pa tilla es cie:n por ciento no quedar embarazá-

M1: $<$ [pero lo que $\mathrm{e}^{\mathbf{h}}$ tá cien por ciento seguro $\mathrm{e}^{\mathbf{h}}$ que-]

$\mathrm{H} 1<[$ sí hay una forma- $]>$

$\mathrm{M} 2<$ [ese e $\mathrm{e}^{\mathbf{h}}$ el problema- $]$

h el momento: TODA percepción va a cambiar | toda percepción va a cambiar-]

M3: $<$ [Es que no $\mathrm{e}^{\mathbf{h}}$ toy de acuerdo con eso, insisto $\rightarrow$ ]

M1: $<$ [sí:- $]$

M3: porque yo creo $\mathrm{la}^{\mathbf{h}} \operatorname{lo}^{\mathbf{h}} \operatorname{sere}^{\mathbf{h}}$ humano tenemo ${ }^{\mathbf{h}}$ la capacidad de regirno ${ }^{\mathbf{h}}$ por, por el pensamiento y en base a eso forjamo ${ }^{\mathbf{h}}$ valore $^{\mathbf{h}}$ entre $\mathrm{lo}^{\mathbf{h}}$ cuale $^{\mathbf{h}}$ e: | cavamos nuestra vida ¿me entendi $i^{\mathrm{h}}$ ? 
H2: pero tú teni ${ }^{\mathbf{h}}$ experiencia en que te van haciendo influir en ti mismo y tú podi ${ }^{\mathbf{h}}$ cambiar esa $^{\text {h }} \operatorname{cosa}^{\text {h- }} \rightarrow$

M3: $<$ [por supuesto que podi ${ }^{\text {h }}$ cambiar pero eso no significa $\left.\rightarrow\right]$

H1: $<$ [ahora- $]$

M1: $<$ [obvio que podi ${ }^{\text {h }}$ cambiar $]>$

H2: < [imagínate cuand- $]$

M3: pero eso no significa que toda la que toda la influencia que pueda tener TÚ opción de vivir la vida se borre al momento que estai al frente de una situación.

H2: Sí | sí| sí.

M3: $<$ [Yo creo que no- $]$

$\mathrm{H} 1:<\left[\mathrm{Yo}_{\mathrm{O}}\right]>$

M1: $<$ Sí: yo e $\mathrm{e}^{\mathbf{h}}$ toy de acuerdo $\mid$ obvio $]>$

M3: $<$ [Por algo mi familia- $]>$

M4: $<$ [Depende de las convicciones $]$

M3: $<$ [Sí:-, o sea- ]

H3: $<$ [pero-]

H2: $<$ [ $\mathrm{e}^{\mathbf{h}}$ mucho ma ${ }^{\mathbf{h}}$ fuerte lo que te $\mathrm{e}^{\mathbf{h}}$ tá pasando imagínate te quedai embarazada uno tiene que $\mathrm{e}^{\mathbf{h}}$ tar en el lugar del otro-]

M3: $<$ [ $\mathrm{e}^{\mathbf{h}}$ que yo creo que eso $\rightarrow$ eso es el producto de de lo que se $\mathrm{e}^{\mathbf{h}}$ tá fomentando- $]$

M2: < [APERRA | APERRA]

H2: $<$ [no me vengai a mi a- $]$

M2: TRES PRIMAS $\rightarrow$, TRES PRIMAS que quedaron embarazá a los dieciocho año ${ }^{\mathbf{h}}$ y querían abortar $\mid$ y nosotra ${ }^{\mathbf{h}} \operatorname{toda}^{\mathbf{h}}$ la $^{\mathbf{h}}$ primah le dijimo "aperra, aperra" y ahora son la persona $^{\mathbf{h}}$ más felice ${ }^{\mathbf{h}}$ del planeta con esa ${ }^{\mathbf{h}}$ guagua $^{\mathbf{h}}$.

H2: no si e $\mathrm{e}^{\mathbf{h}}$ tá bien | no me digai a mí, pero la cosa $\mathrm{e}^{\mathbf{h}}$ que son ella ¿cachái?

M2: $<$ [tiene que haber una-]

M3: $<$ [mira te voy a dar un ejemplo, súper mínimo- $]$

$\mathrm{H} 2<$ [bien | pero a la hora que te pase independiente de lo que haya ${ }^{\mathbf{h}}$ pensado ANTES-]

M4: $<$ YYa pero eh que no te pasa como "OH ME PASÓ”, no po ¿cachái?]

M3<["ME PASÓ":]

\{risas 
$\mathrm{H} 2:<[$ Si te PASA eh porque- $]$

M2: En el momento, $\rightarrow$

H1: $<\left[\right.$ Tení $^{\mathbf{h}}$ que cachar- $]$

$\mathrm{M} 2:<[$ claro $\rightarrow]$

H2: $<$ [Si po: obvio]

M4: En el momento en que te vai a acostar con alguien teni ${ }^{\mathbf{h}}$ que decidir | si la cuestión| "pucha si quedo embarazada | voy a aperrar | si no quedo embarazada | bacán" | no puede ser como "OH se rompió el condón ah chuta compro una la pa ${ }^{\mathbf{h}}$ tilla ${ }^{\mathbf{h}-"}$

M3: $<[$ ahora $\rightarrow]$

M4: "OH no tengo preservativo ya hagámo ${ }^{\mathbf{h}}$ lo igual”.

M3: ahora $\mid$ a $10^{\mathbf{h}}$ dieciocho diecinueve veinte año ${ }^{\mathbf{h}}$ que ya teni ${ }^{\mathbf{h}}$, seguí ${ }^{\mathbf{h}}$ pensando que: que "OH" | que lo hice y que "oh y que no tengo ninguna base para hacer lo que sea"-

H2: $<$ [YO no e ${ }^{\mathbf{h}}$ toy diciendo eso $]$

\section{Descripción del episodio número 4}

Elementos indispensables de la argumentación (Lo Cascio, 1998)

Tema del episodio: La responsabilidad que involucra el inicio de las relaciones sexuales y la decisión de tomar la pastilla del día después.

Tesis: La juventud no saca nada con asumir una responsabilidad porque en el momento en que les ocurra algo tomarán cualquier decisión, la más fácil.

Argumentos: Las palabras se las lleva el viento, niñas católicas de iglesia, al momento de estar en esta situación no dudan en tomar la pastilla.

Regla General: En el momento en que ocurre una situación difícil como por ejemplo un embarazo no deseado es necesario tomar una decisión.

Elementos facultativos de la argumentación (Lo Cascio, 1998)

Refuerzo: las percepciones de la gente cambian al pasar por algo así.

Calificador: probablemente a los 20,19 años ya no se puede seguir pensando cómo actuar en el momento en que pasa un hecho inesperado, debe ser un acto de reflexión previo. 
Refutación, contraopinión o reserva: uno no cambia de manera de pensar solo y exclusivamente cuando se ve en una situación difícil porque el ser humano se rige por el pensamiento.

Falacias argumentativas (Lo Cascio (1998))

Argumentum ad hominem: El argumento se basa únicamente en el universo del protagonista específico sin considerar valores universales.

M2: TRES PRIMAS $\rightarrow$, TRES PRIMAS que quedaron embarazá a los dieciocho año ${ }^{\boldsymbol{h}} \mid \boldsymbol{y}$ querían abortar | $y$ nosotra ${ }^{h}$ toda ${ }^{h}$ la $^{h}$ primah le dijimo "aperra, aperra" y ahora son la ${ }^{h}$ persona $^{h}$ más felice $^{h}$ del planeta con esa ${ }^{h}$ guagua $^{h}$.

Argumentum ad ignorantiam: Se apela a la ignorancia del oponente para probar el punto de vista contrario, a partir de información incompleta.

M2: puede: un montón de cosa ${ }^{h} \mid$ puede quedar MÁS ENCIMA embarazada porque todavía no se asegura| ¿cachái? $\rightarrow$

$H 1<$ [no po-, si no existe na: cien por ciento:]>

M2: todavía no se asegura si es que la pa tilla es cie:n por ciento no quedar embarazá-

Ignoratio elenchi: Se argumenta a partir de información dada por el oponente; no se pone en discusión la tesis a defender. M2 no se centra en la tesis que se está discutiendo en este episodio, se queda con una información que se da en el proceso argumentativo.

M2: ¿sabi ${ }^{h}$ cuál eh el problema? te teni ${ }^{h}$ que preguntar si $e^{h}$ que esa ${ }^{h}$ niñita ${ }^{h}$ cuando fueron a comprar a la farmacia, se preguntaron-

M3: < [e toy di pue ta a- $]>$

M2: NO, no solo eso $\mathrm{ma}^{h}$ allá |de qué produce además| de no quedar embarazada la pa tilla | es una bomba, hormonal ENORME: | Si una niñita NO CONOCE SU: interior, si no va al médico y sabe cómo su organismo re ${ }^{h}$ ponde, puede quedar $e^{h}$ teril | con esa sola $\mathrm{pa}^{\mathrm{h}}$ tilla puede darle cáncer al útero $\rightarrow$

\section{Estrategias de cortesía positiva}

(Brown P. y Levinson S. , 1987): Apele al “terreno común”. - Intensifique el interés hacia $O$. 
Los enunciados de estos segmentos permiten demostrar la aprobación hacia el interlocutor.

Su fuerza ilocutiva se dirige a mantener el contacto y demostrar así el interés y el acuerdo.

H1 : < [sí]

(...)

$M 3<$ [ahá]

(...)

M1: < [Sí: yo e toy de acuerdo | obvio] >

(...)

H2: <[Si po: obvio]

Apele a la pertenencia al mismo grupo que 0 . Use marcadores de identidad de grupo.

El uso de léxico juvenil (bacán), voseo verbal ${ }^{4}$ (vai, teni) léxico espontáneo (cuestión, pucha, aperrar, chuta) da cuenta de que se encuentran en una situación distendida lo que intensifica la pertenencia al grupo y los identifica como miembros del mismo.

M4: En el momento en que te vai a acostar con alguien tení que decidir | si la cuestión| "pucha si quedo embarazada | voy a aperrar | si no quedo embarazada| bacán" | no puede ser como "OH se rompió el condón ah chuta compro una la pa ${ }^{h}$ tilla ${ }^{h-"}$

Apele al punto de vista, opiniones, actitudes, conocimiento, empatía comunes. - Busque el acuerdo. Evite el desacuerdo. Presuponga/ suscite/ manifieste el terreno común. Bromee.

En este segmento se muestra la forma en que los participantes del debate participan y demuestran interés presuponiendo lo que va a decir el otro, ayudándolo a terminar las frases de los enunciados.

M2: ¿sabi ${ }^{h}$ cuál eh el problema? te teni ${ }^{h}$ que preguntar si $e^{h}$ que esa ${ }^{h}$ niñita ${ }^{h}$ cuando fueron a comprar a la farmacia, se preguntaron-

M3: $<\left[e^{h}\right.$ toy di $\boldsymbol{i}^{\boldsymbol{h}}$ pue $\mathrm{h}_{\mathrm{h}}$ a- $]>$

M2: NO, no solo eso $\mathrm{ma}^{h}$ allá |de qué produce además| de no quedar embarazada la pa tilla | es una bomba, hormonal ENORME: | Si una niñita NO CONOCE SU: interior, si no va al médico y sabe cómo su organismo re ${ }^{h}$ ponde, puede quedar $e^{h}$ teril | con esa sola pa ${ }^{h}$ tilla puede darle cáncer al útero $\rightarrow$

Estrategias de atenuación cortés (Briz, 2001)

\footnotetext{
${ }^{4}$ Se observó anteriormente que el uso del voseo verbal en el español hablado en Chile está restringido a situaciones informales. (cfr. pág. 42).
} 
Se aminoran cualidades negativas del tú. El siguiente fragmento muestra como las risas producen empatía y funcionan como una estrategia cortés para hacer disminuir el ataque :

M4: < [Ya pero eh que no te pasa como "OH ME PASÓ”:, no po ¿cachái?]

$M 3<[" M E P A S O ́ ":]$

$\{$ risas\}

$H 2:<$ Si te PASA eh porque-]

M2: En el momento, $\rightarrow$

H1: $<$ [Teni $^{\boldsymbol{h}}$ que cachar-]

M2: $<[$ claro $\rightarrow]$

H2: < [Si po: obvio]

Por otra parte, vemos que hay intentos corteses de atenuar el desacuerdo. Si bien M2 no está de acuerdo con la postura de su interlocutor inicia su enunciado afirmando que está de acuerdo con una parte de lo que está diciendo, afirma que concuerda con lo que se propone; no obstante, inmediatamente inicia su contraargumentación con la conjunción adversativa:

M3: $<$ [por supuesto que podi ${ }^{\text {h }}$ cambiar pero eso no significa $\rightarrow$ ]

H1: $<$ [ahora-]

M1: $<$ [obvio que podi ${ }^{\text {h }}$ cambiar $]>$

H2: < [imagínate cuand-]

M3: pero eso no significa que toda la que toda la influencia que pueda tener TÚ opción de vivir la vida se borre al momento que estai al frente de una situación.

Indicadores gramaticales de atenuación cortés (Kerbrat-Orecchioni) (Haverkate) Se aminoran cualidades negativas del tú (Briz, 2001):

Estrategia que consiste en usar la afirmación, reforzar, primero, lo positivo de la propuesta del otro para luego manifestar los puntos que se tienen en contra (“Sí, pero...”).

Mediante la risa se mitiga el ataque que se esté produciendo contra la imagen de un interlocutor.

Indicadores gramaticales de cortesía positiva y negativa (Kerbrat-Orecchioni/Brown P. y Levinson S. ) (Haverkate)

\section{Indicadores gramaticales de cortesía positiva:}

- Uso de marcadores con intención fática para manifestar que se mantiene el contacto con el otro y la atención temática.

- Uso de léxico juvenil, voseo verbal, léxico espontáneo intensifica la pertenencia al grupo y los identifica como miembros del mismo. 
- Cooperar, interrumpiendo al que habla para ofrecerle léxico pertinente que pueda usar el interlocutor en su discurso; ayudándolo así a terminar su enunciado.

\section{$N^{\circ}$ de episodio: 5}

$\mathrm{H} 1: \mathrm{ya} \rightarrow$ encuentro que $\mathrm{e}^{\mathbf{h}}$ tamo ${ }^{\mathbf{h}}$ pasando por alto un punto súper importante $\rightarrow \mid \mathrm{e}^{\mathbf{h}}$ que no ${ }^{\mathbf{h}} \mathrm{e}^{\mathbf{h}}$ tamo $^{\mathbf{h}}$ centrando en que la pa ${ }^{\mathbf{h}}$ tilla ant- del día de ${ }^{\mathbf{h}}$ pué ${ }^{\mathbf{h}}$ la usaran como solo lo ${ }^{\mathbf{h}}$ jóvene $^{\mathbf{h}}$ ante $^{\mathbf{h}}$ del matrimonio, pero también pasa que existen pareja ${ }^{\mathbf{h}} \mid$ que se dan cuenta de que no $e^{\mathbf{h}}$ llegar, pareja de matrimonio casado ${ }^{\mathbf{h}}$, que no $\mathrm{e}^{\mathbf{h}}$ llegar y tener cinco, seis hijo h ¿cachái? porque: no sé: po, yo me pongo en el caso, una persona, una pareja que vive en la població:n que el papá con esfu:erzo se, gana el sueldo mínimo y la mitad de eso se lo $\mathrm{ga}^{\mathbf{h}}$ ta en alcohol $\rightarrow$

H2: $<$ [si no tení- no botí la plata de todos los meses]

H1: TENE:R cinco seis hijos no $\mathrm{e}^{\mathbf{h}}$ ningún chi $^{\mathbf{h}}$ te tener, tener que gastar en eso ¿cachái? $\rightarrow$ $\mathrm{M} 1<$ [pero-]

$\mathrm{H} 1:<$ entonce $^{\mathbf{h}}$ esperénme , pero déjenme terminar la idea, déjenme terminar el punto-]

H3 : <[¿qué cosa?]

H2: que no po, como lo ${ }^{\mathbf{h}}$ del opu ${ }^{\mathbf{h}}$ dei hacen eso po.

H1: ya:, entonce ${ }^{\mathbf{h}}$ a mí me parece que, la $\rightarrow$

M2 : <[¿qué cosa?, ¿qué cosa?]

H3: tai lleno de prejuicio-

$\mathrm{H} 2:<$ yo tengo familia opus dei, yo tengo familia opus dei] $>$

M1 : $<$ [pero mira te $\mathrm{e}^{\mathbf{h}}$ ta basando en un prejuicio y lo $\mathrm{e}^{\mathbf{h}}$ tay atacando así-]

H1: ya pero déjenme terminar, entonce ${ }^{\mathbf{h}} \mathrm{e}^{\mathbf{h}}$ tamo $^{\mathbf{h}}$ como pensando solamente que la pa ${ }^{\mathbf{h}}$ tilla $\mathrm{e}^{\mathbf{h}}$ como "EL" recurso que tienen la $\mathrm{h}^{\mathbf{h},}$ pareja ${ }^{\mathbf{h}}$ que tienen relacione ${ }^{\mathbf{h}}$ antes y también e ${ }^{\mathbf{h}}$ una herramienta que usan la $^{\mathbf{h}}$ pareja ${ }^{\mathbf{h}}$ de casado ${ }^{\mathbf{h}}$ súper útil, porque no $\mathrm{e}^{\mathbf{h}}$ llegar y tener un hijo si igual $\mathrm{e}^{\mathbf{h}}$ una cosa que de repente $\mathrm{e}^{\mathbf{h}}$ mejor planificarla $\rightarrow$

M1: $<$ [ya: ¿cuántos métodos antionceptivo ${ }^{\mathbf{h}}$ tenemo $^{\mathbf{h}}$ ?]

$\mathrm{H} 2:<[$ existen hartos sí $]>$ 
M2. $<\left[\mathrm{e}^{\mathrm{h}}\right.$ tá el método natural | primero que nada, y que sale MUCHO MÁS BARATO comprarte un condón, que comprarte una de esa ${ }^{\mathbf{h}} \mathrm{pa}^{\mathbf{h}}$ tilla ${ }^{\mathbf{h},}$ ¿ cachái?

M1: para la ${ }^{\mathbf{h}}$ mujere $^{\mathbf{h}}$, pa ${ }^{\mathbf{h}}$ tilla $^{\mathbf{h}}$ anticonceptiva $^{\mathbf{h}}$, inyeccione ${ }^{\mathbf{h}}$, parche $^{\mathbf{h}}$ hormonale $^{\mathbf{h}}$, e:

H1: $<$ [si po sí sé que:, pero:, yo no:-]

M2: $<[$ no espérate $]>$

M1: para el HOMBRE teni ${ }^{\mathbf{h}}$ la ¿cómo se llama ese que le hacen el-?

H1: a lo que yo voy e e $^{\mathbf{h}}$ que: $\rightarrow$

$\mathrm{M} 2:<$ que te toman la temperatura-, todos los días] $>$

H1: pero a lo que yo voy $\mathrm{e}^{\mathbf{h}}$ que no solamente la $\mathrm{pa}^{\mathbf{h}}$ tilla es algo que se que usen lo $^{\mathbf{h}}$ jóvene ${ }^{\mathbf{h}}$ para: $\rightarrow$

M1: < [ya mira YO: ]>

$\mathrm{H} 1: \rightarrow$ también $\mathrm{e}^{\mathbf{h}}$ una herramienta que ocupan la ${ }^{\mathbf{h}}$ pareja $^{\mathbf{h}}$.

M1: para re ${ }^{\mathbf{h}}$ ponder lo que dice el Gonzalo, yo creo que | esa clase de argumento ${ }^{\mathbf{h}}$ son lo ${ }^{\mathbf{h}}$ que llevan a la, insisto, relativización, de los valores | en qué sentido, yo te puedo poner un caso MÁS drástico y contestarte |¿qué pasa con el tema de la: violación? | una niña que e violada y solo ve la: pa ${ }^{\mathbf{h}}$ tilla del día de $^{\mathbf{h}}$ pué $^{\mathbf{h}}$ como SU opción de: e: no quedar embarazada de un violador, ni siquiera e: | algo que yo hice porque quedé ebria o porque quise $\mid \mathrm{e}^{\mathbf{h}}$ una situación mucho má ${ }^{\mathbf{h}}$ extrema $\rightarrow$

H1: ya.

M1: cuando, una persona $\|$ no transa $\mathrm{su}^{\mathbf{h}}$ valore $^{\mathbf{h}}$ esenciale $^{\mathbf{h}}$ en MI caso la protección a la vida $\mid$ ni siquiera en $\mathrm{e}^{\mathbf{h}}$ te caso apoya esa clase de herramienta, por qué, porque limitar una vida en potencia $\mathrm{e}^{\mathbf{h}}$ capa de MI círculo vital, $\mathrm{e}^{\mathbf{h}}$ capa de lo que yo tengo derecho sobre MI cuerpo y lo $\mathrm{e}^{\mathbf{h}}$ toy diciendo como mujer | porque la mayoría de $1 \mathrm{o}^{\mathbf{h}}$ hombre $^{\mathbf{h}}$ o mujere ${ }^{\mathbf{h}}$ e: dicen "la mujer tiene derecho a hacer lo que quiera con su cuerpo" perfecto | con MI vida pero $\rightarrow$

H1: $<$ [sí ,yo también opino que eso e ${ }^{\mathbf{h}}$ capa de su:- $]>$

M1: de ${ }^{\mathbf{h}}$ de el momento en que limito | acabo, pongo fin | a una vida en potencia, no me $\mathrm{e}^{\mathbf{h}}$ toy metiendo en mi territorio.

H3: te e h tái metiendo en territorio de al lado

H1: pero sí, pero yo igual | por qué se asume | que la pa ${ }^{\mathbf{h}}$ tilla anti- e: la pa ${ }^{\mathbf{h}}$ tilla del día de 


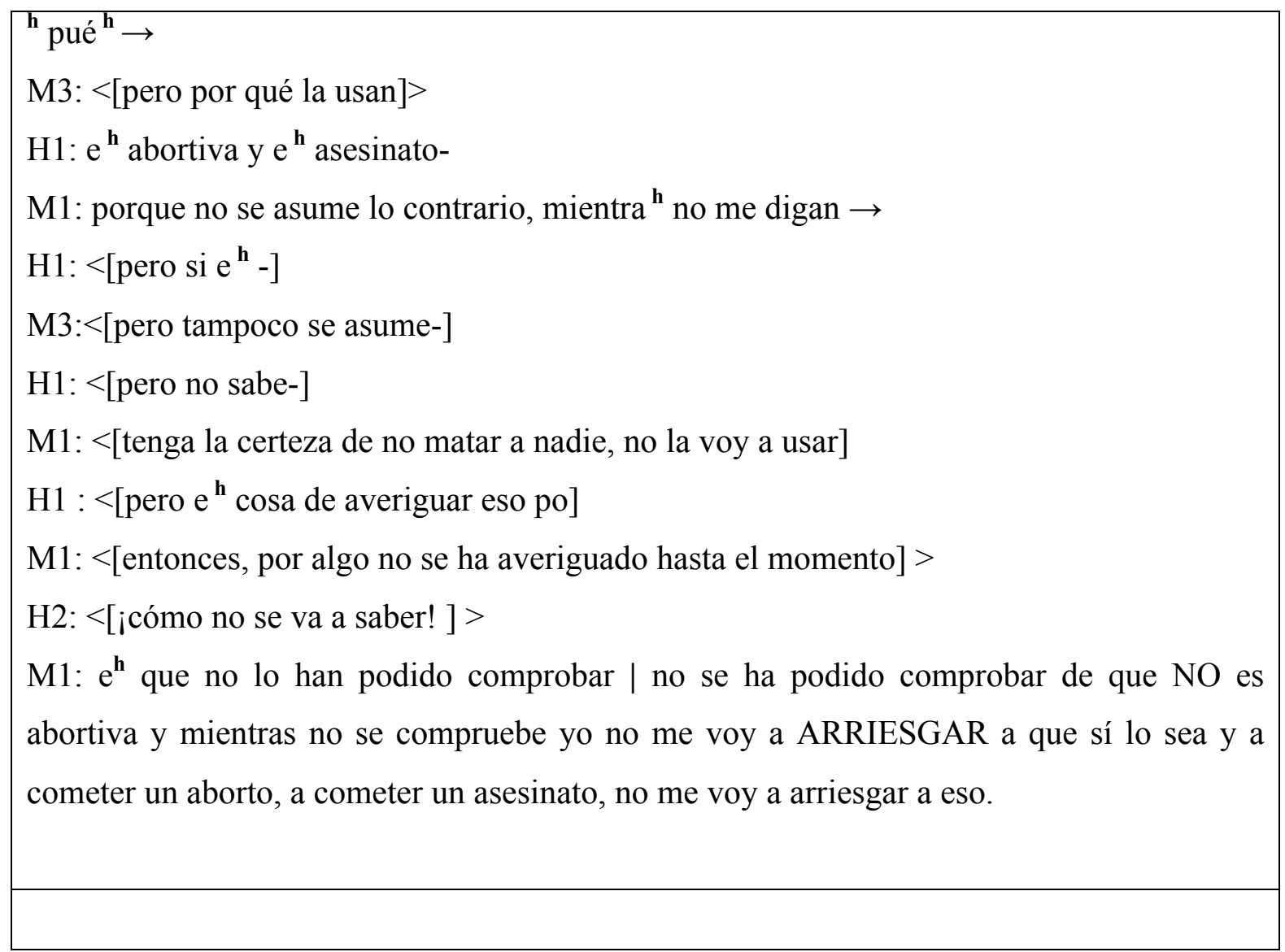

\section{Descripción del episodio número 5}

Elementos indispensables de la argumentación (Lo Cascio, 1998)

\section{Tema: Los destinatarios de la pastilla del día después.}

Tesis: Hay situaciones disitintas a las relaciones fuera del matrimonio en las que la pastilla sería útil: dentro del propio matrimonio y también en los casos de violación.

Argumentos: Así evitarían tener que pasar por una situación económica aún más difícil.

Regla General: son muchos los gastos que involucra la paternidad.

Elementos facultativos de la argumentación (Lo Cascio, 1998)

Refutación, contraopinión o reserva: Sería mejor usar otros métodos previos, preservativos, más económicos. Independientemente de la situación, la protección de la vida es lo más importante.

Falacias argumentativas (Lo Cascio (1998)) 
Argumentum ad personam: Se ejerce una presión sobre la persona, poniendo en discusión la credibilidad de quien se presenta como adversario. En este segmento se pone en duda lo que afirma M1, mediante un ataque, no se reflexiona sobre el argumento que este da. Se comentará más adelante que este tipo de falso argumento también corresponde a una falacia del tipo Argumentum ad ignorantiam pues ciertamente que es una ataque a la otra persona pero mediante una acusación de ignorancia :

M1: < [entonces, por algo no se ha averiguado hasta el momento] > H2: < [icómo no se va a saber!] >

M1: $e^{h}$ que no lo han podido comprobar | no se ha podido comprobar de que NO es abortiva y mientras no se compruebe yo no me voy a ARRIESGAR a que sí lo sea y a cometer un aborto, a cometer un asesinato, no me voy a arriesgar a eso.

Argumentum ad ignorantiam: Se apela a la ignorancia del oponente para probar el punto de vista contrario, a partir de información incompleta. Si bien de cierta forma ambos están utilizando este falso argumento $(\mathrm{M} 1 \mathrm{y} \mathrm{H} 2)$, pues ambos apelan a la ignorancia del oponente, M1 justifica que precisamente debido a que no se puede comprobar lo contrario a su postura no aceptará los otros argumentos como válidos.

M1: < [entonces, por algo no se ha averiguado hasta el momento] $>$ H2: < [icómo no se va a saber!] >

M1: $e^{h}$ que no lo han podido comprobar | no se ha podido comprobar de que NO es abortiva y mientras no se compruebe yo no me voy a ARRIESGAR a que sí lo sea y a cometer un aborto, a cometer un asesinato, no me voy a arriesgar a eso.

\section{Estrategias de cortesía positiva}

(Brown P. y Levinson S. , 1987): Apele al “terreno común”. - Intensifique el interés hacia $O$.

- Exagere (interés, aprobación, simpatía con O)

- Fíjese, atienda a $O$ (a sus intereses, deseos, necesidades, bienes).

Los enunciados de estos segmentos permiten demostrar la aprobación hacia el interlocutor. Estos enunciados intentan mantener el contacto y demostrar así el interés y el acuerdo.

M1: para re ${ }^{h}$ ponder lo que dice el Gonzalo, yo creo (...)

(...) 
H1: < [sí, yo también opino que eso $e^{\boldsymbol{h}}$ capa de su:- $]>$

También se observan conectores pragmáticos metadiscursivos corteses:

H1: ya.

(...)

H1: ya:

Apele a la pertenencia al mismo grupo que 0 . Use marcadores de identidad de grupo.

El uso de léxico juvenil (bacán), voseo verbal ${ }^{5}$ (tení, botí) léxico espontáneo (el Gonzalo ${ }^{6}$ cachar) da cuenta de que se encuentran en una situación distendida lo que intensifica la pertenencia al grupo y los identifica como miembros del mismo.

H2: < [si no teni- no boti la plata de todos los meses]

H1: TENE:R cinco seis hijos no $e^{h}$ ningún chi te tener, tener que gastar en eso ¿cachái? $\rightarrow$ (...)

M1: para re $e^{h}$ ponder lo que dice el Gonzalo (...)

Apele al punto de vista, opiniones, actitudes, conocimiento, empatía comunes. - Busque el acuerdo. Evite el desacuerdo. Presuponga/ suscite/ manifieste el terreno común. Bromee.

En este enunciado se aprecia que el interlocutor quiere hacer partícipe a todos los integrantes del debate. Hace una pregunta general, mediante la cual cede su turno y lo deja libre para que todos participen. Mediante esta estrategia de cortesía se intenta manifestar el terreno común de todos los participantes, terreno en que todos pueden participar y opinar.

M1: < [ya: ¿cuántos métodos antionceptivo ${ }^{h}$ tenemo $^{h}$ ?]

Indicadores gramaticales de cortesía positiva y negativa (Kerbrat-Orecchioni/Brown P. y Levinson S. ) (Haverkate)

Indicadores gramaticales de cortesía positiva:

\footnotetext{
${ }^{5}$ Se observó anteriormente que el uso del voseo verbal en el español hablado en Chile está restringido a situaciones informales. (cfr. pág. 42)

${ }^{6}$ Usar el artículo ante nombre propio es un fenómeno gramatical frecuentemente usado en el español espontáneo y coloquial de Chile. Es usado también por los hablantes perteneciente a la norma culta, siguiendo la clasificación hecha por Rabanales (1992).
} 
- Uso de conectores pragmáticos metadiscursivos que expresan cortesía y una intención fática y de aprobación al manifestar que se mantiene el contacto con el otro y la atención temática.

- Uso de léxico juvenil, voseo verbal, léxico espontáneo intensifica la pertenencia al grupo y los identifica como miembros del mismo.

- Cooperar con el discurso haciendo preguntas al grupo lo que permite ceder el turno y darle la oportunidad al que quiera de participar tomando la palabra.

\section{$\mathrm{N}^{\circ}$ de episodio: 6}

M1: y no solo eso, $\mathrm{e}^{\mathbf{h}}$ tamo ${ }^{\mathbf{h}}$ en una sociedad donde yo creo que, no sé: su característica máxima $\mathrm{e}^{\mathbf{h}}$ la irre ${ }^{\mathbf{h}}$ ponsabilidad en todo sentido $\rightarrow$

M2: $<$ [y tratamo ${ }^{\mathbf{h}}$ de ju ${ }^{\mathbf{h}}$ tificar con cada situación- $]$

M1: Mira, tú te poní en tu lugar ¿qué edad teni ${ }^{\mathbf{h}}$ tú?

H1: dieciocho.

M1: dieciocho año ${ }^{\mathbf{h}}$ ya $\mid$ eri $^{\mathbf{h}}$ una persona que ha vivido, que tiene cierta madurez, que puede opinar | pero qué pasa con toda $\mathbf{h}^{\mathbf{h}} \mathrm{e}^{\mathbf{h}}$ ta $^{\mathbf{h}}$ niñita $^{\mathbf{h}}$ chica ${ }^{\mathbf{h}}$ que lo único que hacen $\mathrm{e}^{\mathbf{h}}$ ver tele, que tienen influencia $\rightarrow$

$\mathrm{H} 1:<[$ si po $]>$

M1: que no tienen madurez, que no piensan, que hacen tonteras ¿qué vamos a hacer con toda $^{\mathbf{h}}$ ella ${ }^{\mathbf{h}}$ ? | tú mismo dijiste, pa un gallo, que no trabaja, que $\mathrm{e}^{\mathbf{h}}$ alcohólico y se gasta la plata en copete, no puede tener hijo pero si le e h tái dando una herramienta va a seguir siéndolo-

M2: no le e h tái dando educación, pero le e h tái dando método ${ }^{\mathbf{h}}$ que ni siquiera saben a qué va

$\mathrm{M} 1:<$ le e h tái diciendo "sé irre ${ }^{\mathbf{h}}$ ponsable, aquí $\mathrm{e}^{\mathbf{h}}$ tá la pa ${ }^{\mathbf{h}}$ tilla haz lo que querai, haz lo que querai]

H2: $\mathrm{e}^{\mathbf{h}}$ que me parece $\rightarrow$

M2: $<$ [mi pregunta- $]$

H2: yo igual no tengo ningún juicio claro de si es buena o es mala, yo solamente como trato de emitir opiniones según lo que me dice la razón, en el momento $\rightarrow$ 
M2: $<[$ mi pregunta- $]>$

H2: pero me parece que, ese no $e^{\mathbf{h}}$ un no $\mathrm{e}^{\mathbf{h}}$ un: motivo para quitarla, la pastilla

M2: pero la sociedad ¿necesita | ESA clase de elementos?

H2: si:

M2: ¿es lo fundamental?

H2: $<$ [yo creo:, sí $\rightarrow$ ]

M2: $<$ [yo creo que es la educación $\rightarrow$ ]

$\mathrm{H} 2:<\left[\right.$ no podi $^{\mathbf{h}}, \mathrm{e}^{\mathbf{h}}$ que no podi $\left.{ }^{\mathbf{h}}-\right]>$

M2: no podi ${ }^{\mathbf{h}}$ entregarle, es como pasarle e: no sé | e: no podí entregarle esa clase de herramienta ${ }^{\mathbf{h}} \operatorname{ANTE}^{\mathbf{h}}$ de darle educación, o sea $\mid \mathrm{ba}^{\mathbf{h}}$ ta con que una niña $\rightarrow$

H2: $<$ [pero e ${ }^{\mathbf{h}}$ que ahí tú- $]$

M3: $<$ ¿¿la gente que no sea ignorante $\mathrm{e}^{\mathbf{h}}$ la que toma la pa ${ }^{\mathbf{h}}$ tilla? yo creo que no]

H2: $<$ [no po, a: $]$

$\mathrm{M} 1:<[$ ¿cómo?]

M2: YO CREO $\rightarrow$

M3: $<$ [yo creo que no solo gente ignorante toma $\mathrm{pa}^{\mathbf{h}}$ tilla $^{\mathbf{h}}$ sino que-]

M2: YO CREO que la $^{\mathbf{h}}$ persona $^{\mathbf{h}}$ la mayoría de la persona ${ }^{\mathbf{h}}$ que son parte de nuestra sociedad hoy en día LAMENTABLEMENTE no tienen no tienen $10^{\mathbf{h}}$ recurso ${ }^{\mathbf{h}}$ o $10^{\mathbf{h}}$ medio ${ }^{\mathbf{h}}$ para poder y ni siquiera lo ${ }^{\mathbf{h}}$ medio incluso la: || la intención de querer educarse sobre el tema entonce ${ }^{\mathbf{h}}$ vamo $^{\mathbf{h}}$ tomando lo que no ${ }^{\mathbf{h}}$ entregan rápido | un grupo de: femini ${ }^{\mathbf{h}}$ ta: extremo: pro: aborto me dice que tengo derecho sobre mi cuerpo sobre mi vida y puedo hacer lo que yo quiera, perfecto, e: la religión me dice que nol tengo base ${ }^{\mathbf{h}}$ amplia $^{\mathbf{h}}$ esa $^{\mathbf{h}}$ la información con la que se manejan esta ${ }^{\mathbf{h}} \operatorname{cosa}^{\mathbf{h}}$

H2: $<$ [sí pero, yo creo que- $]$

M2: $<$ [no manejan concepción ma- $]$

$\mathrm{H} 2:<[$ no podemos $]>$

M3: pero oye, yo pienso que con educación también va a decidir tomársela o no tomársela aunque tenga mucha educación igual se la puede tomar ¿cachái?

M2: $<$ [ipor supue ${ }^{\mathbf{h}}$ to:i]

M3: < [por eso no $\mathrm{e}^{\mathbf{h}}$ una cosa de "hay ma ${ }^{\mathbf{h}}$ educación" ¿cachái? porque eso depende de cada uno-] 
$\mathrm{M} 2:<[\mathrm{NO}:$ la educación no depende de cada $\mathrm{u}: \mathrm{no} \rightarrow]$

M1: $<[$ pero yo creo que- $]>$

M2: yo creo que la educación $\mathrm{e}^{\mathbf{h}}$ un problema nació:n, un problema mundial-]

M1: $<$ [pero yo creo que- $]$

M2: $<$ depende de cada uno $\rightarrow]>$

M3: no depende de cada u:no-

M2: o sea entrai la universidad, porque no te pusieron dependió de ti entrar ¿cachái?

M2: $<$ [no dependió de mí, dependió del medio en el que me encuentro de MI familia de lo

${ }^{\mathbf{h}}$ valore ${ }^{\mathbf{h}}$ que yo tengo- ]

$M 1:<[$ pero una niñita chica que crece sola- $]>$

M3: hay mina ${ }^{\mathbf{h}}$ que $\mathrm{e}^{\mathbf{h}}$ tudian en colegio súper mula ${ }^{\mathbf{h}} \mathrm{y}$ así $\mathrm{y}$ todo pueden entrar a la universidad porque ella ${ }^{\mathbf{h}}$ se $\mathrm{e}^{\mathbf{h}}$ forzaron por $\mathrm{e}^{\mathbf{h}}$ tudiar.

M2: anda a un barrio e: || cómo puedo decirte | e:, má ${ }^{\mathbf{h}}$ marginal-

M3: < [yo vivo en un barrio así-, no tengo ningún problema en decirlo, tengo compañeras $\rightarrow$ ]

M2: $<$ [pero si no, no te $\mathrm{e}^{\mathbf{h}}$ toy diciendo, te $\mathrm{e}^{\mathbf{h}}$ toy diciendo de que si la educación fuera tema de cada uno por sí solo, $\mathrm{e}^{\mathbf{h}}$ to sería muy di ${ }^{\mathbf{h}}$ tinto , no eh así-]

M1: $<$ [pero yo creo que- $]$

M2: por algo somos sociedad $\rightarrow$ por algo somo ${ }^{\mathbf{h}}$ sociedad tenemo $^{\mathbf{h}}$ influencia $^{\mathbf{h}}$ de otra $^{\mathbf{h}}$ persona ${ }^{\mathbf{h}}$.

$\mathrm{H} 1:<[$ a ver yo creo que- $]$

M1: $<$ ¿ ¿en qué lugar $\mathrm{e}^{\mathbf{h}}$ taría YO sin la educación que me dieron mi ${ }^{\mathbf{h}}$ papá $^{\mathbf{h}}$ ? no creo que acá]

M2: $<$ [¿por qué lo ${ }^{\mathbf{h}}$ musulmane ${ }^{\mathbf{h}}$ son musulmane ${ }^{\mathbf{h}}$ ? porque el medio en el que- $]$

H3: yo creo que exi ${ }^{\mathbf{h}}$ ten do ${ }^{\mathbf{h}}$ tipo de educación una eh la educación académica que $\mathrm{e}^{\mathbf{h}}$ la que te da el colegio donde aprendí ${ }^{\mathbf{h}}$ a sumar a re ${ }^{\mathbf{h}}$ tar y a leer $\mid$ y la otra $\mathrm{e}^{\mathbf{h}}$ la que te dan en tu casa- donde te dicen-

M2: $<$ [y esa e $\mathrm{e}^{\mathbf{h}}$ la central po]

M3:[yo creo que-]

M2: $<\left[\right.$ i por qué lo ${ }^{\mathbf{h}}$ musulmane ${ }^{\mathbf{h}}$ son musulmane ${ }^{\mathbf{h}}$ ? porque lo decidieron porque se educan solo $^{\mathbf{h}}$, no porque el medio lo ${ }^{\mathbf{h}}$ influencia-] 
M3: $<$ [una persona puede tomar una ideología- $]$

M2: la cultura que nosotro ${ }^{\mathbf{h}}$ manejamo ${ }^{\mathbf{h}}$ Antonella $\rightarrow$ la cultura que nosotro ${ }^{\mathbf{h}}$ manejamo ${ }^{\mathbf{h}}$ $\mathrm{e}^{\mathbf{h}}$ en parte una herencia social $\mid$ no podemo $^{\mathbf{h}}$ ai $^{\mathbf{h}}$ larno $^{\mathbf{h}}$ de eso $\mid$ no podemos-

H1: $<$ [yo creo que -]

M2: mientra ${ }^{\mathbf{h}}$ má $^{\mathbf{h}}$ educación tiene ${ }^{\mathbf{h}}$ má $^{\mathbf{h}}$ puede $^{\mathbf{h}}$ manejarte sobre eso ${ }^{\mathbf{h}}$ tema $^{\mathbf{h}} \rightarrow$ meno $^{\mathbf{h}}$ educación má ${ }^{\mathbf{h}}$ se reduce tu campo de elección-

H1: a mí me parece que $\mathrm{e}^{\mathbf{h}}$ tán $\rightarrow$ a mí me parece que $\mathrm{e}^{\mathbf{h}}$ tán radicalizando $1 \mathrm{o}^{\mathbf{h}}$ do ${ }^{\mathbf{h}}$ punto ${ }^{\mathbf{h}}$ se $\mathrm{e}^{\mathbf{h}}$ tán yendo a $\mathrm{lo}^{\mathbf{h}} \mathrm{do}^{\mathbf{h}}$ extremo ${ }^{\mathbf{h}}$, yo creo que $\mathrm{e}^{\mathbf{h}}$ mutuo $\mathrm{e}^{\mathbf{h}}$ re $^{\mathbf{h}}$ ponsabilidad de uno el deseo de aprender y también es re ${ }^{\mathbf{h}}$ ponsabilidad del $\mathrm{e}^{\mathbf{h}}$ tado el entregar todas las herramientas para que esa persona pueda hacerlo-

M1: pero yo creo que, la: yo creo que la Antonella tiene razón en ese punto de que hay gente que sabe, hay gente que tiene dinero, hay gente que tiene la cultura y decide tomarse la pa tilla y yo creo que ahí ahí como que | hay como un un error por decirlo así porque | la gente que siempre ha tenido pla:ta $\mid \mathrm{e}^{\mathbf{h}}$ la que-

M4: $<\left[\right.$ má $^{\mathbf{h}}$ usa $]$

M1: $\mathrm{e}^{\mathbf{h}}$ la que ha usado $10^{\mathbf{h}}$ aborto | $\mathrm{e}^{\mathbf{h}}$ la que ha ido a clí:nica ${ }^{\mathbf{h}}$ donde no le ${ }^{\mathbf{h}}$ ha pasado NA:DA porque son MÉ:DICO $10^{\mathbf{h}}$ que $1 \mathrm{e}^{\mathbf{h}}$ hacen $\mathrm{lo}^{\mathbf{h}}$ aborto $^{\mathbf{h}}$ a $^{\mathbf{h}} \operatorname{ta}^{\mathbf{h}} \operatorname{niñita}^{\mathbf{h}} \mathrm{y} \mid$ no le ${ }^{\mathbf{h}}$ pasa nada no se mueren | cero rollo $l^{\mathbf{h}}{ }^{\mathbf{p}}$ papito ${ }^{\mathbf{h}}{ }^{\mathrm{l}} \mathrm{e}^{\mathbf{h}}$ pagan el aborto ¿qué pasa con la ${ }^{\mathbf{h}}$ con la ${ }^{\mathbf{h}}$ niña ${ }^{\mathbf{h}}$ de clase social má ${ }^{\mathbf{h}}$ baja? | abortan, en lugare ${ }^{\mathbf{h}}$ clande $^{\mathbf{h}}$ ti:no ${ }^{\mathbf{h}}$ donde lo ${ }^{\mathbf{h}}$ médico ${ }^{\mathbf{h}}$ no son médico ${ }^{\mathbf{h}}$ no sé qué eran $\mid$ pero $\rightarrow$

H1: $<$ [pero si podí ....rojo y con el apio po] \{risas

M1: claro y: abortan en $\mathrm{e}^{\mathbf{h}}$ to ${ }^{\mathbf{h}}$, con $\mathrm{e}^{\mathbf{h}}$ to $^{\mathbf{h}}$ método $^{\mathbf{h}}$ medio ${ }^{\mathbf{h}}$ clande ${ }^{\mathbf{h}}$ tino entonce ${ }^{\mathbf{h}} \mid$ como que, yo siento que: e: una | como, como que se, no sé según mi ${ }^{\mathbf{h}}$ creencia como que la pa ${ }^{\mathbf{h}}$ tilla viene siendo como u:na forma de abortar, que $\mathrm{e}^{\mathbf{h}}$ mucho más accesible porque $\mathrm{e}^{\mathbf{h}}$ bara:ta, pero: a la vez, e: no ${ }^{\mathbf{h}} \mathrm{e}^{\mathbf{h}}$ tamo $^{\mathbf{h}}$ arriegando a que no sabemo ${ }^{\mathbf{h}}$ qué daño produce en el cuerpo porque, si una niña se toma cada semana una $\mathrm{pa}^{\mathbf{h}}$ tilla $\mathrm{e}^{\mathbf{h}}$ lógico, pero muy lógico que quizá de ${ }^{\mathbf{h}}$ pué $^{\mathbf{h}}$ no pueda tener hijo ${ }^{\mathbf{h}}$ o le va a dar cáncer ¿cachái? $\rightarrow$ $\mathrm{M} 2:<\left[\mathrm{e}^{\mathbf{h}}\right.$ una bomba hormonal horrible $]>$ M1: entonce ${ }^{\mathbf{h}}$ tampoco $\mathrm{e}^{\mathbf{h}}$ como una solución e: que alguien pueda usarla como un método sino que $\mathrm{e}^{\mathbf{h}}$ como algo muy excepcional ¿cachái? 
M4: por ÚLTIMO, por último que haya que pasar por un camino pero extremadamente la:rgo para llegar a ella, pero no llegar, "tut", li $^{\mathbf{h}}$ to.

$\mathrm{M} 2:<[\mathrm{mmm}]$

M4: < [por último, que haya que pasar pasar por un mé:dico, que te pregunten bien, casi como por un sicólogo y que de ahí te la den]>

M4: $<$ claro como que ese $\mathrm{e}^{\mathbf{h}}$ el problema que yo siento que $\mathrm{e}^{\mathbf{h}}$ casi como tener el aborto casi al alcance de la mano, eso $\mathrm{e}^{\mathbf{h}}$ lo que yo siento un poco] $>$

M3: $<$ [ por eso la idea $\mathrm{e}^{\mathbf{h}}$ pa usarla una sola ve ${ }^{\mathbf{h}}$ no para usarla consecutivamente]

M1: $<[\mathrm{a}:]$

M4: claro pero el hecho de que $\mathrm{e}^{\mathbf{h}}$ té tan al alcance $\mathrm{e}^{\mathbf{h}}$ lo que: hace que uno se pregunte ¿qué onda con $\mathrm{e}^{\mathbf{h}}$ ta sociedad? o sea, tenemo ${ }^{\mathbf{h}}$ al alcanc- el aborto al alcance de la mano M2: $<$ [por algo e ${ }^{\mathbf{h}}$ tá- al alcance $]$

M4: ¿cachái? eso $\mathrm{e}^{\mathbf{h}}$ lo que da $\mathrm{su}^{\mathbf{h}}$ to de que cómo no me pude e: yo $\mathrm{mi}^{\mathbf{h}}$ ma cuidar o quizás no, abstenerme de $\mathrm{e}^{\mathbf{h}}$ te momento de placer y matar a mi hijo ¿cachái? o sea, cómo pude haber sido tan irre ${ }^{\mathbf{h}}$ ponsable, tan inconsecuente ¿cachái? porque, yo te-, o sea, encuentro que tení ${ }^{\mathbf{h}}$ mucha razón al plantear eso de que gente con quizá con valore ${ }^{\mathbf{h}} \mathrm{y}$ creencia muy fuerte pueda tomar la $\mathrm{pa}^{\mathbf{h}}$ tilla, o sea, la necesidad tiene cara de hereje ¿cachái? | yo te creo, hay persona ${ }^{\mathbf{h}}$ que no tienen conviccione ${ }^{\mathbf{h}}$ tan fuerte $^{\mathbf{h}} \rightarrow$ M2: sí.

M4: pero ¿cachái que $\mathrm{e}^{\mathbf{h}}$ muy heavy tener todo $\mathrm{e}^{\mathbf{h}}$ to al alcance de la mano? ¿ ¿cachái? como que eso $\mathrm{e}^{\mathbf{h}}$ lo que, por lo meno ${ }^{\mathbf{h}}$ a mí, me impacta.

M3: < [yo lo que pienso con que no te la pongan ahí o la no sé po, la prohíban y todo cualquier persona que se la quiera conseguir se la va a conseguir igual, ese $\mathrm{e}^{\mathbf{h}}$ el punto siempre ¿cachái? siempre $\mathrm{e}^{\mathbf{h}}$ como lo $\mathrm{mi}^{\mathbf{h}}$ mo que la droga si la queri ${ }^{\mathbf{h}}$ conseguir te la vai a conseguir igual.]

$\mathrm{M} 2:<\left[\mathrm{e}^{\mathbf{h}}\right.$ que no $\mathrm{e}^{\mathbf{h}}$ tan así por algo hay tanto tema con con con legitimizar la entrega]

M4: $<$ [claro pero yo creo que- $]>$

M2: $<$ [pero siempre va a existir igual igual que la droga]

M4: pero yo creo $\rightarrow$ yo creo que que si a $t^{\mathbf{h}}:$, a tu ${ }^{\mathbf{h}}:$ niña ${ }^{\mathbf{h}}$ con la que $\mathrm{e}^{\mathbf{h}}$ tabai tú en la iglesia $\mathbf{l}^{\mathbf{h}}$ hubierai dicho ella ${ }^{\mathbf{h}}$ no hubieran tenido la posibilidad de la $\mathrm{pa}^{\mathbf{h}}$ tilla y alguien le hubiera dicho | "bueno vamo ${ }^{\mathbf{h}}$ a abortar $\mid$ yo te pago la clínica vamo ${ }^{\mathbf{h}}$ a abortar, un médico 
te saca la guagua o te la mata" no sé, yo creo que la niña hubiera dicho que no

M3: < [obvio que no]

M4: ¿cachái?, pero pero tomarse una pa ${ }^{\mathbf{h}}$ tilla-

M3: < [eso pasa con la pa ${ }^{\mathbf{h}}$ tilla que se $\mathrm{e}^{\mathbf{h}}$ tá siempre con la incertidumbre entonce ${ }^{\mathbf{h}}$ tú al final, eso pienso yo $\mid$ tú senti $^{\mathbf{h}}$ que lo e h tái haciendo mal]

M4: $<$ [claro e ${ }^{\mathbf{h}}$ que ese $\mathrm{e}^{\mathbf{h}}$ el problema-

M2: yo sí que pienso al revé ${ }^{\mathbf{h}} \mid$ yo creo que como tengo la incertidumbre y no tengo la certeza de que $\mathrm{e}^{\mathbf{h}}$ toy haciendo un daño $\mid$ siempre va a $\mathrm{e}^{\mathbf{h}}$ tar aquí $\rightarrow$

H3: $<$ [va va a e $\mathrm{e}^{\mathbf{h}}$ tar- $]$

M2: el tema de que lo hici $^{\mathbf{h}}$ te $\mid \mathrm{y}$ de hecho en cuanta ${ }^{\mathbf{h}}-$

$\mathrm{H} 1:<$ [ya pero- $]$

$\mathrm{M} 3:<\left[\right.$ sí pero e $^{\mathbf{h}}$ que eso $\mathrm{mi}^{\mathbf{h}}$ mo-]

H1: $<$ [ya si no $\mathrm{e}^{\mathbf{h}}$ tan así tampoco]

M2: $<$ [pero si e ${ }^{\mathbf{h}}$ así]

M3: $<$ [eso $\mathrm{e}^{\mathbf{h}}$ lo que yo te digo yo por eso te digo que la ${ }^{\mathbf{h}}$ palabra ${ }^{\mathbf{h}}$ se la $\mathbf{a}^{\mathbf{h}}$ lleva el viento]

M2: < [Gonzalo no $\mathrm{e}^{\mathbf{h}}$ solo tomarte una $\mathrm{pa}^{\mathbf{h}}$ tilla la $^{\mathbf{h}}$ influencia-, partiendo del punto ma ${ }^{\mathbf{h}}$ ciéntifico ]

H1: $<$ [ya , no e ${ }^{\mathbf{h}}$ que mira primero- $]$

M3: $<$ [o sea hay gente que roba- $]$

\{risas\}

M2: $<$ a: obvio po es verdad, en mi caso sí- $]$

$\mathrm{H} 2:<$ [en mi caso, en mi caso me afectaría]

M3: $<$ [si po en TU caso, pero- $]$

$\mathrm{H} 1:<\left[\right.$ pero igual oye, hacer el amor no $\mathrm{e}^{\mathbf{h}}$ hacer una guagua- po] $>$

$\mathrm{H} 3:<[$ no creo que mi caso sea un caso único $]>$

M2: $<$ [no yo pienso lo $\mathrm{mi}^{\mathbf{h}}$ mo que tú, pero creo que $\rightarrow$ ]

H1: < [entonce $^{\mathbf{h}}$ eh como: ya era raro que fuera a quedar embarazada dependiendo de la fecha en que-]

$\mathrm{M} 2:<[$ mira- $]$

$\mathrm{H} 1:<$ [y que: como y e ${ }^{\mathbf{h}}$ má $^{\mathbf{h}}$ raro que tomándote la pa ${ }^{\mathbf{h}}$ tilla matí $^{\mathbf{h}}$ una guagua $\mathrm{e}^{\mathbf{h}}$ como nunca tanto] 
M4: e h tái limitando una vi:daM2: ¿vi ${ }^{\mathrm{h}}$ te? a ese tema va lo que yo $\mathrm{e}^{\mathrm{h}}$ toy diciendo

\section{Descripción del episodio número 6}

Elementos indispensables de la argumentación (Lo Cascio, 1998)

\section{Tema del episodio: La educación sexual en Chile y la pastilla del día después.}

Tesis: No se puede entregar esta pastilla masivamente porque mucha gente no sabe en qué consiste este método.

Argumentos: la mayoría de la población no tiene los recursos económicos ni acceso para educarse sexualmente.

Regla General: la educación sexual de las personas permitiría entender los riesgos que involucra tomar esta pastilla.

\section{Elementos facultativos de la argumentación}

(Lo Cascio (1998))

Refuerzo: depende de cada uno educarse y estar al tanto de la información.

Calificador: la educación es un problema de todo el país no depende de cada uno.

Refutación, contraopinión o reserva: no es un buen criterio el de la educación porque entonces según este razonamiento sería adecuado que tuvieran acceso a la pastilla solo los que tiene acceso a la educación que corresponde a la gente que tiene más dinero en el país.

\section{Estrategias de cortesía positiva}

(Brown P. y Levinson S. , 1987): Apele al “terreno común”. - Intensifique el interés hacia $O$.

- Exagere (interés, aprobación, simpatía con O)

- Fíjese, atienda a $O$ (a sus intereses, deseos, necesidades, bienes).

En el siguiente segmento se puede apreciar que hay intentos por manifestar el interés. M2 colabora ayudando a terminar el enunciado que postula M1. Además M1 hace preguntas directas a otros participantes para involucrarlos en el debate y demostrar su aprobación: 
M1: y no solo eso, $e^{h}$ tamo $^{h}$ en una sociedad donde yo creo que, no sé: su característica máxima $e^{h}$ la irre ${ }^{h}$ ponsabilidad en todo sentido $\rightarrow$

M2: $<$ [y tratamo ${ }^{h}$ de ju ${ }^{h}$ tificar con cada situación-]

M1: Mira, tú te poní en tu lugar ¿qué edad teni ${ }^{h}$ tú?

H1: dieciocho.

Por su parte, los enunciados de estos segmentos permiten demostrar la aprobación hacia el interlocutor. Estos conectores discursivos pragmáticos metadiscursivos intentan mantener el contacto y demostrar así el interés y el acuerdo.

$M 2:<[\mathrm{mmm}]$

M4: <[por último, que haya que pasar pasar por un mé:dico, que te pregunten bien, casi como por un sicólogo y que de ahí te la den]>

M4: $\leq$ [claro, como que ese $e^{h}$ el problema que yo siento que $e^{h}$ casi como tener el aborto casi al alcance de la mano, eso $e^{h}$ lo que yo siento un poco] $>$

(...)

$M 1: \leq[a:]$

Apele a la pertenencia al mismo grupo que 0 . Use marcadores de identidad de grupo.

El uso de léxico juvenil (heavy, copete, mula), voseo verbal ${ }^{7}$ (estai, vai) léxico espontáneo (gallo, mina, cachar, la Antonella (si bien es un rasgo gramatical, es propio de un registro espontáneo) da cuenta de que se encuentran en una situación distendida lo que intensifica la pertenencia al grupo y los identifica como miembros del mismo.

M1: que no tienen madurez, que no piensan, que hacen tonteras ¿qué vamos a hacer con toda ${ }^{h}$ ella ${ }^{h}$ ? | tú mismo dijiste, pa un gallo, que no trabaja, que $e^{h}$ alcohólico y se gasta la plata en copete, no puede tener hijo pero si le e h tái dando una herramienta vai a seguir siéndolo-

(...)

M3: hay mina $^{\boldsymbol{h}}$ que $e^{\boldsymbol{h}}$ tudian en colegio súper mula $^{\boldsymbol{h}}$ y asi $y$ todo pueden entrar a la universidad porque ella ${ }^{h}$ se $e^{h}$ forzaron por $e^{h}$ tudiar.

(...)

M4: pero ¿cachái que $e^{h}$ muy heavy tener todo $e^{h}$ to al alcance de la mano? I ¿cachái? como que eso $e^{h}$ lo que, por lo meno ${ }^{h}$ a mí, me impacta.

(...)

M1: pero yo creo que, la: yo creo que la Antonella tiene razón en ese punto de que hay gente que sabe

\footnotetext{
${ }^{7}$ Se observó anteriormente que el uso del voseo verbal en el español hablado en Chile está restringido a situaciones informales. (cfr. pág. 42)
} 
Apele al punto de vista, opiniones, actitudes, conocimiento, empatía comunes. - Busque el acuerdo. Evite el desacuerdo. Presuponga/ suscite/ manifieste el terreno común. Bromee.

En los siguientes segmentos se hace explícito el acuerdo:

M1: pero yo creo que, la: yo creo que la Antonella tiene razón en ese punto de que hay gente que sabe, hay gente que tiene dinero, hay gente que tiene la cultura y decide tomarse la pa tilla y yo creo que ahi ahí como que | hay como un un error por decirlo así porque | la gente que siempre ha tenido pla:ta $\mid e^{h}$ la que-

(...)

M4: ¿cachái? eso $e^{\boldsymbol{h}}$ lo que da su ${ }^{\boldsymbol{h}}$ to de que cómo no me pude e: yo mi ${ }^{\boldsymbol{h}}$ ma cuidar o quizás no, abstenerme de $e^{\boldsymbol{h}}$ te momento de placer y matar a mi hijo ¿cachái? o sea, cómo pude haber sido tan irre ${ }^{h}$ ponsable, tan inconsecuente ¿cachái? porque, yo te-, o sea, encuentro que teni ${ }^{h}$ mucha razón al plantear eso de que gente con quizá con valore ${ }^{\boldsymbol{h}}{ }^{y}$ creencia muy fuerte pueda tomar la $\mathrm{pa}^{\boldsymbol{h}}$ tilla, o sea, la necesidad tiene cara de hereje ¿cachái? | yo te creo, hay persona ${ }^{h}$ que no tienen conviccione ${ }^{h}$ tan fuerte $^{\boldsymbol{h}} \rightarrow$

Se hacen bromas que permiten que el ambiente del debate sea más agradable:

M1: $e^{\boldsymbol{h}}$ la que ha usado lo ${ }^{\boldsymbol{h}}$ aborto | $e^{\boldsymbol{h}}$ la que ha ido a clínica ${ }^{\boldsymbol{h}}$ donde no le ${ }^{\boldsymbol{h}}$ ha pasado NA:DA porque son MÉ:DICO lo ${ }^{\boldsymbol{h}}$ que le $\mathrm{l}^{\boldsymbol{h}}$ hacen lo $^{\boldsymbol{h}}$ aborto ${ }^{\boldsymbol{h}}$ a $e^{\boldsymbol{h}}$ ta $^{\boldsymbol{h}}$ niñita ${ }^{\boldsymbol{h}} y \mid$ no le $e^{\boldsymbol{h}}$ pasa nada no se mueren | cero rollo lo ${ }^{\boldsymbol{h}}$ papito $^{\boldsymbol{h}} \mathrm{le}^{\boldsymbol{h}}$ pagan el aborto ¿qué pasa con la ${ }^{\boldsymbol{h}}$ con la ${ }^{\boldsymbol{h}}$ niña ${ }^{h}$ de clase social má ${ }^{h}$ baja? | abortan, en lugare ${ }^{h}$ clande $^{h}$ ti:no ${ }^{h}$ donde lo ${ }^{h}$ médico ${ }^{h}$ no son médico ${ }^{h}$ no sé qué eran $\mid$ pero $\rightarrow$

H1: <[pero si podí ....rojo y con el apio po]

$\{$ risas\}

(...)

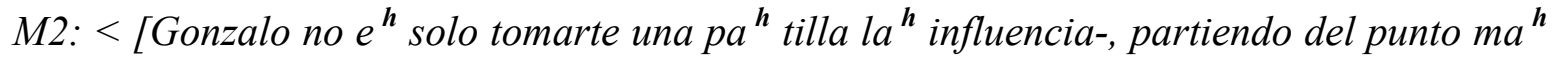
ciéntifico $]$

H1: $<$ [ya, no e $e^{h}$ que mira primero- $]$

M3: < [o sea hay gente que roba-]

$\{$ risas\}

\section{Estrategias de cortesía negativa}

Estrategias de reparación de un acto descortés (Kerbrat-Orecchioni (2004:44)): A comete contra $B$ alguna ofensa (FTA) que inmediatamente intenta reparar por medio de una excusa (FFA). Cuanto mayor es el peso del FTA, tanto más debe ser importante el trabajo reparador.

M2: anda a un barrio e: || cómo puedo decirte |e:, máh marginal-

M3: < <yo vivo en un barrio así-, no tengo ningún problema en decirlo, tengo compañeras $\rightarrow]$

M2: < [pero si no, no te $e^{h}$ toy diciendo, te $e^{\boldsymbol{h}}$ toy diciendo de que si la educación fuera tema de cada uno por sí solo, $e^{h}$ to sería muy di ${ }^{h}$ tinto , no eh así-7 
M2 agrede la imagen de M3 al comentar sobre las conductas de los jóvenes que viven en barrios de escasos recursos, no está al tanto de que M3 vive o vivió cuando niña en un barrio así. Inmediatamente M2 intenta reparar su agresión diciendo que ella no quería decir eso.

Estrategias de atenuación cortés (Briz, 2001)

\section{Se aminoran cualidades, actitudes y acciones del yo y negativas del tú}

Este segmento muestra dos tipos de atenuación de cortesía. En primer lugar vemos que la pregunta que realiza M2 es cortés precisamente porque mitiga el enfrentamiento que puede haber entre dos posturas, ella en vez de mencionar directamente que no está de acuerdo con el uso de la pastilla del día después, permite que todos den su opinión respondiendo a la pregunta y luego ella da la suya. En segundo lugar, hay atenuación en la forma en que se responde la pregunta y en la forma como ella misma (M2) responde a su pregunta.

M2: pero la sociedad ¿necesita $\mid$ ESA clase de elementos?

H2: $s i$ :

M2: ¿es lo fundamental?

H2: $<$ [yo creo:, $\mathrm{si} \rightarrow]$

M2: $<$ [yo creo que es la educación $\rightarrow]$

Indicadores gramaticales de atenuación cortés (Kerbrat-Orecchioni) (Haverkate)

\section{Se aminoran cualidades negativas del tú:}

-Hacer preguntas generales que contengan un contraargumento de la tesis que se debate para suavizar el ataque.

Se aminoran cualidades, actitudes y acciones del yo.

- Usar yo creo antes de presentar el contrargumento o argumento para suavizar el impacto. Indicadores gramaticales de cortesía positiva y negativa (Kerbrat-Orecchioni/Brown P. y Levinson S. ) (Haverkate)

\section{Indicadores gramaticales de cortesía positiva:}

- Uso de marcadores con intención fática y de aprobación para manifestar que se mantiene el contacto con el otro y la atención temática.

- Se colabora terminando los enunciados de los otros participantes.

- Uso de léxico juvenil, voseo verbal, léxico espontáneo intensifica la pertenencia al grupo y los identifica como miembros del mismo.

- Manifestación explícita del acuerdo con el otro: "yo creo que la Antonella tiene razón", "encuentro que tení mucha razón".

- Uso de bromas. 


\section{Indicadores gramaticales de cortesía negativa:}

Reparación de un acto descortés: negación de lo que se dijo y que afectó al otro.

\section{$\mathbf{N}^{\circ}$ de episodio: 7}

H1: $<$ [ya pero esperen, calmao $\mathrm{e}^{\mathbf{h}}$ to no tiene ningún sentido por qué no di ${ }^{\mathbf{h}}$ cutimo $^{\mathbf{h}}$ cue $^{\mathbf{h}}$ tione $^{\mathbf{h}}$ relacionada ${ }^{\mathbf{h}}$ a la a la $\mathbf{p a}^{\mathbf{h}}$ tilla pero que podamo ${ }^{\mathbf{h}}$ di $^{\mathbf{h}}$ cutir por ejemplo | ya la $\mathrm{e}^{\mathbf{h}}$ tán intentando prohibir y: todo el asunto: $y$ : en lo $^{\mathbf{h}}{ }^{\text {consultorio }}{ }^{\mathbf{h}}$ público y: qué pasa con con la h farmacia $^{\mathbf{h}}$ privá $^{\mathbf{h}}$ ]

M1: pero si todo ${ }^{\mathbf{h}}$ todo $^{\mathbf{h}}$ lo $^{\mathbf{h}}$ tema $^{\mathbf{h}}$ abarcan mucha $^{\mathbf{h}} \cos ^{\mathbf{h}}$.

$\mathrm{M} 2:<[$ sí: po $\rightarrow]$

H1: $<$ [no pero por eso-]

M2: < [pero e tamo $^{\mathbf{h}}$ hablando-]

M3: $<$ [pero con ese tema por ejemplo $\rightarrow$ pero con lo que planteai tú yo $\mathrm{e}^{\mathbf{h}}$ toy totalmente en desacuerdo de que la e: si se prohíbe en lugare ${ }^{\mathbf{h}}$ : público $^{\mathbf{h}}$ se deberían prohibir en lugare ${ }^{\mathbf{h}}$ privado $\left.^{\mathbf{h} .}\right]$

H1: $<$ [por eso, pero e ${ }^{\mathbf{h}}$ que ¿y por qué no pasa eso?-]

M2: $<$ [sí yo también]

M4: $<$ [si igual la conseguí $\left.^{\mathbf{h}}-\right]$

$\mathrm{H} 1:<$ [¿por qué no pasa eso?]

M3: pero $\mathrm{e}^{\mathbf{h}}$ que claro $\mathrm{e}^{\mathbf{h}}$ que $\mathrm{e}^{\mathbf{h}}$ muy: $\mathrm{e}^{\mathbf{h}}$ muy: en el fondo no la $\mathrm{e}^{\mathbf{h}}$ tái prohibiendo se la e $\mathrm{h}$ tái $\rightarrow$ se la e h tái quitando a un sector de la sociedad $\rightarrow$

$\mathrm{H1}:<$ [por eso-]

M1: y eso yo lo encuentro muy heavy.

$\mathrm{H1}:<$ [yo igual pienso lo $\mathrm{mi}^{\mathbf{h}}$ mo ¿cachái?]

M2: $<$ [yo soy partidaria de la- $>$

H1: yo igual pienso lo $\mathrm{mi}^{\mathbf{h}}$ mo pero POR QUÉ pasa, por qué el gobierno no $\mathrm{e}^{\mathbf{h}}$ capaz de poder decir ya no la venden y no la venden en ni un lado? 


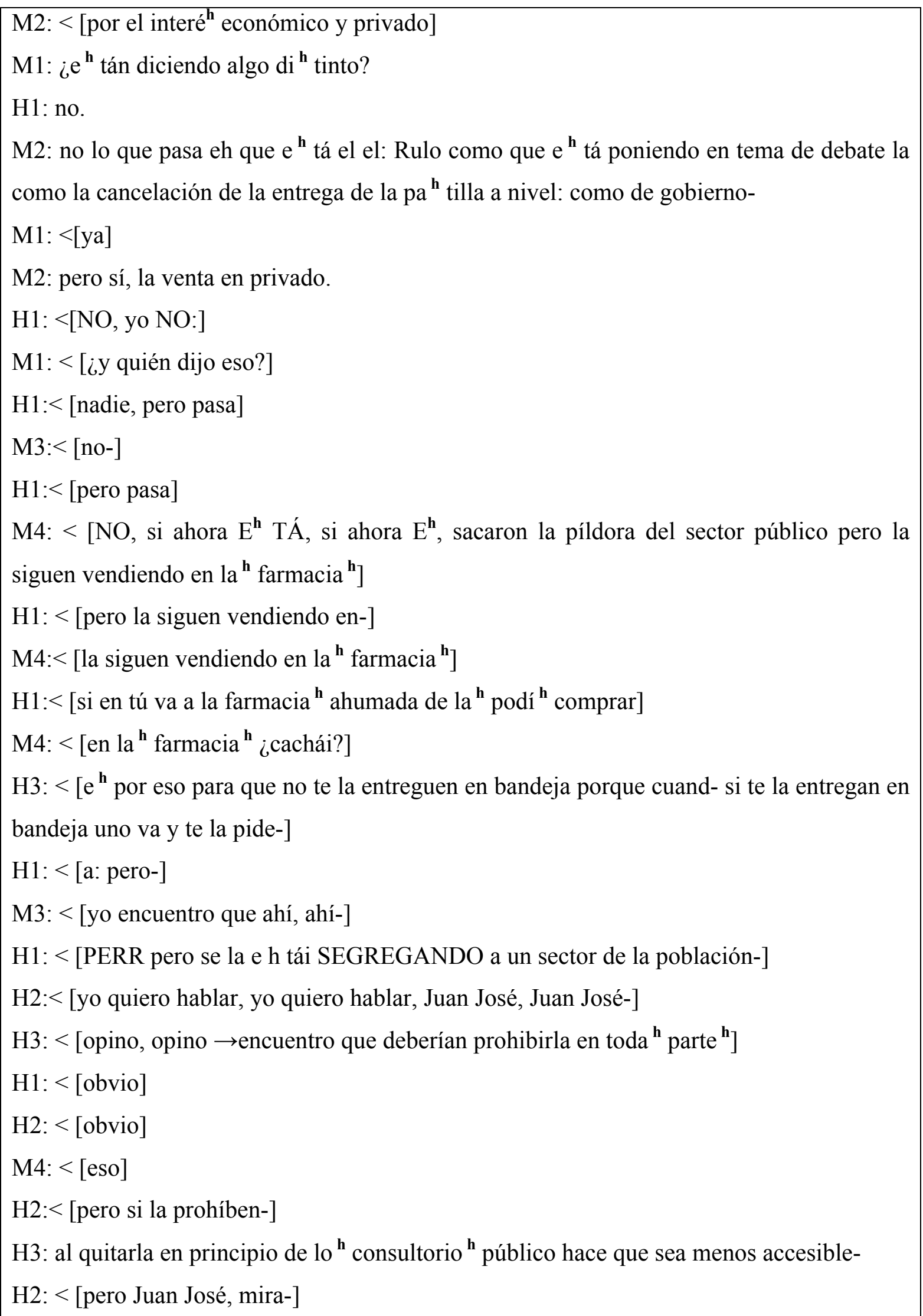


H1: $<$ [pero $\mathrm{e}^{\mathbf{h}}$ que se la $\mathrm{e}^{\mathbf{h}}$ ta limitando a un sector de la población-]

$\mathrm{H} 2:<$ [no tiene ni un $\mathrm{chi}^{\mathbf{h}}$ te]

M2: < [la democracia $\mathrm{e}^{\mathbf{h}}$ todo para todos, si no la vai a tener que no la tenga nadie $]>$

$\mathrm{H} 2:<\left[\right.$ mira digamo ${ }^{\mathbf{h}}$ que $\left.\rightarrow\right]$

$\mathrm{H} 1:<$ [eso no pasa nunca]

H2: digamo ${ }^{\mathbf{h}}$ que vale quince luca ${ }^{\mathbf{h}}$, para alguno $\mathrm{e}^{\mathbf{h}}$ que se la den en bandeja y pa otro ${ }^{\mathbf{h}} \mathrm{e}^{\mathbf{h}}$ inaccesible ¿cachái? y eso no $\mathrm{e}^{\mathbf{h}} \mathrm{ju}^{\mathbf{h}}$ to $\rightarrow$

M2: $<\left[\mathrm{e}^{\mathbf{h}}\right.$ que el tema- $]$

H2: en una democracia no $\mathrm{e}^{\mathbf{h}} \mathrm{ju}^{\mathbf{h}}$ to.

M1: < [a: bueno eh que si $\mathrm{e}^{\mathbf{h}}$ tamo $^{\mathbf{h}}$ hablando de ju ${ }^{\mathbf{h}}$ ticia entonce ${ }^{\mathbf{h}}$ un montón de cosa ${ }^{\mathbf{h}}$ po]

M3: $<$ [pero e ${ }^{\mathbf{h}}$ que en el caso- $]$

$\mathrm{H} 1:<$ [salgámono $^{\mathbf{h}}$ del tema, salgámono ${ }^{\mathbf{h}}$ del tema]

H2: NO pero $\mathrm{e}^{\mathbf{h}}$ que un gobierno no puede decir ya no la vamo ${ }^{\mathbf{h}}$ a: repartir grati ${ }^{\mathbf{h}}$, pero sí en $10^{\mathbf{h}} \mathrm{e}^{\mathbf{h}}$ tablecimiento ${ }^{\mathbf{h}}$ público ${ }^{\mathbf{h}}$.

M2: $<$ [no yo creo yo $\mathrm{e}^{\mathbf{h}}$ toy-].

H3: < [yo también creo que deberían-]

M2: no yo creo, creo que ahí hay un consenso ¿o no? ¿Hay alguien que $\mathrm{e}^{\mathbf{h}}$ té a favor de eso? $\mathrm{e}^{\mathbf{h}}$ tamo $^{\mathbf{h}}$ como di ${ }^{\mathbf{h}}$ cutiendo en la nada.

H1: entonce ${ }^{\mathbf{h}}$ pasamo $^{\mathbf{h}}$ al siguiente tema porque $\mathrm{e}^{\mathbf{h}}$ to $\mathrm{e}^{\mathbf{h}}$ realmente intransable.

H2: no sé yo creo que no nos vamos a poner de acuerdo \{risas\}.

\section{Descripción del episodio número 7}

Elementos indispensables de la argumentación (Lo Cascio, 1998)

Tema del episodio: Venta de la pastilla del día después en las farmacias.

Tesis: Si está a la venta en farmacias también debería estar disponible en lugares públicos.

Argumentos: Estamos en democracia y todos tenemos los mismos derechos. 
Regla General: Que esté disponible en lugares de salud públicos implica que todos los chilenos tengan acceso a la pastilla pues sería entregada de forma gratuita.

Elementos facultativos de la argumentación (Lo Cascio , 1998)

Refutación, contraopinión o reserva: Esta bien que no esté disponible en el sector público porque su uso estaría prácticamente en bandeja y eso no está bien.

\section{Estrategias de cortesía positiva}

(Brown P. y Levinson S. , 1987): Apele al “terreno común”. - Intensifique el interés hacia $O$.

- Exagere (interés, aprobación, simpatía con O)

- Fijese, atienda a $O$ (a sus intereses, deseos, necesidades, bienes).

Los enunciados de estos segmentos permiten demostrar la aprobación hacia el interlocutor. Estos enunciados intentan mantener el contacto y demostrar así el interés y el acuerdo.

$$
\begin{aligned}
& \text { H1: }<\text { [obvio] } \\
& \text { H2: }<\text { [obvio] } \\
& \text { M4: }<\text { [eso] } \\
& (\ldots) \\
& \text { M1: }<[y a]
\end{aligned}
$$

En el siguiente segmento se observa que M2 reconoce el punto de vista que está discutiendo “el Rulo", entonces parafrasea su postura y sintetiza su discurso. Esta estrategia funciona como un acto de reconocimiento a la propuesta discursiva del otro interlocutor y, en definitiva, es un acto halagador ya que no solo demuestra que estaba atenta a lo que su compañero decía, sino que además es capaz de reconstruirlo y resumirlo.

M2: no lo que pasa eh que $e^{\boldsymbol{h}}$ tá el el: Rulo como que $e^{\boldsymbol{h}}$ tá poniendo en tema de debate la como la cancelación de la entrega de la $\mathrm{pa}^{\boldsymbol{h}}$ tilla a nivel: como de gobierno-

Apele a la pertenencia al mismo grupo que 0 . Use marcadores de identidad de grupo. 
El uso de léxico juvenil (heavy), voseo $\operatorname{verbal}^{8}$ (cachái) léxico espontáneo (cachar) da cuenta de que se encuentran en una situación distendida lo que intensifica la pertenencia al grupo y los identifica como miembros del mismo.

M1: y eso yo lo encuentro muy heavy.

H1: < [yo igual pienso lo mi ${ }^{h}$ mo ¿cachái?]

Apele al punto de vista, opiniones, actitudes, conocimiento, empatía comunes. - Busque el acuerdo. Evite el desacuerdo. Presuponga/ suscite/ manifieste el terreno común. Bromee.

En los siguientes segmentos se hace explícito el acuerdo y los intentos por llegar a un consenso final:

M1: y eso yo lo encuentro muy heavy.

H1: < [yo igual pienso lo mi ${ }^{h}$ mo ¿cachái?]

M2: < [yo soy partidaria de la-]>

H1: yo igual pienso lo mi $^{\boldsymbol{h}}$ mo pero POR QUÉ pasa, por qué el gobierno no $e^{\boldsymbol{h}}$ capaz de poner decir ya no la venden y no la venden en ni un lado?

(...)

M2: no yo creo, creo que ahi hay un consenso ¿o no? ¿hay alguien que $e^{\boldsymbol{h}}$ té a favor de eso? $e^{h}$ tamo $^{h}$ como di ${ }^{h}$ cutiendo en la nada.

Indicadores gramaticales de cortesía positiva y negativa (Kerbrat-Orecchioni/Brown P. y Levinson S. ) (Haverkate)

\section{Indicadores gramaticales de cortesía positiva:}

- Uso de marcadores con intención fática y de aprobación para manifestar que se mantiene el contacto con el otro y la atención temática.

- Paráfrasis de los argumentos expuestos por otros participantes.

- Uso de léxico juvenil, voseo verbal, léxico espontáneo intensifica la pertenencia al grupo y los identifica como miembros del mismo.

- Manifestación explícita del acuerdo con el otro: "yo igual pienso lo mismo". Corroborar, mediante una pregunta, que están todos de acuerdo sobre el tema que se discute.

\footnotetext{
${ }^{8}$ Se observó anteriormente que el uso del voseo verbal en el español hablado en Chile está restringido a situaciones informales. (cfr. pág. 42)
} 


\section{$\mathbf{N}^{\circ}$ de episodio: 8}

O: ¿Es posible permitir el matrimonio homosexual en una sociedad como la chilena?, ¿qué pasaría con la adopción de niños?

M1: ¡chan!.

H1: $e^{\mathbf{h}}$ pera, ¿es posible de-

$\mathrm{H} 2:<\left[\mathrm{exi}^{\mathbf{h}}\right.$ te la posibilidad]

O: ¿es posible permitir el matrimonio homosexual-

M1: < [ pregunto]

O: en una sociedad como la chilena? ¿Y qué pasaría con la adopción de niños?

$\mathrm{H} 1:<[\mathrm{ya}]$

M1: Pero ¿qué tipo de matrimonio?

$\mathrm{O}$ : homosexual

$\mathrm{H} 1:<[$ homosexual]

M1: pero civil o:-

H2: civil po ${ }^{\mathbf{h}}$.

$\mathrm{M} 2:<\left[\right.$ da lo $\mathrm{mi}^{\mathbf{h}}{ }^{\mathrm{mo}} \mathrm{mo}$

H1: ¿cómo va a ser religioso?

M4: $<$ [civil]

H1: ya yo creo-

M1: $<$ [no pero eh que hay mucha ${ }^{\mathbf{h}}$ pareja $^{\mathbf{h}}$ de gay que se quieren casar por la iglesia] $\mathrm{H} 1:<$ [a: sí] ya yo creo mi opinión de que si $\mathrm{e}^{\mathbf{h}}$ posible o no $\mathrm{e}^{\mathbf{h}}$ posible ahora de que si $\mathrm{e}^{\mathbf{h}}$ tá correcto o no mi opinión eh que no $\mathrm{e}^{\mathbf{h}}$ tá correcto $\rightarrow$

M2: $<$ [yo creo que no va por el tema de-]

H1: pero $\mathrm{e}^{\mathbf{h}}$ que se supone que $\mathrm{e}^{\mathbf{h}}$ posible porque igual $\mathrm{e}^{\mathbf{h}}$ tamo como en una sociedad que es laica absolutamente, y que se supone que: pucha | cuáles son su ${ }^{\mathbf{h}}$ valore $^{\mathbf{h}}$, o sea en realidad no $\mathrm{e}^{\mathbf{h}}$ que tenga ningún valor sino que se supone que hay un sena:do y di ${ }^{\mathbf{h}}$ cute lo ${ }^{\mathbf{h}}$ te:ma y a la conclusión que llegan ello ${ }^{\mathbf{h}}$ entonce $^{\mathbf{h}} \mid$ si de repente todo lo ${ }^{\mathbf{h}}$ del senado son homosexuale ${ }^{\mathbf{h}} \rightarrow\{$ risas $\} \| \mathrm{e}^{\mathbf{h}}$ posible ¿cachái? | exi ${ }^{\mathbf{h}}$ te la posibilidad ahora, yo no creo que $\mathrm{e}^{\mathbf{h}}$ té bueno porque según yo la homosexualidad $\mathrm{e}^{\mathbf{h}}$ algo como | antinaturaleza | ¿cachái? aparte de diga lo que diga Dios | la homosexualidad $\mathrm{e}^{\mathbf{h}}$ algo que no $\mathrm{e}^{\mathbf{h}}$ natural ¿cachái?, y que $\mathrm{e}^{\mathbf{h}}$ como pa mí $\mathrm{e}^{\mathbf{h}}$ una desviación $\rightarrow$ 
H2: $<$ [pero, pero, pero] $>$

H1: el hombre y la mujer fueron hecho ${ }^{\text {h }}$ de cierta manera, y: | naturalmente el hombre y la mujer se atraen entre ellos, o sea hombre y mujer no hombre hombre mujer con mujer $\rightarrow$

H2: $<$ [ya pero, pero- $]>$

M2: < [yo tengo una visión mucho máh linda de eso] $>$

\{risas\}

H1: y además, me parece que $\rightarrow$

M3: $<[$ ¿cuál? $]>$

H1: $\mathrm{e}^{\mathbf{h}}$ lo mi ${ }^{\mathbf{h}}$ mo | como no podí ${ }^{\mathbf{h}}$ y má ${ }^{\mathbf{h}}$ encima $\mathrm{e}^{\mathbf{h}}$ tá el asunto de la adopción de hijo ¿cachái? una pareja homosexual no puede tener un hijo porque $\mathrm{e}^{\mathbf{h}}$ como | imagínate el trauma para el niño el no saber | quién eh el papá quién eh la mamá, o e ${ }^{\mathrm{h}}$ pera dónde- ¿me entendí ${ }^{\mathbf{h}}$ ?

H2: pero, pero volviendo a lo $\mathrm{mi}^{\mathbf{h}}$ mo tu no eri ${ }^{\mathbf{h}}$ quien para imponer tu: | tu opinión M2: $<$ [entonce ${ }^{\mathbf{h}}$ pa qué $\mathrm{e}^{\mathbf{h}}$ tamo ${ }^{\mathbf{h}}$ hablando si nadie $\mathrm{e}^{\mathbf{h}}$ quien-]

M1: $<$ [imagínate ir a un colegio y que a la ${ }^{\mathbf{h}}$ reunione $^{\mathbf{h}}$ va a ir tu papá $\mid$ y su papá $]$

M3: $<$ [y su papá $]$

$\mathrm{H} 1:<$ [y su papá $]$

\{risas\}

H1: no pero aparte de lo chi ${ }^{\mathbf{h}}$ toso, yo no no $\mathrm{e}^{\mathbf{h}}$ una cue ${ }^{\mathbf{h}}$ tión que por mí yo la quiera imponer $\mid \mathrm{e}^{\mathbf{h}}$ una cosa que yo observo | la nat- mira solamente $\mathrm{e}^{\mathbf{h}}$ observación yo observo cómo la naturaleza, Dios como quieran llamarlo, creó al ser humano hombre mujer que $\mathrm{e}^{\mathbf{h}}$ tán hecho ${ }^{\mathrm{h}}$ para repro- para que se unan y se reprodu ${ }^{\mathrm{h}}$ can-

M3: < [¿Adán y Eva?]

H1: no necesariamente\{risas\}

H1: $\mathrm{e}^{\mathbf{h}}$ que yo trato $\mathrm{e}^{\mathbf{h}}$ que yo de: en $\mathrm{e}^{\mathbf{h}} \operatorname{ta}^{\mathbf{h}} \operatorname{cosa}^{\mathbf{h}}$, aunque tenga $\mathrm{mi}^{\mathbf{h}}$ creencia $^{\mathbf{h}}$ religiosa ${ }^{\mathbf{h}}$ । trato de ser má ${ }^{\mathbf{h}}$ objetivo | me parece que la naturaleza | creó a:1 hombre y mujer y que $\mathrm{e}^{\mathbf{h}}$ tán hecho ${ }^{\mathbf{h}}$ para unirse y que $1 \mathrm{e}^{\mathbf{h}}$ dio hormonas que hacen que se atraigan entre ellos, entonce $^{\mathrm{h}}$ que un: no me pueden decir a mí que un hombre atrae a un hombre porqueM2: $<[$ Gonzalo $]$ \{risas\} 


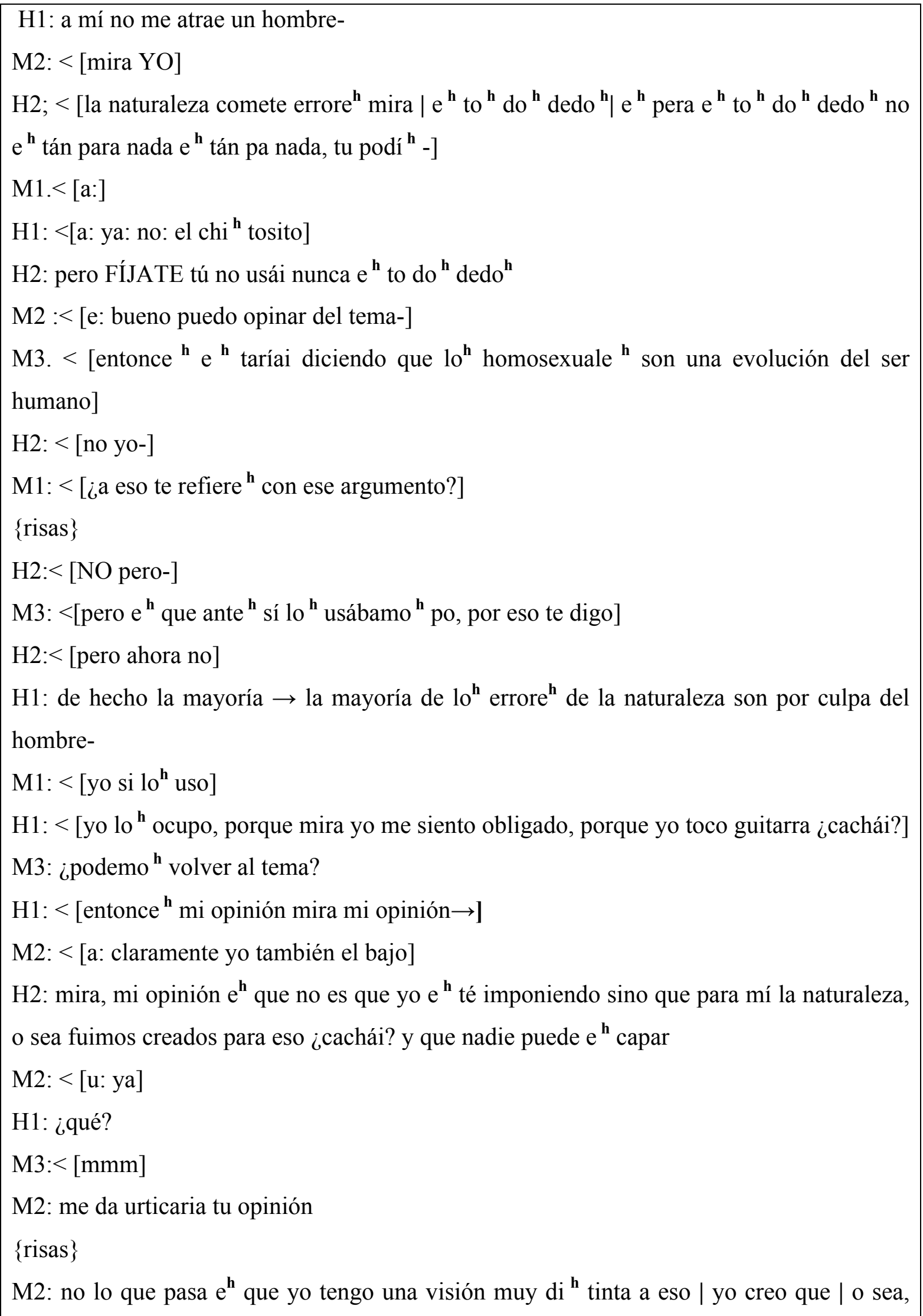


tengo | he logrado deshacerme de las influencias de mi | de mi llámese familia:, colegio e: círculo social etc. , pero YO no sé yo sé que va a ser súper utópico lo que yo digo, pero yo creo que la ${ }^{\mathbf{h}}$ relacione $^{\mathbf{h}}$ de AMOR | no: no la podi $\mathbf{h}^{\mathbf{h}}$ | manife ${ }^{\mathbf{h}} \operatorname{tar}_{\text {tan }}$ drá $^{\mathbf{h}}$ ticamente como con la naturaleza nos creó con hormonas de- , o sea para mí la HOMOSEXUALIDAD | es una manifestación de amor que lamentablemente en el sentido de de que e ${ }^{\mathbf{h}}$ tamo $^{\mathbf{h}}$ involucrado ${ }^{\mathbf{h}}$ en una sociedad coincide en que la persona que amas tiene tu $\mathrm{mi}^{\mathbf{h}}$ mo sexo tu $\mathrm{mi}^{\mathbf{h}}$ mo género, y que por tanto, e: | el daño que involucra $\mathrm{e}^{\mathbf{h}}$ to $\mathrm{e}^{\mathbf{h}}$ básicamente el ca ${ }^{\mathbf{h}}$ tigo social

$\mathrm{H} 1:<$ [mira]

M2: mientra ${ }^{\mathbf{h}}$ la sociedad no acepte $\mathrm{e}^{\mathbf{h}}$ to no se puede manife ${ }^{\mathbf{h}} \operatorname{tar} \mid$ e: $\sin _{\text {consecuencia }}{ }^{\mathbf{h}}$ negativa $^{\mathbf{h}}$, ni matrimonio, ni adopción $\mid$ di ${ }^{\mathbf{h}}$ tinto sería si por ejemplo | e: la homosexualidad fuese aceptada a nivel social | ¿cuál sería el problema de que el niño tuviese papá y papá? Si millone ${ }^{\mathbf{h}}$ de $_{\text {persona }}{ }^{\mathbf{h}}$ se crían solo con mamá ${ }^{\mathbf{h}}$, o solo con papá y con carencia del otro-

H1: < [ya mira-]

M2: en el fondo el: | el e ${ }^{\mathbf{h}}$ quema de familia mamá papá hijo que tan acostumbrado ${ }^{\mathbf{h}} \mathrm{e}^{\mathbf{h}}$ tamo $^{\mathbf{h}}$ a ver yo no creo que afecte, siempre y cuando el círculo social no lo haga así, hace años atrás el no tener mamá, no tener papá era mal vi ${ }^{\mathbf{h}}$ to terrible, o sea, el niño que era mamá soltera | e: DI ${ }^{\mathrm{h}}$ CULPAMÉ recibía una recriminación que hoy en día no se ve porque ya se aceptó socialmente ¿qué pasa con la homosexualidad? Mientras no se acepte socialmente va a seguir adquiriendo e: $\mid$ matice $^{\mathbf{h}}$ negativo $^{\mathbf{h}}$ y va a tener influencia ${ }^{\mathbf{h}}$ negativa $^{\mathbf{h}}$, en la sociedad de hoy en día, YO creo, que es imposible permitir e: | me voy a un tema má ${ }^{\mathbf{h}}$ mayor e: la adopción | básicamente porque ahí ya $\mathrm{e}^{\mathbf{h}}$ tá $^{\mathbf{h}}$ influyendo en otro ser vivo que que va a te- recibir $\mathrm{la}^{\mathbf{h}}$ consecuencia ${ }^{\mathbf{h}}$ de una sociedad que $\mathrm{e}^{\mathbf{h}}$ tá recriminando.

H1: sabí ${ }^{\mathbf{h}}$ lo que pasa $\mathrm{e}^{\mathbf{h}}$ que mira yo | por lo meno ${ }^{\mathbf{h}}$ tengo otra otra visión, mira, EL cuando exi $^{\mathbf{h}}$ te amor el amor tiene como di ${ }^{\mathbf{h}} \operatorname{tinta}^{\mathbf{h}}$ faceta $^{\mathbf{h}}$ ya y exi ${ }^{\mathbf{h}}$ ten como caracterí ${ }^{\mathbf{h}}$ tica $^{\mathbf{h}}$ que e ${ }^{\mathbf{h}}$ tán en toda $\mathbf{~}^{\mathbf{h}}$ en toda $\mathbf{h}^{\mathbf{h}}$ la: $\mid$ como $\mathbf{a}^{\mathbf{h}}$ relacione $^{\mathbf{h}}$ amorosa $^{\mathbf{h}} \mid$ ya, una de esa faceta ${ }^{\mathbf{h}} \mathrm{e}^{\mathbf{h}}$ la atracción ¿cachái? , y y: por lo $\mathrm{mi}^{\mathbf{h}} \operatorname{mo~}^{\mathbf{h}}$ que exi ${ }^{\mathbf{h}}$ te una pareja ¿cachái? porque $\mathrm{e}^{\mathbf{h}}$ verdad que a mí como hombre me atraen las mujere ${ }^{\mathbf{h}}$, pero $\mathrm{e}^{\mathbf{h}}$ como una cosa por $\mid$ cosa de cuerpo $^{\mathbf{h}}$, pero $\mathrm{e}^{\mathbf{h}}$ diferente a la atracción que yo pueda sentir por cualquier mujer | a la que 


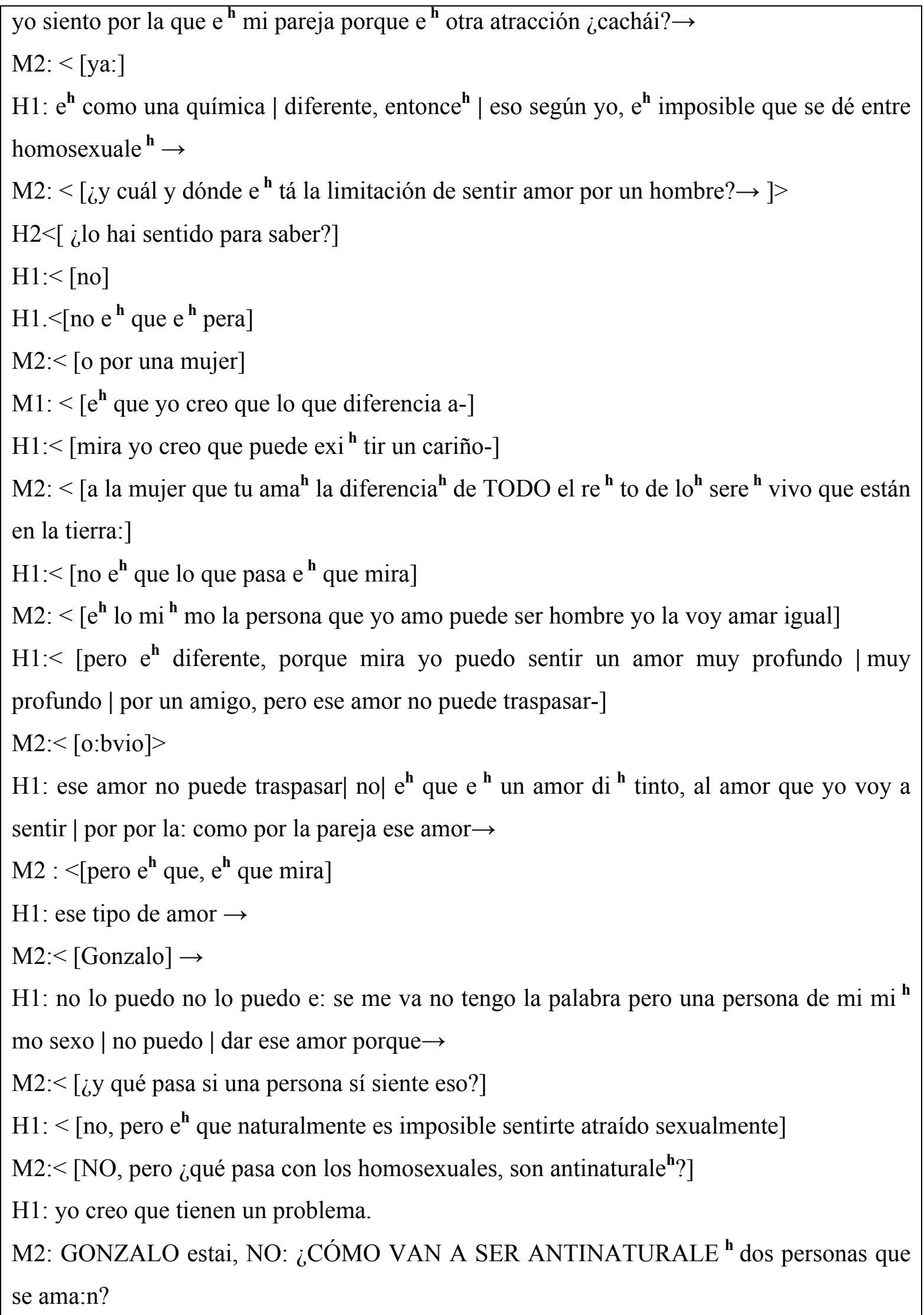


$\mathrm{H} 1:<\left[\mathrm{e}^{\mathrm{h}}\right.$ antinatural ¿qué tiene que ver-?]

$\mathrm{M} 1:<[\mathrm{NO}:]$

H2: es que es como NAZI tu postura po:

$\mathrm{H} 1:<\left[\mathrm{e}^{\mathbf{h}}\right.$ que yo, $\mathrm{e}^{\mathbf{h}}$ mi postura, mira- $]$

H2: NAZI

\section{Descripción del episodio número 8}

Elementos indispensables de la argumentación (Lo Cascio, 1998)

Tema del episodio: El matrimonio homosexual.

Tesis: No estaría bien que se aprobara el matrimonio civil homosexual en Chile.

Argumentos: 1. Porque las relaciones homosexuales son antinaturales. 2. Dos hombres o dos mujeres no pueden educar a un niño. 3. No es el mismo amor el que sienten los homosexuales.

Regla General: Lo natural es el matrimonio entre mujer y hombre al igual que la educación de los niños.

Elementos facultativos de la argumentación (Lo Cascio, 1998)

Refuerzo: (de argumento 2) no es posible la adopción de parte de parejas homosexuales porque la sociedad chilena discriminaría mucho a esos niños.

Calificador: La sociedad chilena no está preparada para afrontar este cambio, habría consecuencias negativas.

Refutación, contraopinión o reserva: El matrimonio homosexual es posible si hay un cambio en la sociedad y se acepta que esto suceda normalmente.

Falacias argumentativas (Lo Cascio (1998))

Argumentum ad consequentiam: Sirve para juzgar negativamente una afirmación, una tesis, no mediante argumentos externos, sino a través de las consecuencias que pueden derivarse de tales afirmaciones.

Este argumento está orientado a reflexionar sobre las consecuencias de que se apruebe el matrimonio homosexual en Chile, ya que se centra en el tema de la adopción de niños. 
H1: $e^{\boldsymbol{h}}$ lo mi ${ }^{\boldsymbol{h}}$ mo | como no podi ${ }^{\boldsymbol{h}}$ y má ${ }^{\boldsymbol{h}}$ encima $e^{\boldsymbol{h}}$ tá el asunto de la adopción de hijo ¿cachái? una pareja homosexual no puede tener un hijo porque $e^{\boldsymbol{h}}$ como | imagínate el trauma para el niño el no saber | quien eh el papá quien eh la mamá, o e ${ }^{h}$ pera dónde- ¿me entendi ${ }^{h}$ ?

\section{Falacias no formales encontradas en este episodio:}

Reductio ad Hitlerum, falacia que si bien puede ser clasificada dentro de la del tipo ad hominem, corresponde más bien a una subclasificación de esta, pues recurre directamente a la figura de Hitler (o a los ideales del nazismo), la cual es comparada con los argumentos a los que alude el interlocutor. En este segmento, H1 propone que no es normal ni natural un tipo de relación homosexual, inmediatamente es criticado por su postura extremista y es catalogado de nazi:

M2: GONZALO estai, NO: ¿CÓMO VAN A SER ANTINATURALE ${ }^{\boldsymbol{h}}$ dos personas que se ama:n?

H1: $<\left[e^{h}\right.$ antinatural ¿qué tiene que ver-?]

$M 1:<[N O:]$

H2: es que es como NAZI tu postura po:

H1: $<\left[e^{h}\right.$ que yo, e mi postura, mira- $]$

H2: $N A Z I$

\section{Estrategias de cortesía positiva}

(Brown P. y Levinson S. , 1987): Apele al “terreno común”. - Intensifique el interés hacia $O$.

- Exagere (interés, aprobación, simpatía con O)

- Fíjese, atienda a $O$ (a sus intereses, deseos, necesidades, bienes).

En estos enunciados los conectores pragmáticos metadiscursivos permiten que la conversación continúe demostrando aprobación hacia el interlocutor, pues manifiestan el interés al intentar mantener el contacto. Estos enunciados intentan mantener el contacto y demostrar así el interés y el acuerdo.

$H 1:<[y a]$

(...)

M2: < [yo tengo una visión mucho máh linda de eso]>

$\{$ risas\}

H1: y además, me parece que $\rightarrow$

M3: < [icuál?]> 
(...)

M2: $\leq[y a:]$

(...)

Apele a la pertenencia al mismo grupo que 0 . Use marcadores de identidad de grupo.

El uso de léxico juvenil $\left(\right.$ chan $\left.^{9}\right)$, voseo verbal ${ }^{10}$ (cachái) léxico espontáneo (cachar, po ${ }^{l 1}$ ) da cuenta de que se encuentran en una situación distendida lo que intensifica la pertenencia al grupo y los identifica como miembros del mismo.

M1: ¡chan!.

(...)

H2: civil po $^{h}$.

(...)

H1: < [yo lo ${ }^{\boldsymbol{h}}$ ocupo, porque mira yo me siento obligado, porque yo toco guitarra ¿cachái?]

Apele al punto de vista, opiniones, actitudes, conocimiento, empatía comunes. - Busque el acuerdo. Evite el desacuerdo. Presuponga/ suscite/ manifieste el terreno común. Bromee.

Se hacen bromas que permiten que el ambiente del debate sea más agradable:

M1: ¡chan!.

(...)

H1: pero $e^{h}$ que se supone que $e^{h}$ posible porque igual $e^{h}$ tamo como en una sociedad que es laica absolutamente, y que se supone que: pucha|cuáles son su ${ }^{\boldsymbol{h}}$ valore $^{\boldsymbol{h}}$, o sea en realidad no $e^{h}$ que tenga ningún valor sino que se supone que hay un sena:do y di ${ }^{\boldsymbol{h}}$ cute lo ${ }^{h}$ te:ma y a la conclusión que llegan ello ${ }^{h}$ entonce ${ }^{h} \mid$ si de repente todo ${ }^{h}{ }^{h}$ del senado son homosexuale $^{h} \rightarrow\{$ risas $\} \|$

Estrategias de atenuación cortés (Briz, 2001)

Se aminoran cualidades, actitudes y acciones del yo.

Este segmento muestra que la pregunta que realiza M2 es cortés precisamente porque mitiga el enfrentamiento que puede haber entre dos posturas, ella en vez de mencionar

\footnotetext{
${ }^{9}$ Fórmula que tiene por intención indicar jocosamente que es polémico el tema que se está conversando.

${ }^{10}$ Se observó anteriormente que el uso del voseo verbal en el español hablado en Chile está restringido a situaciones informales. (cfr. pág. 42)

${ }^{11}$ Pos.marcador discursivo. Pues; se usa para enfatizar o remarcar una aseveración u orden, espontáneo. (DUECh, 2010)
} 
directamente que no está de acuerdo con esta postura, permite que su interlocutor dé su opinión primero y luego ella da la suya.

M2: < [¿y qué pasa si una persona sí siente eso?]

H1: < [no, pero $e^{h}$ que naturalmente es imposible sentirte atraido sexualmente]

M2: $<$ [NO, pero ¿qué pasa con los homosexuales, son antinaturale ${ }^{\boldsymbol{h}}$ ?]

H1: yo creo que tienen un problema.

Indicadores gramaticales de atenuación cortés (Kerbrat-Orecchioni) (Haverkate)

Se aminoran cualidades, actitudes y acciones del yo.

- Preguntar al otro sobre el desacuerdo en vez de decirlo directamente.

Indicadores gramaticales de cortesía positiva y negativa (Kerbrat-Orecchioni/Brown P. y Levinson S. ) (Haverkate) Indicadores gramaticales de cortesía positiva:

- Uso de marcadores con intención fática y de aprobación, asentir, reír, todo esto para manifestar que se mantiene el contacto con el otro y la atención temática.

- Uso de léxico juvenil, voseo verbal, léxico espontáneo intensifica la pertenencia al grupo y los identifica como miembros del mismo.

- Hacer bromas.

\section{$\mathbf{N}^{\circ}$ de episodio: 9}

H1: no $\mid$ mira yo| pero mira, e $^{\mathbf{h}}$ que yo $\mid$ mira, igual mi postura | ya: yo pienso eso | mi postura podrá ser rara, como quieran, pero cuando | si yo conozco homosexuale ${ }^{\mathbf{h}}$ yo no tengo problemas en relacionarme con ello ${ }^{\mathbf{h}}$ | yo no, si yo fuera presidente de un país, rey, dictador, lo que sea, yo no andaría matando homosexuale ${ }^{\mathrm{h}} \rightarrow$

M1: < [o:bvio, todo ${ }^{\mathbf{h}}$ entendemo ${ }^{\mathbf{h}}$ eso $]$

H1: y: de hecho ${ }^{\mathbf{h}}$, para mí, si do ${ }^{\mathbf{h}}$ persona $^{\mathbf{h}}$ se aman | mira, para mí por muy extraño que sea| yo apoyo, de hecho mi hermano tiene una relación muy rara con una mina $\mid$ y a mí no me agrada, pero lo apoyo igual, entonce ${ }^{\mathrm{h}} \mid$ yo creo que en contra, pero en contra de $\mathrm{mi}^{\mathbf{h}}$ valo $^{\mathbf{h}-}$ de mí yo podría apoyar lo que sienten, pero ME parece que, hablando como en la parte teórica | la homosexualidad no está bien.

M1: mira, puede que: | yo estoy de acuerdo en el tema de que hay haya un tema más, más 
biológico comprometido en: en algunos casos de homosexualidad | e: | siento que-

$\mathrm{M} 2:<[$ ¿en qué sentido biológico?]>

M1: ¿ah?

M2: ¿en qué sentido biológico?

M1: tengo entendido de que hay como cierto tema hormona:1, metido en la sexualidad cuando uno tiene desviaciones-

M2: $<$ [ yo fui a uno ${ }^{\mathbf{h}}$ curso máh allá de la malla que lo dan aquí mi ${ }^{\mathbf{h}}$ mo, de hecho $\mathrm{e}^{\mathbf{h}}$ una sicóloga de la homosexualidad, y bueno ella no ${ }^{\mathbf{h}}$ explicó-]

M1: $<$ a: perfecto ahí no ${ }^{\mathbf{h}}$ podí $\mathbf{h}^{\mathbf{h}}$ interiorizar, con mayor base $]>$

M2: no ${ }^{\mathbf{h}}$ dio un montón de prueba ${ }^{\mathbf{h}} \mid$ de que uno no NACE $\mid$ homosexual -

H1: $<$ [no uno no nace homosexual]

M2: uno se HACE y siempre son desvirtuaciones, o sea no es una anormalidad | es una mutua- mutación $\rightarrow$

M1: < [sí po, $\mathrm{e}^{\mathbf{h}}$ tamo $^{\mathbf{h}}$ completamente de acuerdo, si de hecho yo no ocupo la-]

M2: y la LIBERACIÓN |¿cachái? de lo homosexuale ${ }^{\mathbf{h}}$ ante la sociedad, en cierta forma que sea que esta mutua- mutación que se está dando lentamente |empezara a hacerse así | ¿me entendí ${ }^{\mathbf{h}}$ ? entonce ${ }^{\mathbf{h}}$ ello ${ }^{\mathbf{h}} \mathrm{e}^{\mathbf{h}}$ tán liberado en cierta forma dudaban , ¿cachái?, NO eran felice ${ }^{\mathbf{h}}$ porque $10^{\mathrm{h}}$ homosexuale ${ }^{\mathrm{h}}$ no son felice ${ }^{\mathrm{h}}$ cien por ciento ${ }^{\mathbf{h}}$ si tú le preguntai a un homosexuale $^{\mathbf{h}}$ que tiene | una relación que ama, si tú le preguntái en el fondo de su alma "si $\mathrm{e}^{\mathbf{h}}$ feli ${ }^{\mathbf{h}}$ " no, por mucho factore ${ }^{\mathbf{h}}$, sea su familia, sea socialmente, porque su sueño de familia no $10^{\mathbf{h}}$ puede tener etc. ¿cachái? entonce ${ }^{\mathbf{h}} \mathrm{e}^{\mathbf{h}}$ por eso, si uno en cierta forma le ${ }^{\mathbf{h}}$ abre esa ventana $\mid$ a ello ${ }^{\mathbf{h}}$ cachái $\mid$ empieza así no ma ${ }^{\mathbf{h}}$ po.

M1: $<$ [yo quiero- $]$

H1: < [yo por eso no apoyo a lo homosexuale ${ }^{\mathbf{h}}$, de hecho lo explicó mejor que yo]

\section{Descripción del episodio número 9}

Elementos indispensables de la argumentación (Lo Cascio, 1998)

Tema del episodio: La homosexualidad.

Tesis: La homosexualidad es una desviación.

Argumentos: Una persona no nace homosexual, se hace. 
Regla General: La sociedad, el contexto sociocultural conformarían la personalidad de los homosexuales.

Elementos facultativos de la argumentación (Lo Cascio (1998))

Fuentes: cursos realizados en la universidad.

Falacias argumentativas (Lo Cascio (1998))

Argumentum ad populum: Apelar a las emociones de una multitud. Se mencionan datos que pueden sensibilizar al auditorio pues se habla de los sentimientos de insatisfacción de los homosexuales, de sus tristezas.

M2: y la LIBERACIÓN ¿¿cachái? de lo homosexuale ${ }^{h}$ ante la sociedad, en cierta forma que sea que esta mutua- mutación que se está dando lentamente |empezara a hacerse así ¿ime entendi ${ }^{h}$ ? entonce ${ }^{h}$ ello ${ }^{h} e^{h}$ tán liberado en cierta forma dudaban, ¿cachái?, NO eran felice ${ }^{h}$ porque $_{\text {lo }}{ }^{\boldsymbol{h}}$ homosexuale ${ }^{\boldsymbol{h}}$ no son felice ${ }^{\boldsymbol{h}}$ cien por ciento ${ }^{\boldsymbol{h}}$ si tú le preguntái a un homosexuale que tiene | una relación que ama, si tu le preguntai en el fondo de su alma "si $e^{h}$ feli ${ }^{h}$ " no, por mucho factore ${ }^{h}$, sea su familia, sea socialmente, porque su sueño de familia no lo ${ }^{h}$ puede tener etc. ¿cachái? entonce $e^{h} e^{h}$ por eso, si uno en cierta forma le abre esa ventana $\mid$ a ello ${ }^{h}$ cachái $\mid$ empieza así no ma ${ }^{h}$ po.

\section{Estrategias de cortesía positiva}

(Brown P. y Levinson S. , 1987): Apele al “terreno común”. - Intensifique el interés hacia $O$.

- Exagere (interés, aprobación, simpatía con O)

- Fijese, atienda a $O$ (a sus intereses, deseos, necesidades, bienes).

En los siguientes segmentos se pueden apreciar intentos por manifestar el interés. M2 y M1 hacen preguntas directas sobre lo que hablan a otros participantes para involucrarlos en el debate y demostrar así que están atentos a lo que otros dicen. Por su parte H1 manifiesta el acuerdo repitiendo lo que acaba de afirmar M2 y, por último, M1 indica el acuerdo.

M2: < [¿en qué sentido biológico?]>

M1: ¿ah?

M2: ¿en qué sentido biológico?

(...)

M2: no ${ }^{\boldsymbol{h}}$ dio un montón de prueba ${ }^{\boldsymbol{h}} \mid$ de que uno no NACE | homosexual -

H1: < [no uno no nace homosexual]

(...)

M1: < [si po, $e^{h}$ tamo ${ }^{h}$ completamente de acuerdo, si de hecho yo no ocupo la-]

Apele a la pertenencia al mismo grupo que 0 . Use marcadores de identidad de grupo. 
El uso de léxico juvenil (mina), voseo verbal ${ }^{12}$ (entendi, cachái, preguntái) léxico espontáneo (po, cachar) da cuenta de que se encuentran en una situación distendida lo que intensifica la pertenencia al grupo y los identifica como miembros del mismo.

H1: y: de hecho ${ }^{h}$, para mí, si do ${ }^{h}$ persona $^{h}$ se aman | mira, para mí por muy extraño que sea $\mid$ yo apoyo, de hecho mi hermano tiene una relación muy rara con una mina $\mid$

(...)

M2: y la LIBERACIÓN ¿_cachái? de lo homosexuale ${ }^{h}$ ante la sociedad, en cierta forma que sea que esta mutua- mutación que se está dando lentamente |empezara a hacerse así i ¿me entendi $^{h}$ ? entonce $e^{h}$ ello ${ }^{h} e^{h}$ tán liberado en cierta forma dudaban , cachái, NO eran felice ${ }^{\boldsymbol{h}}$ porque $_{\text {lo }}{ }^{h}$ homosexuale $^{h}$ no son felice ${ }^{h}$ cien por ciento ${ }^{h}$ si tú le preguntái a un homosexuale que tiene | una relación que ama, si tu le preguntai en el fondo de su alma "si $e^{h}$ feli $\boldsymbol{h} "$ no, por mucho factore ${ }^{h}$, sea su familia, sea socialmente, porque su sueño de familia no lo ${ }^{h}$ puede tener etc. ¿cachái? entonce $e^{h} e^{h}$ por eso, si uno en cierta forma le $e^{h}$ abre esa ventana $\mid$ a ello ${ }^{h}$ cachái $\mid$ empieza así no $\mathrm{ma}^{h}$ po.

Apele al punto de vista, opiniones, actitudes, conocimiento, empatía comunes. - Busque el acuerdo. Evite el desacuerdo. Presuponga/ suscite/ manifieste el terreno común. Bromee.

Estos segmentos muestran el acuerdo de forma explícita, incluso vemos como M1 realiza un acto halagador para $\mathrm{M} 2^{13}$, pues le cede el turno pidiéndole que profundice en su explicación pues ella está más informada. Luego vemos el otro segmento en el que H1 afirma que M2 explicó el tema mejor que él.

M2: < [ yo fui a uno ${ }^{h}$ curso máh allá de la malla que lo dan aquí mi ${ }^{h}$ mo, de hecho $e^{h}$ una sicóloga de la homosexualidad, y bueno ella no ${ }^{h}$ explicó-]

M1: < [a: perfecto ahi no ${ }^{h}$ podi $^{h}$ interiorizar, con mayor base]>

(...)

H1: < [yo por eso no apoyo a lo homosexuale ${ }^{h}$, de hecho lo explicó mejor que yo]

\footnotetext{
${ }^{12}$ Se observó anteriormente que el uso del voseo verbal en el español hablado en Chile está restringido a situaciones informales. (cfr. pág. 42)

${ }^{13}$ Es interesante que este acto halagador no tenga una retribución de parte de la persona que recibe este reconocimento. De haber sido así, habríamos incluido este segmento entre las estrategias de retribución de un acto halagador $^{13}$ (Kerbrat-Orecchioni): A presta a B algún servicio (FFA) y entonces B intenta producir un FFA (agradecimiento o gentileza), para restablecer el equilibrio ritual entre los interactuantes. Cuanto más importante es el FFA, tanto debe serlo igualmente el FFA recíproco.
} 
Indicadores gramaticales de cortesía positiva y negativa (Kerbrat-Orecchioni/Brown P. y Levinson S. ) (Haverkate)

\section{Indicadores gramaticales de cortesía positiva:}

- Uso de marcadores con intención fática y de aprobación, asentir, hacer preguntas, todo esto para manifestar que se mantiene el contacto con el otro y la atención temática.

- Uso de léxico juvenil, voseo verbal, léxico espontáneo intensifica la pertenencia al grupo y los identifica como miembros del mismo.

- Manifestar el acuerdo explícitamente.

\section{$\mathbf{N}^{\circ}$ de episodio: 10}

M1: yo quiero, quiero tomar lo que dijo la:, pero, yo creo que lo que acaba de decir la Flo no va a vía de nada, o sea, $\mathrm{e}^{\mathbf{h}}$ como una afirmación que yo la voy a tomar ma ${ }^{\mathbf{h}}$ objetiva, ademá $^{\mathbf{h}}$ que, no tengo mayor conocimiento que el de ella en $\mathrm{e}^{\mathbf{h}}$ to $\mid$ de hecho yo no uso la palabra "desviación sexual", porque no creo que lo sea | ahora si tu me decíh que bio- que no hay influencia biológica mejor po me alivianai má ${ }^{\mathbf{h}}$ mi forma de pensar porque ya esto pasa a ser, netamente desarrollo: $\rightarrow$

$\mathrm{H} 1:<[$ sicológico $]$

M1: sí, y para eso me facilita mucho ma ${ }^{\mathbf{h}}$ la posibilidad de pensar que alguien ama de corazón y que no está programado para-

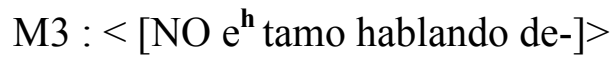

M2 : $<$ [NO, no $\mathrm{e}^{\mathbf{h}}$ tamo hablando de amor]

$\mathrm{H1}:<$ [Francisca mira, ponte, ponte en el siguiente caso]

M1: $<$ [para MÍ e $\mathrm{e}^{\mathbf{h}}$ amor, cuando una persona quiere formar familia con otra-]

$\mathrm{H1}$ : < ¿pero qué familia? si son homosexuales]

M2: $<$ [pero e $\mathrm{e}^{\mathbf{h}}$ que cachái que tu podí- $]$

$\mathrm{H} 1:<[$ si son hombre hombre, no puede existir familia] 
M1: $<$ [GONZA:LO $\rightarrow$ qué pasa si a mí me gut ${ }^{\mathrm{h}}$ ara una mujer ¿yo no tengo derecho a tener familia?]

H1: ¿y el padre de tu hijo, dónde va a estar ahí? $\rightarrow$ [¿dónde, dónde metí al padre?]

M1: < [ e que ahí tiene ${ }^{\mathbf{h}}$ metido el e $\mathrm{e}^{\mathbf{h}}$ quema papá, mamá, hijo]

H1: < [pero ep ${ }^{\mathbf{h}}$ era ¿cómo pensai concebir-?]

$\mathrm{M} 2:<$ claro]

M1: < [y una familia ¿tiene que ser papá, mamá, hijo, tengo que conseguir un niño y una pareja feliz para ser una familia?]

$\mathrm{H} 1:<$ [o sea, $\mathrm{e}^{\mathbf{h}}$ que lo otro $\mathrm{e}^{\mathbf{h}}$ un matrimonio, lo otro $\mathrm{e}^{\mathbf{h}}$ un matrimonio]

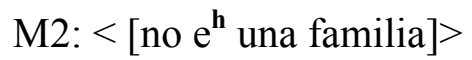

$\mathrm{H} 1:<$ [no $\mathrm{e}^{\mathbf{h}}$ una familia, familia $\mathrm{e}^{\mathbf{h}}$, $\mathrm{e}^{\mathbf{h}}$ que, según yo, a ver, matrimonio, es "la pareja" y familia es "los hijos", ¿me entendí? una fam- $\mathrm{e}^{\mathbf{h}}$ que-]

M1: $<$ [ ya, vamo ${ }^{\mathbf{h}}$ a usar eso término $\left.{ }^{\mathbf{h} \rightarrow} \mathrm{e}:\right]$

H1: ya | ahora, yo te quiero hacer una pregunta antes, solo una , mira, ponte en el siguiente caso imagínate que hay un tipo | con trastornos mentales y es sicópata | y se enamora de ti I ¿a ti te parece, te parece que ESO e $\mathrm{e}^{\mathbf{h}}$ un amor sa:no, que merece apo:yo? ¿cachái?

M1: $<$ [NO porque ahí- $]$

H1: $<$ [Lo mi ${ }^{\mathbf{h}}$ mo que el tema gay]

M1: $<$ [ porque que ahí ya hay condicione ${ }^{\mathrm{h}}$ e: $\mid$ ya extra ${ }^{\mathrm{h}}$ po ma ${ }^{\mathrm{h}}$ patológico $\rightarrow$

H1: $<$ o bueno ya:, tiene otro trastorno no es sicópata, pero tiene trastornos, se cree Napoleón como quería llamarlo]>

H2: <[ise cree Napoleón! $>>$

M1: si de una persona, si de una persona deriva su homosexualidad por ejemplo de una violación | no $\mathrm{e}^{\mathrm{h}}$ tamo hablando de la de la posición que yo tengo po, o sea si yo soi homosexual porque me violaron y quedé con un tra:uma sicológico | no me voy a, no $\mathrm{e}^{\mathrm{h}}$ toy hablando de am:or y todo el cuento $\mathrm{e}^{\mathrm{h}}$ toy hablando de otro tema ya de mucho ma ${ }^{\mathrm{h}}$ delicado y profundo-]

\section{Descripción del episodio número 10}


Elementos indispensables de la argumentación (Lo Cascio, 1998)

\section{Tema del episodio: Homosexualidad y familia}

Tesis: Los homosexuales pueden formar una familia

Argumentos: El amor los mueve.

Regla General: Las parejas de enamorados anhelan formar una familia.

Elementos facultativos de la argumentación (Lo Cascio (1998))

Refutación, contraopinión o reserva: No se puede formar una familia sin hijos y así sería la familia de dos homosexuales.

Falacias argumentativas (Lo Cascio (1998))

Argumentum ad populum: Apelar a las emociones de una multitud. Este falso argumento apela a la sensibilidad opinando que en el caso de que ella fuera lesbiana cómo no podría tener derecho a formar una familia.

M1: < [GONZA:LO $\rightarrow$ qué pasa si a mí me gut ara una mujer jyo no tengo derecho a tener familia?]

H1: ¿y el padre de tu hijo, dónde va a estar ahi? $\rightarrow$ [¿dónde, dónde metí al padre?]

M1: $<$ [ $e^{h}$ que ahí tiene metido el $e^{h}$ quema papá, mamá, hijo]

H1: < [pero ep ${ }^{h}$ era ¿cómo pensai concebir-?]

M2: $<$ [claro]

M1: < [y una familia ¿tiene que ser papá, mamá, hijo, tengo que conseguir un niño y una pareja feliz para ser una familia?]

\section{Estrategias de cortesía positiva}

(Brown P. y Levinson S. , 1987): Apele al “terreno común”. - Intensifique el interés hacia $O$.

- Exagere (interés, aprobación, simpatía con O)

- Fijese, atienda a $O$ (a sus intereses, deseos, necesidades, bienes).

En este segmento se muestra el interés de M1 por lo que dijo anteriormente una participante del debate, retoma lo que dijo anteriormente una de las ellas. Este enunciado es cortés porque pudo no haber mencionado que otra persona estaba hablando precisamente sobre eso, pero sí decide dar el nombre y mencionar al otro.

M1: yo quiero, quiero tomar lo que dijo la:, pero, yo creo que lo que acaba de decir la Flo (...)

Apele a la pertenencia al mismo grupo que 0 . Use marcadores de identidad de grupo. 
El uso de voseo verbal ${ }^{14}$ (entendí, cachai) léxico espontáneo (cachar, la Flo (si bien es un rasgo gramatical, es propio de un registro espontáneo)) da cuenta de que se encuentran en una situación distendida lo que intensifica la pertenencia al grupo y los identifica como miembros del mismo.

H1:< [no $e^{h}$ una familia, familia $e^{h}, e^{h} q u e$, según yo, a ver, matrimonio, es "la pareja” y familia es "los hijos", ¿me entendi? una fam- $e^{h}$ que-]

(...)

H1: (...) I ¿a ti te parece, te parece que ESO $e^{h}$ un amor sa:no, que merece apo:yo? ¿cachái?

(...)

M1: yo quiero, quiero tomar lo que dijo la:, pero, yo creo que lo que acaba de decir la Flo no va a vía de nada(...)

\section{Estrategias de cortesía negativa}

Estrategias de reparación de un acto descortés ${ }^{\mathbf{1 5}}$ (Kerbrat-Orecchioni (2004:44)): A comete contra $B$ alguna ofensa (FTA) que inmediatamente intenta reparar por medio de una excusa (FFA). Cuanto mayor es el peso del FTA, tanto más debe ser importante el trabajo reparador.

En este segmento, M1 si bien manifiesta interés por lo que dijo anteriormente una participante, menciona que no está de acuerdo con lo que postula, no obstante luego trata de suavizar el ataque afirmando que "la Flo" sabe más que ella:

M1: yo quiero, quiero tomar lo que dijo la:, pero, yo creo que lo que acaba de decir la Flo no va a vía de nada, o sea, $e^{h}$ como una afirmación que yo la voy a tomar ma objetiva ademá $^{h}$ que, no tengo mayor conocimiento que el de ella en $e^{h}$ to $\mid$ de hecho yo no uso la palabra "desviación sexual", porque no creo que lo sea | ahora si tu me deci hue bio-que no hay influencia biológica mejor po me alivianai máh mi forma de pensar porque ya esto pasa a ser, netamente desarrollo: $\rightarrow$

Estrategias de atenuación cortés (Briz, 2001)

Se aminoran cualidades, actitudes y acciones del yo.

\footnotetext{
${ }^{14}$ Se observó anteriormente que el uso del voseo verbal en el español hablado en Chile está restringido a situaciones informales. (cfr. pág. 42)

${ }^{15}$ El nombre de esta estrategia no corresponde a ninguna clasificación realizada por Kerbrat-Orecchioni previamente. Corresponde a un parafraseo, creado por la autora de esta investigación, correspondiente a esta técnica verbal.
} 
La estrategia de atenuación es parte del proceso de cortesía negativa que se comentó más arriba. La estrategia atenuadora se usa aquí aminorando cualidades del yo:

M1: yo quiero, quiero tomar lo que dijo la:, pero, yo creo que lo que acaba de decir la Flo no va a vía de nada, o sea, e como una afirmación que yo la voy a tomar ma ${ }^{h}$ objetiva

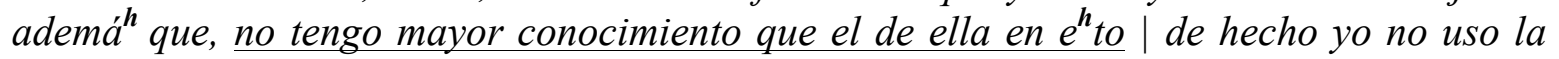
palabra "desviación sexual", porque no creo que lo sea

Indicadores gramaticales de atenuación cortés (Kerbrat-Orecchioni) (Haverkate)

Se aminoran cualidades, actitudes y acciones del yo.

- Estrategia de presentarse como menos informado que el otro: "yo no sé tanto como tú".

Indicadores gramaticales de cortesía positiva y negativa (Kerbrat-Orecchioni/Brown P. y Levinson S. ) (Haverkate)

Indicadores gramaticales de cortesía positiva:

- Uso de voseo verbal y léxico espontáneo que demuestra que comparten una situación comunicativa cómoda y relajada con miembros que tienen la misma jerarquía. Todo esto intensifica la pertenencia al grupo y los identifica como miembros del mismo.

- Manifestar el interés explícitamente retomando las ideas previas de otro mencionando el nombre del que lo dijo.

Indicadores gramaticales de cortesía negativa:

- Estrategias de reparación de un acto descortés: en primer lugar, se ataca la imagen del otro y luego se atenúan las cualidades del hablante.

$\mathrm{N}^{\circ}$ de episodio: 11

M1: $<$ [no sé mira, yo tengo una amiga| que $\mathrm{e}^{\mathrm{h}} \mathrm{le}^{\mathrm{h}}$ biana $\mid \mathrm{y}$ : ella $\mathrm{e}^{\mathrm{h}}$ tá muy consiente de que ella $\mathrm{e}^{\mathrm{h}} 1 \mathrm{e}^{\mathrm{h}}$ biana porque su mamá no vivía con ella, su mamá se fue cuando ella tenía ocho año ${ }^{\mathbf{h}}$, porque su mamá $\mathrm{e}^{\mathbf{h}}$ bipolar| y ella $\mathrm{e}^{\mathrm{h}}$ tá muy consciente de que ella $\mathrm{e}^{\mathrm{h}}$ le $\mathrm{e}^{\mathrm{h}}$ biana, porque su mamá nunca $\mathrm{e}^{\mathbf{h}}$ tuvo con ella- $]>$

H1:: $<$ [ nunca suplió ese afecto, ¿cachái?] $>$ 
M1: entonce ${ }^{\mathrm{h}}$, yo eso encuentro, o sea de ahí, o sea $\mathrm{e}^{\mathrm{h}}$ una anormalidad, o sea, si su mamá se hubiera quedado con ella y no se le hubiera gatillado la bipolaridad, ella no sería le ${ }^{\mathrm{h}}$ biana hoy día-

M2: $<$ [exactamente]

$\mathrm{M} 1:<$ [entonce $^{\mathrm{h}}$, yo encuentro que-]

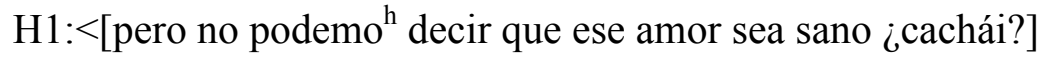

M2: < [tiene razón $]>$

H2: $<$ [yo no $\mathrm{e}^{\mathrm{h}}$ toy de acuerdo]

M3: < [antes que nada otro ejemplo, con lo que decía la la: Florencia $\mid$ yo $\mathrm{e}^{\mathrm{h}}$ tuve e: el año pasado estudié teatro, no voy a decir dónde, para que no quede grabado, $\mathrm{y} \rightarrow$ \{risas\}

H2: $<[$ ¿nos están grabando? $]>$

H1: <[HUEÓN | ¿qué creí que hace eso ahí?]>

$\mathrm{O}:<$ [oculto con un libro]

M3: claro: $\rightarrow$ \{risas\} bueno, YO: estudié teatro el año pasado y todo ${ }^{\mathrm{h}} \mathrm{mi}^{\mathrm{h}}$ compañero ${ }^{\mathrm{h}}$ que entraron | eran homo-, o sea eran heterosexuales, excepto dos, DOS entraron y dijeron abiertamente, "yo soy homosexual"| y todo ${ }^{\mathrm{h}} \mathrm{mi}^{\mathrm{h}} \mathrm{dema}^{\mathrm{h}}$ compañero ${ }^{\mathrm{h}}$ eran heterosexuale $\mathrm{e}^{\mathrm{h}} \mid \mathrm{e}$ : | AHORA | $\mathrm{e}^{\text {ht }} \mathrm{e}$ año, no queda ningún compañero heterosexual, NINGUNO, porque allá, el:, la normalidad | es ser homosexual, y de hecho la persona ${ }^{\mathrm{h}}$ que somo ${ }^{\mathrm{h}}$ heterosexuales allá éramo ${ }^{\mathrm{h}}$ tildada $^{\mathrm{h}}$ de rara $^{\mathrm{h}} \mid$ o sea, “¿QUÉ TE PASA? ¿Por qué ere ${ }^{\mathrm{h}}$ heterosexual, por qué no te gustará una chiquilla?", te juro que era así, entonce ${ }^{\mathrm{h}}$ yo encuentro| o sea, eso |es una exageración-

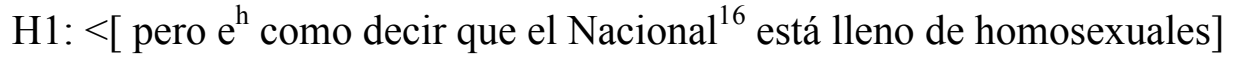

M4: $<[$ pero ¿sabí por qué pasa eso? ] $>$

M3: pero eso en el fondo es una exageración de un modelo que se concibe ¿cachái? por lo $\operatorname{mim}^{\mathrm{h}}$ o yo encuentro, que como que nunca | e: | como que en eto ${ }^{\mathrm{h}}$ cambio $^{\mathrm{h}}$ sociale $^{\mathrm{h}}$ se va como de extremo a extremo y por ejemplo, yendo $\mathrm{ma}^{\mathrm{h}}$ a la pregunta, que si, ahora yo siento que la sociedad chilena no está para nada preparada para el matrimonio homosexual, porque todavía hay mucha discriminación, pero si se diera la oportunidad, yo creo que e:

${ }^{16}$ Con "el Nacional" se refiere a un emblemático colegio público de hombres de Santiago de Chile, el Instituto Nacional, por el que han pasado varios presidentes del país y que se caracteriza por su excelencia académica. 
no sé| compañero: que | nunca pensaron en ser homosexuale ${ }^{\mathrm{h}}$, después de haber entrado a la escuela de teatro, se empezaron a hacer pregunta $^{\mathrm{h}}$ y se sentían extraño ${ }^{\mathrm{h}}$ por ser heterosexuale $^{\mathrm{h}}$, y yo creo mucho de ello ${ }^{\mathrm{h}}$ son heterosexuale ${ }^{\mathrm{h}}$, pero están casi obligado ${ }^{\mathrm{h}}$ a ser homosexuale $^{\mathrm{h}}$, y yo creo que igual como que, eso pasaría en el fondo si: | si dijéramo ${ }^{\mathrm{h}}$ "ya:, junto con $10^{\mathrm{h}}$ matrimonio ${ }^{\mathrm{h}}$ heterosexuale ${ }^{\mathrm{h}}$ van a haber e: matrimonio homosexuale ${ }^{\mathrm{h}}$, porque va a haber gente que va a tener $\operatorname{duda}^{\mathrm{h}} \mid$ y no va a tener como una restricción | va a decir "a: ya no filo se acepta, quizá a: parece que me gu ta un poco mi amigo, ya filo voy a aperrar".

M2: $<$ [pero, $\mathrm{e}^{\mathrm{h}}$ que por algo lo proceso $^{\mathrm{h}}$ sociale $^{\mathrm{h}}$ se van midiendo dentro de $\mathrm{sí}^{\mathrm{mi}} \mathrm{h}^{\mathrm{h}} \mathrm{mo}{ }^{\mathrm{h}}$ creo yo, porque si ahora, por ejemplo, drásticamente pasáramo ${ }^{\mathrm{h}}$ a ese modelo $\mid$ no está $\mid$ como la concepción social de verlo de una manera como: | más concreta entonce ${ }^{\mathrm{h}}$ pasaría lo que tú estai diciendo $\mathrm{e}^{\mathrm{h}}$ como e: | llevarte al ejemplo de que si en algún momento hubiese sido de repente normal que $\mathrm{la}^{\mathrm{h}}$ mujere $^{\mathrm{h}}$ fueran madre $^{\mathrm{h}}$ soltera $^{\mathrm{h}} \mathrm{o}$ : todo teniendo hijo ${ }^{\mathrm{h}} \mathrm{y}^{\mathrm{h}} \mathrm{o}^{\mathrm{h}}$ hombre ${ }^{\mathrm{h}}$ salen madre y: ¿me entendí? entonce ${ }^{\mathrm{h}}$ por algo yo creo que lo proceso ${ }^{\mathrm{h}}$ sociale $^{\mathrm{h}}$ se van midiendo por sí solo ${ }^{\mathrm{h}}$, yo creo que la sociedad que está hoy día | es imposible e: | el: me voy a referir solamente al: al tema de la adopción | porque yo creo que el matrimonio | $\mathrm{e}^{\mathrm{h}}$ una opción personal y creo que debería estar a disposición de $\mathrm{la}^{\mathrm{h}}$ persona $^{\mathrm{h}} \mid$ no creo que sea malo que do $\mathrm{o}^{\mathrm{h}}$ persona $^{\mathrm{h}}$ que tengan el mismo sexo quieran conformarse en matrimonio en base al amor, al re ${ }^{\mathrm{h}}$ peto $\mathrm{y}: \mid$ todo lo que conlleva | pero, creo que con re ${ }^{\mathrm{h}}$ pecto a lo que $\mathrm{e}^{\mathrm{h}}$ la adopción ya $\mathrm{e}^{\mathrm{h}}$ tán involucrando una tercera vida que recibe la influencia de una sociedad no preparada | y mientras sea así e:-

H1: $<$ ¿¿para ti matrimonio sí , familia no?]

M2: ¿qué?

H1: ¿sería matrimonio homosexual sí, familia no?

M2: NO, o sea, yo creo que, que el problema no está en que sea e: normal o anormal, el problema está en que vivimo ${ }^{\mathrm{h}}$ en un medio social $\mathrm{y}$ : | y tenemo ${ }^{\mathrm{h}}$ que que $\mathrm{e}^{\mathrm{h}}$ tar siempre pendiente $^{\mathrm{h}}$ de eso con $\mathrm{la}^{\mathrm{h}}$ persona $^{\mathrm{h}}$ que queremo $^{\mathrm{h}} \mid$ si yo llegase, por ejemplo a tener una pareja de mi sexo y yo quiero tener un hijo no me gu taría que mi hijo recibiera una una recriminación, por lo tanto no lo voy a tener.

H1: pero se supone que tú considerai que no tiene nada de malo ¿por qué te molestaría enseñárselo? 
M2: a MÍ no me molesta, pero creo que sí, socialmente sería castigado por esta visión y yo no pondría a mi hijo a | a expensas de eso $\|$ ¿me entendí o no?

H2: a ver, yo pienso que-

H1: $\mathrm{e}^{\mathrm{h}}$ que no opino igual porque, por ejemplo, en lo tiempo $^{\mathrm{h}}$ antiguo $^{\mathrm{h}}$ cuando el cristianismo era: era castigado | el: yo podría decir | "no: entonce $\mathrm{h}^{\mathrm{h}}$ a mi hijo no le voy a enseñar la biblia porque eso socialmente no $\mathrm{e}^{\mathrm{h}}$ aceptado".

M2: NO:, no, $\mathrm{e}^{\mathrm{h}}$ distinto ENSEÑARLE $\mid$ a ponerlo en el medio $\rightarrow$

H1: $<$ [bueno ya entonce ${ }^{\mathrm{h}}$ no voy a tener hijo porque- $]>$

M2: $<$ Si tú me preguntai yo a mí hijo le enseñaría lo que yo creo que $\mathrm{e}^{\mathrm{h}}$ sobre la homosexualidad, que $\mathrm{e}^{\mathrm{h}}$ que una persona ama a la otra, de hecho creo que a mi prima chica se lo enseño así, pero no las involucraría en el tema de que ella ${ }^{\mathrm{h}}$ tuvieran do ${ }^{\mathrm{h}}$ mamá $^{\mathrm{h}}$ o dos papáh, porque ya eso deja de involucrar el medio que yo pueda manejar sobre mi vida, y volvemo $^{\mathrm{h}}$ al tema anterior de cuando $\mid$ cuando tú pone ${ }^{\mathrm{h}}$ a expensas $\rightarrow$

H2: $<\left[E^{\text {h PERA }]>}\right.$

M2: $<$ [otra vida a tu, a tu forma, a tu-]

H2: < [lyo creo que tenemo ${ }^{\mathrm{h}}$ que separar primero el contexto como SOCIAL, o sea del AMBIENTE, y ya como las cosas personales que le pasan a uno, porque yo creo sinceramente que, esa cue ${ }^{h}$ tión de que la gente se volvía homosexual por el medio simplemente se traduce en una inseguridad de sí $\mathrm{mi}^{\mathrm{h}}$ mo, o sea, mi familia $\mathrm{e}^{\mathrm{h}}$ de do persona | soy yo y mi mamá y no porque toda mi vida nunca, de hecho durante toda mi vida nunca tuve a mi PAPÁ, pero no por eso "no sé lo que es el amor entre hombres, voy a ser gay" | no creo que tenga una cosa así, o sea, o sea-

M2: < [pero hay personas que $1 \mathrm{e}^{\mathrm{h}}$ afecta: má:s]

$\mathrm{H} 2:<\left[\right.$ no pero $\mathrm{e}^{\mathrm{h}}$ que de todas maneras $\mathrm{e}^{\mathrm{h}}$ que, por eso-]

$\mathrm{M} 1:<\left[\mathrm{e}^{\mathrm{h}}\right.$ que se presentan oportunidade ${ }^{\mathrm{h}}$, o sea ella no fue que, o sea, a ella la empezó jotear una mina, y ella está insegura de sí misma, OBVIO, nunca ha tenido una mamá ¿cachái? y por fin recibe el amor de otra mujer, que era más grande que ellaM3: < [ eso $\mathrm{e}^{\mathrm{h}}$ di tinto $\rightarrow$ YO también soy hija de mamá soltera, y tengo proceso ${ }^{\mathrm{h}}$ sicológico $^{\mathrm{h}}$ distinto $^{\mathrm{h}}$-] 


\section{Descripción del episodio número 11}

\section{Elementos indispensables de la argumentación (Lo Cascio, 1998)}

\section{Tema del episodio: La homosexualidad en la sociedad chilena.}

Tesis: El entorno social puede inducir a alguien a la homosexualidad.

Argumentos: Hay mucha presión en el entorno en el que se mueven los jóvenes, presión que obliga a querer probar cosas nuevas.

Regla General: Los jóvenes son muy vulnerables a las presiones del medio.

Elementos facultativos de la argumentación (Lo Cascio, 1998)

Refutación, contraopinión o reserva: no es presión social, son inseguridades de las personas las que llevan a la gente a probar cosas nuevas.

Fuentes: anécdotas de la Facultad de teatro donde se producen situaciones de este tipo.

\section{Estrategias de cortesía positiva}

(Brown P. y Levinson S. , 1987): Apele al “terreno común”. - Intensifique el interés hacia $O$.

- Exagere (interés, aprobación, simpatía con O)

- Fíjese, atienda a $O$ (a sus intereses, deseos, necesidades, bienes).

Los enunciados de estos segmentos permiten demostrar la aprobación hacia el interlocutor y el interés en la comunicación. Estos enunciados y sus conectores metadiscursivos intentan mantener el contacto, (incluso H1 colabora terminando la frase que comenzó M1), manifestar interés en lo que otros dijeron anteriormente, demostrando así la atención y el acuerdo.

M1: < [no sé mira, yo tengo una amiga $\mid$ que $e^{h} l e^{h}$ biana $\mid$ (...) y ella $e^{h}$ tá muy consciente de que ella $e^{h} l e^{h}$ biana, porque su mamá nunca $e^{h}$ tuvo con ella-

H1: < [ nunca suplió ese afecto, ¿cachái?]>

M1: entonce ${ }^{h}$, yo eso encuentro, o sea de ahí, o sea $e^{h}$ una anormalidad, o sea, si su mamá se hubiera quedado con ella y no se le hubiera gatillado la bipolaridad, ella no sería le ${ }^{h}$ biana hoy dia-

M2: $\leq$ [exactamente]

M1: < [entonce ${ }^{h}$, yo encuentro que-]

(...)

M2: < [tiene razón] >

(...)

M2: < [pero, $e^{h}$ que por algo lo proceso ${ }^{h}$ sociale $^{h}$ se van midiendo dentro de si mi $^{h} m o^{h}$ creo yo, porque si ahora, por ejemplo, drásticamente pasáramo ${ }^{h}$ a ese modelo $\mid$ no está $\mid$ como 
la concepción social de verlo de una manera como: | más concreta entonce pasaría lo que tú estai diciendo $e^{h}$ como e: | llevarte al ejemplo de que si en algún momento hubiese sido de repente normal que $l^{h}$ mujere ${ }^{h}$ fueran madre ${ }^{h}$ soltera $^{h}$

Apele a la pertenencia al mismo grupo que 0 . Use marcadores de identidad de grupo. El uso de voseo verbal ${ }^{17}$ (creí, cachái) léxico espontáneo (cachar,huevón, aperrar, filo) y uso de léxico preferentemente juvenil (jotear) dan cuenta de que se encuentran en una situación distendida lo que intensifica la pertenencia al grupo y los identifica como miembros del mismo.

H1: < [HUEÓN | ¿qué creíque hace eso ahi? ]>

(...)

M3: pero eso en el fondo es una exageración de un modelo que se concibe ¿cachái? (...), porque va a haber gente que va a tener $d u d a^{h} \mid y$ no va a tener como una restricción | va a decir "a: ya no filo se acepta quizá a: parece que me gu ta un poco mi amigo, ya filo voy a aperrar".

(...)

M1: $<$ [ $e^{h}$ que se presentan oportunidade ${ }^{h}$, o sea ella no fue que, o sea, a ella la empezó jotear una mina, y ella está insegura de sí misma, OBVIO, nunca ha tenido una mamá ¿cachái? y por fin recibe el amor de otra mujer, que era más grande que ella-

Indicadores gramaticales de cortesía positiva y negativa (Kerbrat-Orecchioni/Brown P. y Levinson S. ) (Haverkate)

\section{Indicadores gramaticales de cortesía positiva:}

- Uso de conectores pragmáticos metadiscursivos de aprobación y cortesía para manifestar que se mantiene el contacto con el otro y la atención temática.

- Uso de léxico juvenil, voseo verbal, léxico espontáneo intensifica la pertenencia al grupo y los identifica como miembros del mismo.

\footnotetext{
${ }^{17}$ Se observó anteriormente que el uso del voseo verbal en el español hablado en Chile está restringido a situaciones informales. (cfr. pág. 42)
} 


\section{$\mathbf{N}^{\circ}$ de episodio: 12}

M1: < [yo le voy a mostrar $\rightarrow$ oye: déjenme contarle ${ }^{\mathrm{h}}$ lo que, lo que: en la clase de más allá de la malla ${ }^{18} \mid$ me: enseñaron sobre la diferencia entre homosexualidad de hombre y lesbianismo | a mí me dijo, no sé si estará bien tampoco lo averigüé, lo tengo que hacer| que en GRECIA era muy común | que: que el maestro y el enseñado $\rightarrow$

M2: $<[$ sí $]>$

H1: <[sí:po]>

M1: tuvieran relacione ${ }^{\mathrm{h}}$ porque era como | como una forma como de: demostrarle-

H1: < [TRIBUTO, pagar] >

$\mathrm{M} 2:<[\mathrm{si}]>$

M1: $<$ [tributo a él, era muy común y corriente y aparte la: $\rightarrow$ la mujer-] $>$

M2: $<[$ no, ¿pagarle? no $]>$

H1: <[SÍ:, pagar] $>$

$\mathrm{M} 2:<[$ ¿era pagarle o era-?] $>$

H1: < [era una forma de pagar, una forma de pagar] $>$

$\mathrm{M} 1:<$ [era muy común $\rightarrow$, rendirle $^{\mathrm{h}} \mid$ honore $^{\mathrm{h}}$ rendirle honore $^{\mathrm{h}}$ a su maestro teniendo relacione $^{\mathrm{h}}$ sexuale $^{\mathrm{h}}$ con ello $^{\mathrm{h}}$, y la mujer era un objeto | era un objeto para tener HIJOS y nada más, ni siquiera placer, ¿cachái? $\rightarrow$

M2: $<[$ sí, claro $]>$

M1: entonce $\mathrm{e}^{\mathrm{h}}$ el lesbianismo salió mucho más adelante con $\mathrm{e}^{\mathrm{h}}$ ta mujer $\mid$ que tenía carencia sentimentale $^{\mathrm{h}}$ ¿cachái?, en cierta forma veía al hombre un monstruo, que la trataba pésimo y veía que la mujere ${ }^{\mathrm{h}}$ sí entendían ¿cachái? , que tenía má ${ }^{\mathrm{h}}$ sensibilidad, que el cariño, que no sé qué , que no sé cuánto, y AHÍ nació como el lesbianismo ¿cachái? como en el apoyo mutuo, porque a nosotra ${ }^{\mathrm{h}}$ no ${ }^{\mathrm{h}}$ trataban como | no sé | como BASURA ¿cachái? | y entre mujere ${ }^{\mathrm{h}}$ como no ${ }^{\mathrm{h}}$ sentíamo $^{\mathrm{h}}$ igual, cachái no ${ }^{\mathrm{h}}$ apoyábamo $^{\mathrm{h}}$ de esa forma, pero totalmente ya no es así, porque como mucha ${ }^{\mathrm{h}}$ vece $^{\mathrm{h}}$ hemo $^{\mathrm{h}}$ vi to pucha la aventura te llama y el: PROBAR | $\mathrm{e}^{\mathrm{h}}$ muy interesante $\rightarrow$

M2: < [no y ahora la juventud está asentada en eso en, “probemo-, por aquí por allá, experimentemos de ${ }^{h}$ pue $^{\mathrm{h}}$ de clase ${ }^{\mathrm{h}}$ vamo $^{\mathrm{h}}$ a atracar-?"]>

M1: ¿¿cómo será, darle un beso a una mujer?, ¿cómo será una mujer?”

\footnotetext{
${ }^{18}$ Planificación que detalla todos los cursos de una carrera universitaria.
} 
M3: $<[$ claro $]$

\section{Descripción del episodio número 12}

Elementos indispensables de la argumentación (Lo Cascio, 1998)

Tema del episodio: El origen de la homosexualidad

Tesis: Primero surgió la homosexualidad masculina en Grecia y después el lesbianismo.

Argumentos: En la antigua Grecia los maestros iniciaban sexualmente a sus alumnos y posteriormente sucedió que las mujeres se sentían vulnerables y explotadas.

Regla General: La homosexualidad puede ser considerada una actitud natural en la historia del hombre.

Elementos facultativos de la argumentación (Lo Cascio, 1998)

Refuerzo: Tener relaciones sexuales con el maestro era una forma de pagarle o de condescendencia.

Fuentes: las clases tomadas en la universidad.

\section{Estrategias de cortesía positiva}

(Brown P. y Levinson S. , 1987): Apele al “terreno común”. - Intensifique el interés hacia $O$.

- Exagere (interés, aprobación, simpatía con O)

- Fíjese, atienda a $O$ (a sus intereses, deseos, necesidades, bienes).

Los marcadores metadiscursivos presentes en los siguientes enunciados de estos segmentos permiten demostrar la aprobación hacia el interlocutor y el interés en la comunicación. Estos enunciados intentan mantener el contacto, manifestar interés en lo que otros dijeron anteriormente, demostrando así la atención y el acuerdo.

M2: $\leq\lceil$ sí $\rceil>$

H1: $\leq[$ sí:po] $>$

M1: tuvieran relacione ${ }^{h}$ porque era como | como una forma como de: demostrarle-

H1: $\leq$ [TRIBUTO, pagar $]>$

$M 2: \leq[$ si] $>$

M1: < [tributo a él, era muy común y corriente y aparte la: $\rightarrow$ la mujer-]> M2: < [no, ipagarle? no] $>$ 
H1: $\leq[S I ́:$, pagar] $>$

(...)

M2: < [sí, claro $]>$

(...)

M3: $\leq$ [ claro]

Apele a la pertenencia al mismo grupo que 0 . Use marcadores de identidad de grupo.

El uso de voseo verbal ${ }^{19}$ (cachái) léxico espontáneo (cachar, po, pucha) dan cuenta de que se encuentran en una situación distendida lo que intensifica la pertenencia al grupo y los identifica como miembros del mismo.

H1: <[si:po]>

(...)

M1: < [era muy común $\rightarrow$, rendirle ${ }^{h} \mid$ honore $^{h}$ rendirle honore ${ }^{h}$ a su maestro teniendo relacione $^{h}$ sexuale $^{h}$ con ello ${ }^{h},(. .)$, ¿cachái? $\rightarrow$

(...)

M1: entonce ${ }^{h}$ el lesbianismo salió mucho más adelante (...) ¿cachái? | y entre mujere como $^{h}$ no ${ }^{h}$ sentíamo $^{h}$ igual , cachái no ${ }^{h}$ apoyábamo ${ }^{h}$ de esa forma, pero totalmente ya no es así, porque como mucha ${ }^{h}$ vece $^{h}$ hemo ${ }^{h} v^{h}$ to pucha la aventura te llama y el: PROBAR | $e^{h}$ muy interesante $\rightarrow$

Indicadores gramaticales de cortesía positiva y negativa (Kerbrat-Orecchioni/Brown P. y Levinson S. ) (Haverkate)

\section{Indicadores gramaticales de cortesía positiva:}

- Uso de marcadores con intención fática y de aprobación para manifestar que se mantiene el contacto con el otro y la atención temática.

- Uso de voseo verbal y léxico propio de situaciones espontáneas intensifica la pertenencia al grupo y los identifica como miembros del mismo.

\section{$\mathrm{N}^{\circ}$ de episodio: 13}

H2: < [Gonzalo, con lo que dijite recién de lo de la biblia, de que cuando estaba prohibido, ahí simplemente no se-, no se-, no se decía a los demás que la persona era cristiana porque te mataban, y segundo, imagínate, que do ${ }^{\mathrm{h}}$ persona ${ }^{\mathrm{h}}$ imagínate, que do ${ }^{\mathrm{h}}$

\footnotetext{
${ }^{19}$ Se observó anteriormente que el uso del voseo verbal en el español hablado en Chile está restringido a situaciones informales. (cfr. pág. 42)
} 
persona $^{\mathrm{h}} \quad$ imagínate que do $^{\mathrm{h}}$ persona $^{\mathrm{h}} \mid$ voy a hablar de do $^{\mathrm{h}}$ persona $^{\mathrm{h}}$ del mismo sexo, no voy a decir el sexo $\rightarrow$

M2: dos personas

H2: construyen una vida junto ${ }^{\mathrm{h}} \rightarrow$

H3: ya:

H2: se compran una casa, un auto, todo lo que: hacen, lo que harían| do ${ }^{\mathrm{h}}$ persona ${ }^{\mathrm{h}}$ que quieren vivir junto ${ }^{\mathrm{h}} \mid$ ¿ya? | de repente || ello ${ }^{\mathrm{h}}$ no tienen ningún tipo de unión porque no existe el matrimonio, no existe ningún tipo de unión $\| \mathrm{e}^{\mathrm{h}}$ ta $^{\mathrm{h}}$ persona $^{\mathrm{h}} \|$ quedan toda ${ }^{\mathrm{h}}$ la $\operatorname{cosa}^{\mathrm{h}}$ a nombre de uno $\|$ como, pasa en el noventa por ciento de $10^{\mathrm{h}}$ caso ${ }^{\mathrm{h}}$, se ponen $\mathrm{la}^{\mathrm{h}}$ $\operatorname{cosa}^{\mathrm{h}}$ a nombre del hombre o de la mujer, a meno ${ }^{\mathrm{h}}$ de que estén casado ${ }^{\mathrm{h}} \mathrm{y}$ sean-

H3: < [sí pero: $>$

$\mathrm{M} 2:<$ [en el ámbito civil también $\mathrm{e}^{\mathrm{h}}$ interesante que-]

$\mathrm{H} 2:<$ [por eso, en este caso, la $\operatorname{cosa}^{\mathrm{h}}$ se tienen que quedar a nombre de uno porque no hay una sociedad, por ende, quedaría a nombre de una persona || imagínate que esa persona se muere || la $\operatorname{cosa}^{\mathrm{h}}$ no va a pasar a ser de la pareja-]

M3: < [igual eso ya está solucionado civilmente ]

H2: ¿sí?

M3: sí, e: o sea lo digo con propiedad porque mi mamá $\mathrm{e}^{\mathrm{h}}$ abogado | y ella me contó que, igual tenían que tener cierta cantidad de año ${ }^{\mathrm{h}}$ de convivencia $\mid$ y tenías que probar esa convivencia no sé, boletas, etcétera que hayan estado junto o testigo ${ }^{\mathrm{h}} \mid$ y eso queda a nombre de la pareja, o sea la pareja se muere, y todo queda acomo herencia]

H2: < [o sea, por eso, creo que es VÁLIDO, que existiera alguna especie de matrimonio o algo que asegurara $\rightarrow$ ]

M3: $<$ [es que- $]$

$\mathrm{H} 2:<$ [que la $\cos ^{\mathrm{h}}$ van a pasar a ser del otro, porque imagínate $\rightarrow$, imagínate, que tú compra $^{\text {h}}$ te una casa, y llegan y dicen "oiga sabe que la casa no va a ser tuya", y normalmente, comúnmente, no voy a generalizar, la familia no apoya al: al $\rightarrow$

M2: $<$ [ a la pareja de- $]$

H2: < [que del hijo o la hija esté una relació:n| homosexual-]

$\mathrm{H} 1:<[\mathrm{si}]>$

H3: $<$ [gay $]$ 


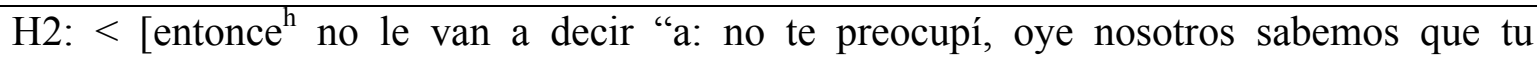
comprast- que la mitad de esta ${ }^{\mathrm{h}} \operatorname{cosa}^{\mathrm{h}}$ son tuya $^{\mathrm{h}}$ así que quédatelas, no, se las van a quedar]

M3: $<$ [pero igual yo creo que por ejemplo ahora hay una, hay una yo creo que ahora sí hay una solución para eso | ¿cachai? | o sea lo que yo decía | claro ahora eso está solucionado,

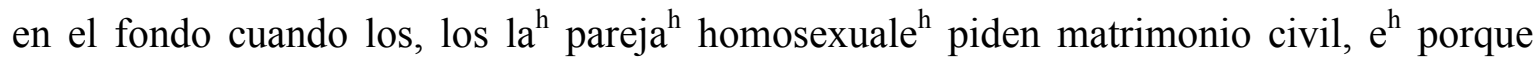
quieren tener e: $10^{\mathrm{h}}$ mimo derecho ${ }^{\mathrm{h}}$ en cuanto a: la adopción| por eso yo creo que está ligada a la pregunta, porque en el fondo ello $^{\mathrm{h}}$ ya no tienen problema con esto, o sea, con $\mathrm{e}^{\mathrm{h}}$ to de que lo tuyo $\mathrm{e}^{\mathrm{h}}$ mío lo mío $\mathrm{e}^{\mathrm{h}}$ tuyo, ya no tienen problema ${ }^{\mathrm{h}}$, o sea, van donde un abogado un notario y lo arreglan ¿cachai? el problema ahora está en esto de la adopción \| ¿cachai?, yo encuentro que, y ahí yo encuentro que $\mathrm{e}^{\mathrm{h}}$ un tema $\mathrm{ma}^{\mathrm{h}}-$

M2: $<$ [demasiado delicado]

\section{Descripción del episodio número 13}

Elementos indispensables de la argumentación (Lo Cascio, 1998)

Tema del episodio: Acuerdos de vida en pareja para los homosexuales.

Tesis: Los homosexuales están desprotegidos al no poder casarse por el civil.

Argumentos: Porque no tienen cómo hacer para que su pareja pueda heredar sus bienes. Por eso luchan legalmente en este tema.

Regla General: Al casarse civilmente son reconocidos por la ley y pueden dejar un testamento con sus bienes a su pareja.

Elementos facultativos de la argumentación (Lo Cascio, 1998)

Calificador: Probablemente, los homosexuales quieren casarse por el civil también para tener derecho a adoptar niños.

Refutación, contraopinión o reserva: Sí es posible demostrar ante un juez años de convivencia para poder heredar los bienes de la pareja.

Fuentes: Información tomada de la madre abogada de uno de los participantes. 


\section{Estrategias de cortesía positiva}

(Brown P. y Levinson S. , 1987): Apele al “terreno común”. - Intensifique el interés hacia $O$.

- Exagere (interés, aprobación, simpatía con O)

- Fijese, atienda a $O$ (a sus intereses, deseos, necesidades, bienes).

Los enunciados de estos segmentos permiten demostrar la aprobación hacia el interlocutor y el interés en la comunicación. Estos enunciados intentan mantener el contacto, manifestar interés en lo que otros dijeron anteriormente, demostrando así la atención y el acuerdo. Es peculiar la estrategia de ayudar al otro interlocutor a terminar las frases, técnica que se ha visto recurrentemente.

H2: < [Gonzalo, con lo que dijithe recién de lo de la biblia, de que cuando estaba prohibido, ahí simplemente no se-, no se-, no se decía a los demás que la persona era

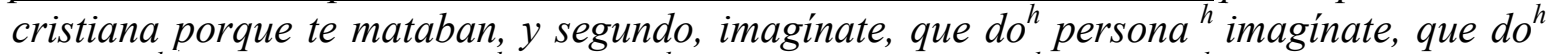
persona $^{h} \mid$ imagínate que do $^{h}$ persona $^{h} \mid$ voy a hablar de do ${ }^{h}$ persona ${ }^{h}$ del mismo sexo, no voy a decir el sexo $\rightarrow$

M2: dos personas

H2: construyen una vida junto ${ }^{h} \rightarrow$

H3: ya:

(...)

M3: < [igual eso ya está solucionado civilmente ]

H2: ¿sí?

M3: sí, e: o sea lo digo con propiedad porque mi mamá e $e^{h}$ abogado |

(...)

H2: (...), comúnmente, no voy a generalizar, la familia no apoya al: al $\rightarrow$

M2: $\leq$ [ a la pareja de-]

H2: < [que del hijo o la hija esté una relació:n| homosexual-]

$H 1: \leq[$ si $]>$

H3: $<$ [gay]

(...)

M3: (...) ¿cachái?, yo encuentro que, y ahí yo encuentro que $e^{h}$ un tema $\mathrm{ma}^{h}-$ M2: < [demasiado delicado]

Apele a la pertenencia al mismo grupo que 0 . Use marcadores de identidad de grupo. 
El uso de voseo verbal $^{20}$ (cachái) léxico espontáneo (cachar) dan cuenta de que se encuentran en una situación distendida lo que intensifica la pertenencia al grupo y los identifica como miembros del mismo.

M3: < [pero igual yo creo que por ejemplo ahora hay una, hay una yo creo que ahora sí hay una solución para eso | ¿cachái?

Indicadores gramaticales de cortesía positiva y negativa (Kerbrat-Orecchioni/Brown P. y Levinson S. ) (Haverkate)

\section{Indicadores gramaticales de cortesía positiva:}

- Uso de conectores pragmáticos metadiscursivos con intención fática y de cortesía al manifestar aprobación y que se mantiene el contacto con el otro y la atención temática. Robar el turno para ayudar al otro interlocutor a terminar su enunciado.

- Uso de voseo verbal y léxico propio de situaciones espontáneas intensifica la pertenencia al grupo y los identifica como miembros del mismo.

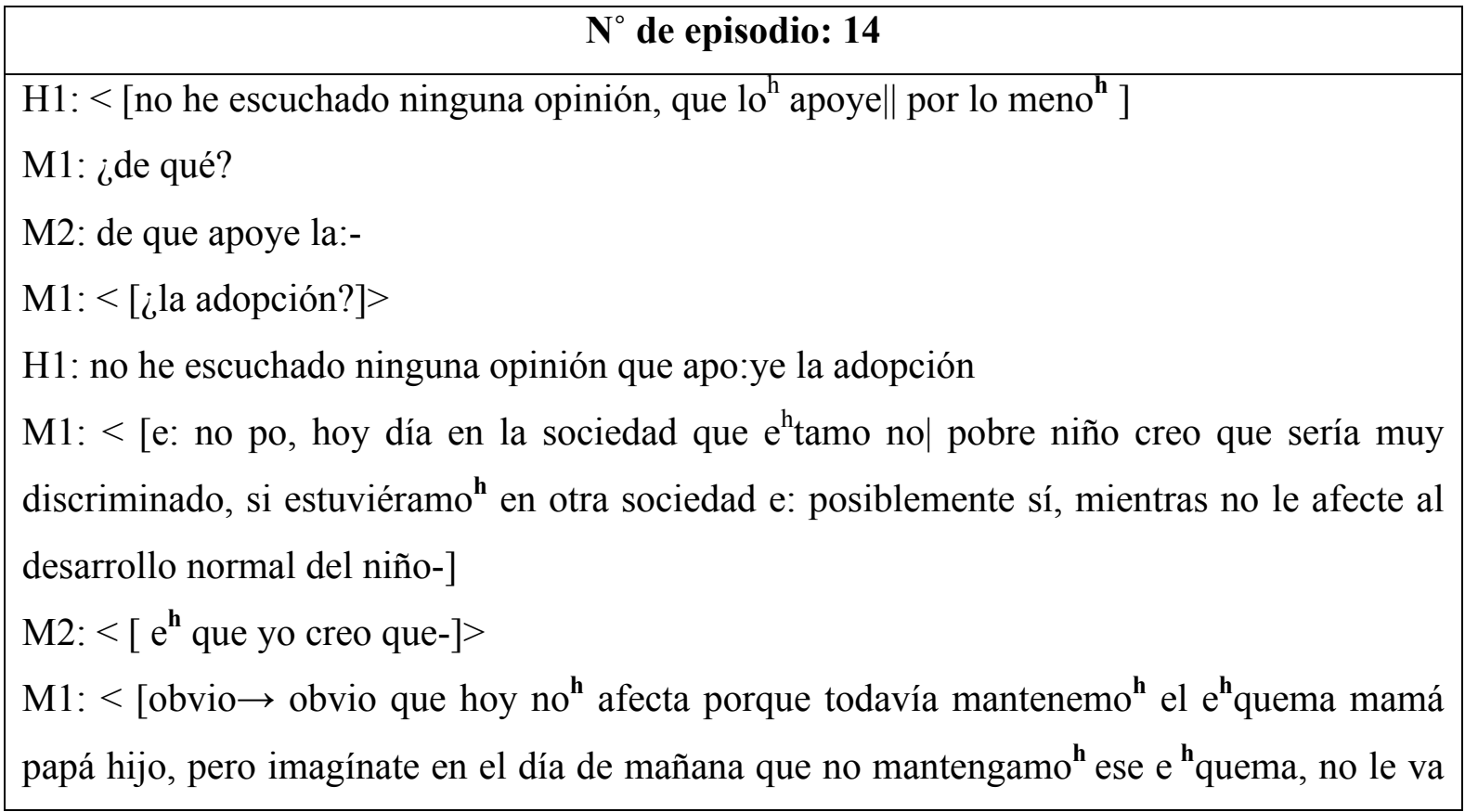

\footnotetext{
${ }^{20}$ Se observó anteriormente que el uso del voseo verbal en el español hablado en Chile está restringido a situaciones informales. (cfr. pág. 42)
} 


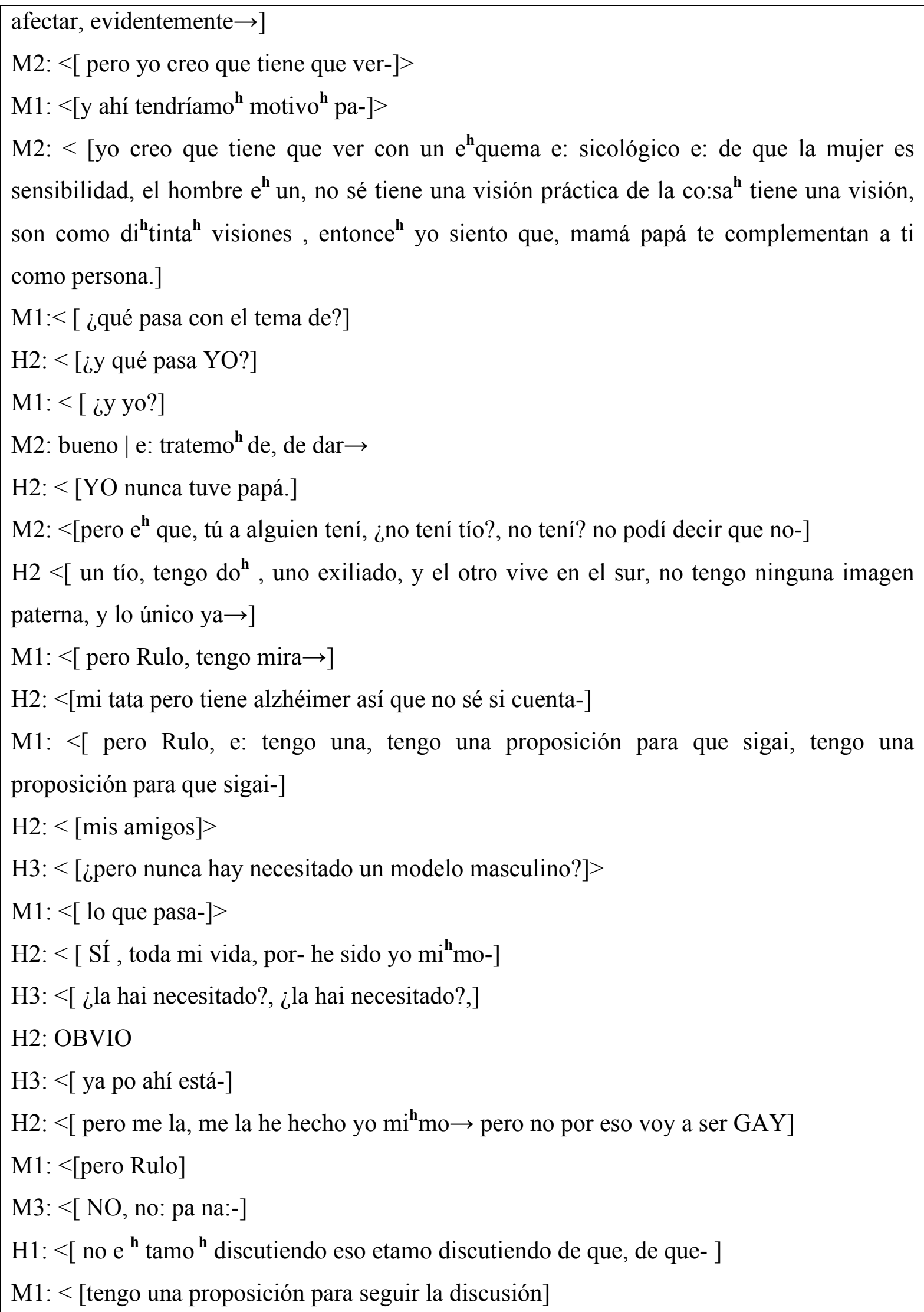




\section{$\mathrm{H} 1:<[\mathrm{ya}]$}

M1: Creo que tenemo ${ }^{\mathbf{h}}$ que abstraerno ${ }^{\mathbf{h}}$ de la personalidade ${ }^{\mathbf{h}}$ para hablar con mayor libertad, no hablar del Rulo sino que del niño que se crió con mamá o con papá porque si no: | podemo ${ }^{\mathrm{h}}$ entrar a ámbito ${ }^{\mathrm{h}} \mathrm{ma}^{\mathrm{h}} \rightarrow$

M2: $<$ [ pero $\mathrm{e}^{\mathrm{h}}$ que, no po- $]$

M1: $<$ [ delicado]

H1: $<$ [ él expuso su-]

M2: $<$ [ el mi ${ }^{\mathbf{h}}$ mo Rulo dijo que él nece- él había necesitado una imagen paterna- $]$

H2: [ o sea, lo necesité pero yo, yo creo que mi desarrollo como persona | sinceramente no se vio para nada opacado por eso, o sea lo necesité en un momento dije "pucha, qué lata cuando voy a la casa de un amigo y $\mathrm{e}^{\mathbf{h}}$ tá el papá y se pone con nosotro ${ }^{\mathbf{h}}$ a conversar y todo el asunto", pero no-]

M1: < [ a mí me pasó lo contrario, tení noción- $]>$

M2: $<$ [igual recién tení dieciocho año $\left.{ }^{\mathbf{h}}-\right]$

H2: < [ no po, pero a mí no me pasa NADA ¿cachái?]

M1: < [ pero a mí me pasó lo contrario, tení noció:n-]

H2: $<$ [ sí: , o sea- $]$

M2: < [te falta la mitad de tu vida, te falta la parte máh importante yo creo- ]

M1: $<$ [ pero no por eso-]

H2: < [ a ver, yo-, mira]

M2: < [desarrollarte como un individuo, ¿cachái?]

H2: < [eso era, cuando era CHICO || chico, o sea YO a partir de lo die ${ }^{\mathbf{h}}$ año yo ya | me importaba una RAJA porque tuve una mamá bacán, y en verdad, o sea $\| \mathrm{e}^{\mathrm{h}}$ brígido ¿cachái? porque, o sea, $\mathrm{mi}^{\mathbf{h}}$ imágene $^{\mathbf{h}}$ paterna $^{\mathbf{h}}$ eran $\mid$ nula ¿me entendí?, o sea, $\mathrm{mi}^{\mathbf{h}}$ propia $^{\mathbf{h}}$ visione $^{\mathbf{h}}$ me la $\mathbf{a}^{\mathbf{h}}$ hacía yo con mi compañero ${ }^{\mathbf{h}}$, o sea | cómo debe actuar un hombre $\|$ o sea, no sé o sea-]

H1: < [demá ${ }^{\mathbf{h}}$ tu punto de vista de cómo debe actuar un hombre no $\mathrm{e}^{\mathbf{h}}$ cien por ciento, porque: YA: Rulo de repente me hai salido con cuestiones como- que tener sed es de mina así]

H2: < [NO:, pero $e^{\mathbf{h}}$ que eso ya $\mathrm{e}^{\mathbf{h}}$ un juego, eso $\mathrm{e}^{\mathbf{h}}$ un jue:go] $\{$ risas 
M1: < [yo quiero aportar a la misma visión del Rulo ante de la conclusión, e: yo por ejemplo soy el caso contrario || yo soy el caso contrario | yo me crié con, mi mamá | teniendo modelos femeninos siempre, o sea, en referencia a mi desarrollo, pero sin el modelo masculino presente de papá, pero con mucho ${ }^{\mathbf{h}}$ personaje $^{\mathbf{h}}$ masculino $^{\mathbf{h}}$ en mi vida | en ese sentido nunca tuve ninguna carencia, nunca me cuestioné NADA e: | gracias e: a mi familia siempre tuve $\mathbf{l a}^{\mathbf{h}} \operatorname{cosa}^{\mathbf{h}}$ clara porque desde pequeña, desde que uno empieza a tomar consciencia de hacer como la ${ }^{\mathbf{h}}$ típica pregunta ${ }^{\mathbf{h}}$ de: “¿y el regalo del día del papá? y no sé qué, mi familia siempre fue superclara con, con todo, nunca me contaron cuento referente a:, a mi: | a mi padre y nunca tuve ningún problema ${ }^{\mathbf{h}}$ en ese sentido y: || no creo tener carencia $^{\mathbf{h}}$ ni, ni visione ${ }^{\mathbf{h}} \operatorname{di}^{\mathbf{h}} \operatorname{tinta}^{\mathbf{h}}$ a cualquier otra persona, y $\mathrm{e}^{\mathbf{h}}$ pero no equivocarme, bueno nunca lo voy a confirmar, pero: -]

M2: $<$ [ según eso, tú quizá ¿erí hijo único o no?]

H2: sí, yo y mi mamá

M2: si tú hubierai tenido una HERMANA, ¿cachái?, mujer $\rightarrow$

M1: $<$ [Yo también soy hija única]

M2: erí hija-, por eso, si tu hubierai tenido, no: $\mathrm{e}^{\mathbf{h}}$ que tu caso e di tinto al de-

M1: $<$ [ sí, eso $\mathrm{e}^{\mathbf{h}}$ taba aclarando $\mathrm{e}^{\mathbf{h}}$ muy di $\mathbf{h}^{\mathbf{h}}$ tinto $]$

M2: si tú hubieras tenido una HERMANA, y tu mamá hubiera criado a tu hermana tu hubieras VISTO cómo era con tu hermana, quizás ahí hubiera pasado "kik" una pequeña tranca, por ejemplo mi hermano chico cuando mi papá estuvo enfermo y faltó, o sea, somos tres mujere ${ }^{\mathbf{h}} \mathrm{y}$ un hombre, y mi hermano chico se sentaba en el baño pa hacer pipí, porque nos imitaba a nosotra ${ }^{\mathbf{h}}$ imitaba a mi mamá porque no tenía la imagen paterna, pero porque había mujere ${ }^{\mathbf{h}}$, obviamente que si hubiera sido él solito ¿cachái?, mi mamá le hubiera enseñado cómo lo hace un hombre, pero si tú hubiera tenido una hermana, ¿cachái? en cierta forma la tení como referencia, cachái, la diferencia, ahí quizá se hubiera producido un problema | yo tuve un amigo que era su mamá su abuela y su hermana, y su tía, y él.

H1: $<$ oh: eso ${ }^{\mathbf{h}}$ tipo, puta que son afeminado $\left.{ }^{\mathbf{h}}\right]>$

M1: $<$ [ si hay millone ${ }^{\mathbf{h}}$ de, generalmente se asocia, eso, que tienen conducta ${ }^{\mathbf{h}}$ femenina $\left.^{\mathbf{h}}-\right]$

H1: $<$ [ a mí me parece que para el desarrollo sano, de una persona es necesario que exista tanto la figura paterna, como la materna, porque por ejemplo yo tengo el caso, mi do ${ }^{\mathbf{h}}$ papá, no el mío sino que mi ${ }^{\text {h }}$ do papáh e: \|] 
O: ¿estamos en la hora?

O2: sí, ya es la hora.

O: ya, un segundo, Pauli, termina la idea.

H1: ya, sí, bueno, mi: a mi mamá la: botaron y la dejaron en otra casa y: la crió como e como el cuento de ¿la cenicienta?, así una señora que le hacía, como que trabajaba para ella $\rightarrow$

M1: $<$ [ya]

H1: ya, y mi papá quedó huérfano, se murió su papá cuando tenía die ${ }^{\mathbf{h}}$ año ${ }^{\mathbf{h}}$, y yo veo que pucha, que tienen tranca $10^{\mathbf{h}}$ do $^{\mathbf{h}}$ y me la han ligado a mí entonce ${ }^{\mathbf{h}}$ yo he vi to que sí afecta cuando falta la figura, $y:$ me parece que, como para resumir, que $\mathrm{e}^{\mathbf{h}}$ necesario que exi $\mathbf{h}^{\mathbf{t a}}$ como la do ${ }^{\mathbf{h}}$ visione $^{\mathbf{h}}$ | como paterna y materna para el desarrollo sano de una persona, entonce $^{\mathbf{h}}$ si: proponemo ${ }^{\mathbf{h}} \mid$ si má $^{\mathbf{h}}$ adelante, cambie como cambie la sociedad lo acepte no lo acepte | proponemo ${ }^{\mathrm{h}}$ que | e:1 exi $\mathbf{h}^{\mathbf{h}}$ ta el matrimonio homosexual y heterosexual, o sea que en realidad exi ${ }^{h}$ ta un matrimonio para todo como quieran darlo $\rightarrow$ \{risas

H1: Bueno, me parece que $\rightarrow$ me parece que, seríamo ${ }^{\mathbf{h}} \mid$ que sí exi ${ }^{\mathbf{h}}$ ten repercusione ¿cachái? por porque la: lo hijo de esa sociedad ¿cómo serían? si van a, o sea, van a PRIMERO, van a nacer con tranca porque, no-

M1: $<$ [yo no tengo ninguna tranca que yo sepa]

$\mathrm{H} 2:<$ toda $^{\mathbf{h}}$ la persona tenemo ${ }^{\mathbf{h}}$ alguna tranca que yo sepa $]>$

H1: $<$ [NO, pero toda ${ }^{\mathbf{h}}$ la persona ${ }^{\mathbf{h}}$ son $_{\text {diferente }}{ }^{\mathbf{h}}, \mathrm{y} \mathrm{exi}^{\mathbf{h}}$ te , cachái, eso $\mathrm{e}^{\mathbf{h}}$ como lo sano, ademáh $^{\mathbf{h}}$ ademá ${ }^{\mathbf{h}} \mathrm{e}^{\mathbf{h}}$ verdad -]

M1: $<$ [ no pero uno identifica, yo cono $^{\mathbf{h}}$ co persona $^{\mathbf{h}}$ que son como hijo ${ }^{\mathbf{h}}$ único $^{\mathbf{h}}$ pero por ejemplo de proceso ya cuando tienen ocho año ${ }^{\mathbf{h}}$ y ya $\mathrm{e}^{\mathbf{h}}$ tán como máh consciente $^{\mathbf{h}}$ del tema y le ${ }^{\text {h }}$ afecta heavy-]

H1: $<$ [ a cada uno le afecta, $\mathrm{e}^{\mathbf{h}}$ que a cada uno le afecta- $]$

M1: < [OBVIO, pero hay persona ${ }^{\mathbf{h}}$ que le $^{\mathbf{h}}$ afecta con mayor grado y otra ${ }^{\mathbf{h}}$ que quizá, ni siquiera lo notamo ${ }^{\mathbf{h}}$ o podemo ${ }^{\mathbf{h}}$ manejarlo de mejor forma.] 


\section{Descripción del episodio número 14}

Elementos indispensables de la argumentación (Lo Cascio, 1998)

Tema del episodio: La adopción de hijos de una pareja homosexual.

Tesis: No es recomendable que se apruebe la adopción por parte de padres homosexuales.

Argumentos: La sociedad actual discriminaría mucho al niño y a los padres. No estamos preparados.

Regla General: La discriminación puede ser silenciosa y muy dañina pues la gente trataría como inferiores a los niños de padres homosexuales.

Elementos facultativos de la argumentación (Lo Cascio, 1998)

Refuerzo: la sociedad chilena todavía no está preparada para un cambio tan grande de mentalidad.

\section{Falacias argumentativas (Lo Cascio (1998)}

Argumentum ad hominem:El argumento se basa únicamente en el universo del protagonista específico sin considerar valores universales.

El contraargumento de $\mathrm{H} 1$ intenta atacar directamente a $\mathrm{H} 2$ mediante una anécdota personal que se limita al universo del protagonista específico.

H2: < [eso era, cuando era CHICO (...) mi propia $^{h}$ visione me la $^{h}$ hacía yo con mi compañero ${ }^{h}$, o sea | cómo debe actuar un hombre \|| o sea, no sé o sea-]

H1: < [demáh tu punto de vista de cómo debe actuar un hombre no $e^{h}$ cien por ciento, porque: YA: Rulo de repente me hay salido con cuestiones como-que tener sed es de mina asi]

Por otra parte, los argumentos que presenta aquí H1 son personales y se limitan a su propia experiencia sin considerar una visión más universal.

H1: ya, y mi papá quedó huérfano se murió su papá cuando tenía die $\boldsymbol{h}^{\boldsymbol{h}} \tilde{n ̃ o}^{\boldsymbol{h}}$, y yo veo que pucha que tienen tranca $l^{\boldsymbol{h}} \mathrm{do}^{\boldsymbol{h}}$ y me la han ligado a mi entonce $\boldsymbol{h}^{\boldsymbol{h}}$ yo he vi ${ }^{\boldsymbol{h}}$ to que si afecta cuando falta la figura, $y$ : me parece que, como para resumir, que $e^{\boldsymbol{h}}$ necesario que exi $\boldsymbol{i}^{\boldsymbol{h}}$ a como la do ${ }^{h}$ visione ${ }^{h}$ | como paterna y materna para el desarrollo sano de una persona, entonce $^{\boldsymbol{h}}$ si: proponemo ${ }^{\boldsymbol{h}} \mid$ si $_{\text {má }} \boldsymbol{h}$ adelante, cambie como cambie la sociedad lo acepte no 
lo acepte | proponemo $^{h}$ que | e:l exi ta el matrimonio homosexual y heterosexual, o sea que en realidad exi ${ }^{h}$ ta un matrimonio para todo como quieran darlo $\rightarrow$

\{risas\}

\section{Estrategias de cortesía positiva}

(Brown P. y Levinson S. , 1987): Apele al "terreno común”. - Intensifique el interés hacia $O$.

- Exagere (interés, aprobación, simpatía con O)

- Fijese, atienda a $O$ (a sus intereses, deseos, necesidades, bienes).

Los enunciados de estos segmentos permiten demostrar la aprobación hacia el interlocutor y el interés en la comunicación. Se hacen preguntan directas a otros participantes lo que manifiesta el interés en este proceso comunicativo. Es peculiar la estrategia de ayudar al otro interlocutor a terminar las frases, técnica que se ha visto recurrentemente.

H1: < [no he escuchado ninguna opinión, que lo apoye ${ }^{h}$ por lo meno $\left.{ }^{h}\right]$

M1: ¿de qué?

M2: de que apoye la:-

M1: < [ila adopción?] $>$

(...)

$H 1:<[y a]$

(...)

M2: < [ según eso, tú quizá ¿erí hijo único o no?]

H2: sí, yo y mi mamá

(...)

M1: $<[y a]$

(...)

Apele a la pertenencia al mismo grupo que 0 . Use marcadores de identidad de grupo.

El uso de voseo verbal ${ }^{21}$ (cachái, entendí) léxico espontáneo (cachar, importar una raja,;puta!, pucha), léxico propiamente juvenil (brígido, heavy) dan cuenta de que se encuentran en una situación distendida lo que intensifica la pertenencia al grupo y los identifica como miembros del mismo.

M2: < [desarrollarte como un individuo, ¿cachái?]

H2: < [eso era, cuando era CHICO || chico, o sea YO a partir de lo die año yo ya | me

\footnotetext{
${ }^{21}$ Se observó anteriormente que el uso del voseo verbal en el español hablado en Chile está restringido a situaciones informales. (cfr. pág. 42)
} 
importaba una RAJA porque tuve una mamá bacán, y en verdad, o sea $\| e^{h}$ brígido ¿cachái? porque, o sea, mi ${ }^{h}$ imágene $^{h}$ paterna ${ }^{h}$ eran | nula ¿me entendi??, o sea, in $^{\boldsymbol{h}}$ propia $^{h}$ visione me la $^{h}$ hacía yo con mi compañero ${ }^{h}$, o sea | cómo debe actuar un hombre \|l o sea, no sé o sea-]

H1: < [demáh tu punto de vista de cómo debe actuar un hombre no $e^{h}$ cien por ciento, porque: YA: Rulo de repente me hay salido con cuestiones como- que tener sed es de mina asi]

(...)

H1: < [oh: eso ${ }^{\boldsymbol{h}}$ tipo, puta que son afeminado $\left.{ }^{\boldsymbol{h}}\right]>$

(...)

M1: < [ no pero uno identifica, yo cono ${ }^{h}$ co persona ${ }^{h}$ que son como hijo ${ }^{h}$ único $^{h}$ pero por ejemplo de proceso ya cuando tienen ocho año ${ }^{h}$ y ya $e^{h}$ tán como máh consciente $^{h}$ del tema y le ${ }^{h}$ afecta heavy-]

(...)

H1: ya, y mi papá quedó huérfano se murió su papá cuando tenía die ${ }^{\boldsymbol{h}}$ año ${ }^{\boldsymbol{h}}$, y yo veo que pucha que tienen tranca

Apele al punto de vista, opiniones, actitudes, conocimiento, empatía comunes. - Busque el acuerdo. Evite el desacuerdo. Presuponga/ suscite/ manifieste el terreno común. Bromee.

En este enunciado se destaca el reconocimiento que hace M1 a lo dicho anteriormente por otro participante.

M1: < Iyo quiero aportar a la misma visión del rulo ante de la conclusión, e: yo por ejemplo soy el caso contrario || yo soy el caso contrario | yo me crié con, mi mamá(...)

\section{Estrategias de cortesía negativa}

Estrategias de reparación de un acto descortés ${ }^{22}$ (Kerbrat-Orecchioni (2004:44)): A comete contra $B$ alguna ofensa (FTA) que inmediatamente intenta reparar por medio de una excusa (FFA). Cuanto mayor es el peso del FTA, tanto más debe ser importante el trabajo reparador.

Este segmento muestra como M2 comete una falta en contra de dos participantes del debate pues afirma que sí es necesaria la presencia de los dos padres en la educación de un niño para la conformación de su personalidad. En ese momento dos participantes que fueron educados por solo uno de los padres reclaman que no es así y que, en el caso de ellos, esto no ha ocurrido y que ellos sí han sido educados adecuadamente teniendo solo una imagen materna o paterna. M2 intenta reparar su afrenta diciendo que igual alguna imagen

\footnotetext{
${ }^{22}$ El nombre de esta estrategia no corresponde a ninguna clasificación realizada por Kerbrat-Orecchioni previamente. Corresponde a un parafraseo, creado por la autora de esta investigación, correspondiente a esta técnica verbal.
} 
masculina habrá tenido en su caso:

M2: < [yo creo que tiene que ver con un $e^{h}$ quema e: sicológico e: de que la mujer es sensibilidad, el hombre $e^{h}$ un, no sé tiene una visión práctica de la co:sa ${ }^{h}$ tiene una visión, son como di tinta $^{\boldsymbol{h}}$ visiones, entonce ${ }^{\boldsymbol{h}}$ yo siento que, mamá papá te complementan a ti como persona.]

M1:< [ ¿qué pasa con el tema de?]

$H 2:<[$ ¿y qué pasa YO?]

M1: < [ ¿y yo?]

M2: bueno | e: tratemo $^{h}$ de, de dar $\rightarrow$

H2: < [YO nunca tuve papá.]

M2: < [pero $e^{h}$ que, tú a alguien tení, ¿no tení tío?, no tení? no podí decir que no-]

H2 < [ un tío, tengo do ${ }^{h}$, uno exiliado, y el otro vive en el sur, no tengo ninguna imagen paterna, y lo único ya $\rightarrow$ ]

Indicadores gramaticales de cortesía positiva y negativa (Kerbrat-Orecchioni/Brown P. y Levinson S. ) (Haverkate)

Indicadores gramaticales de cortesía positiva:

- Uso de conectores pragmáticos metadiscursivos con intención fática y de cortesía al manifestar aprobación y que se mantiene el contacto con el otro y la atención temática. Hacer preguntas para manifestar el interés en el otro.

- Uso de voseo verbal y léxico juvenil y propio de situaciones espontáneas intensifica la pertenencia al grupo y los identifica como miembros del mismo.

\section{Indicadores gramaticales de cortesía negativa:}

- Se intenta mitigar el ataque cometido ampliando más las condiciones particulares del otro, es decir, tratando de explicar que él no se encuentra en los casos que dio como ejemplo porque su situación es distinta. 


\subsection{Análisis del debate de los adultos mayores}

\section{$\mathrm{N}^{\circ}$ de episodio: 1}

Se inicia el episodio con el tema de la pastilla del día después y M1 toma la palabra.

M1: Yo:, yo estoy absolutamente de acuerdo con la píldora del día despue ${ }^{\mathrm{h}}$, a pesar de toda la:

H1: ¿qué significa eso | "a pesar”?

M1: ¿qué significa exactamente?, que yo creo que es necesaria, o sea, claro porque || lo que nunca me quedó claro a mí ||| lo que nunca me quedó claro cuando recién empezó la pa $^{h}$ tilla, e: apareció digamo ${ }^{h}$ esta historia / era pensado por ejemplo para personas que sufrían un atenda:do, una violació:n y despue ${ }^{\mathrm{h}}$ que iba a estar en todo ${ }^{\mathrm{h}}$ lo consultorio ${ }^{\mathrm{h}} \mathrm{y}$ despue $^{\mathrm{h}}$ como que no aparecían en todo ${ }^{\mathrm{h}}$ lo consultorio ${ }^{\mathrm{h}}$, pero yo creo que: | que está bien, creo que está bien, que $1 \mathrm{a}^{\mathrm{h}}$ niña ${ }^{\mathrm{h}}$ que hacen, o sea no sé po, que lo necesitan deberían tomarla, o sea no estoy en contra fíjate.

M2: < [yo estoy de acuerdo también desde un comienzo por lo que fuera para mí la píldora del día despue ${ }^{\mathrm{h}}$ fue como la solución, claro porque, primero por violación con mayor razón-]

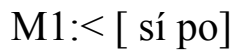

M2: < [ una cabrita de catorce quince año ${ }^{h}$ que se manda un condoro, prefiero que tome una pa $^{\mathrm{h}}$ tilla a que despue ${ }^{\mathrm{h}}$ tengamo $^{\mathrm{h}} \mid$ un embarazo-] $^{-}$

M1: $<[$ No deseado $]$

M2: < [ No desea:do, así que totalmente de acuerdo, y si el paíh ¿ ¿sabí que es lo que me molesta de toda esta historia? es que los políticos HOMBRES, opinen de un tema de mujer | eso me molesta, por lo tanto más encima ]

$\mathrm{H} 1:<\left[\right.$ ¿y yo no puedo opinar entonce ${ }^{\mathrm{h}}$ ?] 
M2 : sí, opinas como hombre pero los políticos lo hacen como algo personal , $\mathrm{e}^{\mathrm{h}}$ la ley, la ley, no le piden la opinión a la mujere ${ }^{\mathrm{h}}$ -

M1: $<$ [claro]

M2 : no yo opino que sí, estoy de acuerdo.

M1: ¿y tú Orianita?

M3: yo también estoy de acuerdo, por dos razones por lo mismo que argumenta la Isabelita, primero por el caso violación lo encontré extraordinario, es lo más importante de todo $\mid$ y en segundo lugar, yo creo que es una manera de aparte de que anden hijos por ahí sin padreo sin , muy a la deriva con niñito ${ }^{h}$ niñta $^{h}$ de catorce año ${ }^{h-}$

M1 : $<$ [ese es el punto a: $]$

M3: y lo otro es también que evita $10^{h}$ aborto $\mid$ claro $\mid \mathrm{e}^{\mathrm{h}}$ una manera de evitar aborto $^{\mathrm{h}} \mid$ con el conflicto de que si $\mathrm{e}^{\mathrm{h}}$ abortiva no $\mathrm{e}^{\mathrm{h}}$ abortiva yo pienso que no $\mathrm{e}^{\mathrm{h}}$ abortiva porque en el fondo $\mathrm{e}^{\mathrm{h}}$ como ta:n reciente $\mid$ ahí $\mathrm{e}^{\mathrm{h}}$ como ahí | como hilar fino

M2: < [ahí, claro]

M3: como que la cosa, pero, yo estoy casi segura que no $\mathrm{e}^{\mathrm{h}}$ abortiva, porque se toma realmente al otro día-

M1: < [justo, claro]

M3: yo lo encuentro positivo, y también estoy en desacuerdo que |e: | un par de persona ${ }^{\mathrm{h}}$ | político $^{\text {h }}$ que se yo quite esa libertad | a la mujer, o sea-

$\mathrm{M} 2:<\left[\mathrm{e}^{\mathrm{h}}\right.$ como $\mathrm{ma}^{\mathrm{h}}$ indignante también $]$

M3: $<$ [sí:, no: $]$

M2: < [Que lo político ${ }^{\mathrm{h}}$, se metan en tema ${ }^{\mathrm{h}}$ de la mujer]

M1: < [y que lo usen todo esto como política, para qué] 


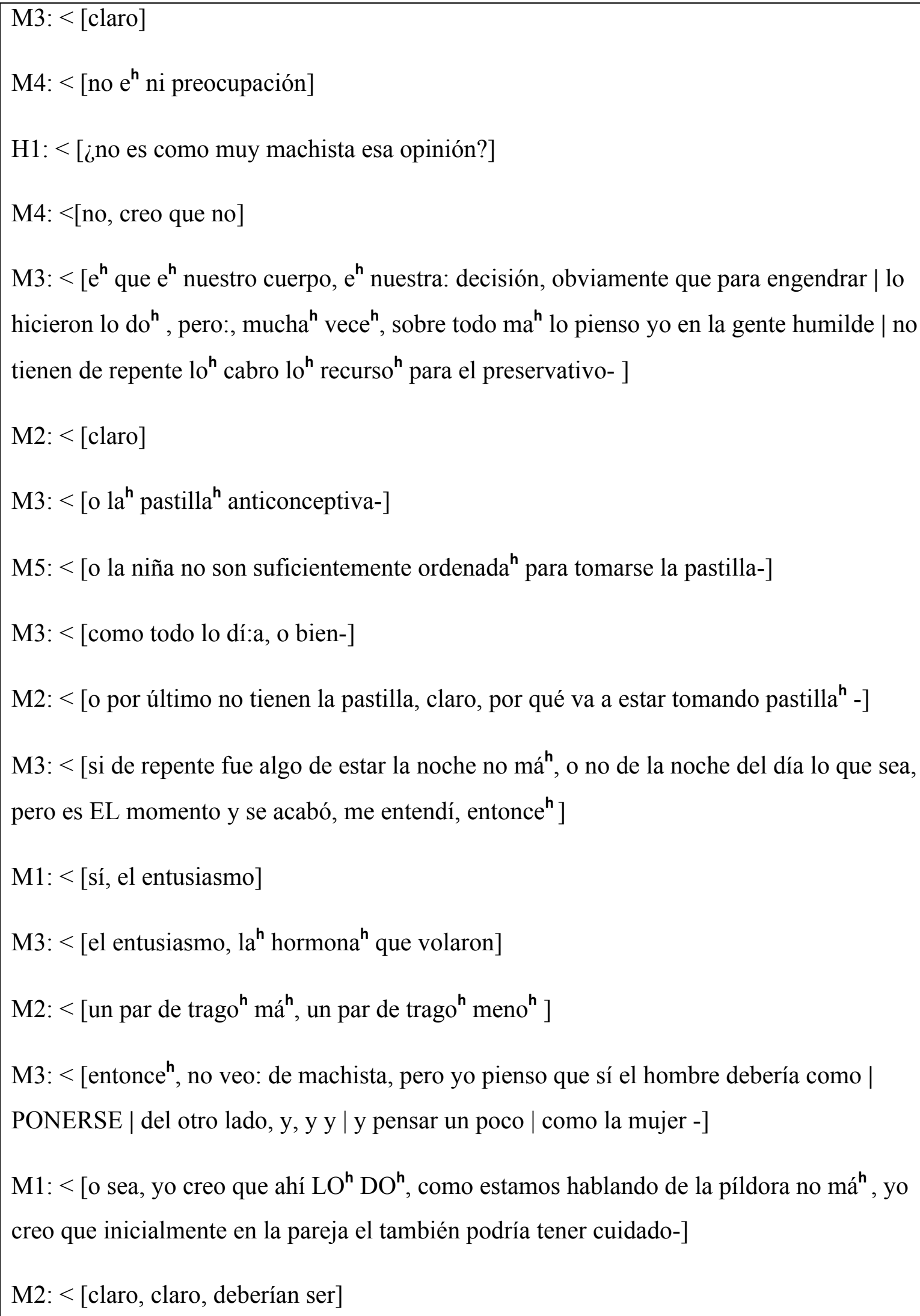




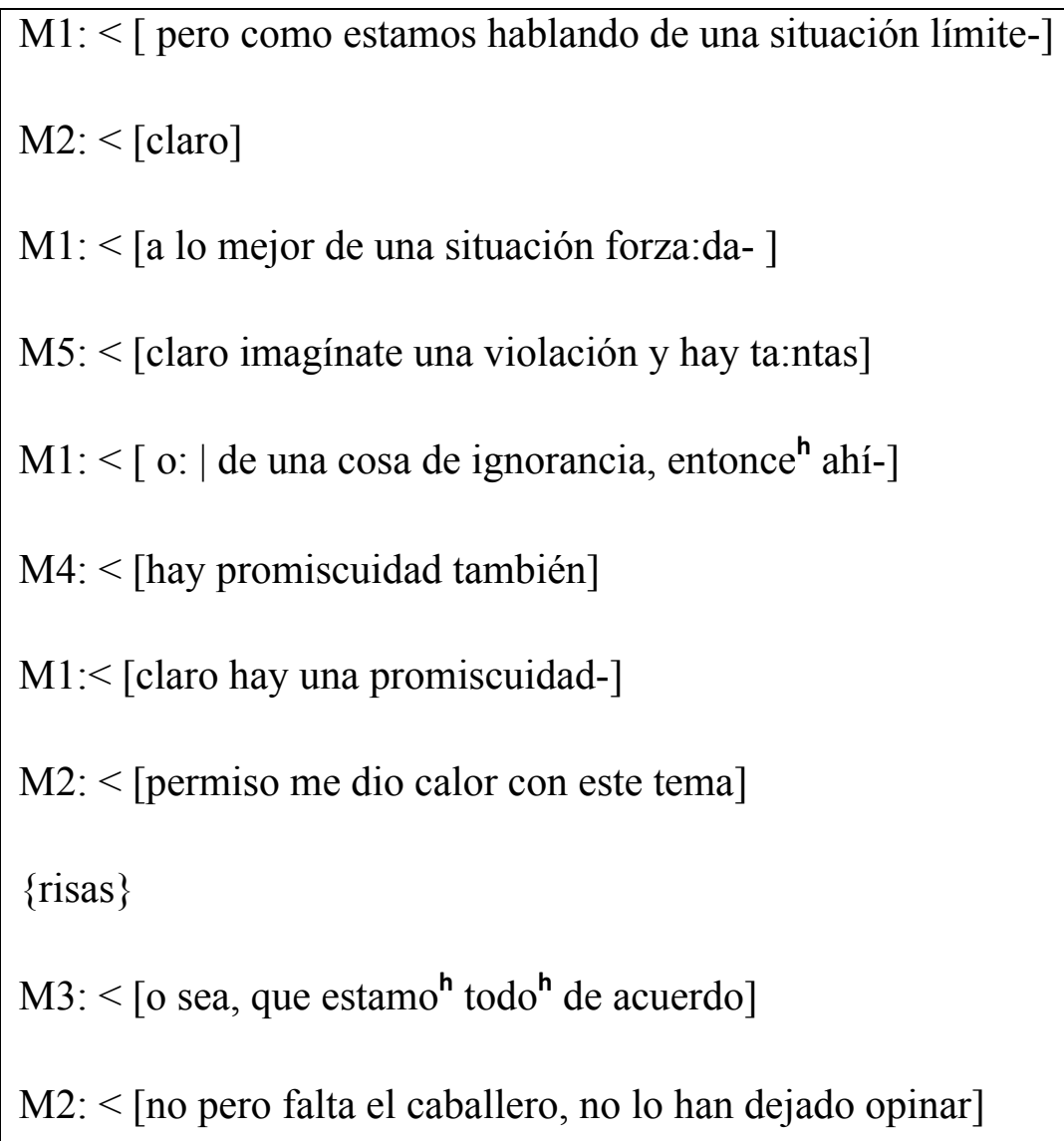

\section{Descripción del episodio número 1}

Elementos indispensables de la argumentación (Lo Cascio, 1998)

\section{Tema: La píldora del día después.}

Tesis $^{23}$ : Está bien que se legalice su uso en el país.

Argumentos: Porque es útil en el caso de una violación y para que adolescentes de escasos recursos tengan una alternativa frente a un embarazo no deseado.

Regla General: Si se legaliza su uso estaría disponible de forma gratuita en consultorios.

Elementos facultativos de la argumentación (Lo Cascio, 1998)

Refuerzo: Es muy útil en el caso de una situación extrema.

Falacias argumentativas (Lo Cascio (1998))

\footnotetext{
${ }^{23}$ Todo el grupo está de acuerdo con el uso de la pastilla del día después, no hubo discusión ni debate en este primer episodio; sin embargo, estrictamente sí hubo argumentación porque sí hubo argumentos para apoyar la tesis propuesta.
} 
Argumentum ad populum:Apelar a las emociones de una multitud.

M2: < [ No desea:do, asi que totalmente de acuerdo, y si el pai ${ }^{h}$, ¿sabi que es lo que me molesta de toda esta historia? es que los políticos HOMBRES, opinen de un tema de mujer | eso me molesta, por lo tanto más encima ]

H1: < [¿y yo no puedo opinar entonce $e^{h}$ ]

M1 : sí, opinas como hombre pero los políticos lo hacen como algo personal, $e^{\boldsymbol{h}}$ la ley, la ley, no le piden la opinión a la mujere ${ }^{h}$ -

H1 apela a la sensibilidad de la audiencia para expresar que está siendo discriminado.

\section{Estrategias de cortesía positiva}

(Brown P. y Levinson S. , 1987): Apele al “terreno común”. - Intensifique el interés hacia $O$.

- Exagere (interés, aprobación, simpatía con O)

- Fíjese, atienda a $O$ (a sus intereses, deseos, necesidades, bienes).

Los enunciados de estos segmentos permiten demostrar la aprobación hacia el interlocutor pues se reconoce explícitamente que se está de acuerdo con su postura. Estos enunciados intentan mantener el contacto y demostrar así el interés y el acuerdo.

M3: yo también estoy de acuerdo, por dos razones por lo mismo que argumenta la Isabelita, primero por el caso violación lo encontré extraordinario, es lo más importante de todo $\mid$ y en segundo lugar, yo creo que es una manera de aparte de que anden hijos por ahí sin padreo sin , muy a la deriva con niñito ${ }^{h}$ niñta $^{h}$ de catorce año ${ }^{h-}$

(...)

En el siguiente segmento se puede apreciar que hay intentos por manifestar el interés. M1 colabora ayudando a terminar el enunciado que postula M2. Es interesante que el receptor de esos mensajes vuelve a repetir la frase que le menciona su interlocutor. Además, M1, hace preguntas directas a otros participantes para involucrarlos cortésmente en el debate:

M2: < [ una cabrita de catorce quince año ${ }^{h}$ que se manda un condoro, prefiero que tome una pa tilla a que despue tengamo $^{\boldsymbol{h}} \mid$ un embarazo-]

M1: $<$ [No deseado] 
M2: < [No desea:do, asi que totalmente de acuerdo, y si el pai ${ }^{h}$, ¿sabi que es lo que me molesta de toda esta historia? es que los políticos HOMBRES, opinen de un tema de mujer | eso me molesta, por lo tanto más encima ]

(...)

M1: ¿y tú Orianita?

(...)

M1: < [ pero como estamos hablando de una situación límite-]

M2: < [claro]

M1: < [a lo mejor de una situación forza:da-]

M5: < [claro imagínate una violación y hay ta:ntas]

M1: < [o: | de una cosa de ignorancia, entonce ${ }^{h}$ ahi- $]$

M4: < [hay promiscuidad también]

M1:< [claro hay una promiscuidad-]

Por su parte, los enunciados de estos segmentos permiten demostrar la aprobación hacia el interlocutor. Estos conectores discursivos pragmáticos metadiscursivos intentan mantener el contacto y demostrar así el interés y el acuerdo, además de permitir que progrese en un ambiente cordial el coloquio.

(...)

M1: < [claro]

(...)

M1:< [sípo]

(...)

M2: < [ahí, claro]

(...)

M2: < [justo, claro]

(...)

M3: < [claro] 
(...)

M2: < [claro, claro, deberían ser]

(...)

$M 1:<[$ ese es el punto $a:]$

Apele a la pertenencia al mismo grupo que 0 . Use marcadores de identidad de grupo.

El uso de voseo verbal ${ }^{24}$ (entendi) léxico espontáneo (po, cabrita, condoro, mandarse un condoro, ) y uso de léxico propio de su grupo etario, correspondiente a adultos mayores, mayores) (fijate) dan cuenta de que se encuentran en una situación distendida lo que intensifica la pertenencia al grupo y los identifica como miembros del mismo.

M2: < [ una cabrita de catorce quince año ${ }^{h}$ que se manda un condoro, prefiero que tome una pa $^{\boldsymbol{h}}$ tilla a que despue tengamo $^{\boldsymbol{h}} \mid$ un embarazo-]

(...)

$M 1:<[$ sípo]

(...)

M3: < [si de repente fue algo de estar la noche no máh, o no de la noche del día lo que sea, pero es EL momento y se acabó, me entendi, entonce $\left.{ }^{h}\right]$

M1: (...)| que está bien, creo que está bien, que la $a^{h}$ niña $a^{h}$ que hacen, o sea no sé po, que lo necesitan deberían tomarla, o sea no estoy en contra, fíjate.

Apele al punto de vista, opiniones, actitudes, conocimiento, empatía comunes. - Busque el acuerdo. Evite el desacuerdo. Presuponga/ suscite/ manifieste el terreno común. Bromee.

Se busca el acuerdo preguntando directamente a los interlocutores:

M3: $<$ [o sea, que estamo ${ }^{h}$ todo ${ }^{h}$ de acuerdo]

Se utiliza una broma para hacer más grato el fin del tema de conversación del episodio:

M2: < [permiso me dio calor con este tema]

\footnotetext{
${ }^{24}$ Se observó anteriormente que el uso del voseo verbal en el español hablado en Chile está restringido a situaciones informales. (cfr. pág. 42)
} 
$\{$ risas $\}$

\section{Estrategias de cortesía negativa}

Estrategias de reparación de un acto descortés ${ }^{25}$ (Kerbrat-Orecchioni (2004:44)): A comete contra $B$ alguna ofensa (FTA) que inmediatamente intenta reparar por medio de una excusa (FFA). Cuanto mayor es el peso del FTA, tanto más debe ser importante el trabajo reparador.

En este segmento Isabel comente una ofensa contra Claudio y luego intenta excusarse:

M2: < [ No desea:do, asi que totalmente de acuerdo, y si el pai ${ }^{h}$, ¿sabi que es lo que me molesta de toda esta historia? es que los políticos HOMBRES, opinen de un tema de mujer [ eso me molesta, por lo tanto más encima ]

H1: < [¿y yo no puedo opinar entonce ${ }^{h}$ ?]

M2 : sí, opinas como hombre pero los políticos lo hacen como algo personal, $e^{h}$ la ley, la ley, no le piden la opinión a la mujere ${ }^{h}$ -

Estrategias de atenuación cortés (Briz, 2001)

Se aminoran cualidades negativas del tú

Se está afirmando algo en contra de lo que se dijo recientemente, pero de forma indirecta, esto es, haciendo una pregunta, aminorando así cualidades negativas del tú. Además que se suaviza el ataque con el uso de como, que tiene aquí el sentido de "un poco", "más o menos"

Claudio: < [¿no es como muy machista esa opinión?]

M4: < [no, creo que no]

Indicadores gramaticales de atenuación cortés (Kerbrat-Orecchioni) (Haverkate) Se aminoran cualidades negativas del tú:

- Hacer preguntas generales que contengan un contraargumento de la tesis que se debate para suavizar el ataque.

${ }^{25}$ El nombre de esta estrategia no corresponde a ninguna clasificación realizada por Kerbrat-Orecchioni previamente. Corresponde a un parafraseo, creado por la autora de esta investigación, correspondiente a esta técnica verbal. 
Indicadores gramaticales de cortesía positiva y negativa (Kerbrat-Orecchioni/Brown P. y Levinson S. ) (Haverkate)

\section{Indicadores gramaticales de cortesía positiva:}

- Uso de conectores pragmáticos metadiscursivos con intención fática y de aprobación para manifestar que se mantiene el contacto con el otro y la atención temática.

- Colaborar terminando los enunciados de los otros participantes. A la vez, lo receptores de estos enunciados aceptan la colaboración de los otros y repiten lo que dijo.

- Uso de voseo verbal, léxico espontáneo y propio de su segmento etario intensifica la pertenencia al grupo y los identifica como miembros del mismo.

- Manifestación explícita del acuerdo con el otro: "por lo mismo que argumenta la Isabelita", "estoy de acuerdo".

- Uso de bromas.

\section{Indicadores gramaticales de cortesía negativa:}

- Reparación de un acto descortés: se intenta dar una excusa frente al ataque.

\section{$\mathbf{N}^{\circ}$ de episodio: 2}

M1: $<$ [no pero falta el caballero, no lo han dejado opinar]

H1: < [yo creo que hoy día la posición de lo político $^{\mathrm{h}}$ que decían ustede ${ }^{\mathrm{h}}$ y la posición de la iglesia, no hemos hablado de la iglesia, qué tiene que decir la iglesia]

$\{$ risas $\}$

H1: < [porque la posición de la iglesia puede ser filosófica, respecto a la vida]

$\mathrm{M} 2:<\left[\right.$ para algún grupo de persona $\left.{ }^{\mathrm{h}}\right]$

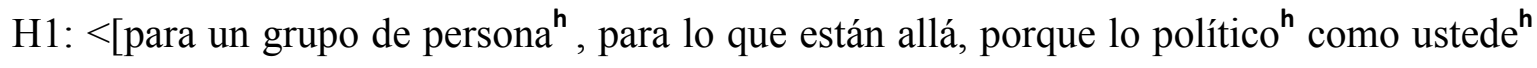




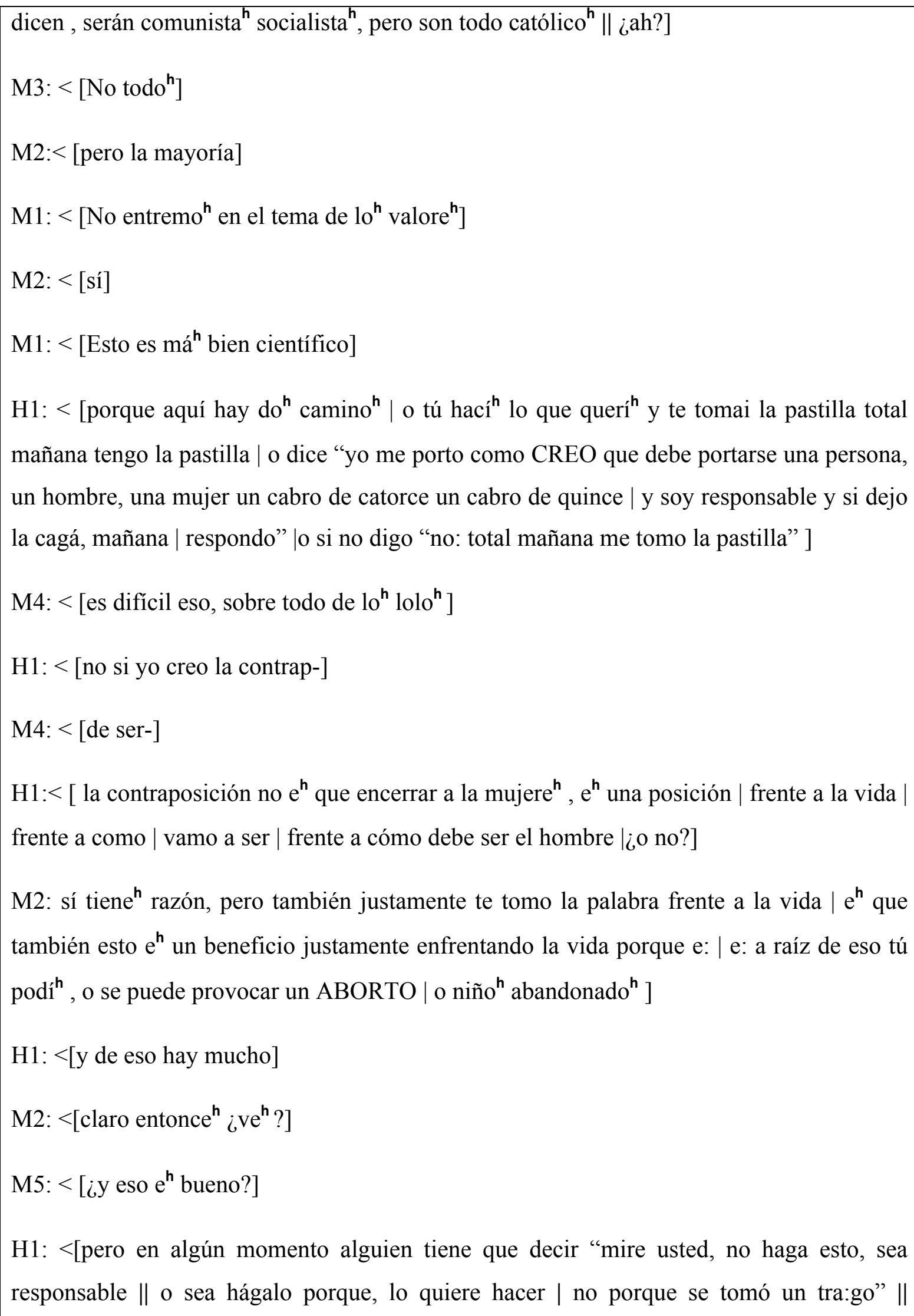


entonce qué pasa cuando tú dice "ya la pastilla está todo bien, no véndanla no má | estay fomentando una posición | una posición frente a la vida, frente al hombre, frente a lo que debe ser el hombre, o sea, $\mathrm{e}^{\mathrm{h}}$ más profundo de que no vendámosle a la $\mathrm{a}^{\mathrm{h}}$ mujere ${ }^{\mathrm{h}}$, que hagámo $^{\text {h }}$ lo que queramo ${ }^{\text {, }}$, no

M1: < [ sí pero ahí hay un tema como bien difícil, o sea aquí vamo ${ }^{\mathrm{h}}$ a entrar a analizar, y así vamo ${ }^{\mathrm{h}}$ a estar toda la noche, y no no ${ }^{\mathrm{h}}$ vamo $^{\mathrm{h}}$ a poner nunca de acuerdo, porque encima va ma ${ }^{\mathrm{h}}$ allá , yo te encuentro toda la razón]

M4: $<$ [sí]

M1: < [Pero hay un tema, que esta pastilla yo la miro má ${ }^{h}$ que nada $10^{h}$ niño $^{h}$ jóvene $^{h}$ entre $10^{h}$ doce dieciséi ${ }^{h}$ año ${ }^{h}$, porque eso ${ }^{h}$ cabro $^{h}$, ni el cabro hijo del mejor latifundista al máh humilde VA A ENTENDER lo que es responsabilidad ante el sexo, JAMÁS | te lo digo, por la experiencia de la vida, a esta altura la: la puedo decir así $\mid$ si estamo ${ }^{\mathrm{h}}$ hablando de

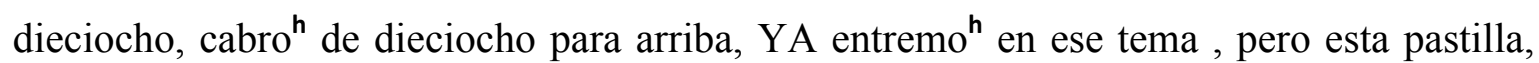

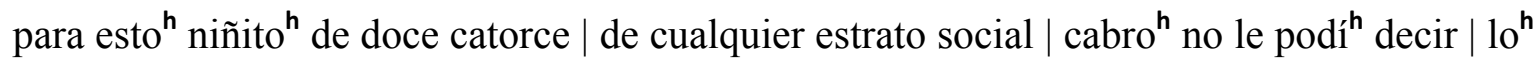
padre le están diciendo a diario "no haga ${ }^{h}$ esto que puede quedar embarazada, niñita esto" qué sé yo bla bla bla $\mid$ igual lo van a hacer, igual, y eso ya $\mathrm{e}^{\mathrm{h}}$ una cuestión ya para la:rgo proceso ||| o sea, para evitar que nazcan guagüitas que despué ${ }^{h}$ quedan ahí a la deriva, yo voy por la pastilla del día despué ${ }^{\mathrm{h}}|| \mid$ y no sé pienso, que en este minuto la están usando este nivel de niño de esta edad $\rightarrow$ que de dieciocho para arriba y más- ]

M3: < [ sí, puede ser]

M1: < Porque $^{\mathrm{h}^{\mathrm{h}}}$ la edad en que hay que cuidar a esta ${ }^{\mathrm{h}}$ niña $^{\mathrm{h}}, \mathrm{y}$ cómo te cuidai, si ya a esta $^{h}$ altura del partido | le habla en el colegio, le habla en la casa, en $10^{h}$ centro $^{\mathbf{h}}$ comunitario $^{h}$ en toda ${ }^{h}$ parte, y vamo ${ }^{h}$ con $1 a^{h}$ cabrita $^{h}$ a $10^{h}$, a $10^{h}$ : matrimonio ¿cómo decía el otro día, esto de $10^{h}$ quince año ${ }^{h}$ ? aparecieron, maternidad a $10^{h}$ quince año ${ }^{h}$-]

M3: < ["Mamá a lo" quince"]

$\mathrm{M} 1:<[$ eso de trece y de doce, qué terri:ble] 
M3: $<$ [ eso, eso e $\mathrm{e}^{\mathrm{h}}$ una- $]$

M1: $<$ [ ite dai cuenta?]

$\mathrm{H} 1:<$ Entonce $^{\mathrm{h}}$ el problema no $\mathrm{e}^{\mathrm{h}}$ de la pastilla $\mathrm{e}^{\mathrm{h}}$ un problema cultural $]$

M3: $<$ [claro que $\mathrm{e}^{\mathrm{h}}$ un problema cultural]

$\mathrm{M} 2:<\left[\mathrm{e}^{\mathrm{h}}\right.$ un problema cultural como TODO $]$

M5: $<\left[\mathrm{e}^{\mathrm{h}}\right.$ un problema cultural $]$

M4: < [es lo que decía la profesora de esa ${ }^{h}$ niñita $^{h}$ de quince, les explicaba todo,y sin embargo van y se embarazan igual]

M3: $<$ [ ¿y hablarían de la pastilla del día despué $\left.{ }^{\mathrm{h}}\right]$

M4: no sé, según ella, $\mathrm{e}^{\mathrm{h}}$ hablaba a calzón quitado

M3: a lo mejor ahí le $\mathrm{e}^{\mathrm{h}}$ faltó decirle $\mathrm{h}^{\mathrm{h}}$

\section{Descripción del episodio número 2}

Elementos indispensables de la argumentación (Lo Cascio, 1998)

Tema: El proceso social que involucra la entrega de la pastilla del día después.

Tesis: El hecho de estar en contra de la legalización de la pastilla del día después debería ser entendido como una postura pro vida.

Argumentos: porque se estaría dando preferencia a la vida y se estaría intentando que la gente tome decisiones responsables frente a la sexualidad.

Regla General: La manera de enfrentar la sexualidad debe ser entendida como un proceso cultural.

Elementos facultativos de la argumentación (Lo Cascio, 1998) 
Refutación, contraopinión o reserva: La legalización de la pastilla del día después también debe ser entendida como una postura pro vida porque su adecuada utilización permitiría que disminuyeran los abortos y los abandonos de bebés no deseados.

\section{Estrategias de cortesía positiva}

(Brown P. y Levinson S. , 1987): Apele al “terreno común”. - Intensifique el interés hacia $O$.

- Exagere (interés, aprobación, simpatía con O)

- Fijese, atienda a $O$ (a sus intereses, deseos, necesidades, bienes).

Los enunciados de estos segmentos permiten demostrar la aprobación hacia el interlocutor pues se reconoce explícitamente que se está de acuerdo con su postura. Estos enunciados intentan mantener el contacto y demostrar así el interés y el acuerdo.

M2: sí tiene $e^{h}$ razón, pero también justamente te tomo la palabra frente a la vida $\mid e^{\boldsymbol{h}}$ que también esto $e^{\boldsymbol{h}}$ un beneficio justamente enfrentando la vida porque e: | e: a raíz de eso tu podi $^{\boldsymbol{h}}$, o se puede provocar un ABORTO | o niño ${ }^{\boldsymbol{h}}$ abandonado $\left.{ }^{\boldsymbol{h}}\right]$

H1: $<$ [y de eso hay mucho]

En el siguiente segmento se puede apreciar que hay intentos por manifestar el interés. M3 manifiesta su acuerdo repitiendo la información principal que dice H1. Es interesante que los otros participantes del debate también repitan parte del mensaje para manifestar su acuerdo:

H1: < [Entonce $e^{h}$ el problema no $e^{h}$ de la pastilla $e^{h}$ un problema cultural]

M3: $<$ [claro que $e^{h}$ un problema cultural]

M2: $<\left[e^{h}\right.$ un problema cultural como TODO]

M5: $<\left[e^{h}\right.$ un problema cultural $]$

Por su parte, los enunciados de estos segmentos permiten demostrar la aprobación hacia el interlocutor. Estos conectores discursivos pragmáticos metadiscursivos intentan mantener 
el contacto y demostrar así el interés y el acuerdo, además de permitir que progrese en un ambiente cordial el coloquio.

$M 2:<[s i]$

(...)

M2: $<$ [claro entonce ${ }^{h}$ ¿ve $\left.{ }^{h} ?\right]$

(...)

M3: < [ sí, puede ser]

En el siguiente segmento se manifiesta el interés de M3, pues responde inmediatamente a la pregunta general que hace M1 sobre el nombre de un programa de televisión:

M1: < [(...) ¿cómo le decía el otro día, esto de lo ${ }^{\boldsymbol{h}}$ quince año ${ }^{\boldsymbol{h}}$ ? aparecieron, maternidad a lo ${ }^{h}$ quince año $\left.{ }^{h}-\right]$

M3: < ["Mamá a lo quince”]

Apele a la pertenencia al mismo grupo que 0 . Use marcadores de identidad de grupo.

El uso de voseo verbal ${ }^{26}$ (hací, querí, tomai) léxico espontáneo (cabro, dejar la cagá, lolo, a calzón quitado, guagüitas) dan cuenta de que se encuentran en una situación distendida lo que intensifica la pertenencia al grupo y los identifica como miembros del mismo.

H1: < [porque aquí hay do ${ }^{h}$ camino $^{h} \mid$ o tú haci $^{h}$ lo que queri ${ }^{h}$ y te tomai la pastilla total mañana tengo la pastilla | o dice "yo me porto como CREO que debe portarse una persona, un hombre, una mujer un cabro de catorce un cabro de quince | y soy responsable y si dejo la cagá, mañana | respondo" | o si no digo "no: total mañana me tomo la pastilla" ]

M4: < [es dificil eso, sobre todo de lo ${ }^{h}$ lolo $\left.^{h}\right]$

(...)

M1: < [Pero hay un tema, que esta pastilla yo la miro má ${ }^{\boldsymbol{h}}$ que nada lo ${ }^{\boldsymbol{h}}$ niño ${ }^{\boldsymbol{h}}$ jóvene $\boldsymbol{h}^{\boldsymbol{h}}$ entre lo ${ }^{\boldsymbol{h}}$ doce dieciséi ${ }^{\boldsymbol{h}}$ año ${ }^{\boldsymbol{h}}$, porque eso ${ }^{\boldsymbol{h}} \underline{\text { cabro }}^{\boldsymbol{h}}$, ni el cabro hijo del mejor latifundista al má ${ }^{\boldsymbol{h}}$ humilde VA A ENTENDER lo que es responsabilidad ante el sexo, JAMÁS | te lo digo, por

\footnotetext{
${ }^{26}$ Se observó anteriormente que el uso del voseo verbal en el español hablado en Chile está restringido a situaciones informales. (cfr. pág. 42)
} 
la experiencia de la vida, a esta altura la: la puedo decir asi $\mid$ si estamo ${ }^{h}$ hablando de dieciocho, cabro ${ }^{h}$ de dieciocho para arriba, (...) ||| o sea, para evitar que nazcan guagüitas que despuéh quedan ahi a la deriva, yo voy por la pastilla del día despuéh || $\mid(\ldots)]$

Apele a la reflexibilidad (si $O$ desea [que $O$ tenga $X$ ], entonces $H$ desea [que $O$ tenga $X$ ] y si $\mathrm{H}$ desea [que $\mathrm{H}$ tenga $\mathrm{X}$ ] entonces $\mathrm{O}$ desea [que $\mathrm{H}$ tenga $\mathrm{X}$ ]). Incluya a ambos, $\mathrm{H}$ y $\mathrm{O}$, en la actividad. Dé (o pida) razones. Asuma o manifieste reciprocidad. Haga regalos a $O$ (bienes, simpatía, comprensión, cooperación).

En estos segmentos $\mathrm{H} 1$ cede su turno mediante una pregunta abierta que permite la colaboración de todo el grupo.

H1: $<$ [para un grupo de persona ${ }^{h}$, para lo que están allá, porque lo politico ${ }^{h}$ como ustede ${ }^{h}$ dicen, serán comunista ${ }^{h}$ socialista ${ }^{h}$, pero son todo católico ${ }^{h} \|$ iah?]

(...)H1:< [ la contraposición no $e^{h}$ que encerrar a la mujere $e^{h}, e^{h}$ una posición $\mid$ frente a la vida $\mid$ frente a como $\mid$ vamo a ser $\mid$ frente a cómo debe ser el hombre $\left.\right|_{\text {¿ o no?] }}$

Estrategias de atenuación cortés (Briz, 2001)

Se aminoran cualidades negativas del tú.

Se está afirmando algo en contra de lo que se dijo recientemente, pero de forma indirecta, esto es, haciendo una pregunta, aminorando así cualidades negativas del tú.

M5: < [ ¿y eso e bueno?]

Indicadores gramaticales de atenuación cortés (Kerbrat-Orecchioni) (Haverkate) Se aminoran cualidades negativas del tú:

- Hacer preguntas generales que contengan un contraargumento de la tesis que se debate para suavizar el ataque.

Indicadores gramaticales de cortesía positiva y negativa (Kerbrat-Orecchioni/Brown P. y Levinson S. ) (Haverkate)

Indicadores gramaticales de cortesía positiva:

- Uso de conectores pragmáticos metadiscursivos con intención fática y de aprobación para manifestar que se mantiene el contacto con el otro y la atención temática.

- Manifestar el acuerdo repitiendo parte del enunciado de otro interlocutor. 
- Expresar el interés respondiendo lo que solicita algún interlocutor.

- Uso de voseo verbal, léxico espontáneo intensifica la pertenencia al grupo y los identifica como miembros del mismo.

- Manifestación explícita del acuerdo con el otro: "te tomo la palabra", “estoy de acuerdo".

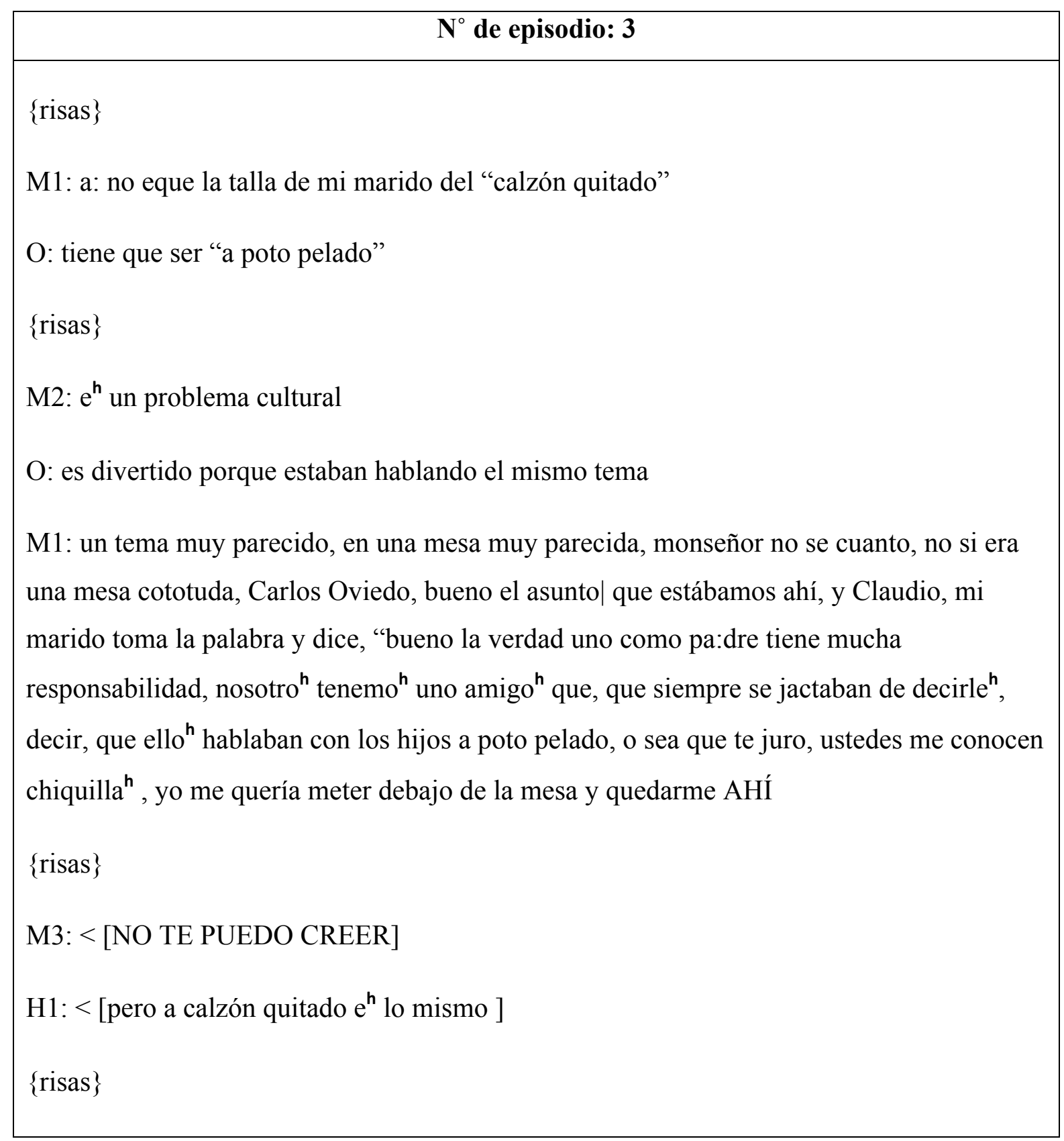


M1: y lo PEOR $\mathrm{e}^{\mathrm{h}}$ que se produjo un silencio, porque si alguien no ${ }^{\mathrm{h}}$ hubiera dicho a:-

M3: $<$ [hubiera pasado desapercibido]

M1: $<$ [no pero se produjo un silencio así, que todo ${ }^{\mathrm{h}}$ se miraban $]$

M2: < [pero son vaca porque te deberían haber apoyado, una sonrisa-]

M3: < [i¿NADIE SE RIÓ?!]

M2: < [no: yo me hubiera reído]

H1: $<$ [lo magnifica ella cree que- $]$

M1: $<$ [no pero fue un minuto TERRIBLE para mí, terrible, espantoso]

H1: en la casa de los Iribarren fue

M1: en la casa de $10^{\mathrm{h}}$ Iribarren, estábamo ${ }^{\mathrm{h}}$ en una reunió:n de pastora:1

H1: ¿y esto ${ }^{h}$ eran lo ${ }^{h}$ Tagle? compañero ${ }^{h}$ del Caco, del colegio

M1: eran papá ${ }^{\text {h }}$ de saben de quién

M3: 1o" que decían "a poto pelado"

M1: ¿han visto "casado con hijo" ${ }^{h "}$, el niño que se cree español, Marcial Tagle?

M3: a:

M1: era compañero de colegio del Caco, compañero de curso | claro y Marcial , papá ${ }^{\text {h }}$ la Ana María, eran amigo nuestro ${ }^{\mathrm{h}}$, ello tenían, tienen cuatro hijo ${ }^{\mathrm{h}}$, y siempre fueron así, de hablar con lo niño ${ }^{h}$, claro, con mucho garabato, y todo, hablar todo, al revé:s de nosotro ${ }^{h}$, pero bueno, éramo ${ }^{h}$ amigo $^{h}$ igual $\mid l a^{h}$ niñita $^{h}, l^{h}$ niñita $^{h}$ estaban en la teresiana $^{h}$, teresiana $^{\mathrm{h}}$ de Pedro de Valdivia, claro, y e:n cuarto medio salió con guagüita M3: de tanto hablarle- 
$\{$ risas

M1: ya hace mucho ${ }^{h}$ año atrá $^{h}$, esto hace nueve año ${ }^{h}$

H1: < [ en el acto presidencial de Frei, porque Frei estaba al lado-]

M3: $<$ [ Tagle era pariente d de loh Ruiz Tagle- $]$

M1: $<$ [claro, bueno el asunt-, no po la: - ]

H1: $<$ [no era Ruiz Tagle $]$

M3: < [¿no era Ruiz Tagle?]

H1: $<$ [no $10^{\mathrm{h}}$ Tagle eran amigo del cle:gio,

M1: $<$ [del colegio]

H1: $<$ [pero lo Frei eran amigo ${ }^{h}$ de e:110 $\left.{ }^{h}-\right]$

M2: < [al final la niñita lo hizo a poto pelado]

$\{$ risas

M1: bueno ahí no había la píldora del día despué

\section{Descripción del episodio número 3}

Elementos indispensables de la argumentación (Lo Cascio, 1998)

Tema: anécdota de la locución adverbial "a calzón quitado"27.

Es un episodio sin proceso argumentativo, es una descripción de anécdotas.

\footnotetext{
27 “poto. (de origen mapuche). M. Trasero, conjunto de nalgas. espon”. En el corpus se usa la expresión "a poto pelado" que se usa equivocadamente, según la anécdota que cuentan los participantes, en vez de usar la expresión "a calzón quitado", que es una locución adverbial que significa generalmente hablar, decir algo "sin restricciones o tapujos".
} 


\section{Estrategias de cortesía positiva}

(Brown P. y Levinson S. , 1987): Apele al “terreno común”. - Intensifique el interés hacia $O$.

- Exagere (interés, aprobación, simpatía con O)

- Fijese, atienda a $O$ (a sus intereses, deseos, necesidades, bienes).

Los enunciados de estos segmentos permiten demostrar la aprobación hacia el interlocutor. Estos conectores discursivos pragmáticos metadiscursivos intentan mantener el contacto y demostrar así el interés y el acuerdo, además de permitir que progrese en un ambiente cordial el coloquio.

M3: < [NO TE PUEDO CREER]

(...)

M3: $a$ :

Apele a la pertenencia al mismo grupo que 0 . Use marcadores de identidad de grupo.

El uso de léxico espontáneo (chiquilla, poto, vaca, po, guagüita) y léxico propio de su grupo etario (cototuda) dan cuenta de que se encuentran en una situación distendida lo que intensifica la pertenencia al grupo y los identifica como miembros del mismo.

M1: un tema muy parecido, en una mesa muy parecida, monseñor no se cuanto, no si era una mesa cototuda, Carlos Oviedo, (...) ello hablaban con los hijos a poto pelado, o sea que te juro, ustedes me conocen chiquilla ${ }^{h}$, yo me quería meter debajo de la mesa y quedarme AHÍ

(...)

M2: < [pero son vaca porque te deberian haber apoyado, una sonrisa-]

(...)

M1: (...) e:n cuarto medio salió con guagüita

(...)

M1:< [claro, beuno el asunt-, no po la: -] 
Apele al punto de vista, opiniones, actitudes, conocimiento, empatía comunes. - Busque el acuerdo. Evite el desacuerdo. Presuponga/ suscite/ manifieste el terreno común. Bromee.

Se hacen bromas con la anécdota que se está contando:

M1: (...) y e:n cuarto medio salió con guagüita

M3: de tanto hablarle-

$\{$ risas\}

$(\ldots)$

M2: < [al final la niñita lo hizo "a poto pelado”]

$\{$ risas $\}$

Apele a la reflexibilidad (si $O$ desea [que $O$ tenga $X$ ], entonces $H$ desea [que $O$ tenga $X$ ] $y$ si $\mathrm{H}$ desea [que $\mathrm{H}$ tenga $\mathrm{X}$ ] entonces $\mathrm{O}$ desea [que $\mathrm{H}$ tenga $X]$ ]). Incluya a ambos, $H$ y $O$, en la actividad. Dé (o pida) razones. Asuma o manifieste reciprocidad. Haga regalos a $O$ (bienes, simpatía, comprensión, cooperación).

En el siguiente segmento, M3 y M2 son solidarias con M1 y le dan su comprensión por la anécdota vergonzosa que está contando. Además es interesante que ellas sugieran que la risa o una sonrisa hubiera ayudado a distender el ambiente en aquella situación vergonzosa que se describe; por tanto ellas creen que la risa y el humor puede servir como estrategia de cortesía para disminuir el ataque personal en una situación como esa:

M1: y lo PEOR $e^{h}$ que se produjo un silencio, porque si alguien no ${ }^{h}$ hubiera dicho a:-

M3: < [hubiera pasado desapercibido]

M1: $<$ [no pero se produjo un silencio así, que todo ${ }^{h}$ se miraban]

M2: < [pero son vaca porque te deberían haber apoyado, una sonrisa-]

M3: < [i¿NADIE SE RIÓ?!]

M2: < [no: yo me hubiera reído]

Indicadores gramaticales de cortesía positiva y negativa (Kerbrat-Orecchioni/Brown P. y Levinson S. ) (Haverkate)

Indicadores gramaticales de cortesía positiva: 
- Uso de conectores pragmáticos metadiscursivos con intención fática y de aprobación para manifestar que se mantiene el contacto con el otro y la atención temática.

- Expresar la comprensión y manifestar el apoyo al interlocutor cuando comenta una situación que ha afectado su imagen personal.

- Uso de léxico espontáneo intensifica la pertenencia al grupo y los identifica como miembros del mismo.

- Bromas que distienden el ambiente.

\section{$N^{\circ}$ de episodio: 4}

O: entonce ${ }^{h}$ estamo $^{h}$ todo, parece que estamo ${ }^{h}$ todo $^{h}$ de acuerdo con el tema

M1: yo por lo menos sí, el caballero, dio una opinión diferente pero-

$\mathrm{M} 2:<$ estamo $^{\mathrm{h}}$ de acuerdo $]$

O: o sea ¿no les importa que sea abortiva, o no? ¿O no hay ningún asunto de ese tipo?

M1: no

M2: yo no creo que sea abortiva

M3: yo tampoco

H1: yo creo que en vez de decir no creo, deberían decir la ciencia dice, ¿la ciencia no tiene nada que ver?

M3: $<$ [pero la ciencia no dice que no]

M2: < [la iglesia dice que sí- $]$

$\mathrm{M} 1:<$ mientra $^{\mathrm{h}}$ no me demuestren- $]$

H1: < [ la iglesia dice que sí -] 
M2: $<$ [hay do ${ }^{h}$ versione $\left.^{h}-\right]$

$\mathrm{H} 1:<\left[\right.$ el único que dice que no $\mathrm{e}^{\mathrm{h}}$ Croxato $^{28}$, que $\mathrm{e}^{\mathrm{h}}$ un señor $]$

M3: $<$ [Yo le creo a Croxato]

H1: lo que pasa $\mathrm{e}^{\mathrm{h}}$ que la ciencia no $\mathrm{e}^{\mathrm{h}}$ infalible.

M1: $1 a^{h}$ ciencia no son exacta ${ }^{\mathrm{h}}$ tampoco, hay una vida de por medio, que hay que ver qué pasa $\mid \mathrm{e}^{\mathrm{h}}$ mi opinión, por lo meno ${ }^{\mathrm{h}} \mathrm{e}^{\mathrm{h}}$ mi opinión, y la mantengo también.

M2: yo estoy de acuerdo

M3: yo también

H1: $<$ [o sea- $]$

M1: < [yo pienso que-]

$\mathrm{H} 1:<$ [porque si uno dice "esta $\mathrm{e}^{\mathrm{h}}$ mi humilde opinión y la mantengo"- quiere decir]

M1: $<$ [la mantengo- $]$

$\mathrm{H} 1:<\left[{ }^{\mathrm{e}} \mathrm{e}^{\mathrm{h}}\right.$ porque ya $\mathrm{e}^{\mathrm{h}}$ raro lo que ustede ${ }^{\mathrm{h}}$ digan ya - $]$

$\mathrm{M} 1:<\left[\mathrm{NO}\right.$, yo respeto el resto de $\mathrm{la}^{\mathrm{h}}$ opinione $^{\mathrm{h}}$ pero mi opinión $\mid$ es esa, o sea $\mathrm{e}^{\mathrm{h}} \mathrm{mi}$ opinión]

H1: < [pero si hay otra opinión que te diga \| argumentadamente, "mira estáh equivocada tú" -]

$\mathrm{M} 1:<\left[\mathrm{e}^{\mathrm{h}}\right.$ su opinión, respetable $]$

M2: $<$ [la respeto $]$

$\mathrm{M} 1:<\left[\right.$ ¿y no va ${ }^{\mathrm{h}}$ a cambiar de opinión?]

$\mathrm{M} 1:<[\mathrm{no}:]$

M3: $<[$ no: $]$

M2: < [no: ¿ por qué?]

$\mathrm{H} 1:<$ entonce $^{\mathrm{h}}$ no $\mathrm{e}^{\mathrm{h}}$ opinión $]$

28 Horacio Croxato es doctor en filosofía de la Universidad de Santiago. Afirmó ante en Tribunal Constitucional de Chile que la píldora del día después no es abortiva. 


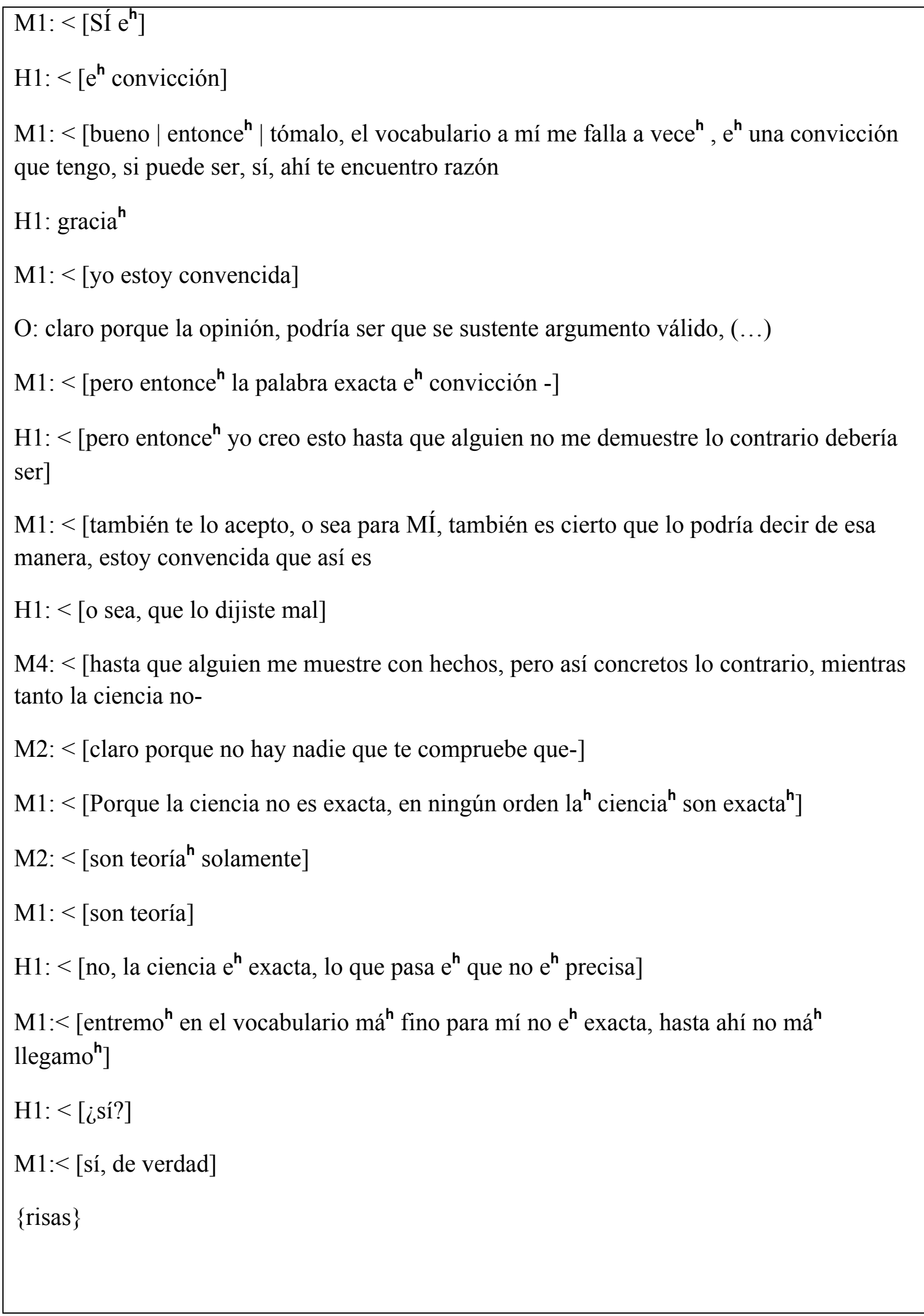




\section{Descripción del episodio número 4}

Elementos indispensables de la argumentación (Lo Cascio, 1998)

Tema: Los cambios de opinión frente a evidencia científica.

Tesis: Uno debería decir: "esta es mi opinión, yo pienso esto mientras nadie pueda probarme lo contrario".

Argumentos: Porque así uno podría dejar de lado lo valórico y limitarse a observar la evidencia científica.

Regla General: Es posible cambiar de opinión.

Elementos facultativos de la argumentación (Lo Cascio, 1998)

Refutación, contraopinión o reserva: La opinión es personal. Por mucho que haya pruebas científicas uno no tiene por qué cambiar su opinión o su postura personal, sustentada en valores.

Falacias argumentativas (Lo Cascio (1998))

Argumentum ad ignorantiam: Se apela a la ignorancia del oponente para probar el punto de vista contrario, a partir de información incompleta.

M1:< [pero la ciencia no dice que no]

M2: < [la iglesia dice que sí-]

M2: < [mientra ${ }^{h}$ no me demuestren-]

H1: < [ la iglesia dice que si -]

M2: $<$ [hay do ${ }^{h}$ versione $\left.{ }^{h}-\right]$

Argumentum ad baculum: Se persuade a través del temor y de la amenaza dirigida hacia el oponente.

En estos dos casos se persuade a través del miedo a ser considerado ignorante por no saber exactamente el significado de las palabras que se están usando, entonces la persona simplemente acepta el argumento como válido.

H1: $<$ [entonce $^{h}$ no $e^{h}$ opinión]

$M 1:<\left[S I ́ e^{h}\right]$ 
$H 1:<\left[e^{h}\right.$ convicción $]$

M1: < [bueno $\mid$ entonce ${ }^{\boldsymbol{h}} \mid$ tómalo, el vocabulario a mí me falla a vece ${ }^{\boldsymbol{h}}$, $e^{\boldsymbol{h}}$ una convicción que tengo, si puede ser, sí, ahi te encuentro razón

(...)

H1: < [no, la ciencia $e^{h}$ exacta, lo que pasa $e^{h}$ que no $e^{h}$ precisa]

M1: $<$ [entremo $^{h}$ en el vocabulario máh fino para mí no $e^{h}$ exacta, hasta ahí no máh llegamo $\left.{ }^{h}\right]$

\section{Estrategias de cortesía positiva}

Estrategia de retribución de un acto halagador (Kerbrat-Orecchioni (2004:44)): M1 presta a H1 un servicio, un reconocimiento a una opinión (FFA) y entonces H1 intenta producir un FFA (agradecimiento o gentileza), para restablecer el equilibrio ritual entre los interactuantes.

H1: $<$ [entonce $e^{h}$ no e $e^{h}$ opinión]

$M 1:<\left[S I ́ e^{h}\right]$

H1: $<\left[e^{h}\right.$ convicción $]$

M1: < [bueno $\mid$ entonce $^{\boldsymbol{h}} \mid$ tómalo, el vocabulario a mí me falla a vece ${ }^{\boldsymbol{h}}, e^{\boldsymbol{h}}$ una convicción que tengo, si puede ser, sí, ahi te encuentro razón

H1: gracia $^{\boldsymbol{h}}$

(Brown P. y Levinson S. , 1987): Apele al “terreno común”. - Intensifique el interés hacia $O$.

- Exagere (interés, aprobación, simpatía con O)

- Fijese, atienda a $O$ (a sus intereses, deseos, necesidades, bienes).

Los enunciados de estos segmentos permiten demostrar la aprobación hacia el interlocutor pues se reconoce explícitamente que se está de acuerdo con su postura. Estos enunciados intentan mantener el contacto y demostrar así el interés y el acuerdo.

M2: yo estoy de acuerdo

M4: yo también 


\section{(...)}

M1: (...) si puede ser, sí, ahí te encuentro razón.

(...)

M1: < [también te lo acepto, (...)]

$(\ldots)$

M1: $<\left[e^{h}\right.$ su opinión, respetable]

También se observa que para manifestar el acuerdo se repite lo que otro dijo:

M2: < [son teoría ${ }^{h}$ solamente]

M1: < [son teoría]

Estrategias de atenuación cortés (Briz, 2001)

Se aminoran cualidades negativas del tú: la risa permite matizar el ataque.

M1: $<$ [entremo $^{h}$ en el vocabulario máh fino para mí no $e^{h}$ exacta, hasta ahí no máh llegamo $\left.{ }^{h}\right]$

$H 1:<[¿ s i ́ ?]$

M1:< [sí, de verdad]

$\{$ risas\}

Indicadores gramaticales de atenuación cortés:

Se aminoran cualidades negativas del tú:

- Risas en el debate para suavizar el ataque.

Indicadores gramaticales de cortesía positiva y negativa (Kerbrat-Orecchioni/Brown P. y Levinson S. ) (Haverkate)

Indicadores gramaticales de cortesía positiva:

- Manifestar el acuerdo repitiendo parte del enunciado de otro interlocutor.

- Manifestación explícita del acuerdo con el otro: "ahí te encuentro razón”, "te lo acepto".

- Retribuir dando las gracias después de recibir un acto halagador. 


\section{$\mathbf{N}^{\circ}$ de episodio: 5}

M1: yo me reconozco que soy bien conservadora, pero AQUÍ |no, o sea, con esta cosa de la píldora creo que, prefiero

O: o sea, nadie piensa tampoco, porque podría ser un argumento por ejemplo, el costo hormonal, el daño que le produce a la niña tomarse la pastilla del día despué ${ }^{h}$, porque tomarse la pastilla no $\mathrm{e}^{\mathrm{h}}$ como quien dice "me voy a tomar una aspirina", esa niña queda con secuela $^{\mathrm{h}}$, y simboliza como una especie de menopausia para esa niña.

M2: < [eso nadie, no lo han dicho]

O: $<$ [sí, o sea, es un golpe hormonal | muy fuerte - $]$

M2: $<$ [ya]

$\mathrm{O}:<$ [esa niña queda con $\mid$ puede quedar con problema para volver a quedar embarazada $\mid$ no puede tomar máh de una-]

M1: $<\left[\right.$ no $\mathrm{e}^{\mathrm{h}}$ normal el poco conocimiento que se tiene es OTRO TEMA, entramo ${ }^{\mathrm{h}}$ en otro tema]

M3: $<$ yo, $\rightarrow$ yo tengo conocimiento de una amiga de una de $\mathrm{mi}^{\mathrm{h}} \mathrm{hija}^{\mathrm{h}} \mid$ que la tomó $\mid$ porque se le rompió el preservativo || y:-]

$\mathrm{O}:<[$ ¿no le pasó nada? porque igual tomarse- $]$

M3: < [no claro, hay un ginecólogo que: | que cómo se llama | que: le dijo ponte tú a una de mi hija que: cuando fue al ginecólogo, pero justamente hablando del tema, pero bien así | preguntando que qué opinaba ella entonce ${ }^{\mathrm{h}}$ igual dijo, había hab- había coincidido justo con $10^{h}$ día $^{h}$ que se sacó, cuando se sacó de $1 a^{h}$ farma:icia ${ }^{h} y$ toda la: todo el leseo || y: y qué | la Coni que justamente ella tenía problema ${ }^{\mathrm{h}}$ hormonale $^{\mathrm{h}}$ ahí y todo el cuento, entonce hablando él de eso dijo que la pastilla, que él estaba de acuerdo con la pastilla del día 
despué $\mid \mathrm{y}$ : en el fondo es un bombazo de pastilla $\mathrm{e}^{\mathrm{h}}$ lo mismo $\mathrm{e}^{\mathrm{h}}$ lo mismo que parece

$\mathrm{O}:<[\mathrm{sí}]$

M3: $<$ [como si tú puede, a: porque justo-]

$\mathrm{O}:<\left[\right.$ se tomara una caja de anticonceptivo $\left.{ }^{\mathrm{h}}\right]$

M3: < [no una caja no, como cinco, si tú tomai cinco pastilla ${ }^{\text {h }}$ anticonceptiva $^{\text {h }} \mid$ de un viaje $\mid$ en el fondo eso te hace el efecto, en el fondo porque eso fue lo que él dijo, en el fondo la: prohibición de venderla en la farmacia se podría suplir igual en eso | pero CLARO eso te lo dice un ginecólogo no $\mathrm{ma}^{\mathrm{h}}$, pero la gente no lo sabe, si toma ${ }^{\mathrm{h}}$ cinco pastilla ${ }^{\mathrm{h}}$ parece que son cinco pastilla ${ }^{\mathrm{h}}$ anticonceptiva $^{\mathrm{h}}$ de un viaje, cinco, te hace el mismo efecto -]

H1: $<$ [el problema $\mathrm{e}^{\mathrm{h}}$ que lo médico son muy ignorantes]

M3: < [pero no:, ponte tú a la amiga de mi hija no le pasó absolutamente nada, es máh despuéh ella se casó y tuvo familia]

H1: $<$ [mira, mira el médico que te digo yo- $]$

$\mathrm{M} 1:<$ bueno eso $\mathrm{e}^{\mathrm{h}}$ como, $\mathrm{e}^{\mathrm{h}}$ como: $\mathrm{e}^{\mathrm{h}} \mathrm{e}^{\mathrm{h}}$ tan variable digamo ${ }^{\mathrm{h}}$ lo que le puede pasar a u:na persona a otra persona-]

M3: < pero yo nunca había escuchado eso de que-]

O: a veces hay secuelas

M3: claro a veces hay secuela ${ }^{h}$

$\mathrm{H} 1:<\left[\mathrm{e}^{\mathrm{h}}\right.$ lo mismo que pasa con el ojo, que tuve una rasgadura en la retina $\mid$ entonce $^{\mathrm{h}}$ veo, vimo $^{h}$ do $^{h}$ medico $\mid$ me tenía que ir a España entonce uno me dijo "mire, puede que pase, o puede que no pase, usted vea, si ya tiene lo pasaje mejor váyase porque, si total, puede que pase o puede que no pase" -]

M2: $<$ [ya] 
H1: $<$ [ y pasó || pero cuando llegué aquí vi a otro médico y me dice "no si es una tontera, cuando a usted le pasa eso hay un setenta y cinco por ciento de probabilidades de que le vuelva a pasar" || que es harto distinto ¿cierto?]

M2: $<$ [sí]

H1: $<$ [y do médico opinaron | "no: puede que sí:, puede que no:”, entonce ${ }^{\mathrm{h}}$ eso tú te pide $\mathrm{h}^{\mathrm{h}}$ eso te está demostrando en este pequeño: que hay do $^{\mathrm{h}}$ tercio $^{\mathrm{h}}$ de médico ${ }^{\mathrm{h}} \mid$ que son IGNORANTES, porque eso es ignorancia PURA | y hay uno que sabía]

$\mathrm{M} 1:<\left[\mathrm{e}^{\mathrm{h}}\right.$ que $\mathrm{e}^{\mathrm{h}}$ a ley de la probabilidade $\left.{ }^{\mathrm{h}}-\right]$

H1: $<[$ no:, claro, bueno]

M2: < [viejo querido, a mi estuvieron do ${ }^{h}$ médico $^{h}$, do $^{h}$, y de la mejore ${ }^{h}$ clínica $^{h}$ uno de ello $^{h}$ el traumatólogo de la Oriana Muñoz que ella $e^{h}$ testigo $\mid$ los dos me diagnosticaron HERNIA en la columna | me faltaba hacerme la RESONANCIA magnética para operarme $\|$ y al médico, porque alguien me lo recomendó, me hicieron un estudio radiológico y lo realmente tengo es $\mid$ ARTROSIS ]

M3: y aparte de eso que la hernia a la columna no te la operan así al tiro tan pocoM2: $<$ [no, pero todo me hablaban de hernia, $10^{h}$ do $^{h}$, y la $\operatorname{artrosi}^{\mathrm{h}}$ es $^{\mathrm{h}} \mathrm{h}^{\mathrm{h}}$ cartílago $^{\mathrm{h}}$ que se están envejeciendo por la edad, $\mathrm{e}^{\mathrm{h}}$ la lógica-]

H1: $<$ [pero tú ere ${ }^{\mathrm{h}}$ joven po]

M2: < [sí:

$\{$ risas

H1: [oye yo tengo un caso mejor-]

M2: < [A mí me, te imaginai si me hubiese dejado estar]

$\mathrm{M} 1:<[$ claro $]$ 
H1: $<$ [oye yo tengo un caso, de un compañero, Manuel Camiruaga]

$\mathrm{M} 1:<[$ ay no Claudio por favor $]$

H1: < [que tenía un dolor en la espalda-]

M1: $<$ [por sobre el nivel de la conversación va bajando un poquito]

$\{$ risas

$\mathrm{M} 1:<[$ pobre cabro]

H1: < ["u: tú tienes un tumor al pulmón”]

M2: < [ya: $]$

H1: < ["hay que operar RÁPIDAMENTE, y: PUM lo metieron adentro, y, y, al quirófano, entonce $^{\mathrm{h}}$ lo llevaron]

M1: $<$ [le hicieron vario ${ }^{\mathrm{h}}$ estudio $^{\mathrm{h}}$ ante $\left.^{\mathrm{h}}\right]$

$\mathrm{M} 2:<$ [ni siquiera la resonancia]

$\mathrm{O}:<$ [claro, parece como que llegó y-]

$\mathrm{H} 1:<$ el asunto $\mathrm{e}^{\mathrm{h}}$ que lo metieron en la clínica, lo pusieron en la cama, en media hora $\mathrm{ma}^{\mathrm{h}}$ lo operamo $\mathrm{h}^{\mathrm{h}}$, llegaron uno cuetione $\mathrm{e}^{\mathrm{h}}$, uno ${ }^{\mathrm{h}}$ camillero $^{\mathrm{h}} \mid$ lo tomaron y lo dieron vuelta para pasarlo a otra cama para llevarlo, cuando lo dieron vuelta, se tiróun peo $\{$ risas

H1: < [y el médico lo quería operar]

M1: $<$ [estaba atascado]

M3: < [cómo estaría que- $]$

$\mathrm{M} 1:<[$ claro $]$ 
H1: $<$ [estaba atravesado]

$\mathrm{O}:<$ a la Mónica, también le pasó, la iban a operar de $\operatorname{APENDICITI}^{\mathrm{h}}$, porque parece que hay algo raro AHÍ con lo gase ${ }^{h}$ que NO SE VEN, o qué diablo ${ }^{h}$ ]

M1: < [claro como que te presionen ese| ese el órgano del apéndice te lo ponen de tal manera |que todo te puede pasar ahí como que se te reviente una tripa, no sé algo-]

M3: $<$ [claro]

$\mathrm{M} 1:<[\mathrm{Y}$ si se sale ese gas -$]$

$\mathrm{H1}$ : $<$ [por eso hay un dicho popular que dice " $\mathrm{ma}^{\mathrm{h}}$ vale perder un amigo-

M2: < [que u peo]

$\mathrm{H} 1:<$ [que una tripa, que una tripa] $\{$ risas

M2: [claro tení ${ }^{\text {h }}$ razón, el dicho es máh vale perder una amigo ]

\section{Descripción del episodio número 5}

Elementos indispensables de la argumentación (Lo Cascio, 1998)

Tema: Opinión de médicos frente a los efectos de la pastilla del día después.

Tesis: La pastilla no produce grandes desórdenes hormonales.

Argumentos: La pastilla del día después equivale a tomarse cinco pastillas anticonceptivas de una vez.

Regla General: cuando una mujer toma la pastilla del día después, que contiene grandes cantidades de hormonas, podría ser perjudicial para el orden normal de su ciclo hormonal. Elementos facultativos de la argumentación (Lo Cascio, 1998)

Refuerzo: Mujeres que la han tomado no han tenido problemas en posteriores embarazos. 
Refutación, contraopinión o reserva: Todo esto dependerá del médico al que uno le pregunte porque generalmente hay desacuerdo entre los médicos.

\section{Fuentes: Ginecólogos.}

\section{Estrategias de cortesía positiva}

Apele al punto de vista, opiniones, actitudes, conocimiento, empatía comunes. - Busque el acuerdo. Evite el desacuerdo. Presuponga/ suscite/ manifieste el terreno común. Bromee.

El siguiente segmento se considera que integra estrategias de cortesía positiva, si bien efectivamente se trata de una interacción irónica ${ }^{29}$ :

M2: < [no, pero todo me hablaban de hernia, $l o^{h} d o^{h}$, y la artrosi $i^{h}$ es $l o^{h}$ cartílago $^{h}$ que se están envejeciendo por la edad, $e^{\boldsymbol{h}}$ la lógica-]

H1: < [pero tú ere ${ }^{h}$ joven po]

M2: < [sí:]

$\{$ risas $\}$

En este otro segmento se cuentan anécdotas y se hacen bromas:

H1: < Lel asunto $e^{h}$ que lo metieron en la clínica, lo pusieron en la cama, en media hora ma $^{h}$ lo operamo ${ }^{h}$,llegaron uno cuetione ${ }^{h}$, uno $^{h}$ camillero $^{h} \mid$ lo tomaron y lo dieron vuelta para pasarlo a otra cama para llevarlo, cuando lo dieron vuelta, se tiró un peo

$\{\operatorname{risas}\}(\ldots)$

H1: < [por eso hay un dicho popular que dice " $m a^{h}$ vale perder un amigo-

M2: < [que u peo]

M2: < [que una tripa, que una tripa]

$\{$ risas $\}$

M2: [claro teni ${ }^{h}$ razón, el dicho es máh vale perder una amigo ]

\footnotetext{
${ }^{29}$ Se discutió anteriormente Alvarado (2005) la presencia de cortesía verbal en un enunciado de tipo irónico que, en definitiva, y contrariamente a lo que se ha creído hasta el momento, es usada para producir cortesía. Vemos en este ejemplo que la ironía tiene aquí un efecto positivo pues lleva consigo cortesía. De esta manera, se relaciona la cortesía con una ironía de efecto positivo.
} 
(Brown P. y Levinson S. , 1987): Apele al “terreno común”. - Intensifique el interés hacia $O$.

- Exagere (interés, aprobación, simpatía con O)

- Fijese, atienda a $O$ (a sus intereses, deseos, necesidades, bienes).

Los enunciados de estos segmentos permiten demostrar la aprobación hacia el interlocutor. Estos conectores discursivos pragmáticos metadiscursivos intentan mantener el contacto y demostrar así el interés y el acuerdo, además de permitir que progrese en un ambiente cordial el coloquio.

$$
\begin{aligned}
& \text { M2: }<[y a] \\
& \text { (...) } \\
& \text { M2: < [sí:] } \\
& \text { (...) } \\
& \text { H1: < [no:, claro, bueno] } \\
& \text { (...) } \\
& \text { M2: < [sí:] } \\
& \text { (...) } \\
& \text { M1: < [claro] }
\end{aligned}
$$

Apele a la pertenencia al mismo grupo que 0 . Use marcadores de identidad de grupo.

El uso de léxico espontáneo (peo, cuestiones, cuento, leseo, po, de un viaje) dan cuenta de que se encuentran en una situación distendida lo que intensifica la pertenencia al grupo y los identifica como miembros del mismo.

M3: $<\left[(\ldots)\right.$ justo con $l^{h}{ }^{h}$ dia $^{h}$ que se sacó, cuando se sacó de la farma:icia ${ }^{h}$ y toda la: todo el leseo || y: y qué | la Coni que justamente ella tenía problema ${ }^{h}$ hormonale $^{h}$ ahí y todo el cuento, (...)]

(...)

M3: < [no una caja no, como cinco, si tú tomai cinco pastilla ${ }^{h}$ anticonceptiva $^{h} \mid \underline{\text { de }}$ un viaje |]

(...) 
H1: < [pero tú ere ${ }^{h}$ joven po]

\section{(...)}

H1: < lel asunto $e^{h}$ que lo metieron en la clínica, lo pusieron en la cama, en media hora ma $^{h}$ lo operamo ${ }^{h}$, llegaron uno cuetione ${ }^{h}$, uno $^{h}$ camillero $^{h} \mid$ lo tomaron y lo dieron vuelta para pasarlo a otra cama para llevarlo, cuando lo dieron vuelta, se tiró un peo]

Indicadores gramaticales de cortesía positiva y negativa (Kerbrat-Orecchioni/Brown P. y Levinson S. ) (Haverkate)

Indicadores gramaticales de cortesía positiva:

- Uso de conectores pragmáticos metadiscursivos con intención fática $\mathrm{y}$ de aprobación para manifestar que se mantiene el contacto con el otro y la atención temática.

- Uso de léxico espontáneo intensifica la pertenencia al grupo y los identifica como miembros del mismo.

- Bromas que distienden el ambiente y el uso de la ironía que causa un efecto de cortesía positiva.

\section{$\mathrm{N}^{\circ}$ de episodio: 6}

O: entonce ${ }^{\mathrm{h}}$ vamos con el siguiente tema que es, la siguiente pregunta ¿es posible permitir el matrimonio homosexual en una sociedad como nuestra sociedad chilena, y qué pasaría por ejemplo con la adopción de niños?

M1 : Yo estoy de acuerdo con el matrimonio, pero no con la adopción de niño ${ }^{h}$

M2: Yo estoy de acuerdo con la parte legal, y digo bueno si ya $\mathrm{e}^{\mathrm{h}}$, y ya están conviviendo, y cada uno hace lo que quiere con su vida, y ese $\mathrm{e}^{\mathrm{h}}$ su cuento de ello ${ }^{\mathrm{h}}$, lo encuentro que sí, por la parte legal sí, porque ello ${ }^{\mathrm{h}}$ arman pareja, compran común con biene $\mathrm{h}^{\mathrm{h}}$ que, de hecho también salió en la televisión, que salió la pareja de uno y: habían comprado montón de cosa en común y la familia del que falleció le quitó todo y lo dejó en la calle-

M3: sí eso $\mathrm{e}^{\mathrm{h}}$ verdad 
M2: estoy de acuerdo sí, e:, pero la adopción de niño ${ }^{h}$ no $\|$ ahí no estoy de acuerdo

M3: < [A mí me hace un poco de ruido el matrimonio, sí creo que debería regularse la unión]

M2: < [pero matrimonio matrimonio así como nosotros, no, creo que no, o sea que se le dice matrimonio, pero creo que tiene que haber una cosa legal que lo ${ }^{\mathrm{h}}$ legalice]

M3: < [o sea legalizar la unión, pero de otra forma]

$\mathrm{M} 2:<[\mathrm{eso}]$

M4: < [a ti qué te molesta Moni, la cosa de la ceremo:nia, la cosa de del matrimonio, ponte tú-]

M3: < [sí, no, no sé, pero, que se llame matrimonio no sé por qué ]

M2: $<$ [claro que se llame matrimonio]

M5: [sí porque en realidad matrimonio siempre es entre un hombre y una mujer]

M2: $<$ [cla: ro, eso choca]

M5: $<$ [nunca en do ${ }^{h}$ hombre o en do ${ }^{h}$ mujere $^{h}$ ]

M3: $<$ [no me molesta que vivan junto, que formen su familia, incluso, no me molestaría que pudieran adoptar $\mid$ yo creo que no: no $\mathrm{e}^{\mathrm{h}}$ problema.]

M2: < [yo ahí todavía no:]

M5: $<$ [la palabra matrimonio $\mathrm{e}^{\mathrm{h}}$ ahí la que no se acepta $]$

M3: < [a mí el matrimonio porque me "hace un poco de ruido", eso me cuesta aceptarlo]

M5: < [fíjate que yo, hasta hace uno diez año atrá $^{\mathrm{h}} \mid \operatorname{lo}^{\mathrm{h}}$ gay $^{\mathrm{h}} \mid$ lejo $^{\mathrm{h}}$, lejo ${ }^{\mathrm{h}}$ conmigo, o sea yo, tenía poca tolerancia y casi nada a lo que fuera homosexual | CERO tolerancia en realidad ||nació un nieto mío || y no sé por qué empecé un día a pensar en todo este tema |y dije bueno yo no puedo ser así toda la vida porque tengo un nieto, en ese minuto empecé 
¿qué sabe Dios lo que va a ser de ese niño? | pero va a ser siempre mi nieto, yo lo voy a apoyar, qué se yo $\mid$ han pasado nueve año ${ }^{h}$ de este tema, y hoy $\mid$ yo acepto $10^{h}$ gay $^{h}$ fíjate, o sea, soy capaz de sentarme a conversar con e:110 ${ }^{h}$, encontrarlo ${ }^{h}$ hasta simpá:tico ${ }^{h} \mid$ no me producen rechazo || pero hablar de matrimonio | NICA.

M3: $<\left[\mathrm{e}^{\mathrm{h}}\right.$ diferente $]$

M5: < [aunque sea mi nieto, lo que sí encuentro es que , una cosa legal, para que esto ${ }^{\mathrm{h}}$ jóvene $^{\mathrm{h}}$ o niña ${ }^{\mathrm{h}}$ cuando se juntan y compran biene ${ }^{\mathrm{h}}$ como dicen, en realidad el que se va quede protegido, porque en el mundo en que vivimo ${ }^{\mathrm{h}}$ la sociedad $\mathrm{e}^{\mathrm{h}}$ cruel en to:do orden de $\cos ^{h}{ }^{h}, 10^{h}$ casado, $10^{h}$ no casado ${ }^{h}, 10^{h}$ viudo $^{h}$, y en el caso mío $10^{h}$ divorciado $^{h} \mid$ hay una parte de la sociedad que: que $\mathrm{e}^{\mathrm{h}}$ como que te rechaza | hay algo raro en la sociedad| entonce $^{h}$ esto $^{h}$ niño también son rechazado ${ }^{h}$ si quiéranlo o no, pero entonce ${ }^{h}$ ello $^{h}$ se tienen que proteger de la parte legal, no sé cómo le llaman, matrimonio no le pongamo ${ }^{\mathbf{h}} \|$ la palabra para mí matrimonio $\mathrm{e}^{\mathrm{h}}$ otra $\mid$ ahí me entra toda la parte: -]

M1: < [negativa]

M4: $<$ [ como valórica $]$

M5: < [católica, apostólica, chilena, no sé , para mí el matrimonio e ${ }^{\mathrm{h}}$ hombre y mujer M1: < [sí: por supuesto] M5: $<$ [no hay má ${ }^{h}$, ahora esta ${ }^{h}$ pareja $^{h}$ que se unen, que se unan en la cosa legal todo lo que sea-]

$\mathrm{H} 1:<[$ ¿sociedad conyugal?]

M5: < [sociedad conyugal, no sé cómo llamarle]

$\mathrm{M} 2:<\left[\mathrm{e}^{\mathrm{h}}\right.$ que matrimonio uno siempre lo asocia iglesia, o sea, matrimonio e la iglesia, pero matrimonio civil e un contrato]

M5: < [sí, ni tanto fíjate, me ha tocado ver tanto matrimonio civil que ya me acostumbré] 


\section{$\{$ risas}

M5: $<$ [claro porque se están casando civil no má $\left.\mathrm{e}^{\mathrm{h}}\right]$

M2: $<$ [claro]

M3: $<\left[\right.$ sí e ${ }^{\text {h }}$ verdad]

M2: < [pero sí encuentro que esto jóvene ${ }^{h}$ tienen derecho, en esta cosa MATERIAL protegida, no sé cómo llamarlo]

\section{Descripción del episodio número 6}

Elementos indispensables de la argumentación (Lo Cascio, 1998)

\section{Tema: Posibilidad de permitir el matrimonio homosexual en una sociedad como la} nuestra.

Tesis: Sí sería adecuada la legalización del matrimonio pero no la adopción de niños.

Argumentos: Los niños adoptados por matrimonios homosexuales serían discriminados y tendrían un ejemplo confuso respecto al concepto de familia.

Regla General: Si se legaliza el matrimonio homosexual los matrimonios homosexuales podrían adoptar niños sin problema.

Elementos facultativos de la argumentación (Lo Cascio, 1998)

Refuerzo: la imagen adecuada de la familia es la de padre y madre.

Refutación, contraopinión o reserva: No sería adecuada la legalización del matrimonio homosexual ni tampoco la adopción de niños, bastaría con un acuerdo de vida en pareja.

Falacias argumentativas (Lo Cascio (1998))

Petitio principii: Usar de un modo implícito la conclusión como una premisa.

M2: < [claro que se llame matrimonio]

M5: [sí porque en realidad matrimonio siempre es entre un hombre y una mujer]

M2 < [cla: ro, eso choca]

M5: < [nunca en do hombre o en do ${ }^{h}$ mujere $^{h}$ ] 


\section{Estrategias de cortesía positiva}

(Brown P. y Levinson S. , 1987): Apele al “terreno común”. - Intensifique el interés hacia $O$.

- Exagere (interés, aprobación, simpatía con O)

- Fijese, atienda a O (a sus intereses, deseos, necesidades, bienes).

Preguntas directas a otros participantes del debate:

M4: < [a ti qué te molesta Moni, la cosa de la ceremo:nia, la cosa de del matrimonio, ponte tú-]

Los enunciados de estos segmentos permiten demostrar la aprobación hacia el interlocutor. Estos conectores discursivos pragmáticos metadiscursivos intentan mantener el contacto y demostrar así el interés y el acuerdo, además de permitir que progrese en un ambiente cordial el coloquio:

M2: < [eso]

(...)

M1: < [sí: por supuesto]

(...)

M2: < [claro]

(...)

M3: $<$ [si e $e^{h}$ verdad]

Apele a la pertenencia al mismo grupo que O. Use marcadores de identidad de grupo.

El uso de léxico espontáneo (nica, hacer ruido) y léxico propio de su grupo etario (fijate) dan cuenta de que se encuentran en una situación distendida lo que intensifica la pertenencia al grupo y los identifica como miembros del mismo.

M5: < [fijate que yo, hasta hace uno diez año atrá ${ }^{h} \mid l^{h}{ }^{h}$ gay $^{h} \mid$ lejo $^{h}$, lejo ${ }^{h}$ conmigo, (...)|| pero hablar de matrimonio $\mid \underline{\text { NICA. }}$

(...) 
M3: < [a mí el matrimonio porque, me hace un poco de ruido, eso me cuesta aceptarlo]

(...)

Exprese que $\mathrm{H}$ y $\mathrm{O}$ son cooperativos. Indique que $\mathrm{H}$ conoce los deseos de $\mathrm{O}$ y los está teniendo en cuenta. Manifieste o presuponga que conoce y se preocupa por los deseos de o. Ofrezca, prometa. Sea optimista.

Se observa interés en ayudar al otro a expresar su idea, terminar su enunciado, ofreciéndole alternativas o reformulando la idea que expresó:

M5: < [no hay máh ${ }^{\text {, ahora esta }}{ }^{h}$ pareja $^{h}$ que se unen, que se unan en la cosa legal todo lo que sea-]

$H 1:<$ [isociedad conyugal?]

M5: < [sociedad conyugal, no sé cómo llamarle]

(...)

M2: < [pero matrimonio matrimonio así como nosotros, no, creo que no, o sea que se le dice matrimonio, pero creo que tiene que haber una cosa legal que lo legalice]

M3: < [o sea legalizar la unión, pero de otra forma]

M2: < [eso]

M5: < [(...), | ahí me entra toda la parte: -]

M1: < [negativa]

M4: $<$ [ como valórica]

Estrategias de atenuación cortés (Briz, 2001)

Se aminoran cualidades, actitudes y acciones del yo.

M4: < [a ti qué te molesta Moni, la cosa de la ceremo:nia, la cosa de del matrimonio, ponte tú-]

M3: < [sí, no, no sé, pero, que se llame matrimonio no sé por qué]

Indicadores gramaticales de atenuación cortés (Kerbrat-Orecchioni) (Haverkate) Indicadores gramaticales de atenuación cortés: 
Disminuye la fuerza de su postura iniciando su argumentación con "no sé". Esta estrategia atenúa el ataque porque insinúa de alguna forma que no está tan segura de pensar o creer o lo que afirma.

Indicadores gramaticales de cortesía positiva y negativa (Kerbrat-Orecchioni/Brown P. y Levinson S. ) (Haverkate)

\section{Indicadores gramaticales de cortesía positiva:}

- Uso de conectores pragmáticos metadiscursivos con intención fática y de aprobación para manifestar que se mantiene el contacto con el otro y la atención temática.

- Uso de léxico espontáneo intensifica la pertenencia al grupo y los identifica como miembros del mismo.

- Se manifiesta el interés haciendo preguntas directas a otros participantes.

- Se ofrece ayuda para terminar las ideas, ofreciendo alternativas con información que se intenta expresar así como también se reformulan ideas de otros.

\section{$\mathbf{N}^{\circ}$ de episodio: 7}

M1: [¿y adopción?]

M2: $<[$ no, nica $]$

M3: $<$ [no la adopción nica]

$\mathrm{H} 1:<$ [porque fíjate que puede haber un par de cómo se llama maricone ${ }^{\mathrm{h}} \mid$ que críen bien a un hijo, que lo quieran, digo de gay-]

M3: $<$ [gay $]$

H1: $<$ [pero bueno si son maricone ${ }^{h}$, o sea, no son heterosexuale $\left.{ }^{h}-\right]$

M1: $<\left[\right.$ lo que pasa $\mathrm{e}^{\mathrm{h}}$ que tenemo ${ }^{\mathrm{h}}$ tanta $^{\mathrm{h}}$ visión, entonce $^{\mathrm{h}}$ hay una gama tan amplia $\mid$ de homosexuale $^{\text {h }}$ | de todo tipo | tú escucha hablar a Simonetti] 


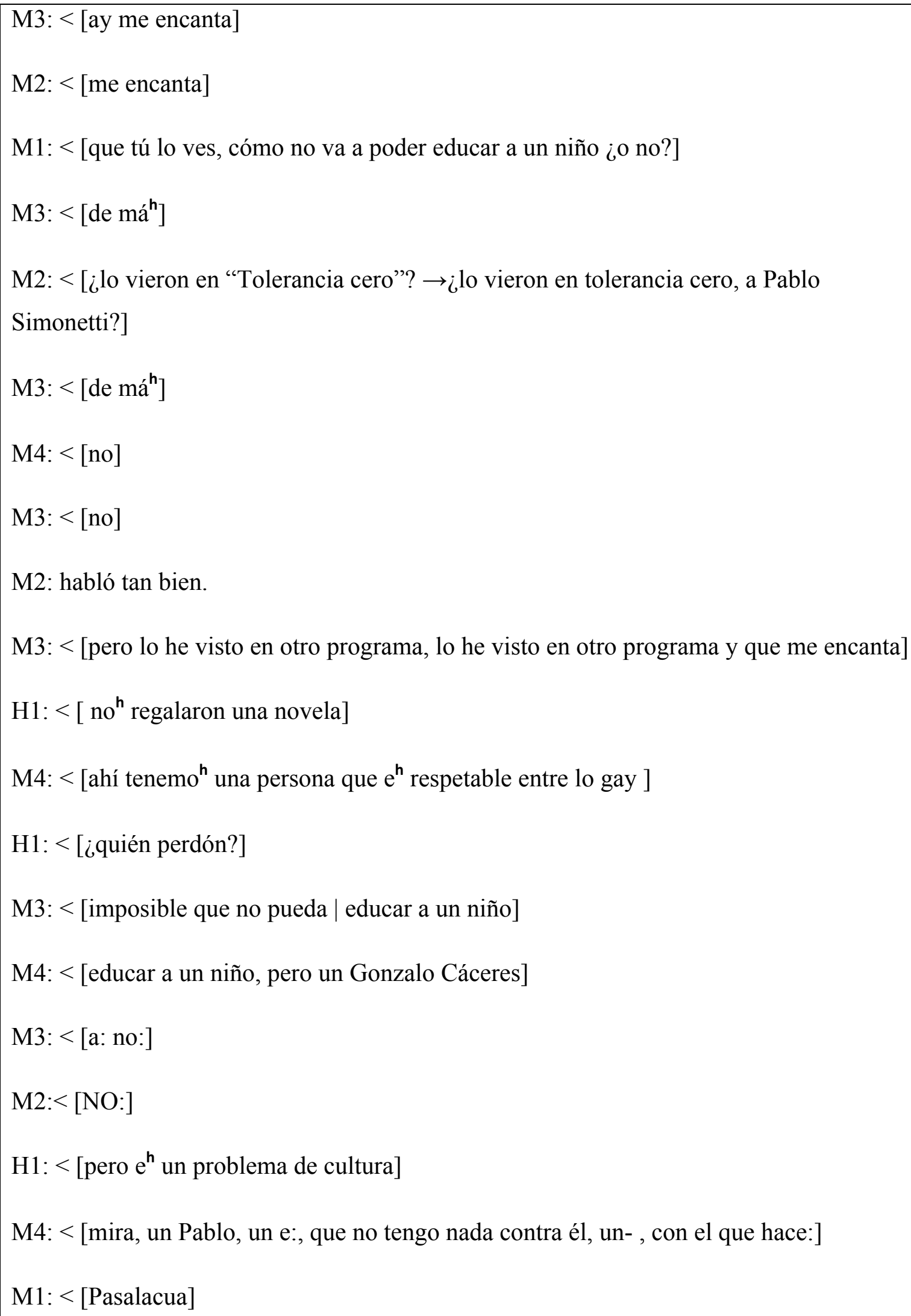




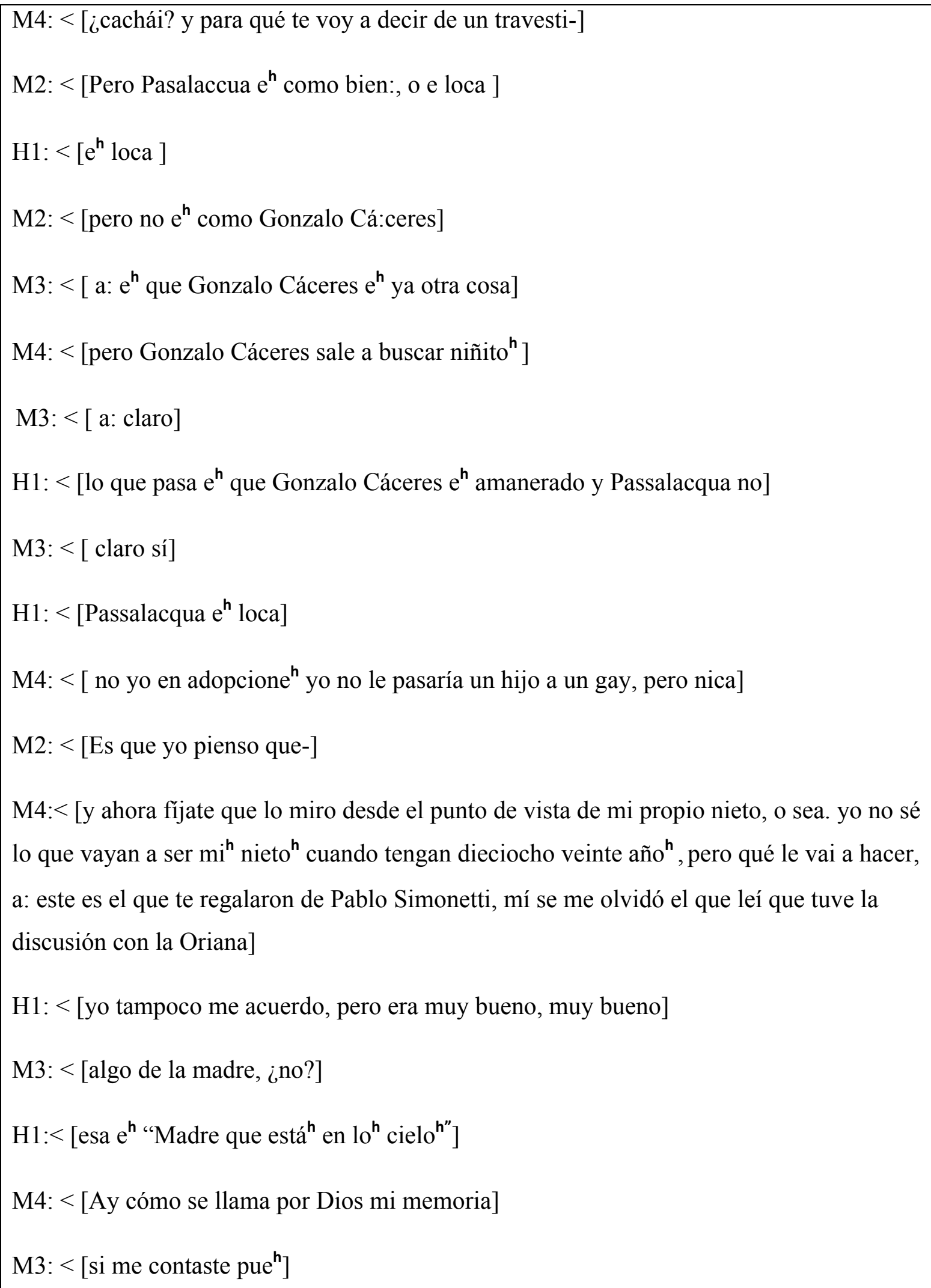




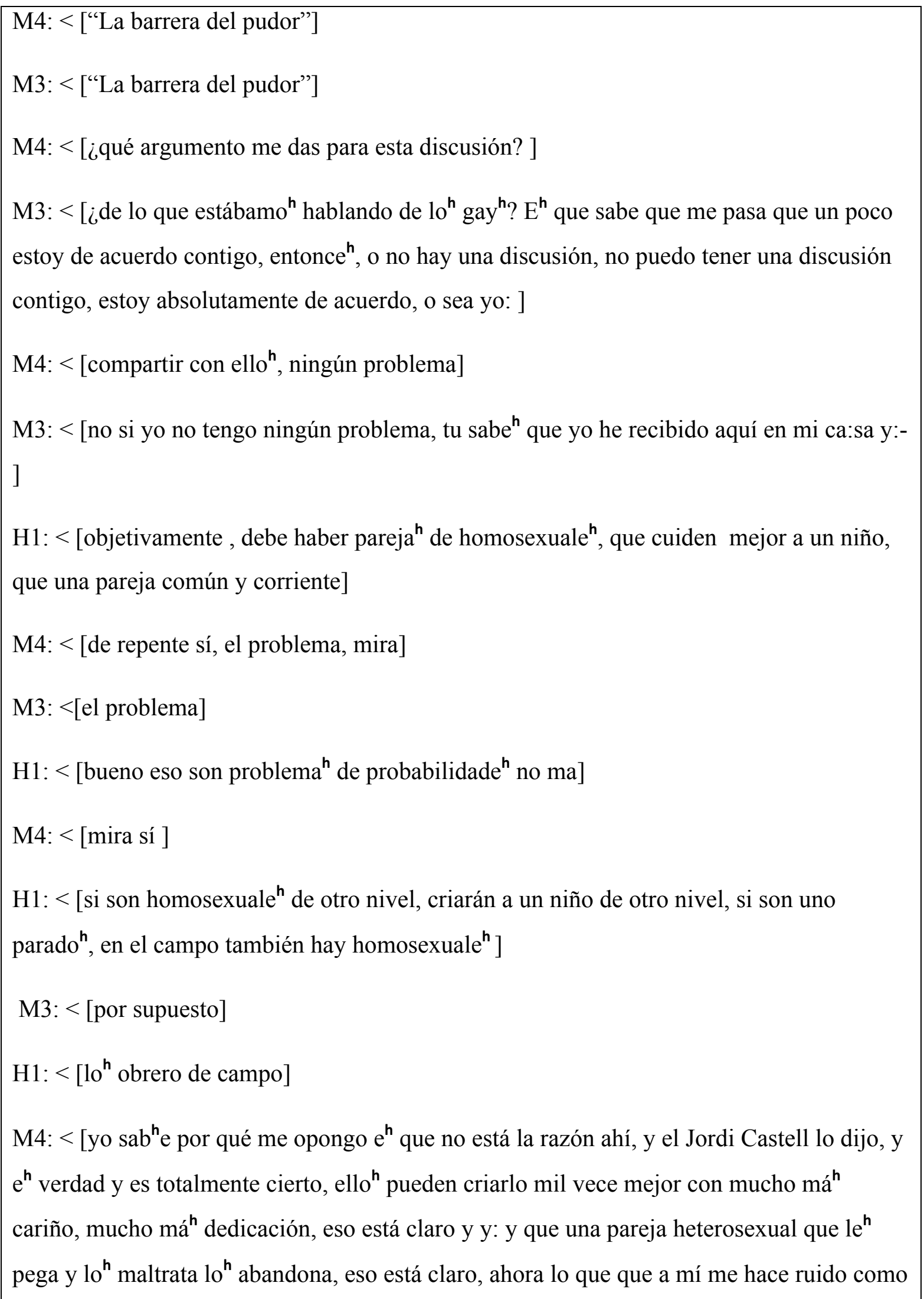


dice la Moni, de repente el: la visión del niño, o do ${ }^{h}$ papá $^{h}$ o do ${ }^{h}$ mamá $^{h}$, entonce ${ }^{h}$, eso eso, yo siento que el niño quedaría como flaqueando de repente, como así no, "no tengo do ${ }^{h}$ mamá, no tengo mamá tengo do ${ }^{h}$ papá", $e^{h}$ como que al niño se le pueda producir un un un cuento no sé]

H1: < ¿¿no será un mito eso, eso de que tiene que haber una imagen del p:adre?, a lo mejor $\mathrm{e}^{\mathrm{h}}$ un mito-]

M4: $<$ [a lo mejor $\mathrm{e}^{\mathrm{h}}$ un mito]

M3: < [porque hay mucho hijo de padre ${ }^{\mathrm{h}}$ separado $^{\mathrm{h}}$, o madre $^{\mathrm{h}}$, o padre $^{\mathrm{h}}$, ausente]

H1: $<$ [siempre hay uno ausente ]

$\mathrm{M} 1:<\left[\right.$ yo creo que al final e como prejuicio no $\left.\mathrm{ma}^{\mathrm{h}}\right]$

M4 : < [sí siempre hay uno ausente, pero cuando hay uno ausente, suponte que el caso sea el papá el ausente la mamá tiene la opción de tener otro \| señor no cierto, podría ser, pero ese niño esa niña va a tener la imagen de lo que es HOMBRE y de lo que $\mathrm{e}^{\mathrm{h}}$ mujer, yo me

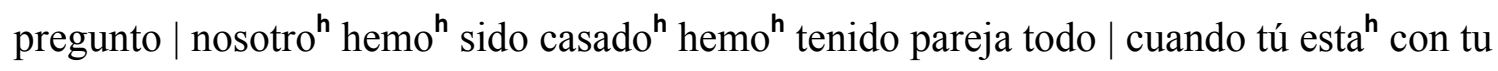
pareja || hombre y mujer || se besan, se agarran, normal ]

H1: < [¿qué significa eso?] $\{$ risas $\}$

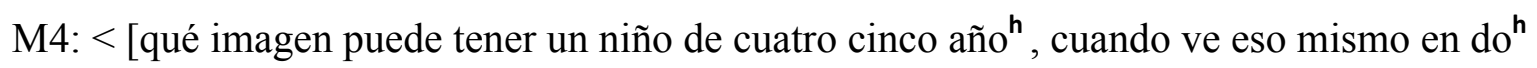
mujere $^{\mathrm{h}} \|$ o en do $^{\mathrm{h}}$ hombre $^{\mathrm{h}}$ mi pregunta | ignorante ¿qué le meten en la cabeza al niño? Que él se puede andar, má ${ }^{h}$ adelante puede tener-]

M2: $<$ [también homosexual $]$

M4 : $<$ [va a tener su pareja igual puede ser, si estamo ${ }^{h}$ hablando de un niñito hombre, "a no yo también puedo tener ma ${ }^{\mathrm{h}}$ adelante una pareja hombre igual" | si él vivió con esa imagen, digo yo, porque quiera ${ }^{\mathrm{h}}$ o no $\|$ los hijos SON reflejo de $10^{\mathrm{h}}$ padres] 


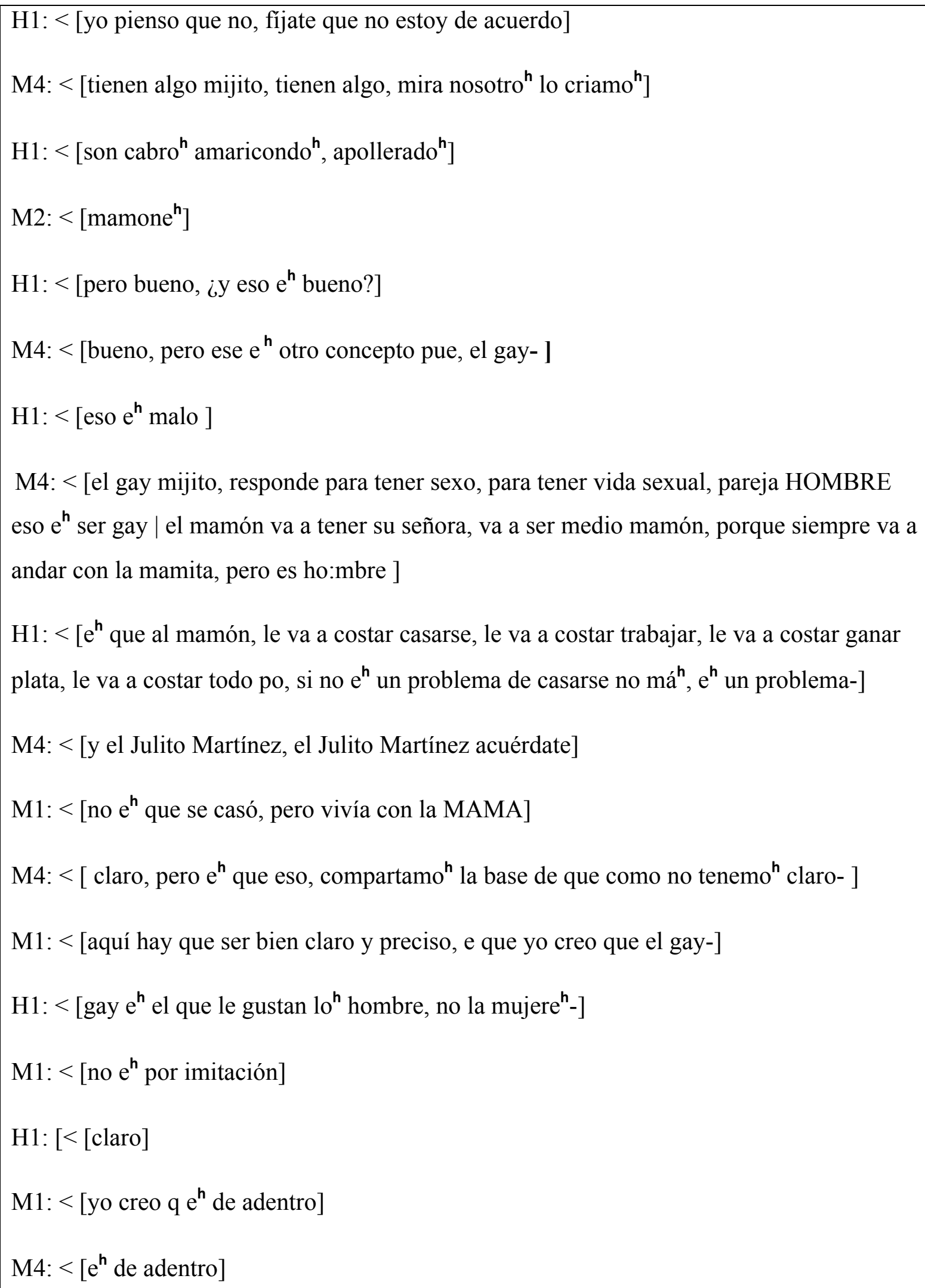


M1: $<\left[\right.$ no $\mathrm{e}^{\mathrm{h}}$ porque lo que vio, no copia, Simonetti justamente]

M4: $<$ [sí porque lo dijo en Tolerancia Cero, que él a los siete año ${ }^{\mathrm{h}}$ le preguntaron “¿cuándo te diste cuenta? Y él dijo que a los siete año ${ }^{h}$ él se dio cuenta que era distinto a su ${ }^{h}$ amiguito $^{h}$, porque a lo siete año ${ }^{h}$ a su amiguito ya le gustaba la: la otra niñita, o la conversacione, entonce él se vino a dar cuenta que era distinto a $10^{h}$ siete año, pero él se rebeló de eso, y él igual despué ${ }^{\text {h }}$ llegó a la adolescencia, pololeó, trató de llevar una vida normal heterosexual, pero a lo dieciocho año ${ }^{\mathrm{h}}$ ya se dio cuenta aquí ya no-]

M1: < [el otro día escuché a este periodista ¿cómo se llama? uno que antes leí la $\mathrm{a}^{\mathrm{h}}$ noticia $\left.{ }^{\mathrm{h}}\right]$ M2: $<$ [a: el amor de la Natalia]

M3: $<$ [a:, que se declaró homosexual $]$

M1 < [él dice que a $10^{h}$ treinta año $^{h}$ se dio cuenta de que era homosexual, tuvo polola, creció normal y a $10^{h}$ treinta año ${ }^{h}$ se dio cuenta-]

M3: < [que también estuvo en La Red]

M1: < [que estuvo en elca:ble tabién]

M4: < [¿no e $\mathrm{e}^{\mathrm{h}}$ moreno?]

M1: $<$ [el que hasta hace poco]

M4: < [a: ya, si sé , si sé cuál $\mathrm{e}^{\mathrm{h}}$ Astorga ]

M3: < [Astorga, exactamente Astorga]

$\mathrm{H} 1:<\left[\right.$ son copuche: $\left.\mathrm{nta}^{\mathrm{h}}\right]$

M3: < [qué buena memoria] $\{$ risas

M2: < [la Katy estaba enamorada de ese niño , pero enamorada hasta la pata- $]$ 


\begin{abstract}
M3: < [Manuel Astorga]
M2: $<$ [hasta que supo que era gay $]$

M1: $<$ [él estuvo conversando con la Tati Penna y dice que a lo treinta año ${ }^{\mathrm{h}}$ ]

M3: $<$ [TREINTA AÑO]

H1: $<\left[\right.$ a $10^{h}$ treinta año ${ }^{h}$ ya pasó tu vida $]$

M2: $<$ [pero yo creo a $10^{h}$ treinta $^{h}$ año ${ }^{h}$ salió del closet $]$

$\mathrm{M} 1:<$ había tenido polola todo, pero dice que recién a $10^{\mathrm{h}} \operatorname{treinta}^{\mathrm{h}}$ año ya llevaba vario año sin tener pareja y, y empezó a darse cuenta de que era distinto, y que tenía, que tenía otro $^{\mathrm{h}}$ interese $\left.^{\mathrm{h}}\right]$

M3: < [claro, yo leí, leí en algún momento que como que lo estaban chantajeando-]

M1: $<$ [chantajeando claro exactamente]

M3: $<$ [porque claro lo habían descubierto un poquito que tenía esta inclinación, y ahí el decidió-]

M1: $<$ [decidió contar $]$

M3: $<\left[\mathrm{e}^{\mathrm{h}}\right.$ un tema complicado $]$

M4: $<$ Pero también $\mathrm{e}^{\mathrm{h}}$ una cosa que se puede nacer así, tuve un primo que ya falleció gay, y que no vinumo ${ }^{\mathrm{h}}$ a enterar, el casado y todo la cosa, pero llevaba doble vida, y mi mamá cuando se enteró porque es por el lado Matzner, por el lado de mi mami, cuando se enteró que su sobrino era gay | e: la familia no lo rechazó ni nada , para nosotros sigue siendo igual, pero el cuento e que ahí mi mami echó para atrá ${ }^{\mathrm{h}} \mid$ y dice que a ella siempre le llamó la atención de que al Dino cuando era niño | era como muy finito en su movimiento $^{\mathrm{h}}$, en su forma de hablar, bailaba, le gustaba mucho como bailar ballet $|\mathrm{y}| \mathrm{y} \mid \mathrm{y}$ bailaba en puntita como muy así, un niñito de cuatro año ${ }^{\mathrm{h}}, \mathrm{y}$ despué ${ }^{\mathrm{h}}$ siempre siguió asíh $^{\mathrm{h}}$ ]
\end{abstract}


$\mathrm{M} 1:<\left[\right.$ con el papá y la mamá normale $\left.{ }^{\mathrm{h}}\right]$

M4: $<$ [claro, hay vece como que se na:ce]

M3: $<$ [se nace $]$

M4: $<\left[\right.$ Con $1 \mathrm{a}^{\mathrm{h}}$ hormona ${ }^{\mathrm{h}}$ distinta $^{\mathrm{h}}$, no sé que será po, la otra vez escuchaba un científi- un médico español que decía que en el cerebro había algo, o sea, teoría hay harta ${ }^{\text {h }}$-]

M3: $<\left[\right.$ teoria $\left.^{\mathrm{h}}\right]$

M4: < [claro, pero este médico español decía que-]

M2: < [yo me declaro IGNORANTE, científicamente ignorante en cuanto a la formación gay, yo no sé, si se nace, o se forma]

M4: $<$ [yo creo que en alguno caso $^{\mathrm{h}}$ se nace- $]$

M2: < [yo no sé, no me he dado el trabajo ni me he dado el tiempo de a lo mejor falta de

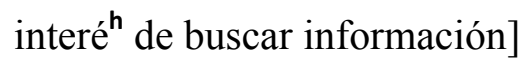

M4: $<$ [lo que decía Pablo Simonetti que a $10^{h}$ siete año $^{h}$ él se dio cuenta, y ahí en vez de gustarle la $^{\mathrm{h}}$ niñita $^{\mathrm{h}}$, a él le atraían lo ${ }^{\mathrm{h}}$ compañero, ahí ya había algo]

M3: $<$ [le atraían lo niño ${ }^{h}$, claro ¿y en la mujere ${ }^{h}$ también será? será por cosa, porque a lo ${ }^{h}$ niño ${ }^{h}$ le pueden gustar la cosa ${ }^{\mathrm{h}}$ de niña ${ }^{\mathrm{h}}$ ¿o no?]

M4: $<$ [no, yo creo que no porque fíjate que en el caso de mi HERMANO, que se crio | a mi hermano le gustó mucho jugar con muñecas de mi hermana, y mi hermano no cuenta , cuando niño chico]

M3: < [¿no tendrá relación la cosa de $10^{\mathrm{h}}$ juguete $^{\mathrm{h}}$ ?]

M4: $<$ [no creo yo]

M1: < [ya] 
M4: < [no sé ¿será la crianza?]

H1: $<$ [porque fíjate que $10^{h}$ griego ${ }^{h}$, apreciaban a $10^{h}$ gay $^{h}$, o sea, era de buen tono $\mid$ tener un amante gay]

M4: $<$ [Oye y lo ${ }^{h}$ hindúe $^{h}$ en la India también]

M2: < [yo tuve un excelente amigo gay cuando joven, cuando tenía el conjunto, cuando guitarreaba, la primera voz de mi conjunto era gay, todo ${ }^{\mathrm{h}}$ sabíamo $^{\mathrm{h}}$ que era gay, MUY buen mozo, lo adorábamo ${ }^{\mathrm{h}}$, porque el gay-]

M4: $<$ [son bueno ${ }^{\mathrm{h}}$ amigo $\left.^{\mathrm{h}}\right]$

M2: $<$ [son bueno ${ }^{h}$ amigo $^{h}$, bien noble pero olvídate, para $10^{h}$ año ${ }^{h}$ que te estoy hablando yo]

M4: $<$ [para la mujere ${ }^{\mathrm{h}}$ son superbueno ${ }^{\mathrm{h}}$ amigo $\left.^{\mathrm{h}}\right]$

M3: < [¿y siempre supieron que era:?]

M2: < [siempre, siempre no era de modale ${ }^{h}$, ni así ni nada, pero siempre nosotro ${ }^{h}$ sabíamo $^{\mathrm{h}}$, y él también, cuando de repente no juntábamo ${ }^{\mathrm{h}} \mid$ con un par de traguito $^{\mathrm{h}} \mathrm{a}^{\mathrm{a}}$ guitarrear hasta alta $^{\mathrm{h}}$ hora $^{\mathrm{h}}$ de la madrugada él siempre decía | una vez contó y ya supimo ${ }^{\mathrm{h}}$ y nadie le hacía burla, lo aceptamo ${ }^{\mathrm{h}}$ todo $^{\mathrm{h}}$ ]

M3: $<$ [nadie se enoja:ba]

M2: < [pero él no era de lo que andaba amanerado ni nada]

M3: $<$ [ya $]$

M2: $<$ [ese $e^{h}$ el gay que tuve máh cerca $]$

H1: $<\left[10^{h}\right.$ amanerado $^{h}$ deben ser de costumbre $]$

M3: < [¿por qué será?]

M2: < [eso travésti eso ${ }^{h}$ gallo $^{h}$ me tienen, me ponen nerviosa a mí, me ponen $\mid$ no la $^{\mathrm{h}}$ 
acepto | yo tuviera un nieto que está cerca de uno, lo agarro lo pesco, no sé por qué | no me pregunti $^{\mathrm{h}} \mid \mathrm{e}^{\mathrm{h}}$ algo | está en la sangre ||| me da susto, imagínateme van a violar al cabro chico]

M3: $<$ [claro]

M2: $<$ [me entendi ${ }^{\mathrm{h}}$ la idea, pero el gay ese gay normal, que tu sabe ${ }^{\mathrm{h}}$ que $\mathrm{e}^{\mathrm{h}}$ gay, y que no se le nota bueno, yo te diría y me siento a la mesa a conversar]

M3: < [fíjate que $\mathrm{e}^{\mathrm{h}}$ cierto lo que tú dice e | el Caco tiene un compañero de universidad que bueno salió del closet se declaró gay y todo el cuento amorosísimo encantador el chico ha estado aquí en la casa mucha ${ }^{\mathrm{h}}$ vece $^{\mathrm{h}}|| \mid$ pero, yo no lo dejaría solo con mi nieto- ]

M2: < [viste, ahí está el problema]

M3: < [no lo dejaría, o sea, yo le digo Caco "nunca dejaría a este niño al cuidado de él po" jamás, prejuicio no sé]

M4: < [pero yo creo que el hecho de ser gay no significa que vaya a ser pedófilo]

M3: < [exactamente, no si está claro, estoy absolutamente de acuerdo, pero es prejuicio de uno]

$\mathrm{M} 2:<$ teni $^{\mathrm{h}}$ que pensar que nosotro ${ }^{\mathrm{h}}$ tenemo $^{\mathrm{h}}$ una mentalidad retrograda todavía, porque pensé la gente de hoy día como como esa niñita jovencita $\mathrm{e}^{\mathrm{h}}$ muy distinto a lo que pensaran-]

M4: $<$ [oye mi $^{h}$ hija $^{h}$ está rodeadada $^{h}$ de puro $^{h}$ gay $^{h}$, la Paola tiene en su pega tre ${ }^{h}$ amigo $^{h}$, tre $^{h}$ compañero $^{h}$ de pega gay ${ }^{h}$, en la financiera también gay, y en la universidad en arquitectura también-]

M2: < [Pero yo no dejaría mi nieto, ese chiquitito el de do año al cuidado de un gay NI CAGANDO, pero no, no me preguntí ${ }^{h}$ por qué, pero un terror-]

M4: $<$ [uno $^{\mathrm{h}}$ declarado $^{\mathrm{h}}$ otro $^{\mathrm{h}}$ no declarado ${ }^{\mathrm{h}}$, pero mil, son excelente amigo ${ }^{\mathrm{h}}$-] 
M2: $<$ [no acepto que tengan niño ${ }^{h}$ esa $^{h}$ persona $]$

\section{Descripción del episodio número 7}

Elementos indispensables de la argumentación (Lo Cascio (1998))

Tema: El proceso de adopción por parte de padres homosexuales.

Tesis: No sería adecuada la adopción.

Argumentos: Es imposible que dos hombres amanerados puedan criar bien a un niño hombre.

Regla General: Un niño necesitaría de la imagen paterna (lado masculino) para desarrollarse adecuadamente.

Elementos facultativos de la argumentación (Lo Cascio (1998))

Refuerzo: El niño necesita de una imagen masculina para desarrollarse adecuadamente.

Calificador: Posiblemente la parte más conservadora de la población de Chile no podría aceptar este cambio tan fácilmente y les costaría aceptar este cambio en la imagen de la familia formada por padre y madre.

Refutación, contraopinión o reserva: Pero si son dos hombres de un nivel sociocultural alto sí sería posible criar a un niño, lo mismo ocurre con los padres que están ausentes de la crianza de los niños.

Falacias argumentativas (Lo Cascio (1998))

Argumentum ad hominem: El argumento se basa únicamente en el universo del protagonista específico sin considerar valores universales.

M2: < [Pero yo no dejaría mi nieto, ese chiquitito el de do año al cuidado de un gay NI

$C A G A N D O$, pero no, no me pregunti ${ }^{\text {h }}$ por qué, pero un terror-]

(...)M2: < [no acepto que tengan niño ${ }^{h}$ esa ${ }^{h}$ persona]

\section{Estrategias de cortesía positiva}

(Brown P. y Levinson S. , 1987): Apele al “terreno común”. - Intensifique el interés hacia $O$.

- Exagere (interés, aprobación, simpatía con O)

- Fíjese, atienda a $O$ (a sus intereses, deseos, necesidades, bienes). 
Los enunciados de estos segmentos permiten demostrar la aprobación hacia el interlocutor. Estos conectores discursivos pragmáticos metadiscursivos intentan mantener el contacto y demostrar así el interés y el acuerdo, además de permitir que progrese en un ambiente cordial el coloquio:

$$
\begin{aligned}
& \text { M3: }<[\text { demáh }] \\
& (\ldots) \\
& \text { M3: }<\text { [a: claro }] \\
& (\ldots) \\
& \text { M3: < [ claro sí] } \\
& (\ldots) \\
& \text { M3: }<\text { [por supuesto] } \\
& (\ldots) \\
& \text { M3: }<\text { [ya }]
\end{aligned}
$$

Los participantes hacen preguntas generales al grupo, estrategia que permite integrarlos a todos y hacer que todos se sientan como parte del grupo:

M2: < ¿¿lo vieron en tolerancia cero? $\rightarrow$ ¿lo vieron en tolerancia cero, a Pablo Simonetti?]

(...)

M1: < [que tú lo ves, cómo no va a poder educar a un niño ¿o no?]

(...)

H1: < [¿quién perdón?]

(...)

M3: < [¿no tendrá relación la cosa de lo ${ }^{h}$ juguete $^{h}$ ?]

$(\ldots)$

Se considera la opinión de otros participantes parafraseando lo que dijeron o reformulando sus posturas: 
M4: < [(...), ahora lo que que a mí me hace ruido como dice la Moni, de repente el: la visión del niño, (...)]

$(\ldots)$

H1: < [¿no será un mito eso, eso de que tiene que haber una imagen del p:adre?, a lo mejor e $e^{h}$ un mito-]

M4: $<$ [a lo mejor $e^{h}$ un mito]

$(\ldots)$

M3: < [porque hay mucho hijo de padre ${ }^{h}$ separado $^{h}$, o madre ${ }^{h}$, o padre ${ }^{h}$, ausente]

H1: < [siempre hay uno ausente $](. .$.

M4 : < [si siempre hay uno ausente, (...) ]

$(\ldots)$

Apele a la pertenencia al mismo grupo que $\boldsymbol{O}$. Use marcadores de identidad de grupo.

El uso de léxico espontáneo (nica, nicagando ,po, pega, mamón, gallo, cabro), uso de voseo verbal (cachái) y uso de léxico propio de su grupo etario (fijate) lo que intensifica dan cuenta de que se encuentran en una situación distendida lo que intensifica la pertenencia al grupo y los identifica como miembros del mismo

H1: < [porque fijate que puede haber un par de cómo se llama maricone ${ }^{\boldsymbol{h}} \mid$ que críen bien a un hijo, que lo quieran, digo de gay-]

(...)

M2: < [no, nica]

M3: < [no la adopción nica]

(...)

M4: < [¿cachái?]

(...)

H1: < [e que al mamón, le va a costar casarse, le va a costar trabajar, le va a costar ganar plata, le va a costar todo po, si no $e^{h}$ un problema de casarse no mán $^{h} e^{h}$ un problema-]

(...) 
M1: < [él dice que a lo ${ }^{h}$ treinta año ${ }^{h}$ se dio cuenta de que era homosexual, tuvo polola, (...)-]

(...)

M2: < [eso travésti eso ${ }^{\boldsymbol{h}}$ gallo $^{\boldsymbol{h}}$ me tienen, me ponen nerviosa a mí, me ponen $\mid$ no la acepto | (...)||| me da susto, imagínateme van a violar al cabro chico]

(...)

M2: < [Pero yo no dejaría mi nieto, ese chiquitito el de do año al cuidado de un gay NI CAGANDO, pero no, no me pregunti ${ }^{\text {h }}$ por qué, pero un terror-]

Apele al punto de vista, opiniones, actitudes, conocimiento, empatía comunes. - Busque el acuerdo. Evite el desacuerdo. Presuponga/ suscite/ manifieste el terreno común. Bromee.

Se evita el desacuerdo:

H1: < [¿qué argumento me das para esta discusión?]

M4: < [¿de lo que estábamo ${ }^{h}$ hablando de $l^{h}$ gay $^{h}$ ? $E^{h}$ que sabe que me pasa que un poco estoy de acuerdo contigo, entonce ${ }^{h}$, o no hay una discusión, no puedo tener una discusión contigo, estoy absolutamente de acuerdo, o sea yo: ]

Se hacen bromas con cierta ironía:

M4 : < [sí siempre hay uno ausente, (...)| cuando tú esta ${ }^{h}$ con tu pareja || hombre y mujer II se besan, se agarran, normal]

H1: < [¿qué significa eso?]

$\{$ risas\}

Estrategias de atenuación cortés (Briz, 2001)

Se aminoran cualidades, actitudes y acciones del yo.

M2: < [yo me declaro IGNORANTE, cientificamente ignorante en cuanto a la formación gay, yo no sé, si se nace, o se forma]

(...)

M4: < [qué imagen puede tener un niño de cuatro cinco año ${ }^{h}$, cuando ve eso mismo en do ${ }^{h}$ mujere $^{h} \|$ o en do hombre ${ }^{h}$ mi pregunta| ignorante ¿qué le meten en la cabeza al niño? Que él se puede andar, máh adelante puede tener-]

Indicadores gramaticales de atenuación cortés (Kerbrat-Orecchioni) (Haverkate) 


\section{Indicadores gramaticales de atenuación cortés:}

- Disminuye la fuerza de su postura iniciando su argumentación indicando que se sienten ignorantes en este tema.

Indicadores gramaticales de cortesía positiva y negativa (Kerbrat-Orecchioni/Brown P. y Levinson S. ) (Haverkate)

\section{Indicadores gramaticales de cortesía positiva:}

- Uso de conectores pragmáticos metadiscursivos con intención fática $\mathrm{y}$ de aprobación para manifestar que se mantiene el contacto con el otro y la atención temática.

- Uso de léxico espontáneo, voseo verbal y uso de léxico propio de su grupo etario lo que intensifica la pertenencia al grupo y los identifica como miembros del mismo.

- Se manifiesta el interés haciendo preguntas generales a otros participantes.

- Se ofrece ayuda para terminar las ideas, ofreciendo alternativas con información que se intenta expresar así como también se reformulan ideas de otros.

- Se evita el desacuerdo explícitamente.

- Se hacen bromas con ironía.

\section{$\mathrm{N}^{\circ}$ de episodio: 8}

M1: < [a mí lo que me sorprend-,no no me sorprende mucho, pero me pasa e que por qué hoy día | dos mil: once estamos | hay tanto ${ }^{\mathrm{h}}$ gay $^{\mathrm{h}} \mid$ tanto $\left.^{\mathrm{h}}\right]$

M2: $<$ [yo creo que salieron todo ${ }^{\mathrm{h}}$ lo conocido- $]$

M3: $<$ [lo que pasa $\mathrm{e}^{\mathrm{h}}$ que claro, todo lo que estaba oculto antes, ahora se supo]

M1: $<$ [o sea, siempre hubo, siempre-] 
M2: $<{\text { [viste } l a^{h} \text { manifestacione }}^{\mathrm{h}}$ que hubo el domingo pasado el sábado ¿cuándo fue?]

M1: < [yo no la vi, pero me imagino la cantidad]

M2: < [yo no la vi, pero en la noticia en la noche te lo muestran]

M3: $<$ [eran todo ${ }^{\mathrm{h}}$ gay $^{\mathrm{h}}$ ]

M2: $<$ [no pero habían otro que apoyaban]

M4: < [claro, pero, ahí $\mathrm{e}^{\mathrm{h}}$ cuando me viene la rabia porque lo gay, son gay gente como todo , pero aparecen esto travesti]

M2: $<$ entonce $^{h}$ con $1 \mathrm{a}^{\mathrm{h}}$ pechuga ${ }^{\mathrm{h}}$ al aire, vuelto loco eso que andan así- ]

M1: $<$ [claro]

M3: $<$ [se visten de mujer-]

M4: $<$ [ESA cuestión me da asco]

M2: $<$ [Preferible que sean gay]

M4: $<$ [gay pero finito, caballero]

M1: $<$ [de comportamiento normal]

M4: < ppero esto $^{\mathrm{h}}$ gallo que son gay $\mathrm{y} \mathrm{ma}^{\mathrm{h}}$ encima se ponen como travesti ${ }^{\text {h }}$ que se disfrazan]

$\mathrm{H} 1:<$ [ero eso $\mathrm{e}^{\mathrm{h}}$ lo mismo que te si guste un hombre, finito, tímido, callado, canchero, machote, leñador, tejano ]

\{risas\}

H1: $<$ [tiene que haber de todo, machote]

O: $<$ [machote claro, pero son HOMOSEXUALE ${ }^{\mathrm{h}}$, entonce ${ }^{\mathrm{h}}$ la variedad no se podría meter en una categoría cerrada-] 


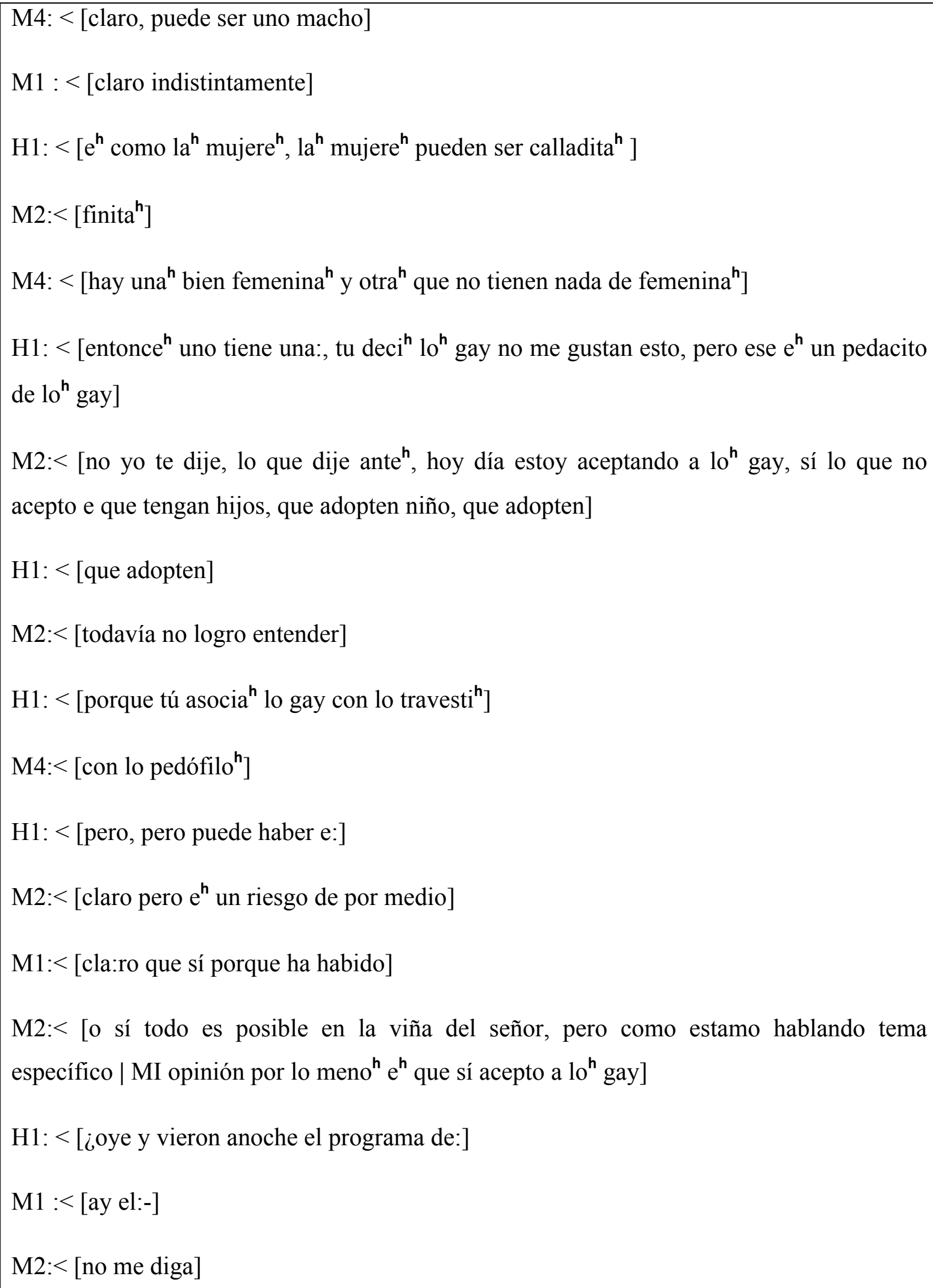


$\mathrm{M} 1:<[$ En la mira $]$

M4: $<$ [anoche estaba con la guata revuelta, y vuelvo a pensar en $10^{\mathrm{h}}$ nieto ${ }^{\mathrm{h}}$ de uno, porque parece que cuando uno tiene nieto ${ }^{h}$ parece que todo ¿qué pasaría cuando un niño? Porque $10^{h}$ nuestro $^{h}$ ya están grande, pero ahora viene la otra generación]

M2:< [la misma del señor de lo infierno, atroz, porque despué ${ }^{\text {h }}$ en el libro | salen e: siquiatra $^{h}$, habla el siquiatra y compañero ${ }^{h}$ de ese cura $e^{h}$ un sicópata]

M1: $<$ [ademá $^{\text {h }}$ q un señor que NUNCA va a reconocer-]

$\mathrm{M} 4:<\left[\right.$ no y manipulador, no $\mathrm{e}^{\mathrm{h}}$ sicópata $]$

M1 $:<[$ manipulado:r $]$

$\mathrm{M} 4:<$ [no atró ${ }^{\mathrm{h}}$, fíjate que el libro $\mathrm{e}^{\mathrm{h}}$ fuerte, pero $\mathrm{e}^{\mathrm{h}}$ má $^{\mathrm{h}}$ fuerte, no por lo: sexual, perdón, por lo sexual que se pueda dar ahí en $10^{h}$ testimonio $^{h}$ sino que en la personalidad del cura, o sea, cómo manipulaba e: no $\mathrm{e}^{\mathrm{h}}$ atro $^{\mathrm{h}}, \mathrm{e}^{\mathrm{h}}$ que de verdad $\mathrm{e}^{\mathrm{h}}$ que mucho ${ }^{\mathrm{h}}$ que tenían hija-]

$\mathrm{M} 2:<\left[\mathrm{e}^{\mathrm{h}}\right.$ que mucho ${ }^{\mathrm{h}}$ le tenían MIEDO $]$

M4: < [CLARO: y cómo manipulaba a la señora de Hamilton, él la manipuló y la cambió totalmente, y el testimonio de la mamá que decía "a mi hija la cambió" "no e que tú no puede usar falda corta no puede pintarte", y era tal el poder que él tenía sobre la gente que ella dejó de pinta:rse, dejó de de ponerse falda co:rta, y andaba desaliña:da, porque el cuento era para que Hamilton, el gay, no le gustara, la señora dejara de gustarle-]

M1: $<$ [ya, dejara de gustarle]

M4: $<$ [ese era el fin, y ella le hacía caso inocentemente así como que fue a manipularse]

$\mathrm{H} 1:<$ [tenía trascendencia ¿tú ere ${ }^{\mathrm{h}}$ meno $^{\mathrm{h}}$ católica ahora con eso?]

M4: $<$ [no fíjate, me sirvió mucho mucho leer el libro, porque sí, me había ido como en la, como un poco a lo negro, pero al revé ${ }^{h}$ porque también hay sacerdote ${ }^{h}$, que son sacerdote de verdad, y que cumplen el celibato | tú tiene la otra parte, y despué ${ }^{\text {h }}$ de también saber de 


\begin{tabular}{|l|} 
la parte siquiátrica del cura, entonce \\
M1: $\mid$ sicópata $^{\mathrm{h}}$ va a haber en todo lado $]$ \\
\hline
\end{tabular}

\section{Descripción del episodio número 8}

Elementos indispensables de la argumentación (Lo Cascio, 1998)

\section{Tema: La homosexualidad}

Tesis: Hay una gran variedad de tipos de homosexuales.

Argumentos: no todos son travestis ni pedófilos.

Regla General: Así como hay diferentes tipos de carácter, hay diferentes tipos de homosexuales.

Elementos facultativos de la argumentación (Lo Cascio, 1998)

Refutación, contraopinión o reserva: No hay gran variedad, los travestis representan la homosexualidad porque siempre aparece algún travesti en manifestaciones homosexuales.

Fuentes: Libro sobre los abusos de un sacerdote contra los jóvenes de su parroquia.

Falacias argumentativas (Lo Cascio (1998))

Argumentum ad consequentiam: Sirve para juzgar negativamente una afirmación, una tesis, no mediante argumentos externos, sino a través de las consecuencias que pueden derivarse de tales afirmaciones.

M4 no acepta a los homosexuales porque piensa en su nieto pequeño, se preocupa por qué pasará cuando sea grande. Este argumento también podría ser considerado ad hominem ya que está basado en argumentos muy particulares.

M4: $<$ [anoche estaba con la guata revuelta, $y$ vuelvo a pensar en $l^{\boldsymbol{h}}{ }^{\text {nieto }}{ }^{\boldsymbol{h}}$ de uno, porque parece que cuando uno tiene nieto ${ }^{h}$ parece que todo ¿qué pasaría cuando un niño? Porque lo $^{h}$ nuestro ${ }^{h}$ ya están grande, pero ahora viene la otra generación] 


\section{Estrategias de cortesía positiva}

(Brown P. y Levinson S. , 1987): Apele al “terreno común”. - Intensifique el interés hacia $O$.

- Exagere (interés, aprobación, simpatía con O)

- Fíjese, atienda a $O$ (a sus intereses, deseos, necesidades, bienes).

Los enunciados de estos segmentos permiten demostrar la aprobación hacia el interlocutor. Estos conectores discursivos pragmáticos metadiscursivos intentan mantener el contacto y demostrar así el interés y el acuerdo, además de permitir que progrese en un ambiente cordial el coloquio:

M1: < [claro]

(...)

M1 : < [claro indistintamente]

\section{(...)}

Los participantes hacen preguntas particulares a integrantes del debate y otras generales a todo el grupo, estrategia que permite integrarlos a todos y hacer que todos se sientan como parte del grupo. Todos están atentos a la respuesta, nadie interrumpe:

M2: < [viste la manifestacione ${ }^{h}$ que hubo el domingo pasado el sábado ¿cuándo fue?]

(...)

H1: < [¿oye y vieron anoche el programa de:]

(...)

H1:< [tenía trascendencia ¿tú ere ${ }^{h}$ meno ${ }^{h}$ católica ahora con eso?]

Apele a la pertenencia al mismo grupo que 0 . Use marcadores de identidad de grupo.

El uso de léxico espontáneo (gallo, pechuga, guata) da cuenta de que se encuentran en una situación distendida lo que intensifica la pertenencia al grupo y los identifica como miembros del mismo. También se observa el uso de la lexía fijate, característica de su grupo etario.

M4: < [pero esto ${ }^{h}$ gallo que son gay y $\mathrm{ma}^{\boldsymbol{h}}$ encima se ponen como travesti ${ }^{\boldsymbol{h}}$ que se disfrazan] 
(...)

M2: $<$ [entonce $^{h}$ con la ${ }^{h}$ pechuga ${ }^{h}$ al aire, vuelto loco eso que andan así- ]

(...)

M2: < [anoche estaba con la guata revuelta,(...)]

(...)

M4: < [no fijate, me sirvió mucho mucho leer el libro]

Apele a la reflexibilidad (si $O$ desea [que $O$ tenga $X$ ], entonces $H$ desea [que $O$ tenga $X$ ] y si $\mathrm{H}$ desea [que $\mathrm{H}$ tenga $X$ ] entonces $\mathrm{O}$ desea [que $\mathrm{H}$ tenga $X$ ]). Incluya a ambos, $H$ y $O$, en la actividad. Dé (o pida) razones. Asuma o manifieste reciprocidad. Haga regalos a $O$ (bienes, simpatía, comprensión, cooperación)

Los interlocutores cooperan entre ellos, son cooperativos con la información. Refuerzan lo que dijo otro:

M2: < [Preferible que sean gay]

M4: < [gay pero finito, caballero]

M1: < [de comportamiento normal]

Indicadores gramaticales de cortesía positiva y negativa (Kerbrat-Orecchioni/Brown P. y Levinson S. ) (Haverkate)

Indicadores gramaticales de cortesía positiva:

- Uso de conectores pragmáticos metadiscursivos con intención fática y de aprobación para manifestar que se mantiene el contacto con el otro y la atención temática.

- Uso de léxico espontáneo y uso de léxico propio de su grupo etario lo que intensifica la pertenencia al grupo y los identifica como miembros del mismo.

- Se manifiesta el interés haciendo preguntas al grupo en general y otras particulares a otros participantes.

- Se ofrece ayuda para terminar las ideas, hay cooperación ofreciendo alternativas con información que se intenta expresar. 


\section{$\mathbf{N}^{\circ}$ de episodio: 9}

O: podríamos pasar al tercer tema, y último tema que es la crianza del niño en un matrimonio homosexual, ¿qué pasaría en CHILE? Como máh conservador, acá si se acepta el matrimonio homosexual ¿qué pasaría si se puede adoptar?¿cómo creen que sería, habría prejuicio contra eso $^{h}$ niño $^{h}$ que han sido educado ${ }^{h}$ en un matrimonio homosexual? por ejemplo ¿qué pasaría con ese niño que $\mathrm{e}^{\mathrm{h}}$ criado por $\mathrm{do}^{\mathrm{h}}$ lesbiana ${ }^{\mathrm{h}}$ o por $\mathrm{do}^{\mathrm{h}}$ gay?

M1:< [sabe cuál $\mathrm{e}^{\mathrm{h}} \mathrm{mi}$ problema aquí, ya sea, a lo mejor soy muy estricta, pero por ejemplo, en un matrimonio | de lesbiana | adopta un niño || despué ${ }^{\mathbf{h}}$ adopta otro niño | y ese niño no va a tener ninguna cosa sanguínea con el PRIMER niño, porque no tiene por qué ser hermano, entonce ${ }^{h}$ ese niño no va a ser hermano con el primer niño]

M2: $<$ [sanguíneo, pero legal sí]

$\mathrm{M} 1:<[\mathrm{SÍ}]$

$\mathrm{M} 2:<\left[\right.$ si lo adoptan sí, $\mathrm{e}^{\mathbf{h}}$ crianza $]$

$\mathrm{M} 1:<[$ claro]

M3 $:<$ [pero $\mathrm{e}^{\mathrm{h}}$ que $\mathrm{e}^{\mathrm{h}}$ lo mismo que la adopción heterosexual, que forman familia $\mathrm{y}$ adoptan do ${ }^{h} \operatorname{tre}^{h}$ niño $\left.{ }^{h}\right]$

$\mathrm{M} 1:<[$ claro]

M3: $<$ [claro, entonce ${ }^{\mathrm{h}}$ pasaría lo mismo]

M1: < [qué pasaría, en el sentido de que son do niñi:ta, que adoptan, yo me armo todo un cuento, de que esta ${ }^{\mathrm{h}}$ do $^{\mathrm{h}}$ niñita ${ }^{\mathrm{h}}$, van a ser entre ella ${ }^{\mathrm{h}}$ como lesbiana ${ }^{\mathrm{h}}$ igual que su mamá, $\mathrm{su}^{\mathrm{h}} \mathrm{do}^{\mathrm{h}}$ mamáh $^{\mathrm{h}}$, se me hace todo un, se me hace un enjambre ]

M2: $<$ [u: terrible un enredo que no.]

$\mathrm{M} 1:<[$ una cuestión compleja-] 


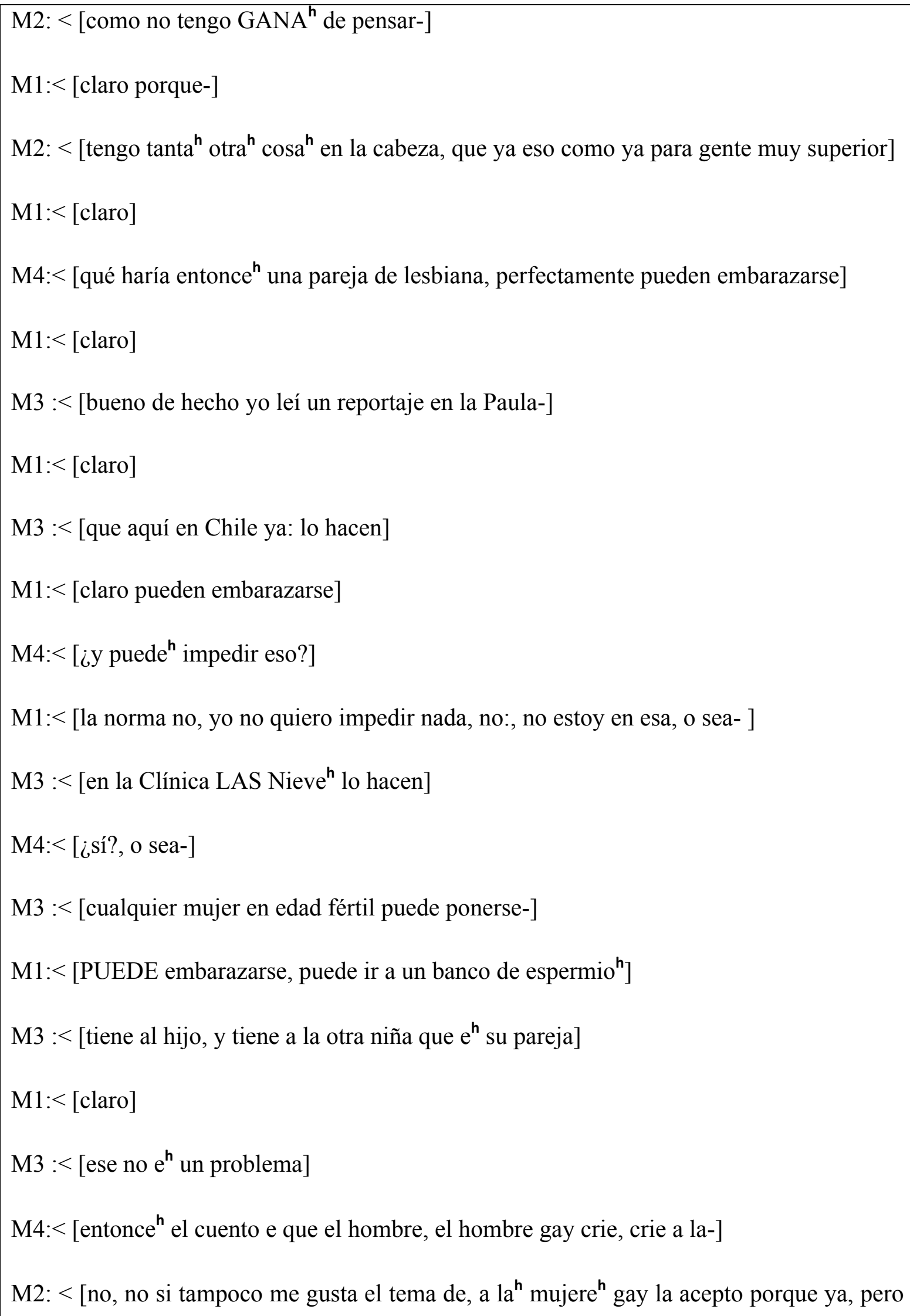




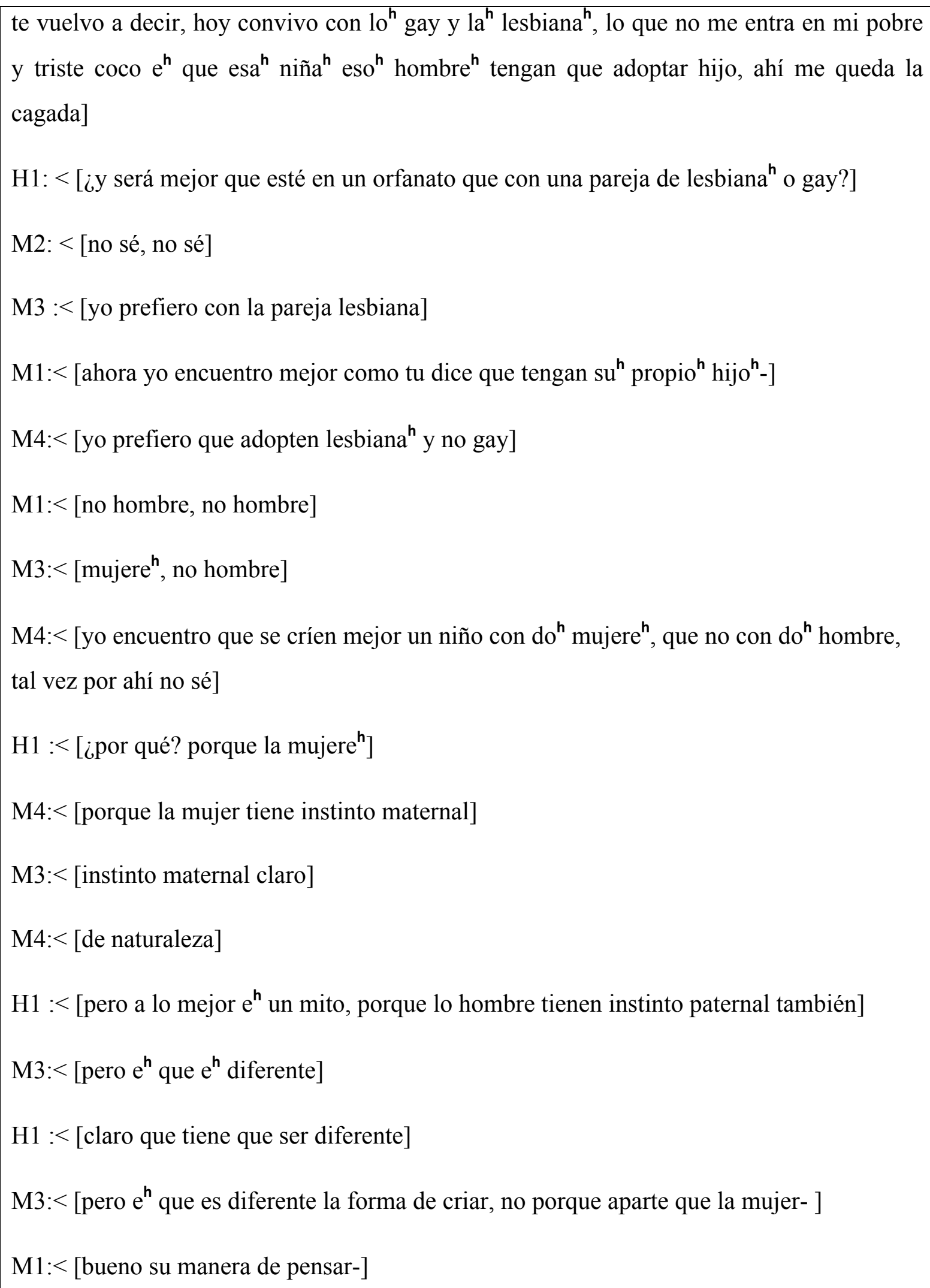




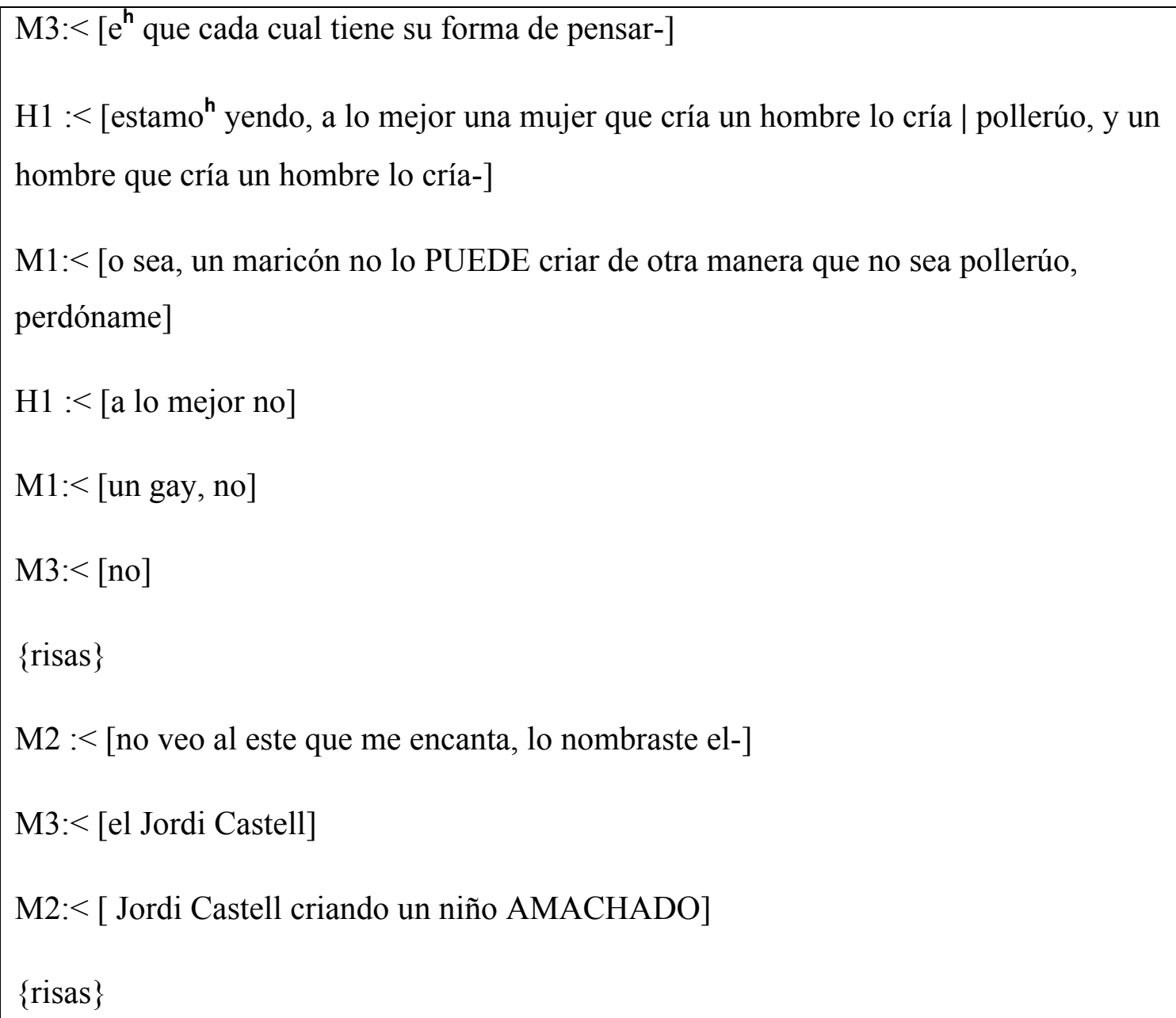

\section{Descripción del episodio número 9}

Elementos indispensables de la argumentación (Lo Cascio (1998))

Tema: La adopcion de un niño en un matrimonio homosexual.

Tesis: No sería positivo para el desarrollo del niño tener padres del mismo sexo.

Argumentos: La convivencia podría ser motivo de promiscuidad debido a que no tendrían ejemplos heterosexuales de relaciones.

Regla General: Es importante el ejemplo de los padres en la formación y educación de los niños.

Elementos facultativos de la argumentación (Lo Cascio (1998)) 
Refutación, contraopinión o reserva: Es mejor que una pareja de lesbianas tenga un hijo que una pareja de dos hombres adoptando un hijo. Además, las parejas de lesbianas pueden embarazarse con inseminación artificial y esto permite que los hermanos y los padres tengan parentesco sanguíneo.

Fuentes: Revista Paula

\section{Estrategias de cortesía positiva}

(Brown P. y Levinson S. , 1987): Apele al “terreno común”. - Intensifique el interés hacia $O$.

- Exagere (interés, aprobación, simpatía con O)

- Fíjese, atienda a $O$ (a sus intereses, deseos, necesidades, bienes).

Los enunciados de estos segmentos permiten demostrar la aprobación hacia el interlocutor. Estos conectores discursivos pragmáticos metadiscursivos intentan mantener el contacto y demostrar así el interés y el acuerdo, además de permitir que progrese en un ambiente cordial el coloquio:

$M 1:<[S I ́]$

(...)

M1:< [claro]

(...)

M3:< [instinto maternal claro]

En el siguiente segmento lo interlocutores manifiestan su acuerdo repitiendo información presentada por los otros participantes:

$H 1:<\left[¿\right.$ ipor qué? porque la mujere $\left.{ }^{h}\right]$

M4: < [porque la mujer tiene instinto maternal]

M3: $<$ [instinto maternal claro]

M4: $<$ [de naturaleza]

(...) 
Apele a la pertenencia al mismo grupo que 0 . Use marcadores de identidad de grupo.

El uso de léxico espontáneo (cagada, coco, pollerúo, maricón) da cuenta de que se encuentran en una situación distendida lo que intensifica la pertenencia al grupo y los identifica como miembros del mismo.

M2: $<\left[(\ldots)\right.$ lo que no me entra en mi pobre y triste coco $e^{h}$ que esa ${ }^{h}$ niña ${ }^{h}$ eso ${ }^{h}$ hombre ${ }^{h}$ tengan que adoptar hijo, ahi me queda la cagada]

(...)

$H 1:<$ [estamo ${ }^{h}$ yendo, a lo mejor una mujer que cría un hombre lo cría $\mid$ pollerúo, (...)]

M1:< [o sea, un maricón no lo PUEDE criar de otra manera que no sea pollerúo, perdóname]

Estrategias de atenuación cortés (Briz, 2001)

Se aminoran cualidades, actitudes y acciones del yo.

M2: < [tengo tanta ${ }^{h}$ otra $^{h} \cos ^{h}$ en la cabeza, que ya eso como ya para gente muy superior]

(...)

M2: < [(...), pero te vuelvo a decir, hoy convivo con lo gay y la lesbiana ${ }^{h}$, lo que no me entra en mi pobre y triste coco $e^{h}$ que esa $a^{h}$ niña ${ }^{h}$ eso ${ }^{h}$ hombre ${ }^{h}$ tengan que adoptar hijo, ahi me queda la cagada]

Se aminoran cualidades negativas del tú.

H1: < [¿y será mejor que esté en un orfanato que con una pareja de lesbiana ${ }^{h}$ o gay?]

Indicadores gramaticales de atenuación cortés (Kerbrat-Orecchioni) (Haverkate) Indicadores gramaticales de atenuación cortés:

- Hacer preguntas que planteen la contraargumentación para suavizar el enfrentamiento de ideas.

- Disminuir la imagen personal afirmando que no se tiene el nivel intelectual tan alto como para dar una buena opinión en estos temas. 
Indicadores gramaticales de cortesía positiva y negativa (Kerbrat-Orecchioni/Brown P. y Levinson S. ) (Haverkate)

\section{Indicadores gramaticales de cortesía positiva:}

- Uso de conectores pragmáticos metadiscursivos con intención fática y de aprobación para manifestar que se mantiene el contacto con el otro y la atención temática.

- Uso de léxico espontáneo que intensifica la pertenencia al grupo y los identifica como miembros del mismo.

Se manifiesta el acuerdo repitiendo la ideas expresadas por otros interlocutores. 


\section{ResUltados DEL ANÁLISIS}

\subsection{Resultados del análisis de los episodios temáticos del debate de los jóvenes}

Luego de realizar el análisis al corpus que contiene la grabación del debate que realizaron los jóvenes, se han obtenido los siguientes resultados.

Las estrategias de cortesía positiva encontradas en este corpus son las siguientes:

\begin{tabular}{|c|c|}
\hline ias de & $\begin{array}{l}\text { Estrategia de retribución de un acto halagador" (Kerbrat-Orecchioni } \\
(2004: 44) \text { ): } \\
\text { 1. Parafrasear la postura y sintetizar el discurso de otro. Esta } \\
\text { estrategia funciona como un acto de reconocimiento a la propuesta } \\
\text { discursiva del otro interlocutor y es un acto halagador ya que no } \\
\text { solo demuestra que el emisor estaba atento a lo que su compañero } \\
\text { decía, sino que además es capaz de reconstruirlo y resumirlo } \\
\text { temáticamente en una sola palabra. } \\
\text { Apele al "terreno común" (Brown P. y Levinson S., 1987). } \\
\text { 1. Intensificar el interés hacia el otro parafraseando, resumiendo o } \\
\text { retomando las propuestas expresadas por otro interlocutor o } \\
\text { diciendo explícitamente que se está de acuerdo con la postura de } \\
\text { tal persona. }\end{array}$ \\
\hline
\end{tabular}

${ }^{30}$ El nombre de esta estrategia no corresponde a ninguna clasificación realizada por Kerbrat-Orecchioni previamente. Corresponde a un parafraseo, creado por la autora de esta investigación, correspondiente a esta técnica verbal.

${ }^{31}$ La risa permite reducir la imposición del moderador de volver al tema que se propone. Como ya se comentó anteriormente, Leech insiste en que esta actitud cortés está dentro de las máximas de cortesía, específicamente dentro de la máxima de simpatía: "Reduzca al mínimo la falta de simpatía entre el yo y el otro: aumente al máximo la simpatía entre el yo y el otro" (cfr. pág. 63). 
3. Demostrar la aprobación explícitamente hacia el interlocutor, mediante conectores pragmáticos metadiscursivos ${ }^{32}$ que permiten manifestar cortesía. La fuerza ilocutiva de estos conectores se dirige a permitir que la conversación fluya pues permiten que el contacto se mantenga y se demuestra así el interés. Los conectores metadiscursivos encontrados en el corpus son: sí, eso/si $\mathrm{po}^{33} / \mathrm{sip}$ lahá /sí/ Sí: yo e toy de acuerdo/ obvio/ Sí po: obvio/ ya $a^{34}$ / ya:/ mmm / claro/ a: / obvio / eso/ exactamente / tiene razón/ sí, claro / claro / ¿si??

Apele a la pertenencia al mismo grupo que $\boldsymbol{O}$. Use marcadores de identidad de grupo. (Brown P. y Levinson S. , 1987).

1. Utilizar un marcador de identidad de grupo: describen anécdotas comunes o relevantes para todos los interlocutores.

2. Uso de léxico: se observa que este remite a un registro coloquial y espontáneo. El uso de palabras y de sintagmas como: cuestión, pucha, te juro que o de la locución verbal importar una raja ${ }^{35}$ muestra que estos jóvenes se sentían conversando entre pares, lo que sirve también como un marcador de identidad de grupo. En síntesis, se encontró en el corpus léxico propiamente juvenil $\left(\right.$ heavy $^{36}$, bacán $^{37}$, mula $^{38}$, copete $^{39}$, chan $^{40}$, jotear $^{41}$, brígido $\left.^{42}\right)$,

\footnotetext{
${ }^{32}$ Los conectores pragmáticos metadiscursivos, "en su papel metadiscursivo, de marcadores de transiciones del habla (...) son trazos o señales de la actividad discursiva, "asideros" de los hablantes para la formulación de unos mensajes que se producen cara a cara y en un espacio y tiempo determinados; marcas por tanto, del progreso y desarrollo coherente de los mismos. En este sentido podría decirse que los conectores participan en la organización del habla y de ahí se deriva su papel metadiscursivo estructurador, sus valores conversacionales" (Briz/Hidalgo, 1988: 141).

33 "pos. marc. disc. Pues; se usa para enfatizar o remarcar una aseveración u orden.espon. Observ. Normalmente sufre acortamiento hasta llegar a pronunciarse [po] o simplemente [p]". (DUECh, 2010)

34 “ya. fórm. Se usa para mostrar actitud de aprobación o acuerdo. espon". (DUECh, 2010) Se usa en registros espontáneos. Si bien es una palabra polisémica y es usada por la totalidad de los hispanohablantes, este uso en particular es diferencial del español de Chile; usamos como referencia de este contraste el uso peninsular.

35 "raja//una raja: los.adv. vulgar. Nada o muy poco. Observ. Con verbos que expresan 'importar". (DUECh, 2010)

${ }^{36}$ Voz espontánea y coloquial, indica que algo es muy bueno o sorprendente.

${ }^{37} \mathrm{La}$ voz bacán corresponde gramaticalmente a un adjetivo. "Especialmente entre los jóvenes, muy bueno o muy bien. espon." (DUECh, 2010)
} 


\begin{abstract}
voseo verbal ${ }^{43}$, y léxico espontáneo (pokemón ${ }^{44}$, pucha $^{45}$, po, cuestión $^{46}$, cachar $^{47}$, aperrar ${ }^{48}$, chuta ${ }^{49}$, el + nombre propio (i.e.el Rulo) $)^{50}$, gallo ${ }^{51}$, mina, huevón, filo ${ }^{52}$, iputa;, importar una raja ). Todo esto permite afirmar que los interlocutores se encontraban en una situación comunicativa para ellos cotidiana lo que les permitió utilizar locuciones y léxico espontáneo y juvenil.
\end{abstract}

Apele al punto de vista, opiniones, actitudes, conocimiento, empatía comunes. - Busque el acuerdo. Evite el desacuerdo. Presuponga/ suscitel manifieste el terreno común. Bromee. (Brown P. y Levinson S. , 1987).

1. Buscar el acuerdo, opinando que las dos alternativas que se están discutiendo pueden ser válidas.

2. Hacer preguntas particulares, esto es, dirigidas a un solo participante; esta estrategia permite evitar el desacuerdo directamente, desarrollando previamente el tema, al pedir una mayor participación de parte de los interlocutores.

3. Bromear.

4. Participar y demostrar interés presuponiendo y anticipando lo que

${ }^{38}$ La voz mula es usada en sus dos acepciones: "f. argumento o discurso rebuscado y poco veraz.espon." y también gramaticalmente como un adjetivo:"de mala calidad". (DUECh, 2010)

39 “copete.m. bebida alcohólica. espon." (DUECh, 2010)

${ }^{40}$ Expresión usada entre los jóvenes utilizada para indicar que el asunto que se discute puede ser polémico.

41 "jotear. Tr. Asediar a alguien para conseguir su atención amorosa.espon.desp." (DUECh, 2010)

42 "brígido,-a.adj. Especialmente entre los jóvenes, de gran peligro o dificultad.espon." (DUECh, 2010)

${ }^{43}$ Se observó anteriormente que el uso del voseo verbal en el español hablado en Chile está restringido a situaciones informales. (cfr. pág. 42)

${ }^{44}$ pokemón es un sustantivo y adjetivo, lo defino con mis propias palabras: joven que se caracteriza por usar ropa y accesorios coloridos y llamativos, además de un corte de pelo innovador. Corresponde a una de las llamadas "tribus urbanas" juveniles que imitan algunos rasgos de la animación japonesa.

45 "Pucha" es una interjección que "expresa enojo o sorpresa, o bien una mezcla de ambos. espon." (registro espontáneo). (DUECh, 2010)

46 “cuestión.f. Cosa.espon.” (DUECh, 2010)

47 “cachar.tr. Percibir con la visión o los oídos. espon (...).2. tr. Conocer, tener conocimiento.espon. (...) 3. tr. Entender, comprender.Espon. (...)4. tr. Suponer, creer.espon”. (DUECh, 2010)

48 “aperrar. Intr. Asumir con tenacidad una tarea difícil. espon”. (DUECh, 2010)

49 "!Chuta! Interj..euf. Expresa enojo o sorpresa, o bien una mezcla de ambos.espon”. (DUECh, 2010)

50 Como se comentó anteriomente, si bien se trata de un fenómeno gramatical, se utiliza en regristos espontáneos, por lo tanto, cumple la msma función enunciativa que tiene el uso de léxico espontáneo. 51 “gallo,-a. my f. persona.espon”. (DUECh, 2010)

52 "fillo.fórm. Especialmente entre los jóvenes, se usa para mostrar indiferencia ante algo y al mismo tiempo la intención de seguir adelante sin tenerlo en cuenta. espon”. (DUECh, 2010) 
va a decir el otro, ayudándolo a terminar las frases de los enunciados.

5. Hacer preguntas generales, mediante las cuales se cede el turno y se deja libre para que todos participen. Mediante esta estrategia de cortesía se intenta manifestar el terreno común de todos los participantes, terreno en que todos pueden participar y opinar.

6. Hacer explícito el acuerdo con el otro y comentar su postura.

7. Ceder el turno a otro pidiéndole que profundice en su explicación pues se cree que el otro está más informado.

8. Afirmar que otro explicó el tema mejor que él.

9. Retomar lo que otro dijo anteriormente y comentarlo, haciendo mención explícita de quién mencionó esa idea antes.

Las estrategias de cortesía negativa encontradas en este corpus son las siguientes:

\begin{tabular}{|l|l|}
\hline Estrategias de & $\begin{array}{l}\text { Estrategias de reparación de un acto descortés (Kerbrat-Orecchioni } \\
(2004: 44)): \text { A comete contra B alguna ofensa (FTA) que inmediatamente } \\
\text { negativa } \\
\text { intenta reparar por medio de una excusa (FFA). Cuanto mayor es el peso } \\
\text { del FTA, tanto más debe ser importante el trabajo reparador. }\end{array}$ \\
- & Las risas son usadas como medio reparador. Además de \\
constituir una estrategia de cortesía positiva, siguiendo las \\
máximas propuestas por Leech, como se dijo antes, las \\
risas suavizan el ataque entre interlocutores. \\
Acto reparador de una ofensa: si bien se manifiesta interés \\
por lo que dijo anteriormente otro interlocutor, se \\
menciona el desacuerdo y luego se intenta suavizar el \\
ataque afirmando que el otro sabe más que él. \\
Se comete un ataque contra dos interlocutores que se \\
sienten identificados con una generalización al describir a
\end{tabular}




\begin{tabular}{|c|c|}
\hline un grupo de personas. Luego se intenta reparar lo dicho \\
buscando una excusa insinuando que su caso es distinto al \\
mencionado. \\
- Se intenta reparar una agresión por medio de la explicación \\
y apelando a que la postura fue malentendida. \\
Comunique que $\boldsymbol{H}$ (el hablante) no quiere afectar a $\boldsymbol{O}$ (Brown P. y \\
Levinson S. , 1987 ). Pida disculpas. Impersonalice a $H$ y Ovite la \\
primera y segunda persona del singular. Plantee las AAI (acciones que \\
amenazan la imagen pública) como una regla general. \\
Estrategia de la impersonalización. Se intenta \\
impersonalizar el tema que se discute, evitando así el \\
ataque directo que se cometería al usar la primera y \\
segunda persona del singular.
\end{tabular}

Las estrategias de atenuación cortés encontradas en este corpus son las siguientes:

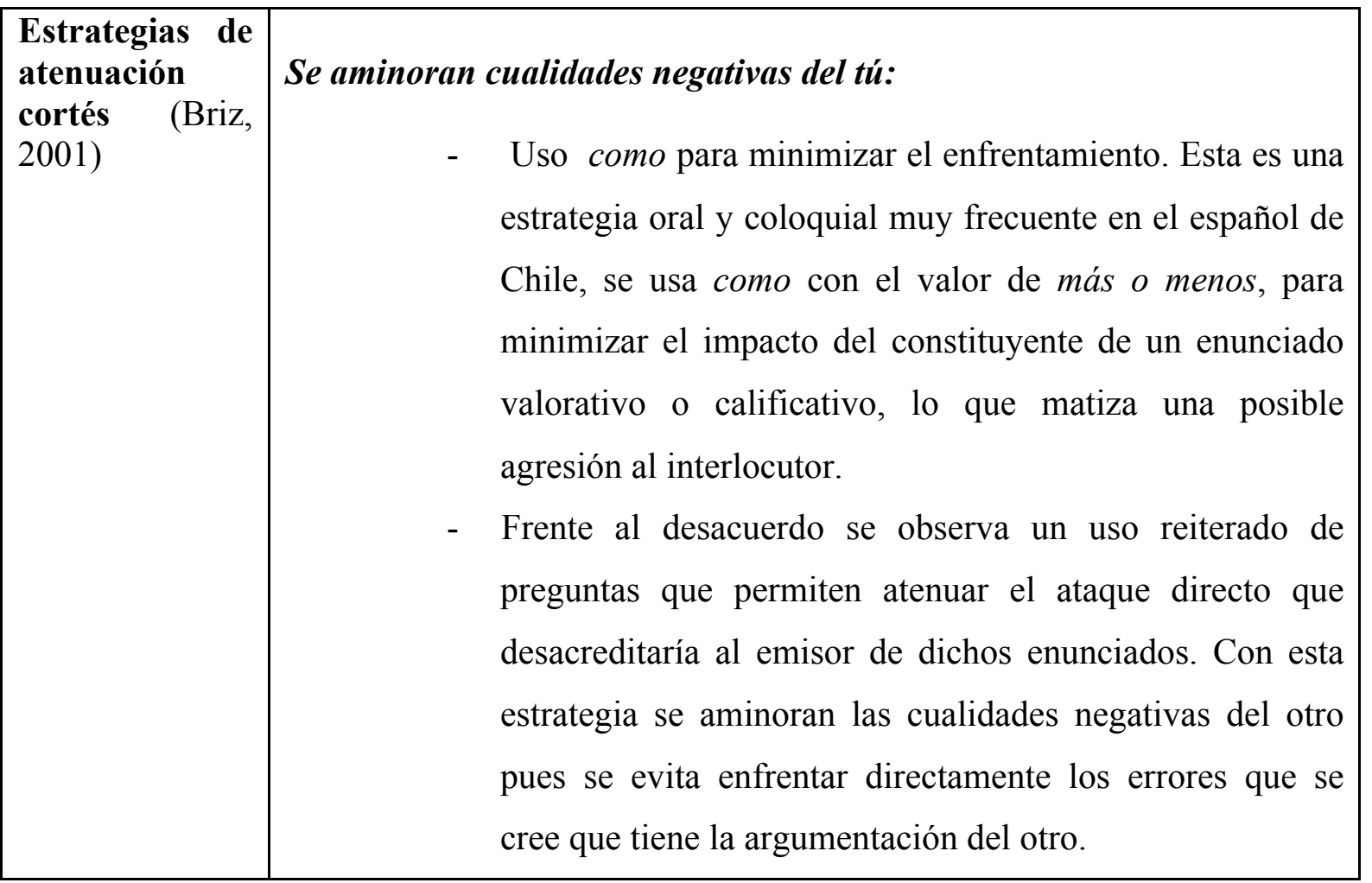


- Como un intento cortés de buscar el acuerdo, el interlocutor inicia su enunciado afirmando que encuentra excelente lo que dice otro y que concuerda con lo que se propone. Inmediatamente inicia su contraargumentación con la conjunción adversativa pero.

- Uso de risas que producen empatía y funcionan como una estrategia cortés para hacer disminuir el ataque.

Se aminoran cualidades, actitudes y acciones del yo:

- Uso de no sé, yo creo con el interlocutor pretende enfrentarse menos directamente a una postura diferente a la de alguno de los participantes del debate. Disminuye su imagen, no intenta agrandarla ni pretende presentarse de forma superior frente a los demás, actúa de forma humilde.

- Afirmación de que otro interlocutor sabe más, aminorando cualidades del yo.

Los indicadores gramaticales de atenuación cortés y de cortesía positiva y negativa encontrados en el corpus son los siguientes:

\begin{tabular}{|c|c|}
\hline $\begin{array}{l}\text { Indicadores gramaticales de } \\
\text { atenuación cortés (Kerbrat- } \\
\text { Orecchioni) (Haverkate) }\end{array}$ & $\begin{array}{l}\text { Se aminoran cualidades, actitudes y acciones del yo } \\
\text { (Briz, 2001): } \\
\text { - Actitud lingüística mediante la cual se observa que } \\
\text { se aminoran cualidades, actitudes y acciones del } \\
\text { yo, la llamaremos "negación o atenuación } \\
\text { positiva del enunciado". En este caso es usada }\end{array}$ \\
\hline
\end{tabular}




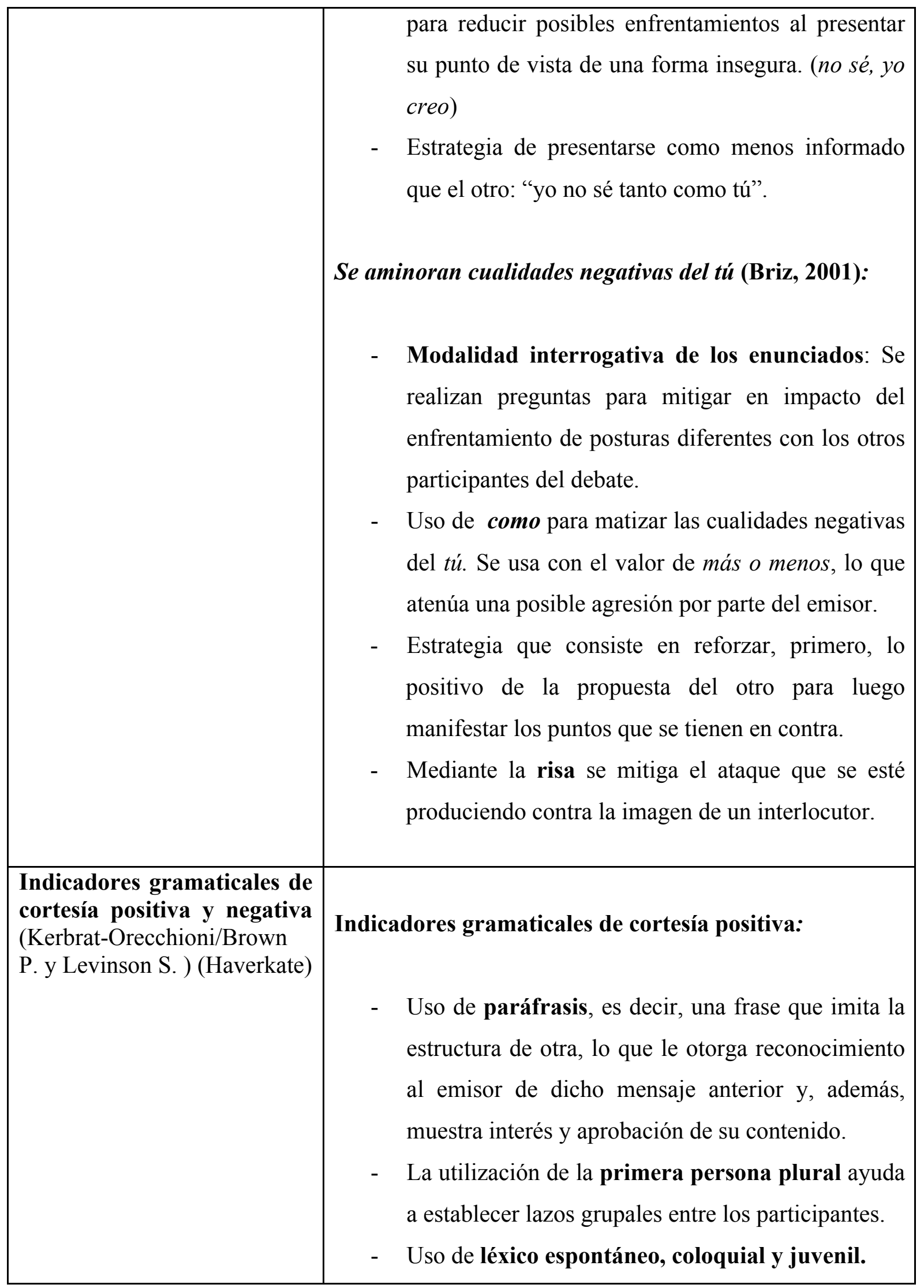


- Relevancia temática: preferencia por temas que son conocidos por todos y que los involucran a todos.

- Uso de reformuladotes discursivos Sí, pucha/ o sea/ pero es que/ eso es lo que pasa: que intentan evitar constantemente el desacuerdo o mostrar aprobación, expresando, en el caso del desacuerdo, que las dos alternativas que se están discutiendo pueden ser válidas.

- Risas: a través de la risa se distiende el ambiente, con la broma, y se suaviza la agresión cometida contra $\mathrm{H} 1$.

- La modalidad interrogativa del enunciado da flexibilidad al debate, pues le otorga más vigor a la cesión de turnos.

- $\quad$ Síntesis de la propuesta discursiva del otro.

- Uso de conectores pragmáticos metadiscursivos que permiten manifestar cortesía, pues su intención fática permite demostrar aprobación con el otro y facilitar que la conversación continúe ágilmente.

- Utilizar bromas para hacer más agradable la situación comunicativa.

- Cooperar con el discurso del otro ayudándolo a terminar su enunciado.

- Manifestación explícita del acuerdo con el otro.

Indicadores gramaticales de cortesía negativa:

- Reparación de un acto descortés: negación de lo que se dijo y que afectó al otro.

- Estrategias de reparación de un acto descortés: en primer lugar, se ataca la imagen del otro y luego se 


\begin{tabular}{|l|l|}
\hline & atenúan las cualidades del hablante. \\
- & Se intenta mitigar el ataque cometido ampliando \\
& más las condiciones particulares del otro, es decir, \\
tratando de explicar que él no se encuentra en los \\
casos que dio como ejemplo porque su situación es \\
distinta.
\end{tabular}

Por otra parte, las falsas argumentaciones más usadas durante el debate de los jóvenes fueron las siguientes. Se muestra un ejemplo en cada caso que explica su uso:

\begin{tabular}{|c|c|}
\hline Petitio principii & $\begin{array}{l}\text { Usar de un modo implícito la conclusión } \\
\text { como una premisa. } \\
\text { M1: Te juro que lo hubiera leido to: si } \\
\quad \begin{array}{l}\text { hubiese tenido tiempo, lo encontré } \\
\text { muy interesante. }\end{array} \\
\text { H1: NO:, a mi me pareció: como: } \rightarrow \\
\begin{array}{l}\text { (..) } \\
\text { H1: desubicao: }\end{array} \\
\text { Los protagonistas de este par de } \\
\text { adyacencia no argumentan las razones de } \\
\text { por qué encuentran interesante, por un } \\
\text { lado, y desubicado, por otro, el envío de } \\
\text { los correos masivos. La conclusión a la que } \\
\text { llegan la exponen como una premisa. }\end{array}$ \\
\hline Argumentum ad ignorantiam & $\begin{array}{l}\text { Se apela a la ignorancia del oponente para } \\
\text { probar el punto de vista contrario, a partir } \\
\text { de información incompleta. } \\
\text { M1: < [.pero por eso no:| no se sabe-] } \\
\text { M2: ya sea esté en esa situación o no, el } \\
\text { mismo hecho de que no se sepa, no me da } \\
\text { la certeza de que no lo hago, así que no lo } \\
\text { ocuparía, ¿me entiendeh? }\end{array}$ \\
\hline
\end{tabular}




\begin{tabular}{|c|c|}
\hline & $\begin{array}{l}\text { Debido a que existe una información que } \\
\text { no se sabe en profundidad, argumentan que } \\
\text { mientras no se pueda demostrar lo } \\
\text { contrario no pueden estar de acuerdo con } \\
\text { lo que se propone, en este caso: la } \\
\text { legalización de la pastilla del día después. }\end{array}$ \\
\hline Argumentum ad baculum & $\begin{array}{l}\text { Se persuade a través del temor y de la } \\
\text { amenaza dirigida hacia el oponente. } \\
\text { H2: ¿cachái? No podí } \rightarrow \text { no podí decir que } \\
\text { porque algo eh impuesto está malo } \\
\text { ¿cachái? Porque hay cosah impuestah que } \\
\text { igual son útileh, valiosah y que, por } \\
\text { ejemplo, yo creo que a ti no te gustaría que } \\
\text { llegara alguien a tu casa y te robara todah } \\
\text { tuh cosah, violara y matara a tu mamá, no } \\
\text { cachái } \rightarrow \\
\text { Se presenta una falsa argumentación que } \\
\text { provoca miedo a los otros interlocutores } \\
\text { pues el argumento está sustentando en } \\
\text { posibles sucesos que ocurrirían. }\end{array}$ \\
\hline Argumentum ad hominem & $\begin{array}{l}\text { En este segmento el argumento se basa } \\
\text { únicamente en el universo del protagonista } \\
\text { específico sin considerar valores } \\
\text { universales. } \\
\text { H1: personalmente creo que en el } \\
\text { momento en que una persona comienza a } \\
\text { tener relacioneh sexualeh, firma una } \\
\text { especie de contrato, con uno mismo y con } \\
\text { la otra persona donde uno asume una } \\
\text { responsabilidad de que si, de esa relación } \\
\text { va a nacer un hijo lo va a tener que, } \\
\text { asumir, yo personalment-o sea PARA MI } \\
\text { personalmente mi virginidad eh un tema } \\
\text { súper importante yo:, PRETENDO llegar }\end{array}$ \\
\hline
\end{tabular}




\begin{tabular}{|c|c|}
\hline & $\begin{array}{l}\text { virgen al matrimonio, y: no me gustaría } \\
\text { porque no-, o sea, porque no me } \\
\text { gustaría|| estar en la situación de tener } \\
\text { que pensar "le digo que se tome la pastilla } \\
\text { o que no se la tome"|| ahora, si llegara } \\
\text { esa situación yo creo que tomaría la } \\
\text { decisión de que no se la tomara, porque yo } \\
\text { no me gustaría, cargar con el cargo de } \\
\text { concienc-cargar con la conciencia, en mi } \\
\text { cabeza de que porque yo le dije "hahlo", } \\
\text { matamoh a un, a un } \rightarrow\end{array}$ \\
\hline Non sequitur & $\begin{array}{l}\text { Se extrae una conclusión que no se sigue. } \\
\text { H2: no, yo tampoco estoy de acuerdo } \\
\text { porque, con } \rightarrow \text { pahtilla y sin pahtilla } \\
\text { siempre ha habido promihcuidad, hemoh } \\
\text { estudiado que loh griegoh hacian lah } \\
\text { mediah orgíah, y teniendo, NO pero } \\
\text { TENIENDO } \rightarrow \\
\text { (...) } \\
\text { H2: no| pero, eh que igual ¿cachái? pero } \\
\text { eh que mira la promihcuidad va a existir o } \\
\text { no, o- si o no. } \\
\text { H1: <. entonceh erradiquemoh a loh } \\
\text { pokemoneh para evitar la promiscuidad } \\
\text { po.] } \\
\text { En este segmento se está discutiendo si la } \\
\text { pastilla del día después promueve o no la } \\
\text { promiscuidad, no quién es promiscuo en la } \\
\text { sociedad chilena ni tampoco si hay que } \\
\text { eliminarlos o segregarlos de nuestra } \\
\text { sociedad. }\end{array}$ \\
\hline Ignoratio elenchi & $\begin{array}{l}\text { Se argumenta a partir de información dada } \\
\text { por el oponente; no se pone en discusión la } \\
\text { tesis a defender. } \\
\text { M2: ¿sabíh cuál eh el problema? te tenih } \\
\text { que preguntar si eh que esah niñitah } \\
\text { cuando fueron a comprar a la farmacia, se } \\
\text { preguntaron- } \\
\text { M3: < [ehtoy dihpuehta a-]> }\end{array}$ \\
\hline
\end{tabular}




\begin{tabular}{|c|c|}
\hline & $\begin{array}{l}\text { M2: NO, no solo eso mah allá } \mid \text { de qué } \\
\text { produce además } \mid \text { de no quedar } \\
\text { embarazada la pahtilla | es una bomba, } \\
\text { hormonal ENORME: | Si una niñita NO } \\
\text { CONOCE SU: interior, si no va al médico } \\
\text { y sabe cómo su organismo rehponde, } \\
\text { puede quedar ehteril | con esa sola pahtilla } \\
\text { puede darle cáncer al útero } \rightarrow\end{array}$ \\
\hline Argumentum ad personam & $\begin{array}{l}\text { Se ejerce una presión sobre la persona, } \\
\text { poniendo en discusión la credibilidad de } \\
\text { quien se presenta como adversario. En este } \\
\text { segmento se pone en duda lo que afirma } \\
\text { M1, mediante un ataque, no se reflexiona } \\
\text { sobre el argumento que este da. } \\
\text { M1: < [entonces, por algo no se ha } \\
\text { averiguado hasta el momento]> } \\
\text { H2: < [icómo no se va a saber!] }> \\
\text { M1: eh que no lo han podido comprobar } \\
\text { no se ha podido comprobar de que NO es } \\
\text { abortiva y mientras no se compruebe yo no } \\
\text { me voy a ARRIESGAR a que sí lo sea y a } \\
\text { cometer un aborto, a cometer un asesinato, } \\
\text { no me voy a arriesgar a eso. }\end{array}$ \\
\hline Argumentum ad consequentiam & $\begin{array}{l}\text { Sirve para juzgar negativamente una } \\
\text { afirmación, una tesis, no mediante } \\
\text { argumentos externos, sino a través de las } \\
\text { consecuencias que pueden derivarse de } \\
\text { tales afirmaciones. } \\
\text { Este argumento está orientado a reflexionar } \\
\text { sobre las consecuencias de que se apruebe } \\
\text { el matrimonio homosexual en Chile, ya } \\
\text { que se centra en el tema de la adopción de } \\
\text { niños. }\end{array}$ \\
\hline & H1: eh lo mi h mo $\mid$ como no podí hy má $h$ \\
\hline
\end{tabular}




\begin{tabular}{|c|c|}
\hline & $\begin{array}{l}\text { encima e h tá el asunto de la adopción de } \\
\text { hijo ¿cachái? una pareja homosexual no } \\
\text { puede tener un hijo porque e h como } \\
\text { imagínate el trauma para el niño el no } \\
\text { saber | quien eh el papá quien eh la mamá, } \\
\text { o e h pera dónde- ¿me entendi h? }\end{array}$ \\
\hline Argumentum ad populum & $\begin{array}{l}\text { Apelar a las emociones de una multitud. Se } \\
\text { mencionan datos que pueden sensibilizar al } \\
\text { auditorio pues se habla de los sentimientos } \\
\text { de insatisfacción de los homosexuales, de } \\
\text { sus tristezas. } \\
\text { M2: y la LIBERACIÓN |¿cachái? de lo } \\
\text { homosexualeh ante la sociedad, en cierta } \\
\text { forma que sea que esta mutua- mutación } \\
\text { que se está dando lentamente |empezara a } \\
\text { hacerse así| ¿me entendih? entonceh elloh } \\
\text { ehtán liberado en cierta forma dudaban, } \\
\text { cachái, NO eran feliceh porque loh } \\
\text { homosexualeh no son feliceh cien por } \\
\text { ciento h si tu le preguntai a un } \\
\text { homosexualeh que tiene | una relación que } \\
\text { ama, si tu le preguntai en el fondo de su } \\
\text { alma "si eh felih" no, por mucho factoreh, } \\
\text { sea su familia, sea socialmente, porque su } \\
\text { sueño de familia no loh puede tener etc. } \\
\text { ¿cachái? entonceh eh por eso, si uno en } \\
\text { cierta forma leh abre esa ventana | a elloh } \\
\text { cachái | empieza así no mah po. }\end{array}$ \\
\hline
\end{tabular}

Falacias no formales encontradas en el corpus:

Argumento de la pendiente resbaladiza: este argumento dice que si ocurre un evento, otros eventos peligrosos ocurrirán igualmente; sin embargo, no hay prueba de que otros eventos peligrosos sean causados por el primer evento. En el corpus se usa este tipo de argumento cuando se afirma que si la pastilla del día después estuviera disponible para todo el mundo, incluso la gente que piensa que no la usaría, por motivos morales o religiosos, al poder obtenerla fácilmente, sí la usaría. 
Reductio ad Hitlerum: falacia que si bien puede ser clasificada dentro de la del tipo ad hominem, corresponde más bien a una subclasificación de esta, pues recurre directamente a la figura de Hitler (o a los ideales del nazismo), la cual es comparada con los argumentos a los que alude el interlocutor. En este corpus, particularmente, un interlocutor propone que no es normal ni natural un tipo de relación homosexual, inmediatamente es criticado por su postura extremista y es catalogado de nazi.

\subsection{Resultados del análisis de los episodios temáticos del debate de los adultos mayores}

Luego de realizar el análisis al corpus que contiene la grabación del debate que realizaron un grupo de adultos mayores, se han obtenido los siguientes resultados.

Las estrategias de cortesía positiva encontradas en este corpus son las siguientes:

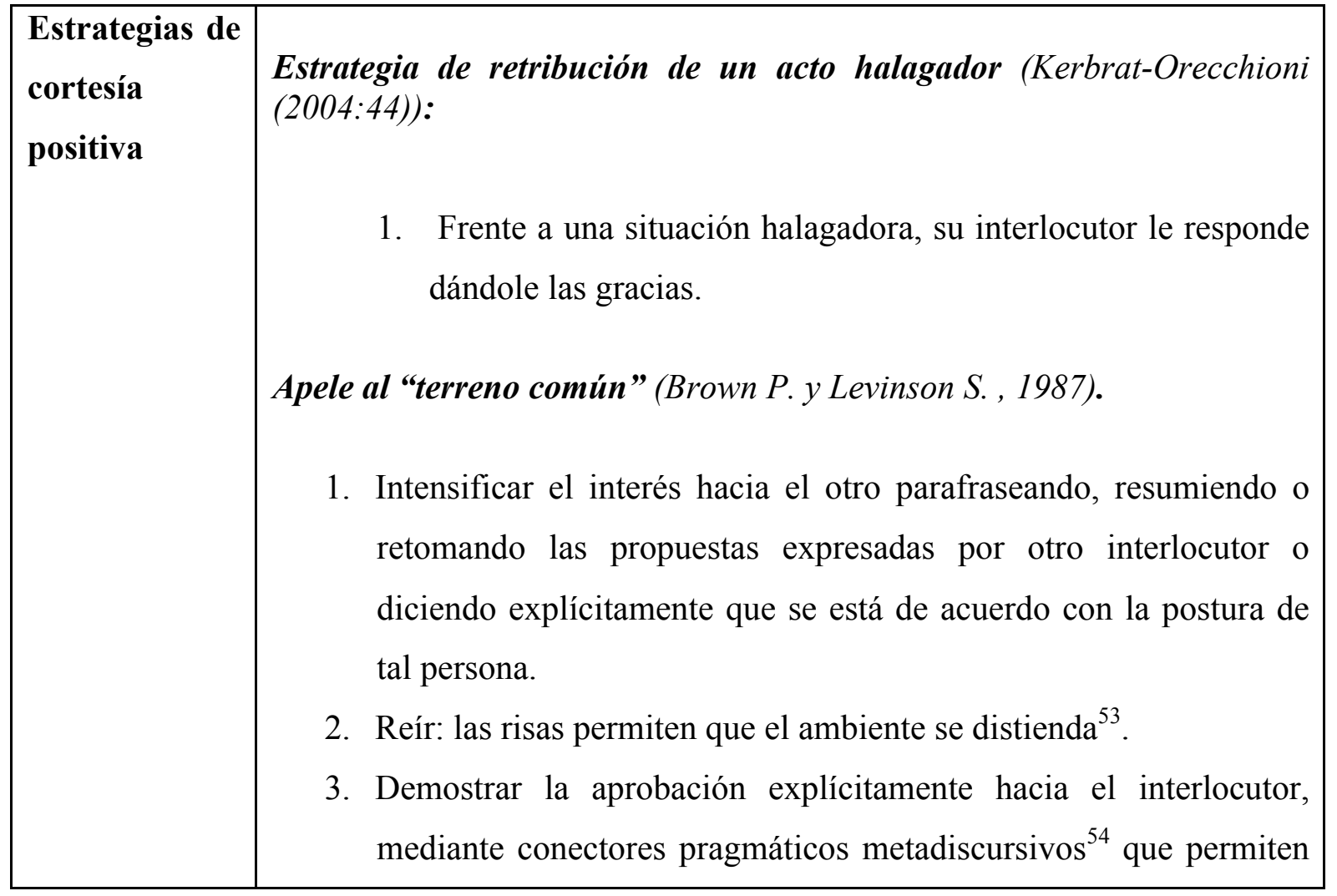

\footnotetext{
${ }^{53}$ La risa permite reducir la imposición del moderador de volver al tema que se propone. Como ya se comentó anteriormente, Leech insiste en que esta actitud cortés está dentro de las máximas de cortesía, específicamente dentro de la máxima de simpatía: "Reduzca al mínimo la falta de simpatía entre el yo y el otro: aumente al máximo la simpatía entre el yo y el otro" (cfr. pág. 63).
} 


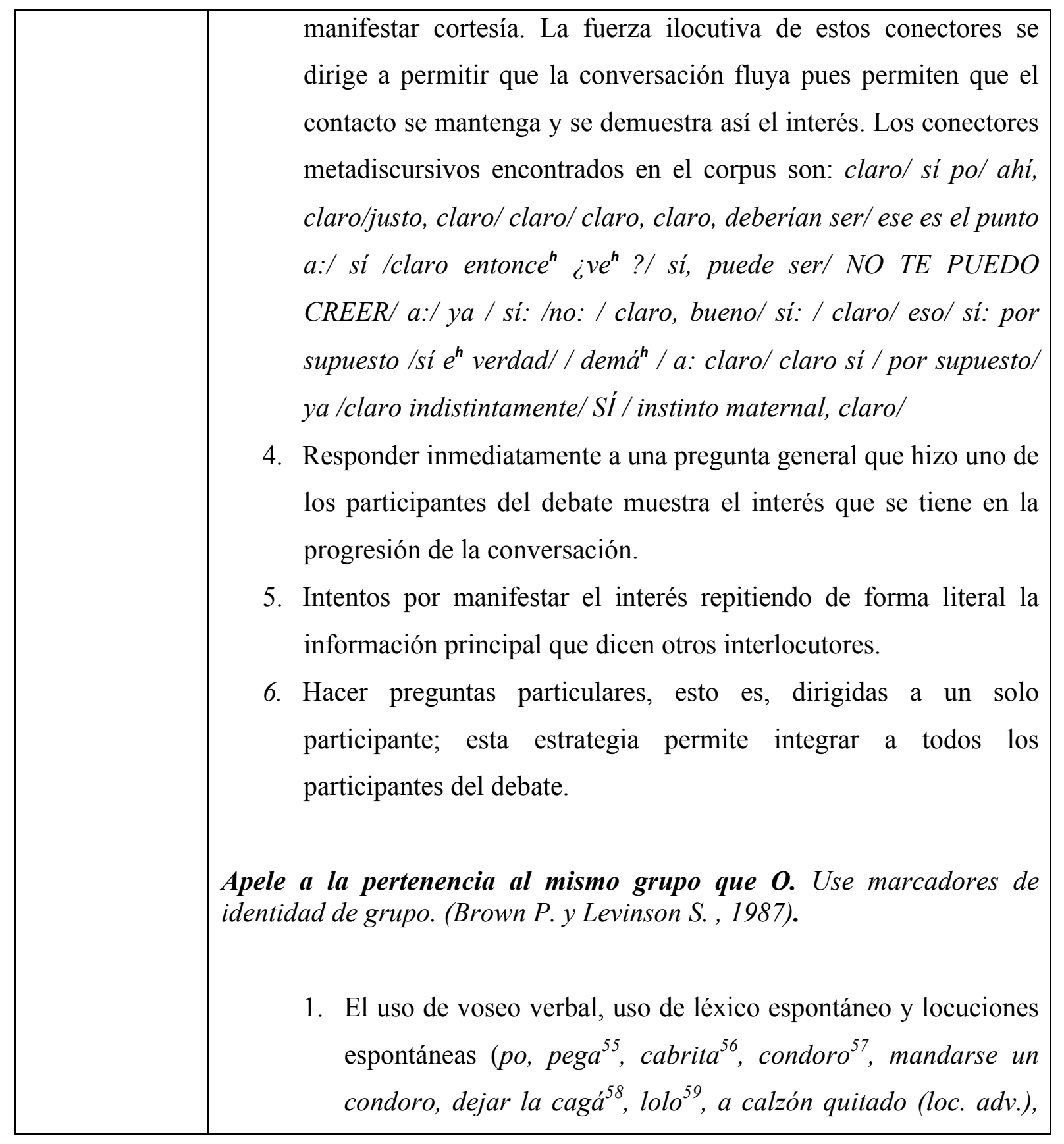

\footnotetext{
54 "En su papel metadiscursivo, de marcadores de transiciones del habla, los conectores pragmáticos son trazos o señales de la actividad discursiva, "asideros" de los hablantes para la formulación de unos mensajes que se producen cara a cara y en un espacio y tiempo determinados; marcas por tanto, del progreso y desarrollo coherente de los mismos. En este sentido podría decirse que los conectores participan en la organización del habla y de ahí se deriva su papel metadiscursivo estructurador, sus valores conversacionales" (Briz/Hidalgo, 1988: 141).

55 Sustantivo coloquial, "Trabajo"

56 “cabro,-a. m y f. Persona joven. espon". (DUECh, 2010)

57 “condoro. m. Error, equivocación. espon”. (DUECh, 2010)

58 “cagada. f. vulgar. Situación caracterizada por la confusión y el desorden. Observ. Normalmente con verbos como "quedar", "dejar" o "estar", y con el artículo "la"." (DUECh, 2010)

59 "lolo,-a. my f. Adolescente.espon”. (DUECh, 2010)
} 
guagüita $^{60}$, chiquilla, poto $^{61}$, vaca $^{62}$, peo $^{63}$, cuestiones, cuento, leseo ${ }^{64}$, po, de un viaje (loc. adv.) nica ${ }^{65}$, hacer ruido (loc. verb.) nicagando, mamón ${ }^{66}$, gallo, pechuga, guata ${ }^{67}$, cagada, coco, pollerúo ${ }^{68}$, maricón) y uso de léxico propio de su grupo etario (fijate ${ }^{69}$, cototuda ${ }^{70}$ )dan cuenta de que se encuentran en una situación distendida lo que intensifica la pertenencia al grupo y los identifica como miembros del mismo.

Apele al punto de vista, opiniones, actitudes, conocimiento, empatía comunes. - Busque el acuerdo. Evite el desacuerdo. Presuponga/ suscite/ manifieste el terreno común. Bromee. (Brown P. y Levinson S. , 1987).

1. Bromear. Se utilizan bromas para hacer más grata la conversación.

2. Interacción bromista e irónica ${ }^{71}$ :

60 “guagua. m-f. bebé, niño de pecho. espon”. (DUECh, 2010). Voz de origen quechua, huahua, "niño de corta edad'. Una de las derivaciones de este término es guagualón 'adulto, pueril, aniñado'.

61 "poto. (de origen mapuche). M. Trasero, conjunto de nalgas. espon". En el corpus se usa la expresión "a poto pelado" que se usa equivocadamente, según la anécdota que cuentan los participantes, en vez de usar la expresión "a calzón quitado", que es una locución adverbial que significa generalmente hablar, decir algo "sin restricciones o tapujos".

62 “vaca. Adj/sust. Referido a persona, ruin, miserable.espon”. (DUECh, 2010)

63 “peo. M. Gas maloliente que se expulsa por el ano. espon”. (DUECh, 2010)

64 “leseo. M. Acción de lesear (no hacer nada provechoso.espon)". (DUECh, 2010)

65 “nica. adv. De ninguna manera. espon". (DUECh, 2010)

66 "mamón. Adj./sust. Referido a una persona, que tiene mucho apego o dependencia de sus padres, especialmente de la madre. espon. desp". (DUECh, 2010)

${ }^{67}$ Del mapuche wata. Tanto en el español como en el mapudungun esta lexía tiene el significado de 'barriga', 'vientre'. Expresiones asociadas al término son la locución verbal echar guata y el adjetivo guatón. "guata.

(1) (De origen mapuche). f. Vientre, estómago. espon”. (DUECh, 2010)

68 "pollerudo. 1. adj./sust. Referido a una persona, especialmente un hombre, que se apega a las faldas de su madreo de otras mujeres de las que depende. espon. desp. (...) 2. adj/sust. Pusilánime. espon. desp. (DUECh, 2010)

${ }^{69}$ La voz fijate corresponde más bien a un conector pragmático metadiscursivo ya que permite que la conversación continúe y permite además mantener la atención en la interacción comincativa. Corresponde a una fórmula usada para mantener el contacto con el interlocutor y a la vez ir progresando en la conversación. Se decidió incluirlo en esta sección junto con el léxico que permite marcar identidad, y no entre los conectores pragmáticos, porque si bien ayuda a la progresión del debate, es usado preferentemente por la gente mayor, entonces marca muy claramente la identidad de grupo.

70 “cototudo,-a. adj. Difícil, complicado.espon". (DUECh, 2010)

${ }^{71}$ Se discutió anteriormente Alvarado (2005) la presencia de cortesía verbal en un enunciado de tipo irónico que, en definitiva, y contrariamente a lo que se ha creído hasta el momento, es usada para producir cortesía. Vemos en este ejemplo que la ironía tiene aquí un efecto positivo pues lleva consigo cortesía. De esta manera, se relaciona la cortesía con una ironía de efecto positivo. 
3. Se cuentan anécdotas.

4. Participar y demostrar interés presuponiendo y anticipando lo que va a decir el otro, ayudándolo a terminar las frases de los enunciados. Se colabora ayudando a terminar el enunciado que postula otro. Es interesante que el receptor de esos mensajes vuelve a repetir la frase que le menciona su interlocutor.

5. Hacer preguntas generales, mediante las cuales se cede el turno y se deja libre para que todos participen. Mediante esta estrategia de cortesía se intenta manifestar el terreno común de todos los participantes, terreno en que todos pueden participar y opinar.

6. Hacer explícito el acuerdo con el otro y comentar su postura.

7. Retomar lo que otro dijo anteriormente y comentarlo, haciendo mención explícita de quién mencionó esa idea antes.

8. Decir expresamente que no se quiere estar en desacuerdo y que se busca el acuerdo.

Apele a la reflexibilidad (si $O$ desea [que $O$ tenga $X$ ], entonces $H$ desea [que $O$ tenga $X]$ y si $H$ desea [que $H$ tenga $X$ ] entonces $O$ desea [que $H$ tenga $X$ ]). Incluya a ambos, Hy $O$, en la actividad. Dé (o pida) razones. Asuma o manifieste reciprocidad. Haga regalos a $O$ (bienes, simpatía, comprensión, cooperación).

1. Los interlocutores muestran solidaridad con una persona que cuenta una anécdota vergonzosa, le dan su comprensión. Es interesante que ellas sugieran que la risa o una sonrisa hubiera ayudado a distender el ambiente en aquella situación vergonzosa que se describe; por tanto ellas creen que la risa y el humor puede servir como estrategia de cortesía para disminuir el ataque personal en una situación como esa.

Exprese que $\mathrm{H}$ y $\mathrm{O}$ son cooperativos. Indique que $\mathrm{H}$ conoce los deseos de $\mathrm{O}$ y los está teniendo en cuenta. Manifieste o presuponga que conoce y se preocupa por los deseos de O. Ofrezca, prometa. Sea optimista.

1. Se observa interés en ayudar al otro a expresar su idea, terminar su enunciado, ofreciéndole alternativas o reformulando la idea que 


\section{expresó. Son cooperativos.}

Las estrategias de cortesía negativa encontradas en este corpus son las siguientes:

\begin{tabular}{|l|l|}
\hline Estrategias de \\
cortesía \\
negativa & $\begin{array}{l}\text { Estrategias de reparación de un acto descortés }{ }^{72} \text { (Kerbrat-Orecchioni } \\
(2004: 44)): \text { A comete contra B alguna ofensa }(F T A) \text { que inmediatamente } \\
\text { intenta reparar por medio de una excusa }(F F A) \text {. Cuanto mayor es el peso } \\
\text { del FTA, tanto más debe ser importante el trabajo reparador. }\end{array}$ \\
1. Se intenta reparar una agresión por medio de la \\
explicación y la excusa.
\end{tabular}

Las estrategias de atenuación cortés encontradas en este corpus son las siguientes:

\begin{tabular}{|l|l|}
\hline $\begin{array}{l}\text { Estrategias de } \\
\text { atenuación cortés } \\
\text { (Briz, 2001) }\end{array}$ & $\begin{array}{l}\text { Se aminoran cualidades negativas del tú: } \\
\text { Uso reiterado de preguntas que permiten atenuar el ataque directo que } \\
\text { desacreditaría al emisor de dichos enunciados. } \\
\text { Uso de risas que producen empatía y funcionan como una estrategia } \\
\text { cortés para hacer disminuir el ataque. } \\
\text { Se aminoran cualidades, actitudes y acciones del yo: } \\
\text { Uso de no sé, yo creo con el que el interlocutor pretende enfrentarse } \\
\text { menos directamente a una postura diferente a la de alguno de los } \\
\text { participantes del debate. Disminuye su imagen, no intenta agrandarla }\end{array}$ \\
\hline
\end{tabular}

${ }^{72}$ El nombre de esta estrategia no corresponde a ninguna clasificación realizada por Kerbrat-Orecchioni previamente. Corresponde a un parafraseo, creado por la autora de esta investigación, correspondiente a esta técnica verbal. 
ni pretende presentarse de forma superior frente a los demás, actúa de forma humilde.

La estrategia atenuadora se usa aminorando cualidades del yo, afirmando que otro interlocutor sabe más que él porque él es ignorante en este tema o que son temas muy profundos y difíciles para su entendimiento.

Los indicadores gramaticales de atenuación cortés y de cortesía positiva y negativa encontrados en el corpus son los siguientes:

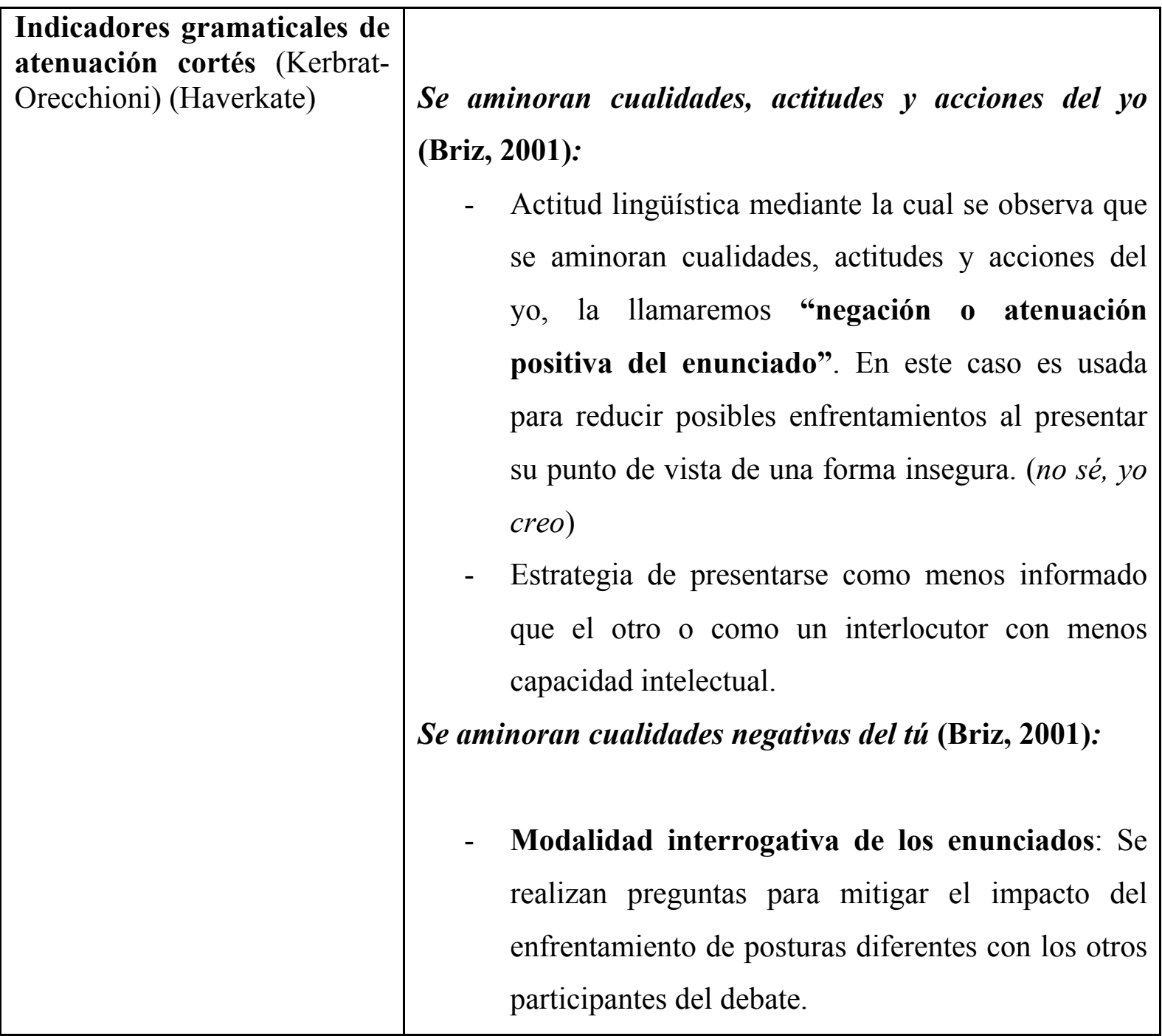




\begin{tabular}{|c|c|}
\hline & $\begin{array}{l}\text { - Mediante la risa se mitiga el ataque que se esté } \\
\text { produciendo contra la imagen de un interlocutor. }\end{array}$ \\
\hline $\begin{array}{l}\text { Indicadores gramaticales de } \\
\text { cortesía positiva y negativa } \\
\text { (Kerbrat-Orecchioni/Brown } \\
\text { P. y Levinson S. ) (Haverkate) }\end{array}$ & 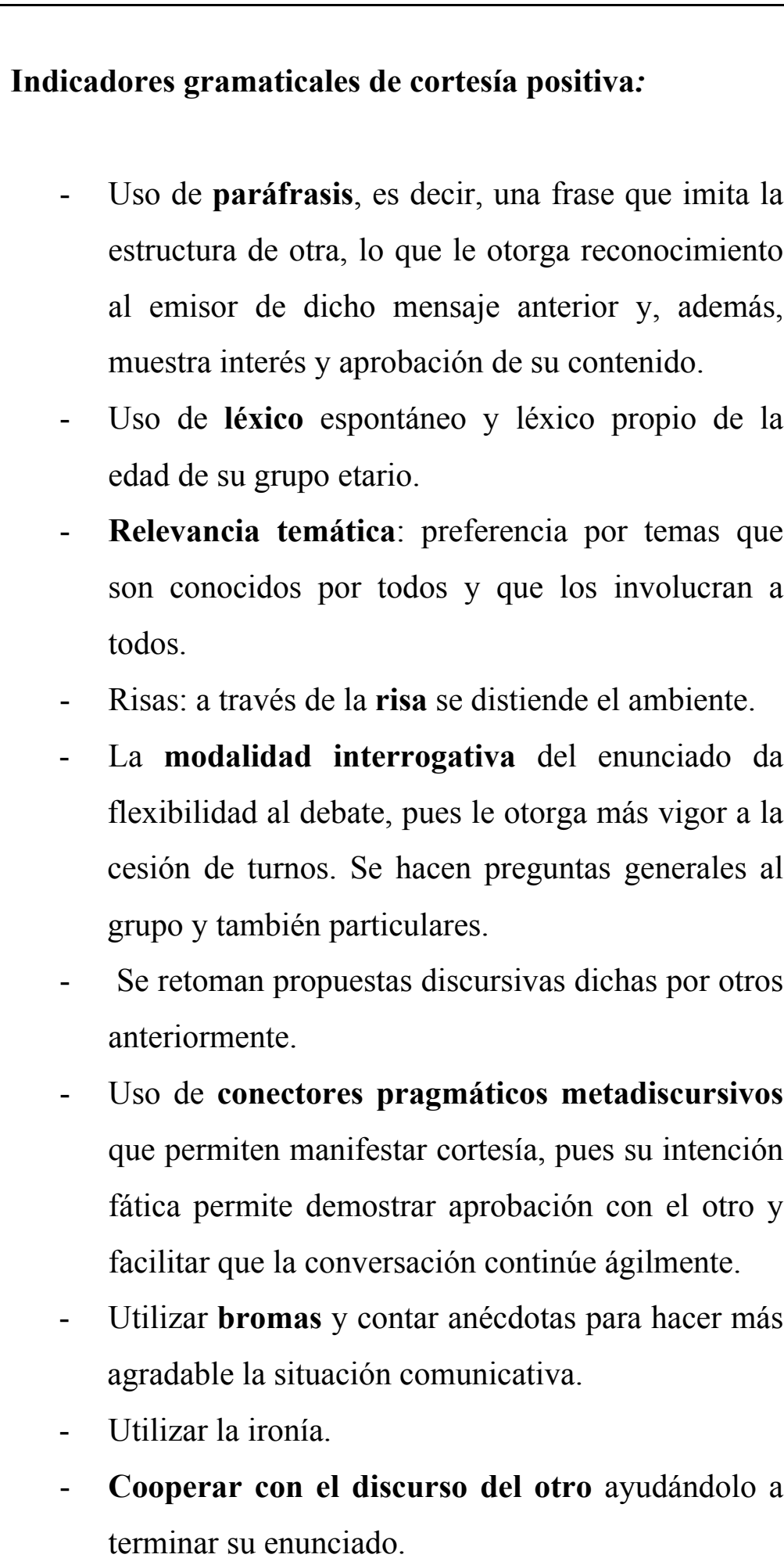 \\
\hline
\end{tabular}


- Manifestación explícita del acuerdo con el otro.

- Decir expresamente que se quiere evitar el desacuerdo.

- Solidaridad entre los interlocutores.

Indicadores gramaticales de cortesía negativa:

- Reparación de un acto descortés: excusas sobre lo que se dijo.

Por otra parte, las falsas argumentaciones más usadas durante el debate de los adultos mayores fueron las siguientes. Se muestra un ejemplo en cada caso que explica su uso:

\begin{tabular}{|c|c|}
\hline Petitio principii & $\begin{array}{l}\text { Usar de un modo implícito la conclusión } \\
\text { como una premisa. } \\
\text { M1: < [claro que se llame matrimonio] } \\
\text { M2: [sí porque en realidad matrimonio } \\
\text { siempre es entre un hombre y una mujer] } \\
\text { M1 < [cla: ro, eso choca] } \\
\text { M2: < [nunca en do hombre o en do }{ }^{h} \\
\left.\text { mujere }{ }^{h}\right]\end{array}$ \\
\hline Argumentum ad ignorantiam & $\begin{array}{l}\text { Se apela a la ignorancia del oponente para } \\
\text { probar el punto de vista contrario, a partir } \\
\text { de información incompleta. } \\
\text { M1:< [pero la ciencia no dice que no] } \\
\text { M2: < [la iglesia dice que sí-] } \\
M 1:<\text { [mientra }{ }^{h} \text { no me demuestren-] } \\
\text { H1: < [ la iglesia dice que sí-] } \\
\left.M 1:<\text { [hay do } \text { versione }^{h}-\right]\end{array}$ \\
\hline Argumentum ad baculum & $\begin{array}{l}\text { Se persuade a través del temor y de la } \\
\text { amenaza dirigida hacia el oponente. En }\end{array}$ \\
\hline
\end{tabular}




\begin{tabular}{|c|c|}
\hline & 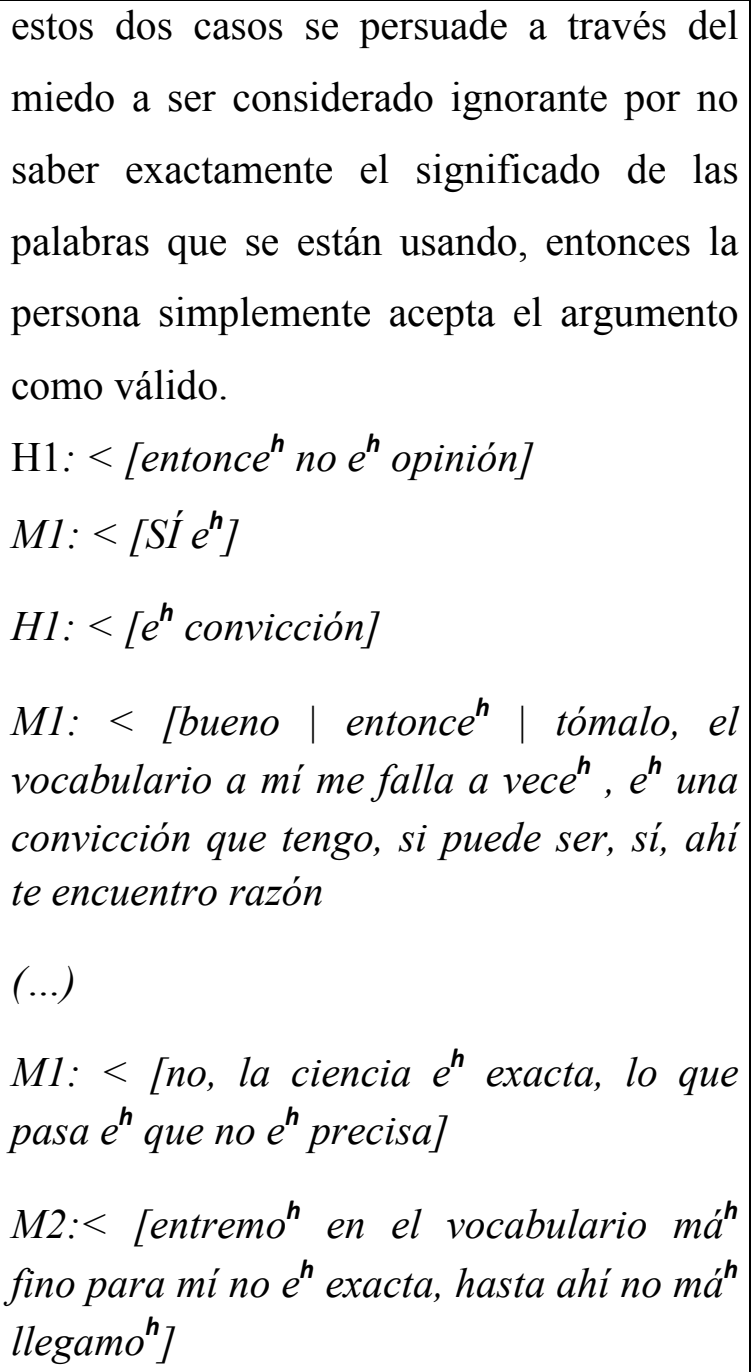 \\
\hline Argumentum ad hominem & $\begin{array}{l}\text { En este segmento el argumento se basa } \\
\text { únicamente en el universo del protagonista } \\
\text { específico sin considerar valores } \\
\text { universales. } \\
\text { M1: < [Pero yo no dejaría mi nieto, ese } \\
\text { chiquitito el de do año al cuidado de un } \\
\text { gay NI CAGANDO, pero no, no me } \\
\text { pregunti }{ }^{h} \text { por qué, pero un terror-] } \\
\text { (...)M1: } \leq \text { [no acepto que tengan niño } \\
\text { esa }{ }^{h} \text { persona] }\end{array}$ \\
\hline
\end{tabular}




\begin{tabular}{|c|c|}
\hline Argumentum ad consequentiam & $\begin{array}{l}\text { Sirve para juzgar negativamente una } \\
\text { afirmación, una tesis, no mediante } \\
\text { argumentos externos, sino a través de las } \\
\text { consecuencias que pueden derivarse de } \\
\text { tales afirmaciones. } \\
\text { Isabel no acepta a los homosexuales } \\
\text { porque piensa en su nieto pequeño, se } \\
\text { preocupa por lo que pudiera pasar en el } \\
\text { futuro cuando sea grande. Este argumento } \\
\text { también podría ser considerado ad } \\
\text { hominem ya que está basado en } \\
\text { argumentos muy particulares. } \\
\text { Ml:< [anoche estaba con la guata } \\
\text { revuelta, y vuelvo a pensar en lo nieto de } \\
\text { uno, porque parece que cuando uno tiene } \\
\text { nieto }{ }^{h} \text { parece que todo ¿qué pasaría } \\
\text { cuando un niño? Porque lo }{ }^{h} \text { nuestro }{ }^{h} \text { ya } \\
\text { están grande, pero ahora viene la otra } \\
\text { generación] }\end{array}$ \\
\hline Argumentum ad populum & $\begin{array}{l}\text { Apelar a las emociones de una multitud. } \\
\text { H1 apela a la sensibilidad de la audiencia } \\
\text { para expresar que está siendo discriminado. } \\
\text { M1: < [ No desea:do, así que totalmente } \\
\text { de acuerdo, y si el pai }{ }^{h} \text {, ¿sabí que es lo que } \\
\text { me molesta de toda esta historia? es que } \\
\text { los políticos HOMBRES, opinen de un } \\
\text { tema de mujer | eso me molesta, por lo } \\
\text { tanto más encima] } \\
\text { H1: < [iy yo no puedo opinar entonce }{ }^{h} \text { ] } \\
\text { M1 : sí, opinas como hombre pero los } \\
\text { políticos lo hacen como algo personal, } e^{h}\end{array}$ \\
\hline
\end{tabular}


la ley, la ley, no le piden la opinión a la mujere $^{h}$ - 


\section{CONCLUSIONES}

Luego de revisar los resultados que se obtuvieron al analizar y describir el corpus de esta investigación y después de haber aplicado las plantillas a cada episodio temático, se han podido hacer reflexiones y, como consecuencia de ellas, obtener las conclusiones que se desarrollan a continuación.

De forma general, es posible afirmar que los resultados obtenidos del análisis del corpus dan cuenta de diferencias en las estrategias de cortesía verbal y de atenuación cortés utilizadas por los dos grupos etarios que forman parte de la muestra. Se verán en detalle en las siguientes líneas las principales distinciones que se obtuvieron a lo largo del análisis.

Respecto a la metodología de investigación es importante destacar que la incorporación al proceso de análisis de temas relativos a la argumentación y falsas argumentaciones permitió detenerse en asuntos de la temática que se discutía en cada uno de los episodios, lo que permitió analizar en profundidad, por tanto, los enunciados, desentrañando la fuerza ilocutiva de ciertos mensajes. Si bien el reconocimiento de los elementos de la estructura interna de la argumentación no ayudó directamente a tratar el tema de la cortesía verbal, sí fue de gran ayuda en el análisis general pues permitió profundizar en la organización temática de cada uno de los episodios, entender la propuesta argumentativa y pretensión discursiva de estos, así como también suscribir actitudes de cortesía en la reiterada utilización de argumentos falaces.

En efecto, las falacias descritas en cada episodio permitieron dar cuenta de que en los episodios del corpus de los jóvenes se utiliza una mayor variedad de estas estrategias de falsa argumentación, en cuya diversidad se encontraron incluso estrategias de falsos argumentos que no pertenecen a la clásica caracterización de la retórica antigua (i.e. Argumento de la pendiente resbaladiza, Reductio ad Hitlerum). Una posible explicación a este hallazgo es afirmar que estos jóvenes están ciertamente más abiertos a la discusión y más incentivados para intentar convencer a sus interlocutores sobre la legitimidad de su postura. Por este motivo, en sus enfrentamientos verbales seleccionaron con frecuencia más 
argumentos en apariencia eficaces y, por lo tanto, en la mayoría de los casos más falaces, y no aquellos argumentos estrictamente certeros y objetivos. Es necesario mencionar en este punto que las falacias, o falsos argumentos, son estrategias discursivas que usamos en la mayoría de nuestras interacciones cotidianas, por tanto, pueden ser consideras parte de la norma en las interacciones argumentativas. Son relevantes pues permiten ponernos en contacto con nuestro interlocutor para presentarle una nueva posibilidad de ver un asunto desde otra perspectiva. Este interés por entablar contacto con nuestros interlocutores, de una u otra manera, transparenta estrategias discursivas de cortesía positiva al expresar el interés hacia el otro y apelar al terreno común.

Los jóvenes de esta muestra utilizaron también más estrategias de cortesía negativa, debido a la constante confrontación con los otros participantes de ese debate, pues evidentemente al haber más enfrentamiento en sus interacciones hubo también más intentos por suavizar o excusar estos ataques. En efecto, se observa una serie de estrategias de reparación de un acto descortés a las que los adultos no tuvieron necesidad de recurrir, puesto que se enfrentaron indudablemente a menos situaciones de riesgo. Estas estrategias reparadoras utilizadas solo por los jóvenes son las siguientes:

- La risa que suaviza el ataque producido contra otro interlocutor.

- Mención explícita de que el otro está más informado y sabe más que él, luego de haber manifestado que no se está de acuerdo con su postura por ciertas razones.

- Luego del ataque a la imagen de otro interlocutor se afirma que se malentendió lo que se quiso expresar. Otra estrategia similar a esta fue intentar explicar que la otra persona no pudo haberse sentido dañada por lo que se dijo ya que su situación es distinta y no tiene nada que ver con la referida por él.

- Impersonalización del tema que se discute, no se utilizan las formas personales en el momento de contrargumentar.

En cuanto a las estrategias de cortesía positiva se observó que el corpus del grupo de los adultos mayores utilizó una serie de estrategias corteses que los jóvenes no consideraron; estas son: 
- Usar la ironía como estrategia cortés para hacer una broma.

- Dar las gracias explícitamente como retribución a un acto hhalagador.

- Repetir literalmente ideas o comentarios de otros interlocutores con lo que se comparte algún acuerdo como un gesto de aprobación e interés.

- Manifestar expresamente que se quiere evitar el desacuerdo.

- Expresar solidaridad y apoyo a los otros interlocutores, ofreciendo alternativas léxicas para que estos terminen sus enunciados.

- Decir explícitamente que se es solidario con el otro.

Observamos así que el grupo de los adultos mayores utiliza la ironía como estrategia de cortesía positiva; se propone, entonces, en este análisis que la ironía verbal tiene mucha relación con la cortesía, pues indudablemente es posible observar la presencia de cortesía verbal en un enunciado de tipo irónico y que, en definitiva, y contrariamente a lo que se pueda pensar a simple vista, es usada para producir cortesía positiva, en el sentido de que permite demostrar el interés hacia el interlocutor y solidarizarse con el otro. El efecto que causa particularmente la ironía en los segmentos del corpus en que fue encontrada va en la dirección de hacer una broma, distender el ambiente y hacer que todos se sientan más en confianza. Se plantea, así, que la ironía puede causar un efecto positivo en ciertos intercambios comunicativos ya que si bien no se está entregando información de una forma clara y precisa, justamente por medio de la indireccionalidad por la que se comunica el mensaje trata de mostrarse interés, pues se está bromeando, y se hace explícita la atención hacia los participantes de una conversación.

Como vimos anteriormente Lakoff (1990) hace hincapié en que en la mayoría de las conversaciones informales, la comunicación real de ideas importantes es algo secundario respecto a la intención de afirmar y estrechar las relaciones. De ahí que las máximas conversacionales se respeten de forma estricta solo en aquellos intercambios comunicativos en los que el contenido que se comunica es más importante que el acto de dialogar. Sin duda, la estrategia discursiva que involucra la emisión de una ironía es muy interesante pues hemos visto que para que se produzca una completa comprensión de la finalidad 
enunciativa del mensaje es necesario que el interlocutor realice un proceso interpretativo que vas más allá de la disquisición meramente semántica, ya que es necesario realizar inferencias que permitan deducir lo implícito. Por cierto que el proceso involucra riesgos ya que en el caso de no ser entendida la ironía o, más bien, si el interlocutor se detiene en el primer nivel de interpretación de la comunicación, la ironía podría ser interpretada, y malentendida como una acción descortés. Se cree que gracias al tono coloquial que tenía el encuentro, en el que la comida ${ }^{73}$ y la bebida pueden haber ayudado a distender el ambiente, además de la homogeneidad sociocultural que caracterizó al grupo, fue posible que la intención irónica de estos enunciados fuese comprendida y que precisamente sirviera para afianzar el vínculo comunicativo.

Otra estrategia interesante de cortesía positiva encontrada en el corpus de los adultos mayores fue la expresión directa de enunciados que afirmaban que no se quería estar en desacuerdo con el otro, posiblemente debido a que se pensaba que una situación de enfrentamiento de ideas podría haber puesto en peligro la armonía del coloquio. Los temas que se discutieron fueron analizados por este este grupo desde una perspectiva liberal, todos estuvieron de acuerdo en que el uso de la "píldora del día después" debería ser legal en nuestro país, así como también se mostraron a favor de que se instituya el matrimonio homosexual en Chile, aunque no así la adopción por parte de padres homosexuales.

Fue interesante observar que el grupo de los jóvenes expuso apreciaciones divergentes frente al uso de la "píldora del día después", destacándose un grupo con ideas muy conservadoras y otro con propuestas progresistas. Lo mismo ocurrió con los temas sobre el matrimonio homosexual y la adopción homoparental. Los jóvenes en ningún caso intentaron sesgar la evidente polaridad de sus puntos de vista; muy por el contrario, no le temieron al enfrentamiento verbal e incluso debatieron con argumentos muy personales para darle más fuerza a sus pretensiones retóricas.

\footnotetext{
${ }^{73}$ En efecto, la comida se puede considerar como un elemento que promueve la socialización grupal, “ella actúa como una instancia que permite socializar libremente, cuyo carácter ceremonial se manifiesta en los procesos de preparación y producción colectiva de alimentos" (Harvey A. y Oyanedel M., 2010: 71).
} 
Debido a tales divergencias de opinión en el grupo de los más jóvenes, se observó que estos utilizaron una mayor diversidad de estrategias de atenuación cortés para intentar mitigar el impacto que pudieran producir las confrontaciones de opiniones y mantener así los lazos de filiación. Para lograr dicho objetivo se observó el uso de estrategias tales como aminorar su propia imagen afirmando que otro interlocutor sabe más sobre este tema que él o haciendo disminuir las cualidades negativas del otro destacando primero lo bueno de su discurso para luego contraargumentar.

Una vez realizado el análisis ha sido posible concluir que la tesis planteada inicialmente y que sustenta esta investigación acertó al intuir que existen diferencias estratégicas en cuando a las técnicas de atenuación cortés y cortesía verbal usadas por los jóvenes y adultos que forman parte de esta muestra. Efectivamente, existen diferencias en la descripción de estrategias corteses usadas por jóvenes y por adultos en una situación en la que deben confrontar ideas y atacar la imagen de otro para expresar sus puntos de vista divergentes. Si bien ha sido posible afirmar que los adultos dieron cuenta de una mayor variedad de estrategias de cortesía positiva, el hecho de que los jóvenes no utilicen entre sus estrategias comunicativas una gran variedad de estas técnicas no debe ser entendido en ningún caso como descortesía por parte de ellos ${ }^{74}$; solo podremos afirmar que, luego de este breve análisis, los jóvenes de esta muestra son menos corteses o simplemente son no corteses en esta interacción particular de debate semipautado. Sin embargo, debido a que ellos no le temen al enfrentamiento verbal sí utilizaron una mayor variedad de estrategias de atenuación cortés, precisamente para mitigar sus enfrentamientos verbales.

\footnotetext{
${ }^{74}$ La plantilla de análisis que se ha propuesto en esta investigación se cree que servirá como base para futuras investigaciones puesto que es apta para ir completándola o adaptándola a nuevas especificidades, agregándole nuevas valoraciones lingüísticas que sean posibles de describir en situaciones de debate. Particularmente, se consideraría adecuado que en futuras investigaciones se le incorpore un ítem que considere aspectos, por ejemplo, sobre la descortesía verbal.
} 

12 BIBLIOGRAFÍA

Academia Chilena de la lengua (2010) DUECh, Diccionario de uso del español de Chile. Santiago: Editorial MN.

Alvarado, $M^{\mathrm{a}}$. (2005)

"La ironía y la cortesía: una aproximación desde sus efectos". Alicante: Revista ELUA, Estudios de lingüística, Universidad de Alicante. $N^{\circ} 19$. [en línea]. [07/06/2012] Disponible en la web: http://rua.ua.es/dspace/bitstream/10045/6090/1/EL UA_19_02.pdf

Alvarez, G. (1996)

Textos y Discursos. Introducción a la lingüística del texto. Concepción: Universidad de Concepción.

Alvarez, M. (1994)

Tipos de escrito II: exposición y argumentación. Madrid. Arco Libros.

Anscombre J. y Ducrot O. (1994) La argumentación en la lengua. Madrid. Gredos.

Asociación de Academias de la lengua española (2010) Diccionario de americanismos. Madrid: Santillana

Austin, J. L. (1971)

Cómo hacer cosas con palabras. Barcelona: Paidós Ibérica. 
Bajtín, M.M. (2002)

Bassols M. y Torrent A. (1997)

Blum-Kulka, Sh. (2000)
Estética de la creación verbal. Buenos aires. Editores siglo veintiuno.

Modelos textuales. Teoría y práctica. Barcelona: Octaedro.

"Pragmática del discurso", en $E l$ discurso como interacción social, estudios sobre el discurso, tomo II (67). Barcelona: Editorial Gedisa.

Una metodología para el análisis interaccional del texto escrito. Venezuela: Centro cultural de Venezuela.

Pragmática sociocultural: estudios sobre el discurso de cortesía en español. España: Ariel.

"Tensión entre universalidad y relatividad en las teorías de la cortesía", en Pragmática sociocultural: estudios sobre el discurso de la cortesía en español. (15-33). Barcelona: Editorial Ariel Lingüística.

¿Cómo se comenta un texto coloquial? Barcelona: Editorial Ariel Practicum. 
(2001) El español coloquial en la conversación, esbozo de pragmagramática. Barcelona: Editorial Ariel.

(1997) "Los intensificadores en la conversación coloquial" en Pragmática y gramática del español hablado. El español coloquial. (13-36) (Ed., A.Briz, J. R. Gómez Molina, M. J. Martínez Alcalde y grupo Val. Es. Co.) Zaragoza: Pórtico.

Briz, A. e Hidalgo A. (1988) “Conectores pragmáticos y estructura de la conversación", en Los marcadores del discurso. (121-142) Coords. María A. Martín Zorraquino y Estrella Montolío D. Madrid: Arco.

Brown P. y Levinson S. (1987) Politeness, some universals in language usage. Estados Unidos: Cambridge University Press.

Brown G. y Yule G. (1993) Análisis del discurso. Madrid: Visor libros.

Calsamiglia H. y Tusón A. (1999/2008) Las cosas del decir, manual de análisis del discurso. Barcelona: Ariel.

Correa, M. (2001)

"Influencias de las lenguas indígenas en el español de Chile". Espéculo. Revista de estudios literarios. Madrid: Universidad Complutense de Madrid. [en línea]. [01/05/2012] Disponible en la web: http://www.ucm.es/info/especulo/numero17/mapuche. html 
Escandell, $M^{\mathrm{a}}$. V. (2006)

(1995)

(s/fecha) "Aportaciones de la pragmática". Departamento de

(s/fecha) "Politeness: a relevant issue for relevance theory".

Foucault, M. (1992) Lengua española y Lingüística general. [en línea]. [01/03/2012] Disponible en la web: http://www.uned.es/dpto-leng-esp-y-linggral/escandell. Revista Alicantina de estudios ingleses 11. [en línea]. [01/03/2012] Disponible en la web: http://www.uned.es/dpto-leng-esp-y-linggral/escandell/papers/PolitenessRT.PDF

Introducción a la pragmática. Barcelona: Editorial Ariel Lingüística.

"Cortesía, fórmulas convencionales y estrategias indirectas", en Revista española de lingüística, España: Editorial Gredos. [en línea]. [06/06/2012] Disponible en la web: http://www.uned.es/sel/pdf/ene-jun-95/25-1Escandell.pdf

El orden del discurso. Lección inaugural en el Collège de France pronunciada el 2 de diciembre de 1970. Buenos Aires: Tusquets Editores. 
Fuentes, C. (2000)

Goffman E. (1959)

Grice, H.P. (1998)
Lingüística pragmática y análisis del discurso. Madrid: Arco libros.

The presentation of self in everyday life. New York: Doubleday.

"Presuposición e implicatura conversacional" en Textos clásicos de pragmática. (105-124). Compilación de textos y bibligrafía: María Teresa Julio y Ricardo Muñoz. Madrid: Arco libros.

Studies in the way of the words. Massachusetts: Harvard University press, Cambridge.

"Submission strategies as an expression of the ideology of politeness: reflections on the verbalisations of social power relations". Pragmatics 9:1.21-36. International Pragmatics Association. [en línea] [10/06/2012] Disponible en la web:

http://elanguage.net/journals/pragmatics/article/vie wFile/279/213

Gutiérrez Ordoñez, S. (2002)
De pragmática y semántica. Madrid: Arco libros. 
Harvey A. y Oyanedel M. (2010) “El grupo de estudio: conceptualización y actualización discursiva" en Alfabetización académica y profesional en el siglo XXI: leer y escribir desde las disciplinas. (71-93) Ed. Giovanni Parodi. Santiago: Ariel.

Haverkate, H. (2004)

"El análisis de la cortesía comunicativa: categorización pragmalingüística de la cultura española" en Pragmática sociocultural: estudios sobre el discurso de la cortesía en español. (55-64). Barcelona: Editorial Ariel Lingüística. 2004.

La cortesía verbal: estudio pragmalingüístico. Madrid: Editorial Gredos. "A speech act analysis of irony". North-Holland: Journal of pragmatics 14. (77-109).

(S/fecha)

"Los aspectos alocutivos de la oración española: una contribución a la Pragmática lingüística". Centro virtual Cervantes. [en línea] [01/03/2012] Disponible en la web: http://cvc.cervantes.es/literatura/aih/pdf/06/aih_06 1_096.pdf. 
Hernández, M. y Pazos, J. (1988) Ingeniería del Conocimiento. “Categorías de Razonamiento". (235-240). Cordoba: Sociedad para estudios pedagógicos argentinos.

Jucker A. y Ziv Y. (eds.) (1998) Discourse Markers. Descriptions and theory. Pragmatics and beyond new series. Ámsterdam/Philadepphia: John Benjamins publishing company.

Kerbrat-Orecchioni, C. (2004) “Es universal la cortesía?”, en Pragmática sociocultural: estudios sobre el discurso de la cortesía en español. (39-53). Barcelona: Editorial Ariel Lingüística.

(1998)

Gestión de conflictos y constitución de coaliciones en los polígonos. París: Gric. CNRS-Université lumiére-Lyon 2.

(1992) Les interactions verbales. Tome II. Paris: Editorial Armand Colin.

(1983) La connotación. Buenos Aires: Hachette S.A.

Ladegaard, H. (2004)

"Politeness in young children's speech: context, peer group influence and pragmatic competence" 
en Journal of pragmatics 36. North-Holland:

Journal of pragmatics. [en línea] [06/06/2012]

Disponible en la web:

http://www.sciencedirect.com/science/article/pii/S0

$\underline{378216603001772}$

Lakoff, R. (1998)

"La lógica de la cortesía, o acuérdate de dar las gracias", en Textos clásicos de pragmática. (259278). Compilación de textos y bibligrafía: María Teresa Julio y Ricardo Muñoz. Madrid: Arco libros.

(1990) Talking power, the politics of language. Estados Unidos: Editorial Basic Books.

(1973) The logic of politeness. Estados Unidos: Chicago Linguistic Society.

Leech, G. (1998)

Principios de la pragmática (traducción, notas y prólogo Felipe Alcántara) España: Universidad de la Rioja, servicio de publicaciones.

Lo Cascio, V. (1998)

Gramática de la argumentación. Madrid: Alianza Universidad. 
López, C. (1996)

Llorente, $M^{\mathrm{a}}$. (1996)

Matsumoto, Y. (1988)

Medel, A. (2011)

Mills, S. (2003)
Modos de razonamiento. Introducción a la teoría de la argumentación. Santiago: Universidad Andrés Bello.

Organizadores de la conversación. Operadores discursivos del español. España: Publicaciones Universidad Pontificia Salamanca.

"Reexamination of the universality of Face: Politeness phenomena in Japanese". Journal of Pragmatics 12. (403-426).

El voseo verbal chileno: diseño de una unidad didáctica de nivel B2 basada en un enfoque por tareas. Memoria de maestría. Universidad de León (en colaboración con la Fundación universitaria iberoamericana (FUNIBER). [en línea] [01/03/2012] Disponible en la web: http://blogs.funiber.org/formacionprofesores/files/2011/07/MedelMaraboliA_Mem.pdf

Gender and Politeness. Reino Unido: Cambridge University Press.

(1997) Discourse. New York: Routledge. 
Montecino, L. (2005)

“Cortesía, ideología y representaciones discursivas en la gestión conversacional de jóvenes chilenos" en Onomazein, Revista de Lingüística, Filología y Traducción de la Facultad de Letras de la Pontificia Universidad Católica de Chile, 12. (9-22). Santiago: Ediciones Universidad Católica.

"Estrategias de intensificación y de atenuación en la conversación coloquial de jóvenes chilenos". Onomazein, Revista de Lingüística, Filología y Traducción de la Facultad de Letras de la Pontificia Universidad Católica de Chile, vol. 2, núm, 10. (932). Santiago: Ediciones Universidad Católica. [en línea] [12/06/2012] Disponible en la web: http://redalyc.uaemex.mx/redalyc/pdf/1345/134517 755001.pdf

Moreno, F. (1998)

Principios de sociolingüística y sociología del lenguaje. Barcelona: Editorial Ariel lingüística.

Murillo, J. (2008)

"Actos de habla y cortesía en distintas variedades del español: perspectivas teóricas y metodológicas". En Actas II coloquio internacional del programa EDICE. [en línea] Disponible en la web: http:www.edice.org. 
Nieto, J. M. (1995)

Núñez Ladevéze, L. (1993)
Introducción al análisis del discurso hablado. Granada: Universidad de Granada.

Teoría y práctica de la construcción del texto: investigación sobre gramaticalidad, coherencia y transparencia de la elocución. Barcelona: Editorial Ariel.

Perelman, Ch. y Olbrechts-T. L. (1989) Tratado de la argumentación. La nueva retórica. Madrid: Gredos.

Pérez M. y Vega O. (2003)

Técnicas argumentativas. Santiago de Chile: Ediciones Universidad Católica.

Placencia, $\mathrm{M}^{\mathrm{a}}$. y García C. (2007) Research on politeness in the spanish- speaking world. New Jersey: Lawrence Erlbaum associates, publishers.

Plantin, Ch. (2004)

"Pensar el debate" en Revista Signos, 37(55). (121129). Valparaíso: Escuela de lingüística de Valparaíso.

(2001) La Argumentación. Barcelona. Editorial Ariel.

PNUD (informe) (2009) y (2004) Informe de desarrollo humano en Chile. [en línea] [01/03/2012] Disponible en la web: http://www.pnud.cl/prensa/4.asp\#Informes_de_Desar rollo_Humano_en_Chile 
Puga, J. (1997)

Rabanales, A. (1992)

Renkema, J. (1999)

Rivadeneira V. (2009)

Schiffrin, D. (1990)

Searle, J. (1994)
La atenuación en el español de Chile. Un enfoque pragmalingüistico. Valencia: Tirant lo Blanch.

"El español de Chile: situación actual”. En Historia y presente del Español de América. (565-592). Coord: César Hernández Alonso. Valladolid: Junta de Castilla y León.

"Perfil lingüístico de Chile". Logos Semantikos $V$. Historia y arquitectura de las lenguas. In Honorem E. Coseriu. (447-464) Editorial Gredos.1981.

Introducción a los estudios sobre el discurso. Barcelona: Editorial Gedisa.

El voseo en medios de comunicación de Chile. Descripción y análisis de la variación dialectal y funcional. Tesis doctoral, UPF. 80 . [en línea] [01/03/2012] Disponible en la web: http://www.tesisenxarxa.net/TESIS_UPF/AVAILAB LE/TDX-1209109-131417//TMRV.pdf)

"El análisis de la conversación" en Panorama de la lingüística moderna, Universidad de Cambridge, vol. IV: El lenguaje: contexto sociocultural. (299-328) Cambridge: Visor.

Actos de habla. Madrid: Ediciones Cátedra. 
Sperber D. y Wilson D. (1998)

Stubbs, M. (1996)

Tannen, D. (1984)

Toulmin, S. (1974)

Tusón A. (2008)
"Sobre la teoría de la conversación de Grice" en Textos clásicos de pragmática (145-172). Compilación de textos y bibligrafía: María Teresa Julio y Ricardo Muñoz. Madrid: Arco libros.

La relevancia, comunicación y procesos cognitivos. Madrid: Visor.

Text and corpus analysis. Massachussets: Blackwell publishers.

"The pragmatics of cross-cultural communication". Applied Linguistic, Vol. 5, N³. (189-195) [en línea] [11/06/2012] Disponible en la web: http://www9.georgetown.edu/faculty/tannend/pdfs/t he_pragmatics_of_crosscultural_communication.p df The uses of argument. Cambridge: University press. Análisis de la conversación. Barcelona: Ariel.

Eemeren V. y Grootendorst R. (2002) Argumentación, comunicación y falacias, una perspectiva pragma-dialéctica. Chile: Ediciones Pontificia Universidad Católica. 
Van Dijk, T. (2000)

(1997)

(1989)

Vignaux, G. (1986)

Watts, R. (2003)
El discurso como estructura y proceso, estudios sobre el discurso, tomo I. Barcelona: Editorial Gedisa.

Racismo y análisis crítico de los medios. Barcelona: Ediciones Piados.

Análisis del discurso, su desarrollo y aplicación a la estructura de las noticias. Santiago: Journal of communication. Traducción, Aguilera $\mathrm{O}$.

La ciencia del texto. Buenos Aires: Paidós.

"Episodes as unit of discourses analysis", en Deborah Tannen (ed.) Analyzing discourse: text and talk. (177-195). Washington: Georgetown University press.

La argumentación. Ensayo de la lógica discursiva. Buenos Aires: Hachette.

Politeness, key topics in sociolinguistics. Reino Unido: Cambridge University Press.

Politness in language. Studies in its history, theory and practice. Berlin-New York: Mourton de Gruyter. Studies and monographs, 59. 
Wenzel, J. (1992)

Wierzbicka, A. (1991)

Zimmermann, K. (1995)
"Perspectives on argumentation". En Readings in argumentation. Eds. W. L. Benoit, D. Hample \& P. J. Benoit. (121-143). Berlin: Foris Publications.

Cross-cultural pragmatics: The semantics of human interactions. Berlín-New York: Walter de Gruyter.

Aspectos teóricos y metodológicos del contacto de lenguas. Madrid: Biblioteca ibero-americana. 